\title{
Testing and assessment of FRP strengthened concrete T-beam bridges in Pennsylvania
}

Adam L. Justice

West Virginia University

Follow this and additional works at: https://researchrepository.wvu.edu/etd

\section{Recommended Citation}

Justice, Adam L., "Testing and assessment of FRP strengthened concrete T-beam bridges in Pennsylvania" (2010). Graduate Theses, Dissertations, and Problem Reports. 2151.

https://researchrepository.wvu.edu/etd/2151

This Thesis is protected by copyright and/or related rights. It has been brought to you by the The Research Repository @ WVU with permission from the rights-holder(s). You are free to use this Thesis in any way that is permitted by the copyright and related rights legislation that applies to your use. For other uses you must obtain permission from the rights-holder(s) directly, unless additional rights are indicated by a Creative Commons license in the record and/ or on the work itself. This Thesis has been accepted for inclusion in WVU Graduate Theses, Dissertations, and Problem Reports collection by an authorized administrator of The Research Repository @ WVU. For more information, please contact researchrepository@mail.wvu.edu. 


\title{
Testing AND AssessMent OF FRP STRENGTHENED CONCRETE T-BEAM BRIDGES IN Pennsylvania
}

\author{
Adam L. Justice \\ Thesis submitted to the \\ College of Engineering and Mineral Resources \\ at \\ West Virginia University \\ in partial fulfillment of the requirements \\ for the degree of \\ Master of Science \\ in \\ Civil and Environmental Engineering \\ Julio F. Davalos, Ph. D., Chair \\ An Chen, Ph. D., Co-Chair \\ Indrajit Ray, Ph. D. \\ Department of Civil and Environmental Engineering
}

Morgantown, West Virginia

2010

Keywords: fiber reinforced polymer (FRP), concrete t-beam bridge, load testing, finite element model (FEM), load rating, live load distribution, FRP strengthening design 


\title{
Testing and Assessment of FRP Strengthened Concrete T- Beam Bridges in Pennsylvania
}

\author{
Adam Levi Justice \\ Dr. Julio F. Davalos, Thesis Advisor
}

\begin{abstract}
It is increasingly becoming of great concern that the transportation infrastructure is in poor condition and in need of rehabilitation. Reinforced concrete (RC) structures such as bridges are a prime example for displaying rehabilitation needs. Harsh environmental conditions and age, along with the use of deicing salts in the winter seasons, greatly increase deterioration rates. Addressing bridge conditions in an effective manner and ensuring the safety of the public is a challenge for engineers and owners.

The Pennsylvania Department of Transportation - District 3 (PennDOT - D3) initiated a program to address the condition of their concrete T-Beam bridges. 128 concrete T-Beam bridges constructed between 1920 and 1960 are included in the district's bridge inventory. Many of these bridges have become structurally deficient or obsolete due to aging and deterioration. PennDOT-D3 paired with West Virginia University researchers to develop a program that would use FRP rehabilitation technology to repair and strengthen its large number of concrete T-Beam bridges.

The work presented in this thesis focuses on the third phase of a three-phase project concerning the rehabilitation of bridge \#49-4012-0250-1032 built in 1934 near Sunbury, Pennsylvania. Quality control and assurance was performed with several field visits during the construction process. Load testing was performed to replicate the load testing performed prior to rehabilitation in Phase II of the project. Data resulting from load tests before and after rehabilitation was compared. An FE model of the bridge was developed and calibrated using field testing data and inspection. The FE model was subjected to the same loading conditions as applied in the field and also compared for a more thorough structural evaluation. The FE model was also subjected to AASHTO standard live loading conditions to investigate current load rating methods for these types of structures. Discrepancies resulting from accurate FE analyses when compared to simplified methods of analysis are discussed. Based on existing literature and knowledge gained throughout the project, design, construction, and testing/long-term monitoring guidelines were drafted in PennDOT-D3 desired formats. These guidelines are considered important outcomes for Phase III of the project and for the development of this thesis. The guidelines were developed for incorporation into PennDOT standard documentation for the successful transfer of knowledge concerning the FRP repair technology. With the design guidelines, an FRP design program was created specifically for simple span concrete T-Beam bridges. The design program is user friendly and allows for detailed input based on field inspection. The program gives structural capacities for the original, existing, and strengthened conditions of primary bridge members. Load rating factors are also presented for the existing and strengthened TBeam analysis.
\end{abstract}




\section{ACKNOWLEDGEMENTS}

The author would like to thank West Virginia University for an exciting and educational life experience. More professors than can be named have had many positive influences on the author. With this, special thanks should go to the faculty members of the Department of Civil and Environmental Engineering. Among these influential faculty members, the guidance and support offered by Dr. Davalos, Dr. Chen, and Dr. Ray will never be forgotten.

The author would like to thank Dr. Davalos for the opportunity to achieve desired educational goals. His cultured personality, enthusiasm for teaching, and passion for life in general has helped the author have a more enjoyable and well rounded graduate education.

The author would especially like to thank Dr. Chen and Dr. Ray for their never ending advice and optimistic attitude. Discussions concerning research and general life matters have led to the development of a strong professional bond and a strong friendship. Dr. Chen's guidance and help with the research was invaluable.

The author also owes many thanks to the classmates and officemates throughout the years. The laughter shared and the help provided can never be replaced. Giving this, separate thanks must go to Matt Anderson, a fellow graduate student, and to Jared Grimm, a research technician. Without these two men, a large part of the research could have never been completed.

Thanks to the author's mom and brothers shall be given for there support and encouragement throughout the years. 


\section{Table of Contents}

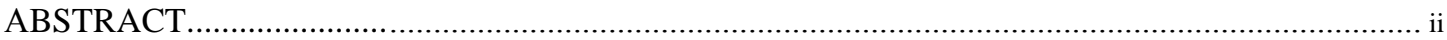

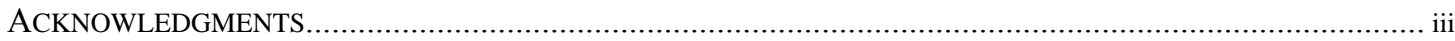

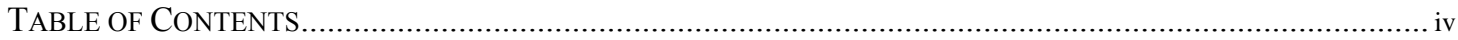

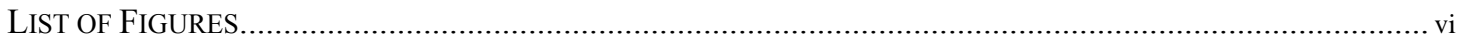

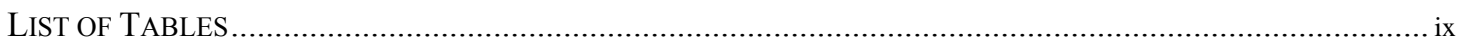

\section{CHAPTER 1 - INTRODUCTION}

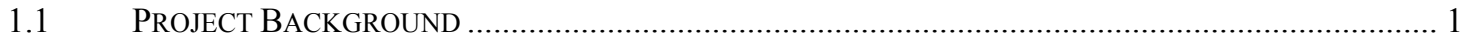

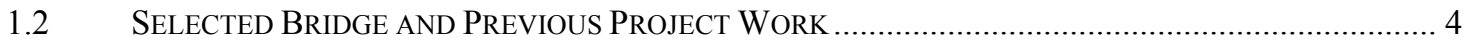

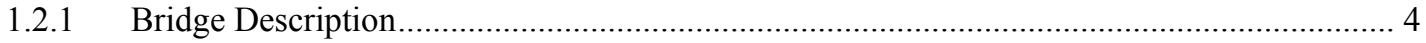

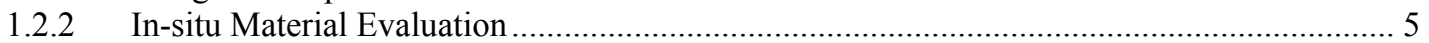

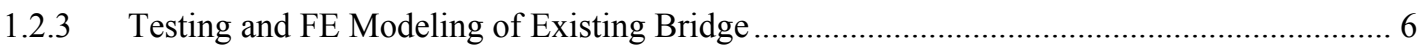

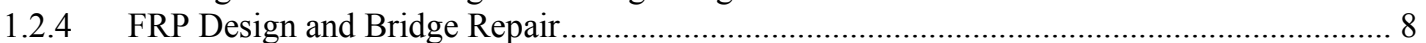

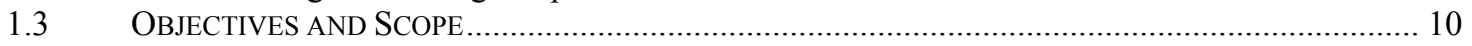

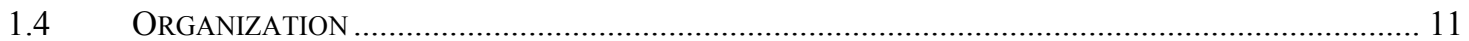

\section{CHAPTER 2 - LITERATURE REVIEW}

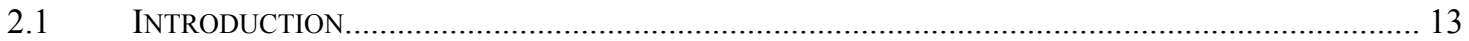

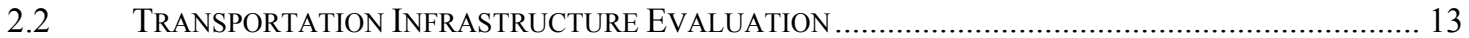

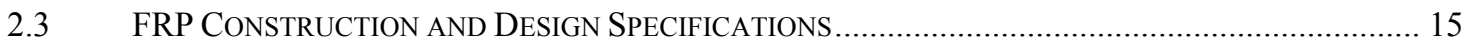

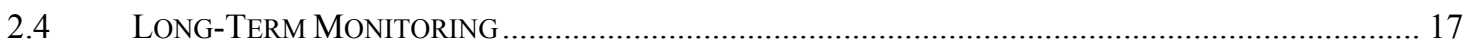

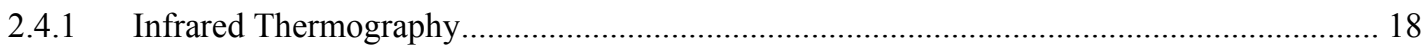

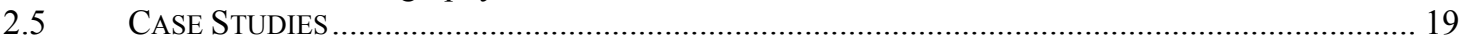

\section{CHAPTER 3 - LOAD TESTING AND FE MODELING}

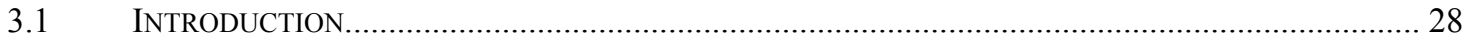

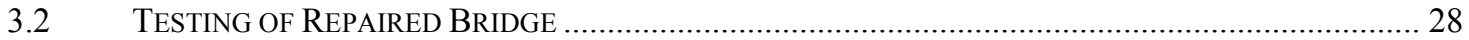

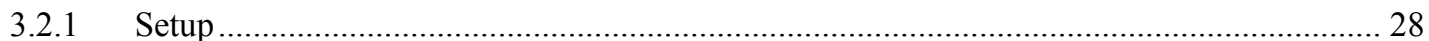

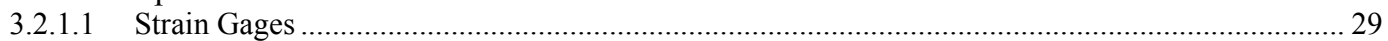

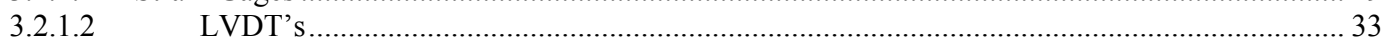

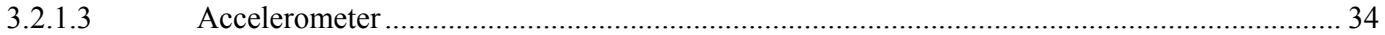

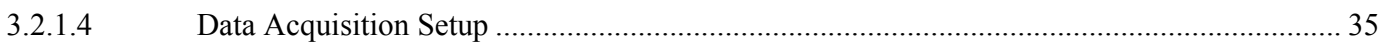

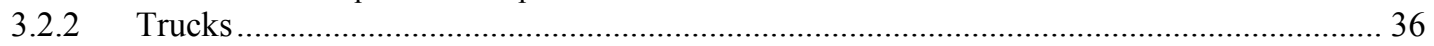

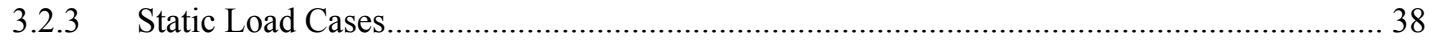

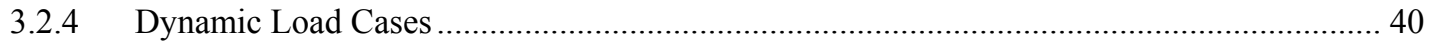

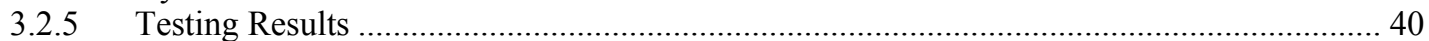

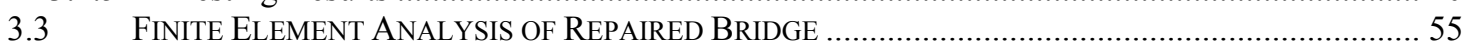

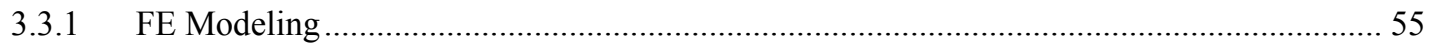

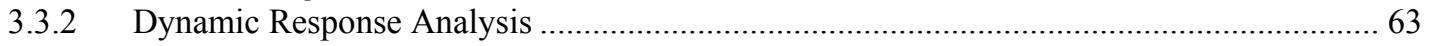

\section{CHAPTER 4 - DESIGN PROGRAM}

$4.1 \quad$ INTRODUCTION

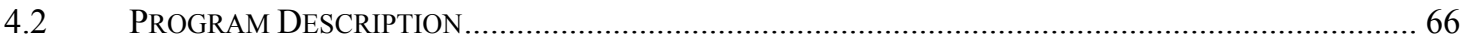

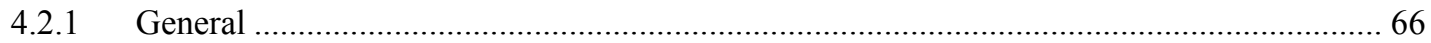

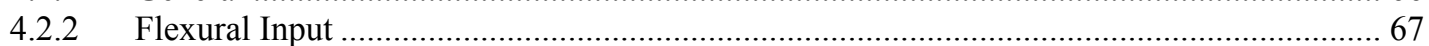

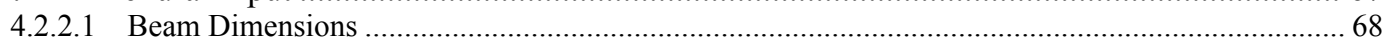

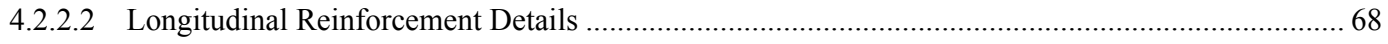

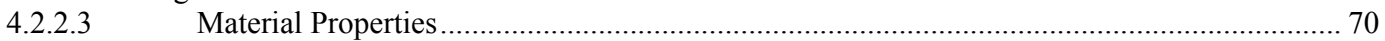




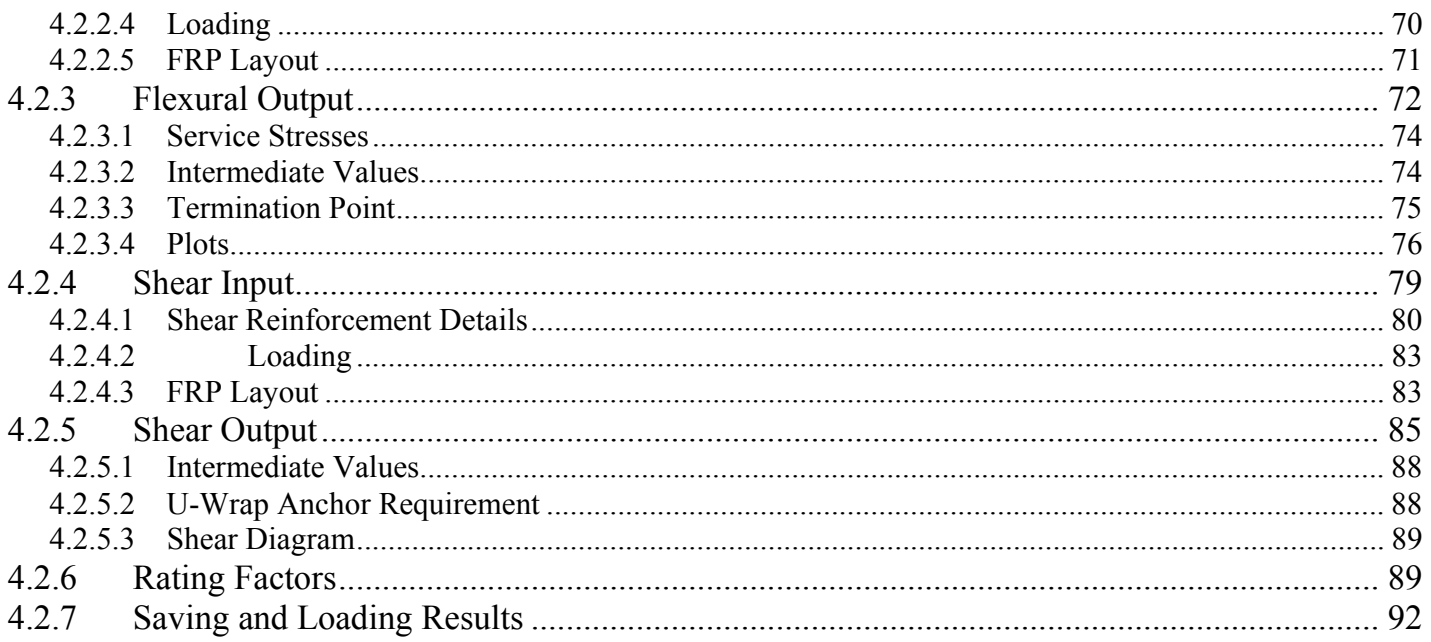

\section{CHAPTER 5 - DESIGN AND ANALYSIS CORRELATIONS}

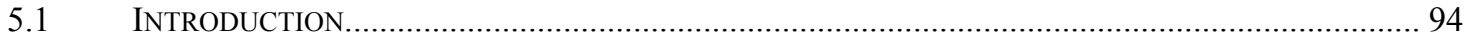

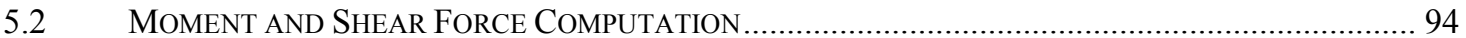

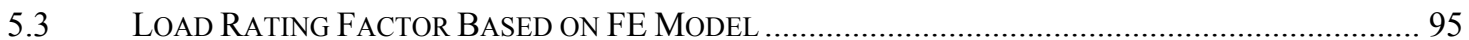

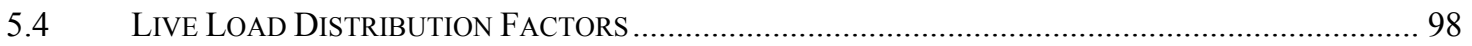

\section{CHAPTER 6 - QUALITY CONTROL AND ASSURANCE}

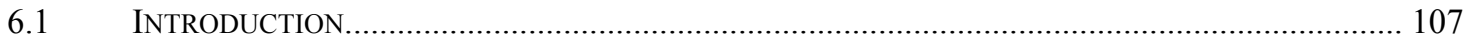

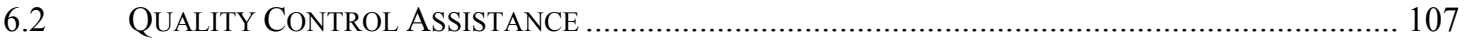

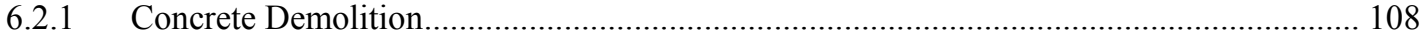

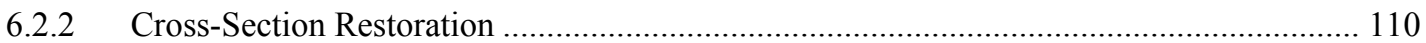

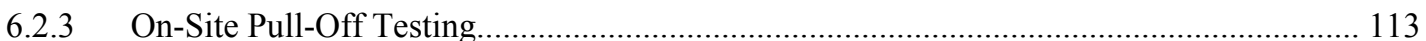

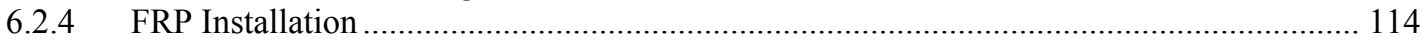

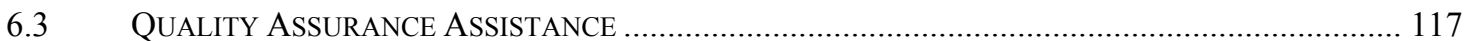

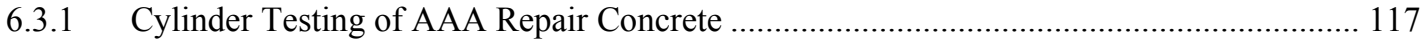

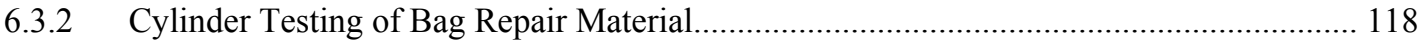

6.3.3 Bond Strength between Old and New Concrete ........................................................ 120

6.3.4 Prism Rebound Hammer Tests ......................................................................... 122

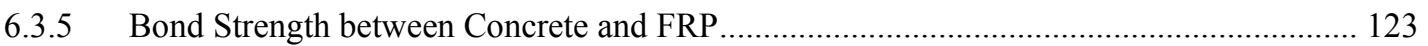

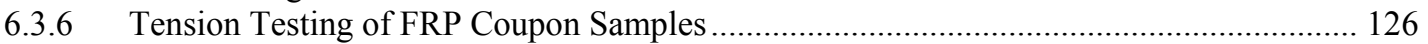

\section{CHAPTER 7 - CONCLUSIONS}

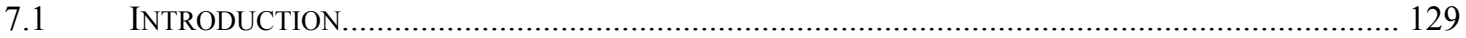

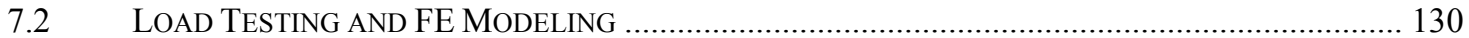

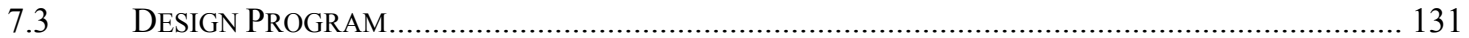

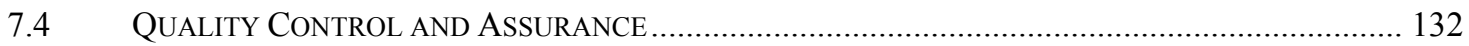

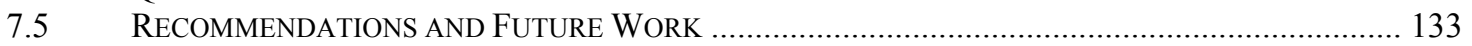

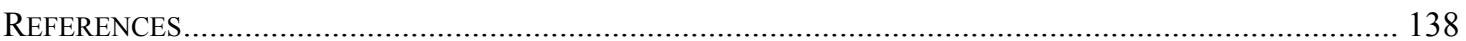

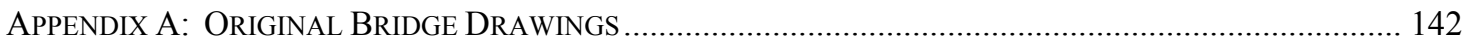

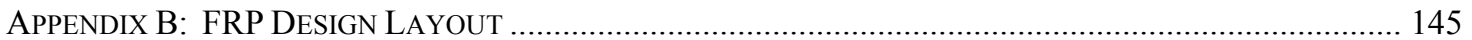

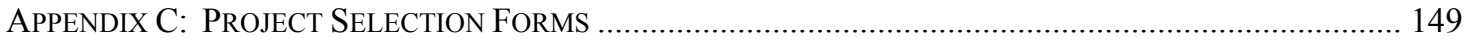

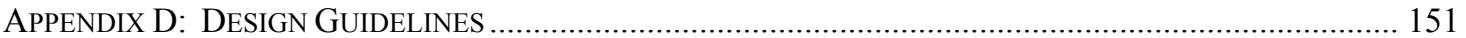

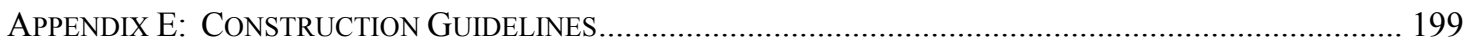

APPENDIX F: LONG-TERM TESTING AND MONITORING GUIDELINES ....................................................... 218 


\section{List of Figures}

Figure 1.1 Bridge Girder Elevation View (Sasher, 2008) ........................................... 4

Figure 1.2 Bridge Girder Cross-Section View (Sasher, 2008) .................................... 5

Figure 1.3 Bridge Condition Photographs ............................................................ 5

Figure 1.4 Beam 1 and 2 FRP Reinforcement ..................................................... 9

Figure 1.5 Beam 5 FRP Reinforcement .................................................................. 9

Figure 3.1 Plan View Instrumentation Setup ............................................................ 29

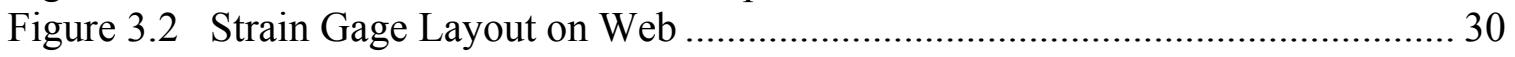

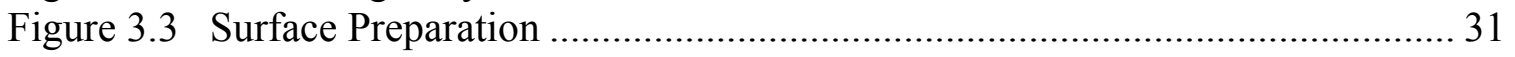

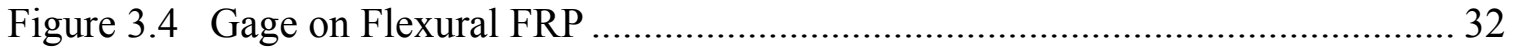

Figure 3.5 Concrete Gage with Barrier E Protective Coating …................................. 32

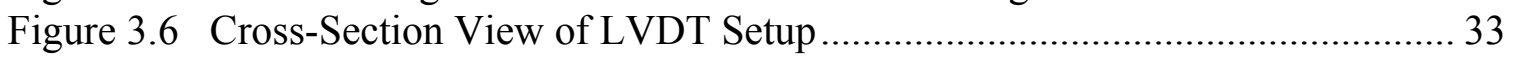

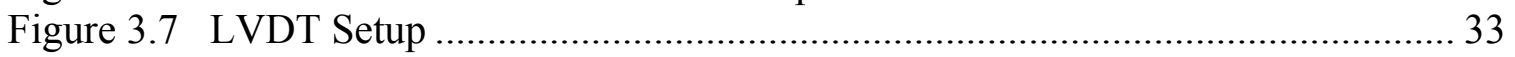

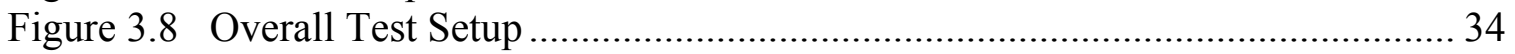

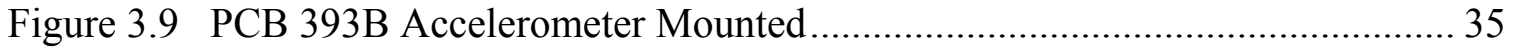

Figure 3.10 Cross-Section View Instrumentation Setup........................................ 35

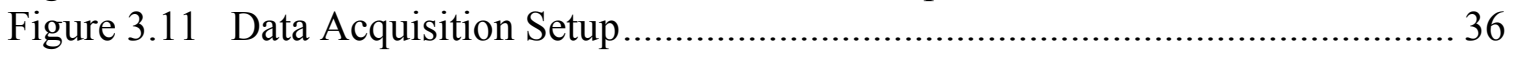

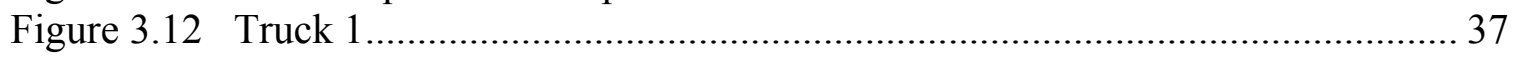

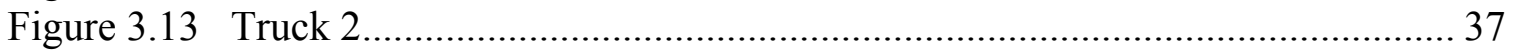

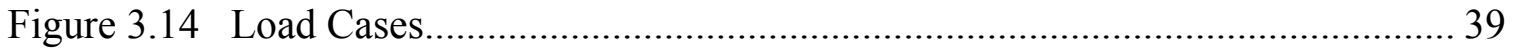

Figure 3.15 Modified Load Cases............................................................................... 39

Figure 3.16 Load Case 1 Deflection Results ........................................................ 42

Figure 3.17 Load Case 2-2 Deflection Results .......................................................... 43

Figure 3.18 Load Case 2-1 Deflection Results ...................................................... 43

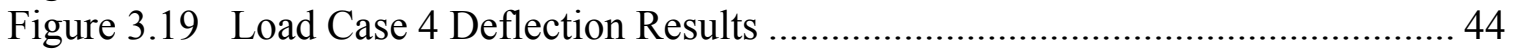

Figure 3.20 Load Case 5 Deflection Results ............................................................ 44

Figure 3.21 Load Case 6 Deflection Results ............................................................ 45

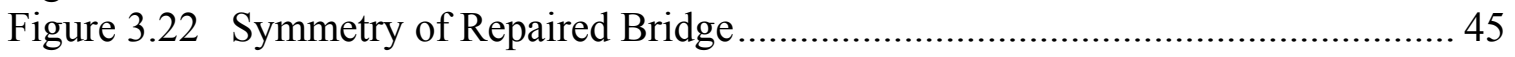

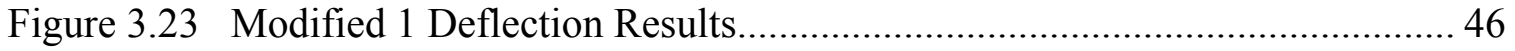

Figure 3.24 Modified 2 Deflection Results.............................................................. 46

Figure 3.25 Load Case 1 Strain Results.................................................................... 47

Figure 3.26 Load Case 2-2 Strain Results ................................................................ 48

Figure 3.27 Load Case 2-1 Strain Results ................................................................. 48

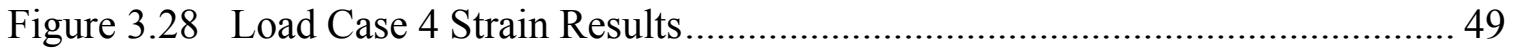

Figure 3.29 Load Case 5 Strain Results.................................................................... 49

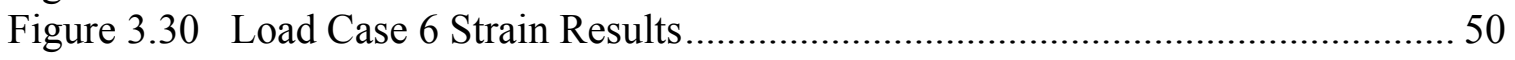

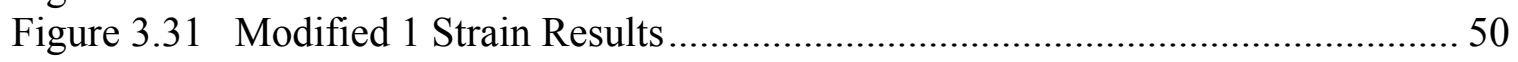

Figure 3.32 Modified 2 Strain Results................................................................... 51

Figure 3.33 Concrete Strain from Load Case \#1 (G1) ............................................... 52

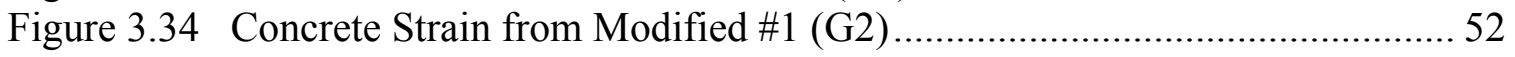

Figure 3.35 Concrete Strain from Modified \#2 (G3) ................................................ 52

Figure 3.36 Concrete Strain from Load Case \#1 (G4) ................................................. 53

Figure 3.37 Concrete Strain from Load Case \#2-2 (G5) ............................................ 53

Figure 3.38 Concrete Strain from Modified \#2 (G6) ................................................. 53 
Figure 3.39 Natural Frequency Chart …………………......................................... 54

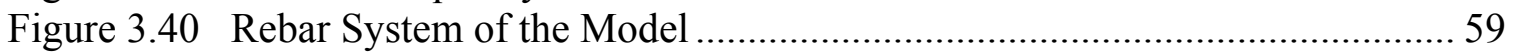

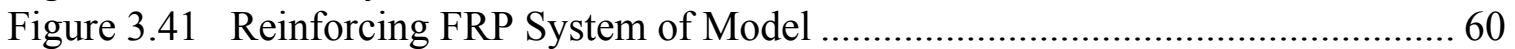

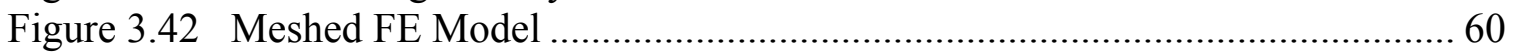

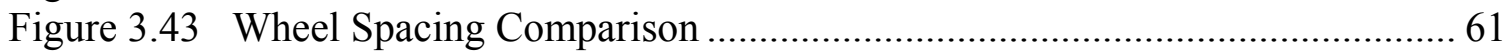

Figure 3.44 Tandem Truck Load Position ................................................................. 62

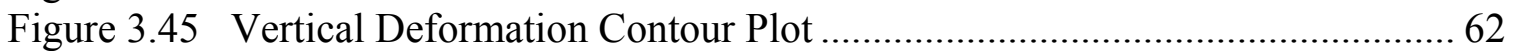

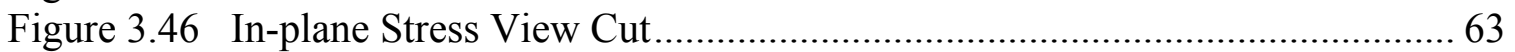

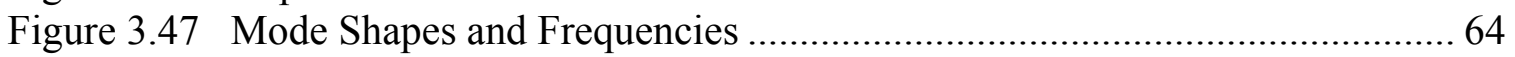

Figure 4.1 Tabbing Organization of Program.............................................................. 66

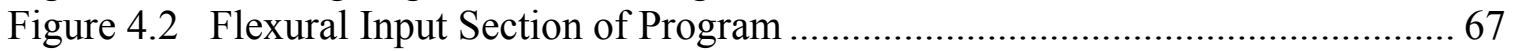

Figure 4.3 Enlarged Flexural Steel Details Panel ...................................................... 68

Figure 4.4 Longitudinal Steel Input Dialog Box - 2 and 3 Layers Selected................... 69

Figure 4.5 FRP Width Error Dialog Box ................................................................ 72

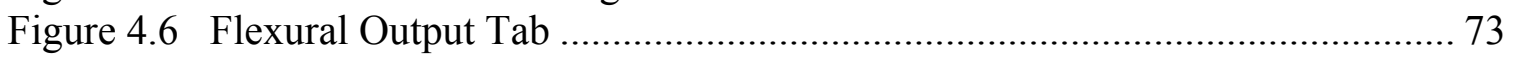

Figure 4.7 Enlarged Intermediate Values Panel ....................................................... 75

Figure 4.8 Factored Moment and Cracking Moment................................................... 77

Figure 4.9 Example Cross-Section Diagram ………….............................................. 77

Figure 4.10 Example Elevation Diagram................................................................ 78

Figure 4.11 Example Cross-Section Strain Plot …………….................................... 78

Figure 4.12 Shear Specific Input Section of Program ............................................... 79

Figure 4.13 Enlarged Shear Sections Selection Menu.............................................. 81

Figure 4.14 Input Dialog Boxes for Shear Sections - 4 Sections Selected..................... 82

Figure 4.15 Section Distance Error Dialog Box …………........................................ 82

Figure 4.16 FRP Shear Reinforcement for 8 Sections ................................................ 84

Figure 4.17 FRP Shear Reinforcement for 4 Sections .................................................. 84

Figure 4.18 Example Shear Output - 8 Shear Sections............................................... 86

Figure 4.19 Example Shear Output - 4 Shear Sections ................................................ 87

Figure 4.20 Enlarged Shear Intermediate Values Panel ................................................ 88

Figure 4.21 Rating Factors Section of Program....................................................... 90

Figure 4.22 Shear Rating Factors - 4 Sections Selected .............................................. 92

Figure 4.23 File Menu - Save ............................................................................... 92

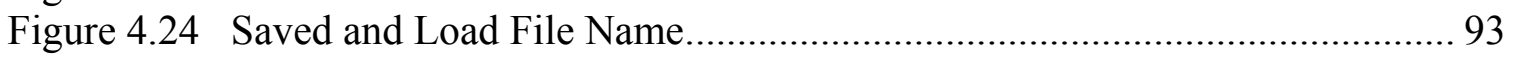

Figure 5.1 Interior Live Load Moment Distribution Factors..................................... 102

Figure 5.2 Exterior Live Load Moment Distribution Factors....................................... 103

Figure 5.3 Comparison of AASHTO Standard and AASHTO LRFD LDF Values..... 105

Figure 6.1 Concrete Demolition - (a) Beam 1 (b) Beam 6....................................... 108

Figure 6.2 Missing Reinforcement Exposed in Beam 6 ............................................ 109

Figure 6.3 Concrete Restoration Area …………................................................ 111

Figure 6.4 Patch Repairing Formwork along Beams 3 \& 4 ..................................... 112

Figure 6.5 Patch Formwork Detail...................................................................... 112

Figure 6.6 Formwork along (a) Beam 5 \& (b) Beam 1 ............................................ 112

Figure 6.7 Patch Surface \& Adhesion Testing Attachment ......................................... 113

Figure 6.8 FRP Reinforcement Layout (a) Beam 1 \& (b) Beam 5 ............................... 115

Figure 6.9 FRP Reinforcement Layout for Beams $2 \& 3$....................................... 115

Figure 6.10 Testing Prism FRP Application (a) Primer (b) Saturant (c) Fiber Sheet... 116 
Figure 6.11 FRP Panel Fabrication for Tension Testing

Figure 6.12 Bag Material Cylinder Tests (a) Compression (b) Splitting-Tensile......... 119

Figure 6.13 Schematics of Pull-Off Test for Material Interface .................................. 120

Figure 6.14 Concrete Pull-Off Test (a) Drill Setup (b) Tested Core ............................ 120

Figure 6.15 Dyna Z16 Pull-Off Tester..................................................................... 121

Figure 6.16 Pull-Off Testing Preparation (a) Cutting (b) Attached Disks................... 124

Figure 6.17 FRP Pull-Off Test (a) Mounted Tester (b) Cohesive Failure .................... 125

Figure 6.18 FRP Coupon Tension Test Setup ....................................................... 127

Figure 6.19 1-Ply Tension Coupon Samples ............................................................. 128

Figure 6.20 2-Ply Tension Coupon Samples ..................................................... 128 


\section{List of Tables}

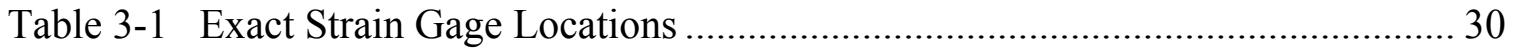

Table 3-2 Summary of Static Load Cases................................................................ 38

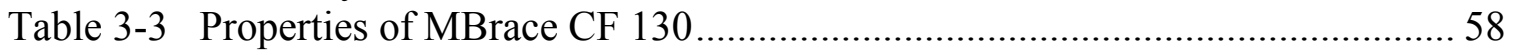

Table 3-4 Wheel Loading (lbs) for AASHTO HS20 and Tandem Trucks ..................... 61

Table 5-1 Maximum Moments and Shear Forces for Girders ................................... 95

Table 5-2 Girder Rating Factors ............................................................................... 96

Table 5-3 Comparison of AASHTO Live Load Moment Distribution Factors............ 101

Table 5-4 Regression Function of Distribution Factors (Zou, 2008) .......................... 102

Table 6-1 Field Adhesion Testing Results of Repair Material .................................. 114

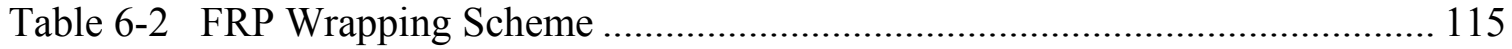

Table 6-3 PennDOT Provided Compressive Strength (AAA) ................................... 118

Table 6-4 WVU Provided Strength and Modulus of Elasticity (AAA) ........................ 118

Table 6-5 Bag Repairing Material Testing Results.............................................. 119

Table 6-6 Rebound Hammer Test Results ................................................................... 123

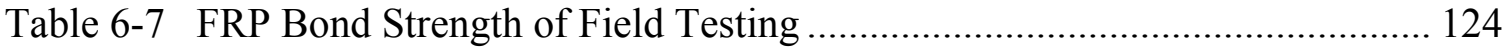




\section{CHAPTER 1 - INTRODUCTION}

\subsection{Project BACKground}

Reinforced concrete (RC) structures such as bridges are increasingly in need of rehabilitation as a result of deterioration. In colder regions, deterioration results largely from the use of deicing salts to clear roadways in the winter seasons. These deicing salts lead to chloride ingression which eventually corrodes the reinforcing steel. The corrosion product of the steel (rust) tends to occupy much more volume, leading to spalling of concrete cover and section loss of rebar. Due to the large quantity of RC bridges reaching this condition, repair and strengthening must be performed as economically as possible.

The Pennsylvania Department of Transportation - District 3 (PennDOT - D3) initiated a program to address the condition of their concrete T-Beam bridges. 128 concrete T-Beam bridges constructed between 1920 and 1960 are included in the district's bridge inventory. Due to deterioration, many of these bridges are in need of repair and strengthening.

The program initiated by PennDOT - D3 incorporates the use of externally bonded fiber-reinforced polymers (FRP) to strengthen deteriorated bridges. The strengthening will effectively improve the load capacity and remove load restrictions on a bridge in an economical fashion. The project has been carried out in three phases as explained below. The work presented in this thesis focuses on the majority of tasks performed in Phase III. 
In Phase I, technical and economic feasibility of different rehabilitation options were considered along with developing a preliminary selection process for these options. The preliminary selection process developed in this phase used several factors including: age, span length, average daily traffic and average daily truck traffic (ADT/ADTT), and damage based on photographic evidence as well as visual inspection (Brayack, 2005). A bridge was placed into one of three classes based on this selection system. These classes included: Class 1 (prime candidate), Class 2 (moderate candidate), and Class 3 (low candidate. Based on the proposed classification system, a Class 1 candidate bridge was chosen and Phase II of the project was started.

It should be stated here that throughout Phase III of the project, two additional factors were added to the bridge selection process. These factors include the functional class of highway that a given bridge serves and the bridge capacity appraisal of a bridge. Functional class of highway shall be deemed important as it considers the type of route such as interstate, principal arterial, minor arterial, etc. that a bridge facilitates and thereby directly relates to the importants of that transportation segment. Bridge capacity appraisal inclusion into the selection process was deemed necessary as it gives insight into the structural capacity of a bridge in relation to allowable state legal loads. The ratio of the capacity to the legal load can lead to logical determinations as to whether or not any type of repair could be favorable as apposed to total replacement. Low ratios should suggest replacement whereas high ratios could suggest minor repair to be sufficient. This updated project selection system was incorporated into a drop-down form as well as a simple Graphical User Interface (GUI) for quick bridge assessments. Updating the 
project selection process was an important outcome carried out in Phase III, and as such, the proposed project selection form and GUI are presented in Appendix C.

Phase II work consisted of performing bridge condition assessment and preliminary FRP strengthening design (Sasher, 2008). Load testing was carried out on the bridge prior to strengthening in an effort to evaluate pre- and post-retrofitting effects. An externally bonded FRP strengthening design program was developed using Excel during this Phase. The program also incorporated a live load generator in which load rating factors based on various AASHTO live loadings could be computed. This live load generator was developed in an effort to understand how PennDOT's load rating and analysis program (BAR7) worked.

Phase III includes the implementation of the FRP strengthening system and poststrengthening load testing and assessment. Using established specifications and information gathered during much of the project, various guidelines relating to FRP strengthening were to be developed in PennDOT desired formats. The development of these guidelines was considered a significant contribution to Phase III of the project. The guidelines are also an important component of this thesis. The intention was that draft guidelines could eventually be incorporated into PennDOT's standard design manuals and construction specifications. This thesis focuses on the tasks, results, and work outcomes of Phase III activities.

With the completion of this project, PennDOT - D3 will have obtained the information and knowledge necessary to implement a rehabilitation program that will enable district forces to independently classify, evaluate, and rehabilitate concrete TBeam bridges in an economical manner using FRP strengthening systems. Based on the 
extensiveness of the repair, PennDOT shall either: contract out all work (Level 1 repair), combine outside contracting with inside district forces (Level 2 repair), or perform the work entirely with district forces (Level 3 repair).

\subsection{Selected Bridge and Previous Project Work}

\subsubsection{Bridge Description}

The bridge selected for this demonstration project was constructed in 1934 and is located near Sunbury, Pennsylvania (PennDOT Bridge \#49-4012-0250-1032). The bridge carries two traffic lanes on Creek Road over a small creek. It is a simply supported concrete T-Beam structure spanning $48 \mathrm{ft}$ with $45 \mathrm{ft}$ from abutment to abutment. For analysis purposes, a span length of $45 \mathrm{ft}$ is used. Six beams supporting a $26 \mathrm{ft}-11$ in wide and 8.5 in thick concrete deck make up the superstructure of the bridge. Resting on the deck is a 2.5 in asphalt overlay. Figures 1.1 through 1.3 illustrate the selected bridge, showing various reinforcement layouts and photographical indication of damage prior to the start of Phase III.

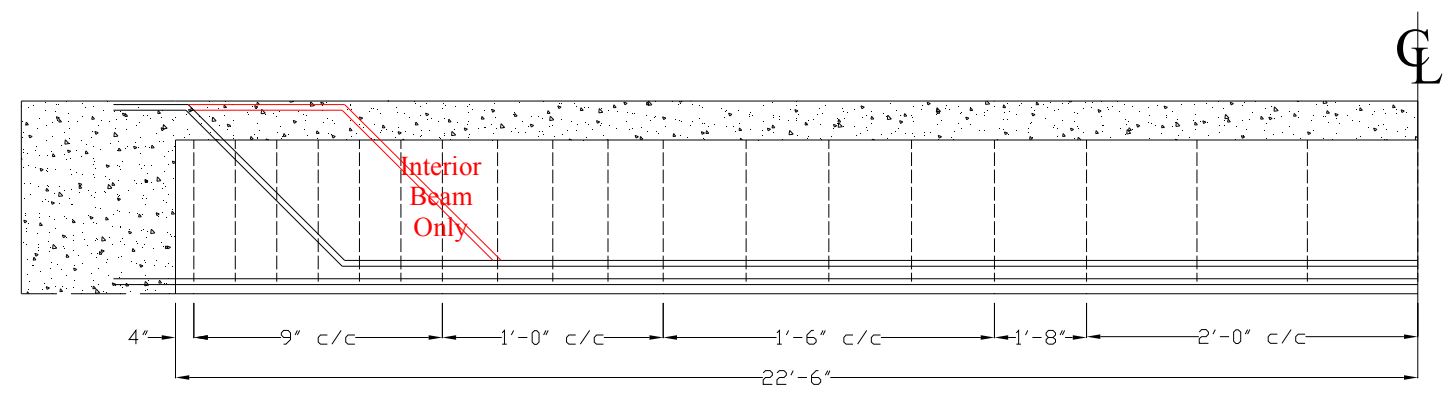

Figure 1.1 Bridge Girder Elevation View (Sasher, 2008) 


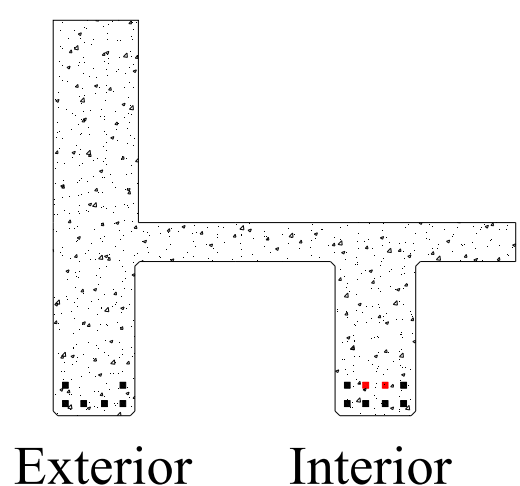

Figure 1.2 Bridge Girder Cross-Section View (Sasher, 2008)

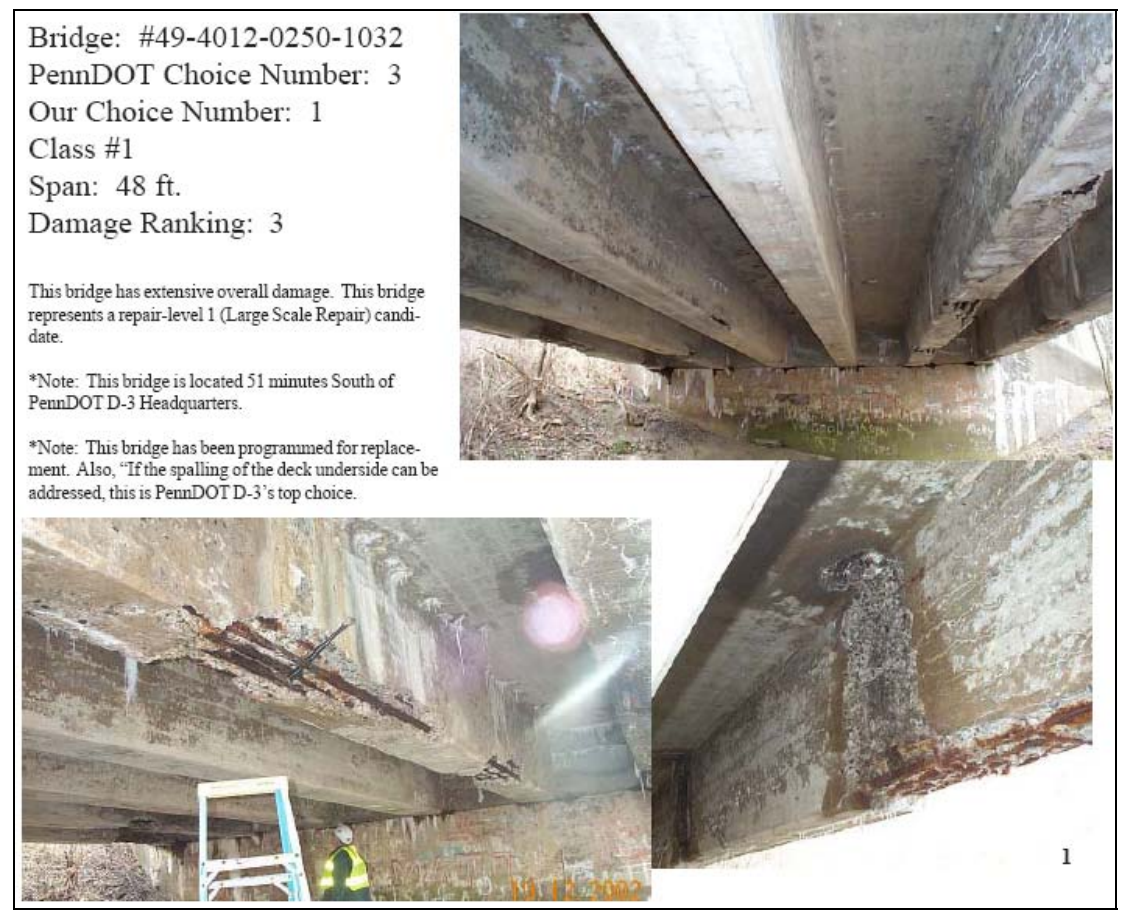

Figure 1.3 Bridge Condition Photographs

\subsubsection{In-situ Material Evaluation}

In assessing the condition of the existing bridge, two core samples were obtained from the bridge deck using a core drill; one at the mid-span and one at the quarter-point. Each core represented the entire depth of the deck. A sample of flexural reinforcing steel 
was taken from the fascia side of beam 6 . This reinforcement sample was easily extracted as it was completely exposed due to corrosion and spalling of concrete cover. The core samples were tested in compression in accordance with ASTM C42, and the average strength was found to be 5783 psi. The flexural reinforcing steel sample was tested in accordance with ASTM E8. The average yield strength was $37 \mathrm{ksi}$ and the average ultimate strength was $64 \mathrm{ksi}$. Also, two non-destructive tests were performed at the bridge site on the concrete beams: an ultrasonic pulse velocity test in accordance with ASTM C597, and a rebound hammer test in accordance with ASTM C805. From the visual inspection, the external beams showed the most damage with severe delamination and spalling. The interior beams showed less damage with localized delamination and spalling.

To recap, several tests and analyses were performed on material samples extracted from the bridge, including core sample compression test, concrete carbonation test, Scanning Electron Microscopy (SEM) and Energy Dispersive X-Ray (EDX) analyses, chemical analysis of concrete powder samples, and steel tension test. All results obtained from the in-situ material evaluation and bridge sample testing was used for developing the FE model and for performing accurate strength assessments in designing the FRP reinforcement layout.

\subsubsection{Testing and FE Modeling of Existing Bridge}

In order to investigate the response of the selected bridge under various loading conditions, a field test was conducted by applying tandem truck(s) on one and two lanes. Field testing data was compared to the results of the FE model in order to verify the model's accuracy. Displacement transducers (LVDTs) were used to obtain deflections of 
the reinforced concrete girders. The natural frequency was determined by utilizing an accelerometer attached to beam 4. All of the data was recorded at the mid-spans of the girders, and all of the response data was recorded with a data acquisition system.

The full response of the bridge under loading was observed by crossing the trucks at several different transverse locations. These locations were selected to maximize the deflections of the girders. The maximum deflection occurred when the truck's center of gravity was directly over the centerlines of the girders. In the static tests, each truck moved at a crawl speed. In the dynamic tests, the truck approached the bridge at $30 \mathrm{mph}$ to $50 \mathrm{mph}$ and excited the bridge by slamming on the brakes when approximately over the mid-span. There were a total of six dynamic load field tests. The data from the accelerometer showed that the natural frequency of the bridge was about 14.66 Hertz. The bridge load test is discussed with greater detail in Chapter 3 as it was repeated for the repaired bridge. Testing of the repaired bridge included the additional implementation of strain gages. Relative graphs and figures are presented in Chapter 3 as well.

An FE model of the bridge was constructed using the commercial program ABAQUS (2005). The information for the FE model development and analysis was acquired from a combination of available design documents (Appendix A) and gathered field information. Chapter 3 presents a more detailed discussion of the FE model construction and analysis. The model was developed in order to determine existing capacities of the bridge, to identify critical load conditions for field testing, and to compare predictions with field test responses. Once created, the model was calibrated using field testing results and modified as needed to enhance its accuracy. After dynamic analysis, the natural frequency was predicted to be 13.33 Hertz, which is about a $10 \%$ 
difference when compared to the natural frequency of 14.66 Hertz resulting from field testing.

\subsubsection{FRP Design and Bridge Repair}

The FRP repair system was designed by the system manufacturer and was reviewed by WVU based on ACI 440.2R-02 (2002) design guidelines. The FRP design layout is presented in Appendix B for each beam.

It was initially desired to develop an FRP design that would replace a known area of corroded reinforcing steel. Although, upon removal of deteriorated concrete from the exterior beams, it was found that about $20 \%$ of the tensile reinforcement and some of the diagonal shear reinforcing bars and vertical stirrups were missing. It was logically assumed that the rest of the beams were also missing this reinforcement. With this finding, a new FRP design approach had to be discussed. WVU researchers recommended designing the FRP system to sustain an HS-20 AASHTO truck loading. More specifically, the FRP strengthening system was designed to increase the capacity of each beam so that an Inventory Rating Factor (IRF) of at least 1.0 could be achieved. Load rating factors are discussed in more detail in Chapter 5. In this manner, the design process did not have to consider any discrepancies between original bridge design plans and as-built conditions. This method provided a rational basis for design while avoiding excess application of external FRP reinforcing fabrics. With the success of this design approach, it could be used as an example for future FRP retrofit projects.

The construction and repair process is discussed in Chapter 6. The repair was performed in accordance with ACI 546R and ICRI No. 03730 guidelines. Removed cross-sectional area was restored with concrete repairing materials before FRP 
application. Figure 1.4 and Figure 1.5 illustrate the applied FRP layout for various beams.

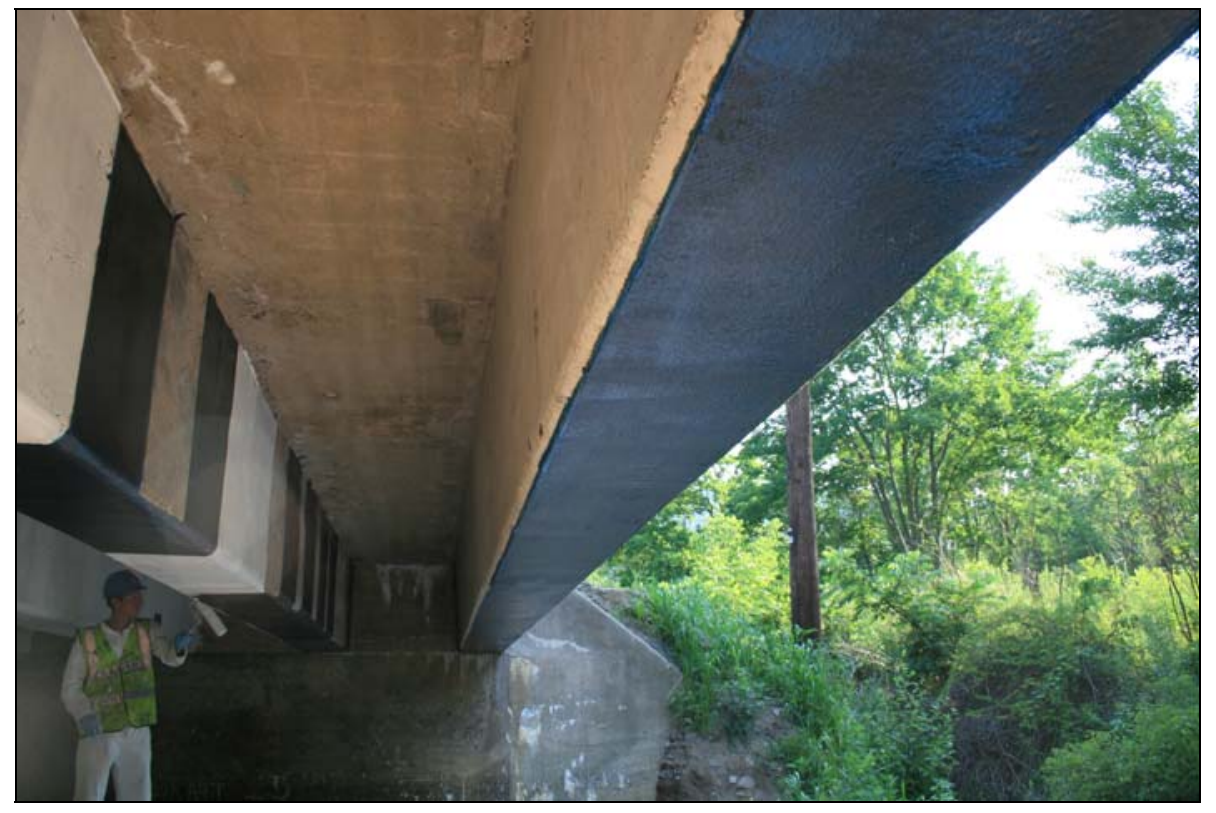

Figure 1.4 Beam 1 and 2 FRP Reinforcement

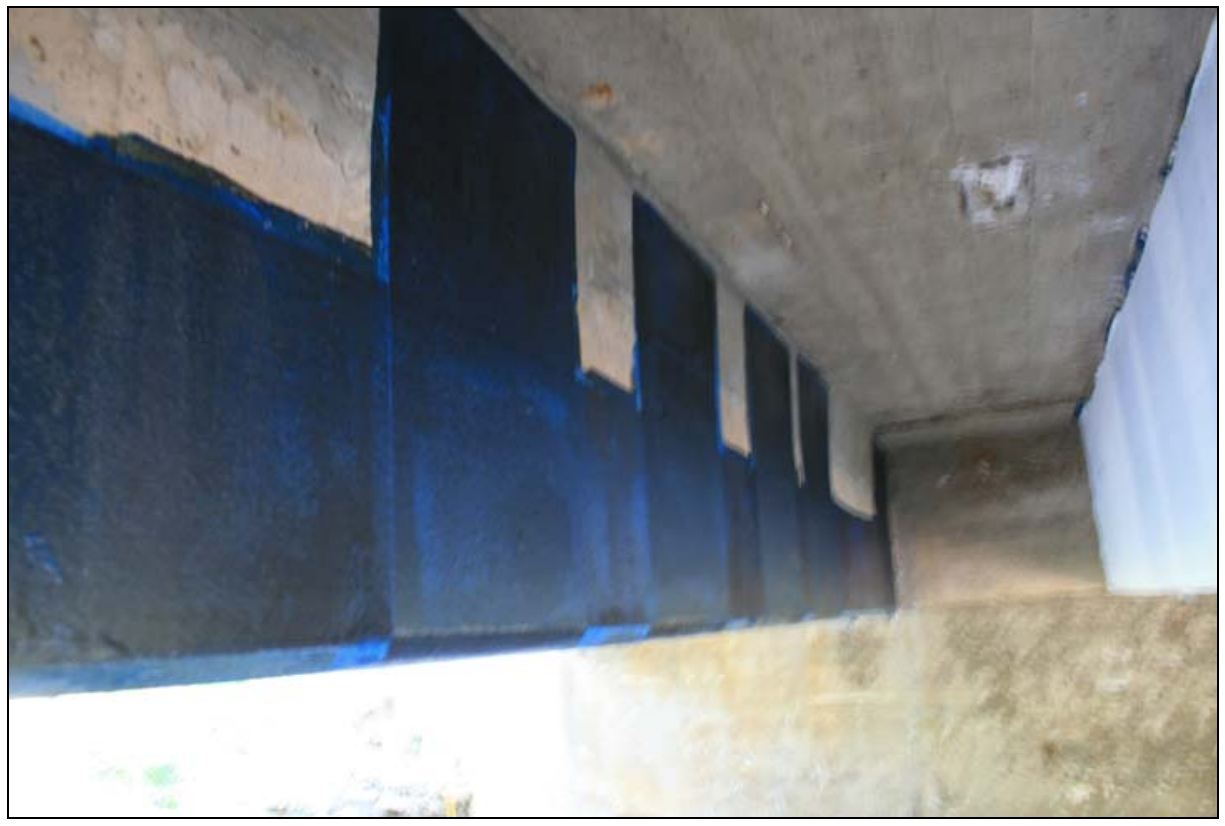

Figure 1.5 Beam 5 FRP Reinforcement 


\subsection{OBJECTIVES AND SCOPE}

This thesis focuses on the FRP strengthening construction and design work, along with post-strengthening field testing and Finite Element (FE) analysis. Several visits to the bridge site were made to observe construction work and FRP application details. The site visits allowed for an assessment of quality control and quality assurance (QC and QA) aspects during the rehabilitation project through direct communication with the contractor and through site inspection. QA testing was performed on site as well as in West Virginia University laboratories. Extended duration site visits were made upon completion of the FRP application to perform field testing in an effort to compare with the results of testing prior to strengthening.

Within the scope of work for this thesis, various guidelines were to be developed in PennDOT - D3 desired formats. These guidelines included: FRP strengthening design guidelines in PennDOT DM-4 format, construction guidelines in PennDOT Publication 408 format, and guidelines for testing and long-term monitoring. DM-4 is PennDOT's Design Manual and Publication 408 is PennDOT's construction specifications. As a result of the desired formats, all guidelines developed are presented in the Appendices: FRP strengthening design guidelines (Appendix D), construction guidelines (Appendix E), and testing/long-term monitoring guidelines (Appendix F). These guidelines are considered significant contributions to Phase III of the project and to this thesis. For this reason, Appendix D through Appendix F shall be regarded as essential components for the comprehensiveness of this thesis.

A user friendly design program was developed to aid the design guidelines. The program includes many issues and analysis concepts important for concrete T-Beam 
bridge FRP rehabilitation. The program follows American Association of State Highway and Transportation Officials (AASHTO) and American Concrete Institute (ACI) guidelines and specifications (AASHTO 1996, ACI 440.2R-08 2008).

Efforts were made to relate design with analysis. This was performed by comparing member force effects resulting from the FE model with resulting force effects using an AASHTO analysis. Rating factors were computed for each set of force effects, which give insight as to whether or not standard design methodologies lead to over- or under-conservative results. Further, several methods for computing live load distribution factors were used and compared. Field testing and FE model deflection and strain data was used to compute live load distribution factors. These values were compared with those obtained via the AASHTO LRFD and AASHTO Standard (LFD) bridge codes, as well as with those obtained via series solution (Zou, 2008).

\subsection{Organization}

The majority of work performed and undertaken in Phase III of the project is collected and presented within this thesis. The organization of the above mentioned thesis work is presented in this section in relation to each chapter. Chapter 2 consists of a comprehensive literature review detailing transportation infrastructure assessment and rehabilitation strategies. Founding and existing design and construction specifications are discussed. Concerns relating to the long-term monitoring of such repair systems are expressed and various case studies are reviewed. Chapter 3 provides information relating to field testing and finite element analysis of the repaired bridge. Testing results are analyzed and discussed. It should be noted that the FE model was created by a separate researcher. The present author altered loading conditions to this model and analyzed 
various results. Chapter 4 details all aspects of the design program created for enhancing the outcomes of the project. This chapter doubles as a user's manual within the program itself and can be accessed by simply selecting "Help" in the file menu. Chapter 5 discusses correlations between design and analysis. The FE model was loaded in accordance with AASHTO, and comparisons were made between force effects resulting from the accurate FE model and force effects resulting from AASHTO Standard specifications. Discrepancies concerning the different analysis methodologies are discussed in terms of load rating factors and live load distribution factors. Chapter 6 presents aspects and knowledge gathering based on field visits for quality control and quality assurance during the repair. During this stage of work, sample testing was performed both on-site and in the laboratory to assess total work quality. Chapter 7 presents final results and conclusions of the work. The Appendices present supplementary details and major project contributions such as the proposed draft guidelines. 


\section{CHAPTER 2 - LITERATURE REVIEW}

\section{$2.1 \quad$ INTRODUCTION}

The research review presented here-in was performed in an effort to assess the structural condition of concrete T-Beam bridges after strengthening with externally bonded FRP. Proper evaluation of any structural rehabilitation project cannot be performed without adequate comparison of the structure before and after retrofit. The literature review shall also address concerns relating to the long-term performance of such strengthening systems. Long-term monitoring techniques for evaluating externally bonded FRP systems for strengthening of RC structures are still largely in the research phase. The literature review will assist WVU researchers in developing a rehabilitation program for PennDOT.

\subsection{TRANSPORTATION INFRASTRUCTURE EVALUATION}

The transportation infrastructure in continuously exposed to environmental conditions that have major deleterious effects over time. This is especially true in regions with varying climates that can cause freeze-thaw and wet-dry cycles. The use of deicing salts during the winter seasons greatly enhances the deterioration. Along with the accelerated aging of bridges, more complications arise as a result of inaccurate bridge records and constantly changing design specifications. Assessing the structural condition of these bridges has quickly become an important research topic. There is much need for improving the cost effectiveness of such structural condition assessments as well as a 
need for economical rehabilitation strategies since the maintenance needs for older bridges have far outpaced available resources.

As reported by Mayo et al. (1999), over 40\% of the nation's bridges are in need of repair or replacement due to poor condition ratings that are often subjective and reported inaccurately. Bridge inspection relies largely on visual assessment which is subjective in nature. Inspection methods that decrease the degree of subjectivity are greatly needed. These methods are gaining research interest. Work should be focused on using measurable criteria to aid in calculating the reduced load bearing capacities of such structures.

Pennsylvania has the third largest concrete T-Beam population in the United States. This means that the state possesses and maintains 2,440 out of the 38,170 concrete T-Beam bridges in the nation (Sasher, 2008). The majority of these bridges (78\%) are simple spans. $60 \%$ of these simple span bridges were built before 1950 and have a maximum life span of 101 years (Catbas et al. 2003). It is also known that these bridges were supposed to be built in accordance with a standard set of design drawings which may not accurately depict the as-built conditions of the structure (Catbas et al. 2003). For these reasons, Pennsylvania can serve as a great state to demonstrate the wide range of applications for rehabilitation with externally bonded FRP.

The use of externally bonded FRP can be very beneficial and economical due to its ease of installation, high strength to weight ratio, and minimum required application space. Also, as opposed to traditional methods in which steel plates would be used to strengthen member, FRP is non-corrosive which decreases future deterioration rates. 


\subsection{FRP CONSTRUCTION AND DESIGN SPECIFICATIONS}

Structural strengthening with FRP composite technology has quickly gained acceptance as a rehabilitation technique with many application possibilities. There has been much research concerning the complexities and susceptibilities of the short term performance of FRP composites throughout the last several decades. Using the results and conclusions of such research, various government agencies have developed construction and design specifications to allow for the adequate use of FRP technologies for structural rehabilitation.

In 1991, an assembly of European nations planned one of the first field applications of FRP composites when the Ibach Bridge in Lucerne, Switzerland was strengthened. Later, in 1993, a research program was carried out in Europe known as EUROCRETE for the intended purpose of developing FRP reinforcement for concrete. Research members from the United Kingdom, Switzerland, France, Norway, and The Netherlands were included in the program.

FRP has been used for construction purposes in Japan since the 1980s. It wasn't until after the Hyogoken Nanbu earthquake in 1995, that FRP technologies were developed for the retrofit of structures. Following this development, the Japanese quickly became leaders in the field of FRP reinforcement applications with about 1,000 demonstration/commercial projects in 1997. Also noteworthy, the Japanese were one of the first civilizations to develop and implement FRP design guidelines which were incorporated into the standard specifications produced by the Japan Society of Civil Engineers (Rizkalla et al. 2003). 
The Swedish Bridge Code: BRO 94 incorporated design guidelines for externally strengthening with FRP in 1999 (Taljsten, 2002). Canada, another leader in the field of development and applications with FRP technologies, published FRP design guidelines in their ISIS Design Manual 3 in 2001. The Taylor Bridge in Headingley, Manitoba employed the use of CFRP in 4 of its 40 precast concrete girders and was opened in 1998.

Design guidelines were published in the United States by Committee 440 of the American Concrete Institute in 2002 titled Guide for the Design and Construction of Externally Bonded FRP Systems for Strengthening Concrete Structures (ACI 440.2R-02). In 2008 these guidelines were updated (ACI 440.2R-08). The document contains information on material background, design recommendations, construction recommendations, drawing specifications, and design examples. Updated ACI guidelines were used for structural analysis, design program development, and for the development of various design and construction guidelines resulting from this research.

The short term behavior of FRP composites were investigated under the National Cooperative Highway Research Program (NCHRP) Project 10-59A (Dolan, 2006). NCHRP Report 514 Bonded Repair and Retrofit of Concrete Structures Using FRP Composites: Recommended Construction Specifications and Process Control Manual was created in 2004 as a direct result of Project 10-59A. The document contains in depth recommended construction specifications along with guidelines for submittals, storage, quality assurance, and cost analysis (Sasher, 2008). This document is still under review by the AASHTO Highway Subcommittee on Bridges and Structures for possible implementation into their specifications for highway bridges. 
NCHRP Report 514 and ACI 440.2R-08 were extensively used for the design and construction aspects of the concrete T-Beam demonstration project used throughout this research. If not for this pre-existing documentation, the project task of developing design and construction guidelines in PennDOT desired formats would have been much more strenuous.

\subsection{LONG-TERM MONITORING}

It is well known within the structural engineering community that retrofitting $\mathrm{RC}$ structures with externally bonded fiber-reinforced polymers (FRP) is gaining increased acceptance. With much approval for the use of this technology to effectively extend the life of concrete structures, adequate conclusions and approval for practical long term monitoring techniques have yet to be made and are still largely in the research phase. This is an important aspect to consider giving that the effectiveness of the FRP for strengthening is strongly dependent on perfect adhesion between the concrete substrate and the FRP material. Therefore, it is imperative that Non-Destructive (ND) methods be used for inspection of these repair systems. ND methods may include visual inspection, audio or tap testing, ultrasonics, infrared thermography, and selective bond pull-off testing. Out of these, there has been considerable research on the implementation of infrared thermography (IRT) to detect defects in FRP concrete systems. Increasing research has focused on validating infrared thermography testing by inducing defects of known characteristics, such as type, depth from the surface, and dimensions. Since one task of Phase III for the PennDOT project is the development of guidelines for long-term inspection and monitoring of rehabilitation work with FRP, as presented in Appendix F, a more detailed investigation into the practical use of NDT techniques such as infrared 
thermography is of great interest. As a result, some of the case studies included in this chapter review published work on the use of infrared thermography to detect sub-surface defects in composite FRP-concrete systems.

\subsubsection{Infrared Thermography}

Infrared thermography is concerned with the measurement of radiation in the infrared range of the electromagnetic spectrum. With the measurements of radiation made, thermal images called thermograms can be developed. Temperature differences observed on these thermal images can be used to detect the presence of subsurface anomalies and defects.

There are two general techniques used for infrared thermography, passive thermography and active thermography. In passive thermography, the surface is naturally heated by the sun. Passive thermograhy is commonly employed for non-destructive testing of bridge decks and other large, flat surfaces that are easily penetrated by the sun's rays. In active thermography, an external heat source such as a heating lamp is used to heat the surface of an object to be tested. The type of test set-up and choice of algorithm for analysis needs to be properly selected and calibrated for the specific problem evaluated. Algorithms considered as suitable for discovering sub-surface defects are principal component analysis (PCA), pulse phase thermography (PPT), and thermal tomography (TT). PCA considers the statistical characteristics of a data set. A covariance matrix represents variations in temperature history profiles for individual pixels in comparison to average temperature profiles of the data. PPT processes data sets in terms of magnitude and phase of specific frequencies of the Fourier Transform of the surface temperature following pulse heating (Valluzzi et al. 2008). A Fast Fourier 
Transform algorithm transforms the temperature profiles. TT processes surface temperature data by selecting adequate calibration functions to characterize defects in depth and thickness. TT is the simplest way to evaluate delamination distance form the surface (Vavilov et al. 1992).

\subsection{Case Studies}

A wide variety of topics and issues with FRP composites have been researched. This is due to the materials many application possibilities. The following information is more related to the work performed for this research project. Much of the reviewed literature is concerned with CFRP repair and post-repair assessment. Moreover, the FRP repair system considered is externally bonded. Some of the research is very similar to the present project in which bridge rehabilitation has been performed and various conclusions of such a project are gathered. Other case studies focus on possible conditions of such a repair project many years after its initial application, along with evaluating suitable methods for monitoring these externally bonded FRP systems. Longterm monitoring literature is reviewed first while lab testing and field testing of FRP applications is reviewed second.

Work performed by Valluzzi et al. (2008) investigated the interface bond between FRP laminates and RC beams by infrared thermography. For the study, a set of RC and prestressed reinforced concrete (PCR) beams reinforced for flexure by applying ordinary and pre-tensioned CFRP pre-impregnated laminates to the bottom face were analyzed with active thermography, before and during bending tests.

Teflon strips, silicon grease, and nylon for packaging were used to create the defects. The equipment used for the preliminary tests on these specimens was equipment 
that is commonly used for pulsed thermography. The tests incorporated the use of two flash lamps that delivered energy of 2,400 $\mathrm{J}$ in about $10 \mathrm{~s}$ and a FLIR ThermaCAM SC3000 as the thermal camera that was sensitive in the long wave band.

An active technique was used. The thermographic system was placed about 80 $\mathrm{cm}$ away from the surface of the samples and the surface temperature versus time was measured by capturing data at $20 \mathrm{~ms}$ time intervals. Then, various algorithms could be used to compare cooling phases for various surface elements.

After preliminary testing, thermographic tests were performed on two full-scale beams, $10 \mathrm{~m}$ long and $30 \times 50 \mathrm{~cm}$ in section. The pre-impregnated CFRP laminates used to strengthen the underside of both beams were $1.2 \mathrm{~mm}$ thick and $80 \mathrm{~mm}$ wide. The tensile strength and the elastic modulus of the CFRP laminate were 2,800 MPa and 166 GPa, respectively.

The method was very capable of locating defects at the interface of the concrete and FRP and also gave rough estimates of defect size. The results indicate that IRT is particularly effective in discovering construction defects and imperfections, and also may be capable of locating potential weak or missing bond areas if data is examined by trained personnel. The method can make it possible to follow progression of defects during loading. The reliability of the method has been verified by means of visual inspection after testing.

Since current ACI guidelines call for repair of rehabilitation work based on defect size and frequency, future work should be performed on enhancing the thermographic testing capabilities to determine the defect size. Due to the complexities associated with the testing equipment set-up, it is easy to conclude that this IRT application may still not 
be easily implemented for large-scale field structural components. The testing would be very time consuming as it would most often have to be performed manually as a result of the difficulties associated with employing an automated data acquisition system due to accessibility restrictions that are faced in field applications.

Work performed by Corvaglia et al. (2007) focused on developing a reliable technique for testing by infrared thermography. The work was to result in a testing method that supplied results that personnel could be confident in. Hidden defects in FRP-reinforced concrete structures were to be examined by pulse heating thermography (PT) and lock-in thermography (LT). A concrete sample was reinforced with FRP and defects with known sizes and locations were created at the interface. The two IRT methods were carried out and their respective results compared.

Two types of defects were created with different shapes and dimensions. The researchers were able to conclude that lock-in thermography was able to detect delaminations more successfully than pulsed thermography.

The researchers concluded that the following parameters should be used with LT, to enhance defect visibility: start frame in correspondence to heating start and $(\mathrm{n}+0.75)$ numbers of sampled cycles. With these parameters, the thermal images are distinguished by a lower contrast value but, at the same time, also by a lower noise value. This is the first conclusion of this type for literature concerning LT, as all previous research in this area concludes that a whole number of sampled cycles results in the most enhanced defect visibility.

$\mathrm{LT}$ is the only technique that can estimate lack-of-bonding dimensions. LT is not sensitive to the testing setup either, which can be quite advantageous. In general, 
thermographic analysis should be considered as a very quick and cheap technique for insitu evaluation of bond quality for FRP-concrete systems. The most adequate technique, PT or LT, will depend on the specific application, along with the corresponding properties of the materials investigated.

Blok et al. (2009) conducted very interesting research on thermal imaging to monitor and evaluate load-induced delaminations of FRP composites bonded to small scale RC beams for flexural strengthening. In the study, two beams ( 3.5 in x 4.5 in $x 58$ in) were loaded monotonically and two beams were subjected to fatigue loading. For the monotonically loaded beams, IRT inspections were performed at various load levels up to failure, using a phase imaging technique. For the beams subjected to fatigue loading, periodic IRT inspections were performed at 50,000-cycle intervals. The long-term objective, according to the researchers, was to develop a general framework to perform quantitative IRT inspections of FRP-Concrete systems and to incorporate this framework into acceptance criteria for installations and estimates of service life remaining for FRP systems.

The research demonstrates that the delamination characteristics of an FRPreinforced concrete system can be evaluated dynamically with IRT techniques during monotonic or cyclic loading (Blok et al. 2009). The work signifies considerable progress for creating a practical framework for accomplishing quantitative IRT inspections for FRP-concrete systems. The results can be used to develop acceptance criteria for new installations and estimates for remaining FRP service life.

Ball (1998) used a reliable instrumentation plan and data analysis to monitor the change in the behavior of reinforced concrete beams in order to understand the effect 
externally bonded FRP has on reinforced concrete structures. More specifically, the change in behavior of reinforced concrete beams as externally bonded carbon FRP plates and sheets were placed on the tension zone of RC structures was studied.

Ball found that FRP reinforced beams showed an $11.5 \%$ to $58.6 \%$ reduction in steel strains over baseline tests and a $3.0 \%$ to $33.5 \%$ reduction in the compressive concrete strains. An observable downward shift in the neutral axis location occurred, in accordance with a more over-design condition and higher reinforcing ratio.

Two reinforced concrete bridges were rehabilitated using externally bonded FRP as well. These bridges were load tested and data from instrumentation were obtained. The strain and deflection values obtained were too small to draw any conclusions regarding the performance of FRP on the bridges.

Bonfiglioli et al. (2004) performed research incorporating lab scale dynamic testing to investigate methods of determining the long term effectiveness of externally bonded FRP composites on beams. Modal analysis was used in the testing procedure to determine stiffness variations resulting from damage and strengthening of the beams. It was concluded that damaged areas can be detected and localized by this testing technique but it is not capable of estimating the global behavior of the structure after rehabilitation. As such, the research suggests that modal testing is a viable form of non-destructive testing for interpreting the effectiveness of a strengthening system on damaged reinforced concrete beams.

Hag-Elsafi et al. (2000) researched the use of FRP composite laminates to strengthen an aging reinforced concrete T-beam bridge in Rensselaer County, New York. The bridge was a single span structure with considerable moisture and salt infiltration. 
Built with an integral deck in 1932, the bridge is $12.19 \mathrm{~m}$ long and about $36.58 \mathrm{~m}$ wide. It was supported by 26 beams spaced at $1.37 \mathrm{~m}$ center to center. Structural integrity and safety of the bridge was of great concern. The bridge lacked any documents pertaining to the design, such as rebar size, steel type, concrete strength, and design loads. Pre and post load testing was performed on the structure to assess the effectiveness of the strengthening system and explore its effect of structural behavior.

The design of the FRP for flexural and shear was based on an assumed $15 \%$ loss, due to corrosion, of the reinforcing steel rebar area. The nine center beams of the bridge were instrumented. For flexural analysis, steel-rebars and laminate strains were acquired at the midspan of beams to provide information on live-load distribution. A chosen center beam of the bridge (beam 11) was also instrumented near the support to examine the effect of the strengthening system on shear, and at quarter and midspan to assess laminate bond to concrete and laminate stresses.

Using strain data, the researchers were able to compare "before" and "after" liveload distribution factors for beam 11 . They concluded a slight increase of about $12 \%$ in live-load distribution after laminate installation. This increase was contributed to the laminates bonded to the underside of the deck, between beams. Compressive strains in the concrete were found to be higher after the laminates were installed. Upon determining the neutral axis locations, if was found that the neutral axis location for beam 11 had migrated downwards by about $33 \mathrm{~mm}$ due to the flexural laminates.

Overall, load tests results revealed that, after laminate installation, main rebar stresses were somewhat reduced, concrete stresses moderately increased and transverse live-load distribution to the beams slightly improved under service loads. Expected 
moment and shear forces were significantly reduced due to the inherent fixity of the beam ends. The research also concluded that the total cost of rehabilitation was around $\$ 300,000$ whereas replacement of the structure required $\$ 1.2$ million.

Alkhrdaji and Nanni (1999) performed tests on two types of FRP strengthening methods with two identical bridges. The two types of FRP strengthening methods were Near Surface Mounted (NSM) FRP rods and externally bonded FRP sheets via wet layup application. The design of each FRP system was one in which the flexural strength of each bridge would be effected in the same way. Each bridge was a three-span concrete slab structure composed of simple spans and it was constructed in 1932. Increasing traffic demands lead to the bridges being labeled for demolition. Cost, labor requirements, and construction process were investigated to assess the overall effectiveness of the FRP as a strengthening system. The rehabilitated structures were tested to failure. The FRP systems were applied in one week with no traffic delays. Test results confirmed that each of the FRP systems provided significant improvement over the un-strengthened deck.

A team of researchers in Missouri (Alkhrdaji, Nanni, Chen, Barker, 1999) conducted destructive and non-destructive testing techniques on FRP strengthening systems. The effectiveness and feasibility of two FRP strengthening systems on reinforced concrete bridge decks with the intent of increasing flexural capacity by $30 \%$ were to be determined. The two FRP systems included NSM carbon rods and externally bonded CFRP sheets. Three bridge decks built in 1932 were tested. Of these three, two were strengthened with the FRP systems. The decks were statically and dynamically tested before and after rehabilitation. The Missouri Department of Transportation 
(MoDOT) recommended material properties of $33 \mathrm{ksi}$ yield strength for steel and $2.5 \mathrm{ksi}$ concrete compressive strength. Although, for a more accurate analysis, material samples were collected from the field and tested. The material sample testing indicated a steel yield strength that was $31 \%$ higher (43 ksi) than MoDOT's suggested value while showing a concrete compressive strength that was $226 \%$ higher ( $8147 \mathrm{psi}$ ). Actions were taken to try and limit the effects of secondary structural elements such as composite action of parapets and fixity at the supports. Although with the effects of these secondary structural elements unavoidable, the bridge decks displayed strength characteristics in excess of those predicted by standard design manuals. In any case, the final failure mode was found to be pseudo-ductile behavior with a combination of CFRP rupture and delamination of the sheets.

Lopez and Nanni (2006) carried out research relating to increasing load carrying capacity and removing load postings. Four concrete T-Beam bridges and one slab bridge in Missouri were used in the study. Externally bonded FRP composites were applied in such a way to resist an increase of up to $30 \%$ in live load capacity. Load testing was conducted before and after strengthening. Load Factor Rating (LFR) method was used for the load rating analysis while considering an HS20-44 truck loading. The steel yield strength used was $40 \mathrm{ksi}$ as recommended by AASHTO, while concrete core samples were taken and tested to present a concrete compressive strength between 4.0 and $6.8 \mathrm{ksi}$. ACI 440.2R-02 guidelines were followed to design the FRP strengthening system. Uniquely, deflection measurements were taken using a Total Station which is an instrument most commonly used in surveying. Upon obtaining the results and conclusions of the study, MoDOT opted to remove the load posting on all the bridges 
strengthened. In order to evaluate possible stiffness degradation with increasing time and environmental exposure, it was concluded to perform semi-annual tests until 2011. 


\section{CHAPTER 3 - LOAD TESTING AND FE MODELING}

\subsection{INTRODUCTION}

Details and results of the bridge load testing and FE modeling and analysis are presented within this chapter. All load testing preparation work and the instrumentation setup along with corresponding figures are shown. Static and dynamic loading cases are illustrated. Loading trucks used in the research are detailed, presenting individual wheel loads and wheel spacing. FE model construction and analysis is discussed. Displacements, strains, and dynamic responses of the un-repaired and repaired structure are presented.

\subsection{TESTING OF REPAIRED BRIDGE}

The objective of testing the repaired bridge was to acquire data that would be useful in correlating with results from the FE analysis, and for calibrating and improving the accuracy of the FE model, so that an accurate analysis of the bridge could be performed with allowances for unknown variables; and to compare with data obtained from testing the un-repaired bridge to illustrate the effectiveness of the repair technology.

\subsubsection{Setup}

Similar to the testing plan of the un-repaired bridge, strains and displacements were recorded at the center of the bridge span under each girder. Accelerations were recorded at the mid-span under Girder \#4. See Figure 3.1 for the position of instruments. 


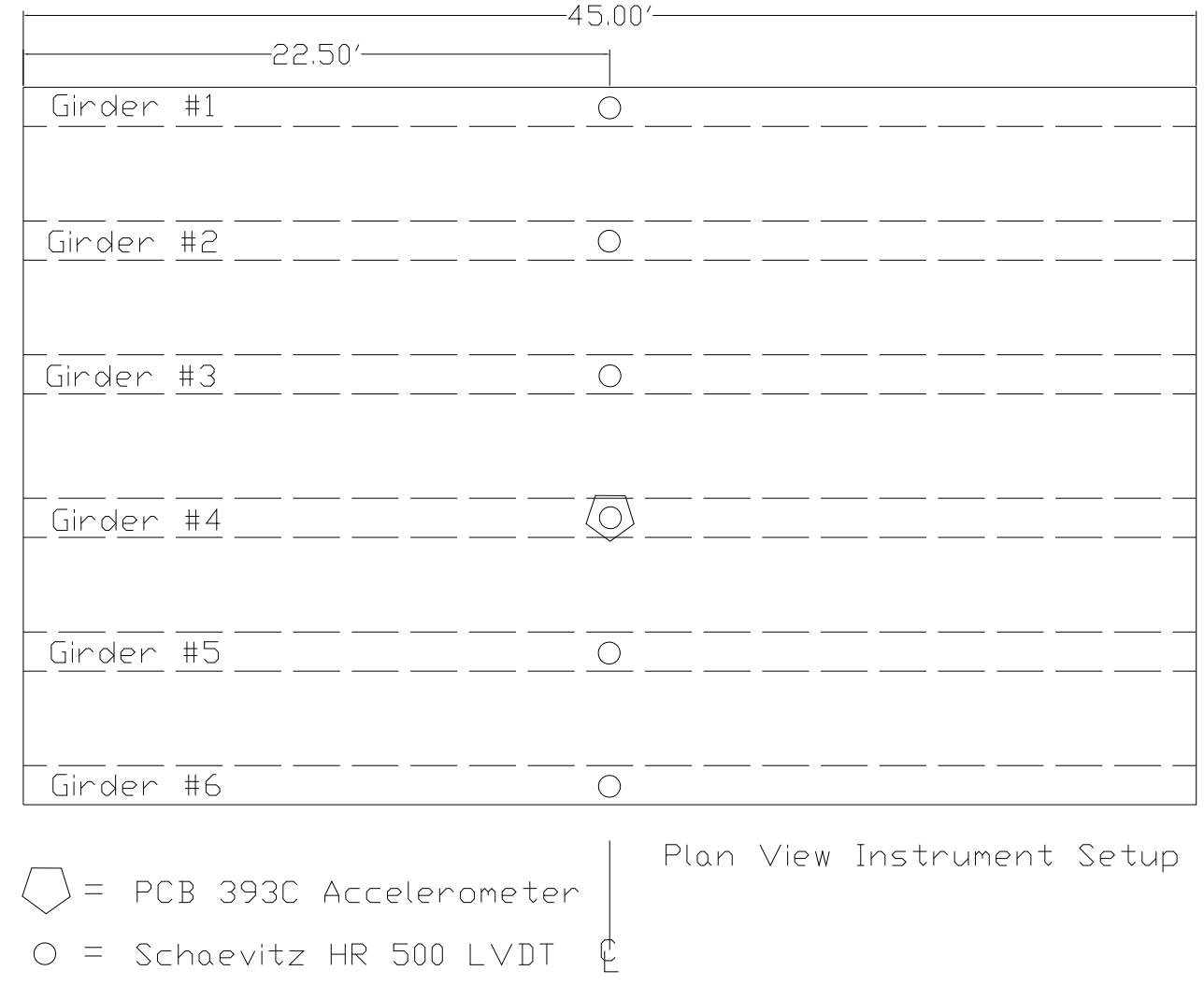

Figure 3.1 Plan View Instrumentation Setup

\subsubsection{Strain Gages}

In order to find the neutral axis of each girder under loading, four strain gages were to be placed on each girder. Three gages would be placed at the quarter, half, and three-quarter height of the girder web, measured from the bottom of the deck to the bottom of the T-beam. All of these gages would be bonded to concrete, with the exception of the gage at the three-quarter point of Girder \#5 which was bonded to a shear reinforcing FRP strip due to the FRP design. It was observed that, as with most concrete surfaces, irregularities were present at some of these locations. As a result, those locations were altered slightly in an attempt to avoid irregularities and obtain better strain data. Refer to Figure 3.2 and Table 3-1 for a general layout on vertical girder faces and 
exact locations of strain gages, respectively. The fourth gage was placed at the center of the bottom face of the T-beam bonded to a flexural reinforcing FRP strip. All gages used on concrete were 4-inch general-purpose strain gages (Vishay Model N2A-06-40CBY350/P), while all gages used on FRP were 2-inch general-purpose strain gages (Vishay Model N2A-06-20CBW-350/P).

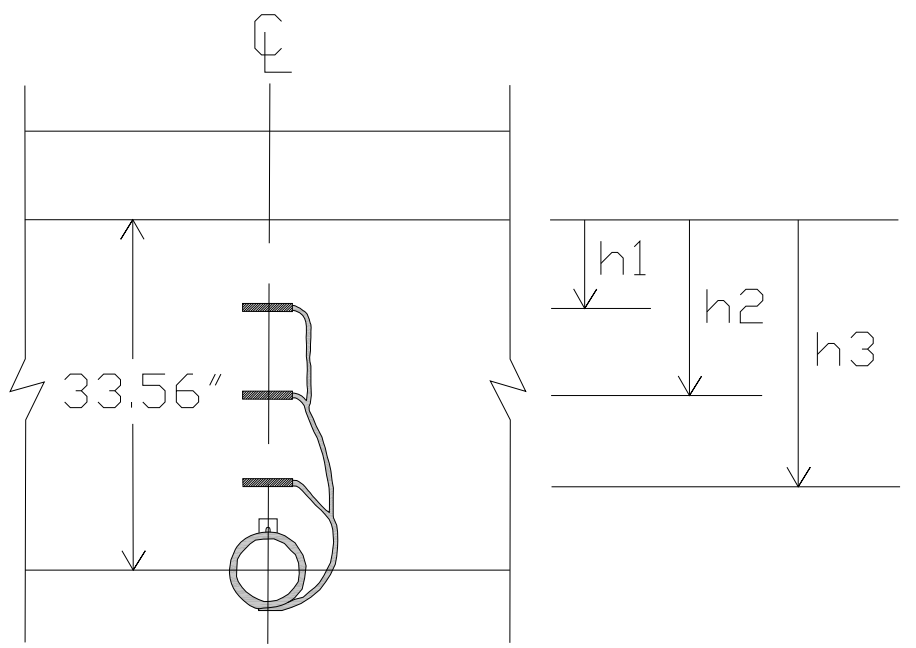

Figure 3.2 Strain Gage Layout on Web

Table 3-1 Exact Strain Gage Locations

\begin{tabular}{|c|c|c|c|c|c|c|c|}
\hline & \multicolumn{6}{|c|}{ Girder \# } \\
\hline & & 1 & 2 & 3 & 4 & 5 & 6 \\
\hline \multirow{3}{*}{ త্ } & h1 & 9.3 & 8.5 & 8.3 & 8.9 & 9.0 & 9.2 \\
\hline & h2 & 15.8 & 16.5 & 17.6 & 17.8 & 17.2 & 17.8 \\
\hline & h3 & 25.5 & 25.5 & 25.5 & 26.0 & 25.6 & 26.4 \\
\hline
\end{tabular}

For the un-repaired bridge testing, the concrete surface preparation was attempted but was not successful because the $100 \%$ solid adhesive chosen at that time, Vishay M-Bond 
AE-10, could not cure at temperatures below $75^{\circ} \mathrm{F}$. In an effort to solve this problem, under the advice of Vishay applications engineers, a different adhesive was chosen for the void filling process during this test. This adhesive, Vishay M-Bond 300, would allow for curing under a much broader range of temperatures. The curing requirements were: 24 hours at $+40^{\circ} \mathrm{F}, 18$ hours at $+60^{\circ} \mathrm{F}$, and 12 hours at $+75^{\circ} \mathrm{F}$. With this wide range of curing temperatures, the surface preparation was successfully performed. When the preparation was complete, each gage was bonded using Vishay M-Bond 200 and covered with Vishay Barrier E for protection. Figure 3.3 through Figure 3.5 illustrate some of these aspects with the strain gage application process.

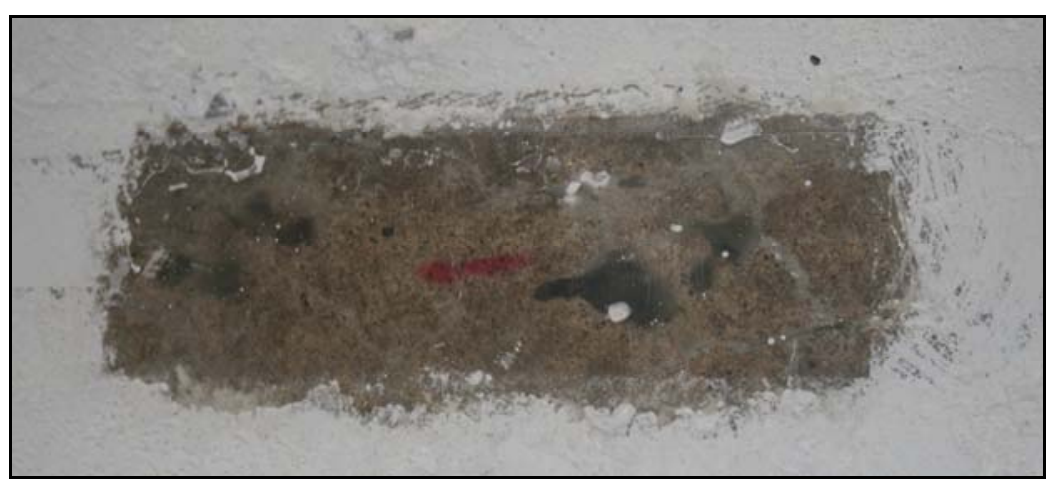

Figure 3.3 Surface Preparation 


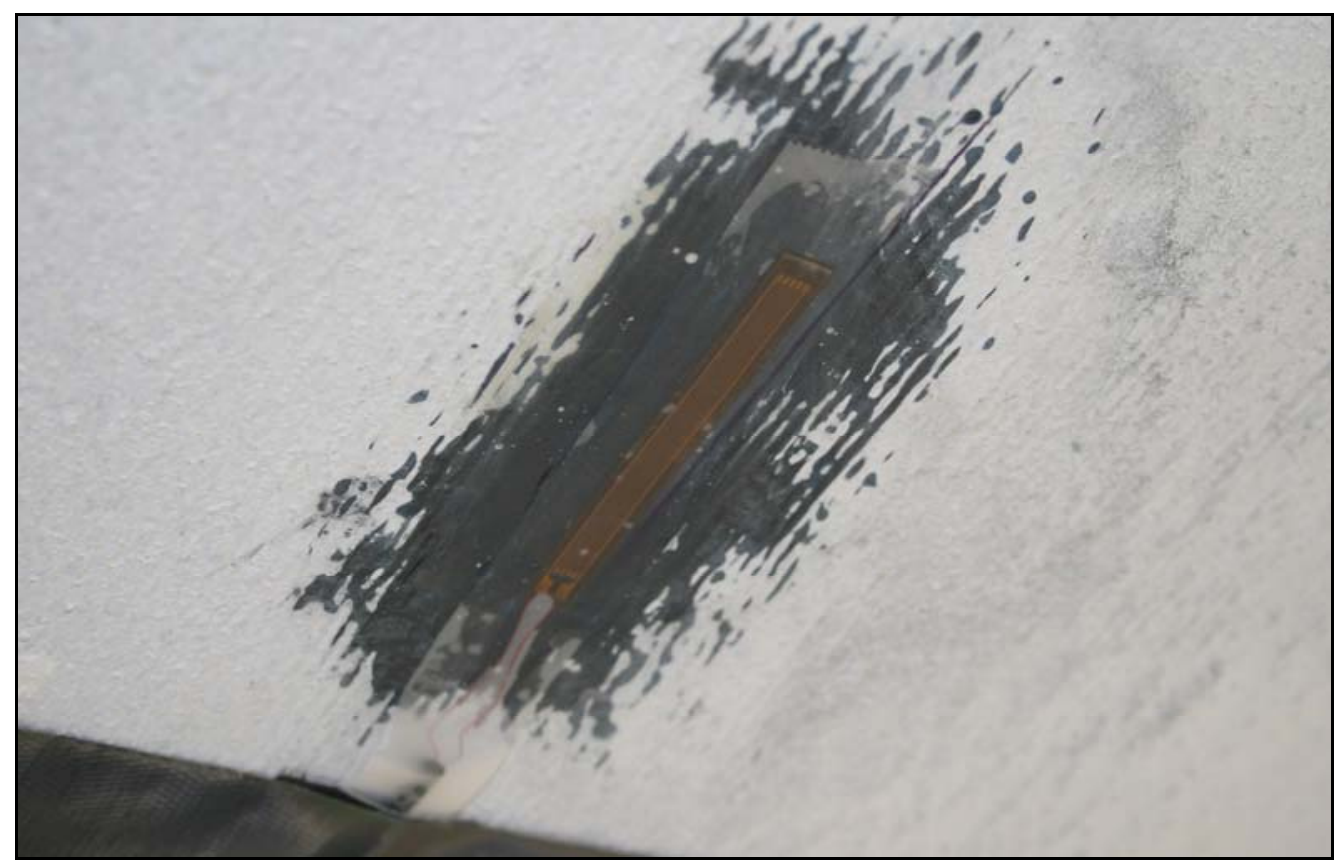

Figure 3.4 Gage on Flexural FRP

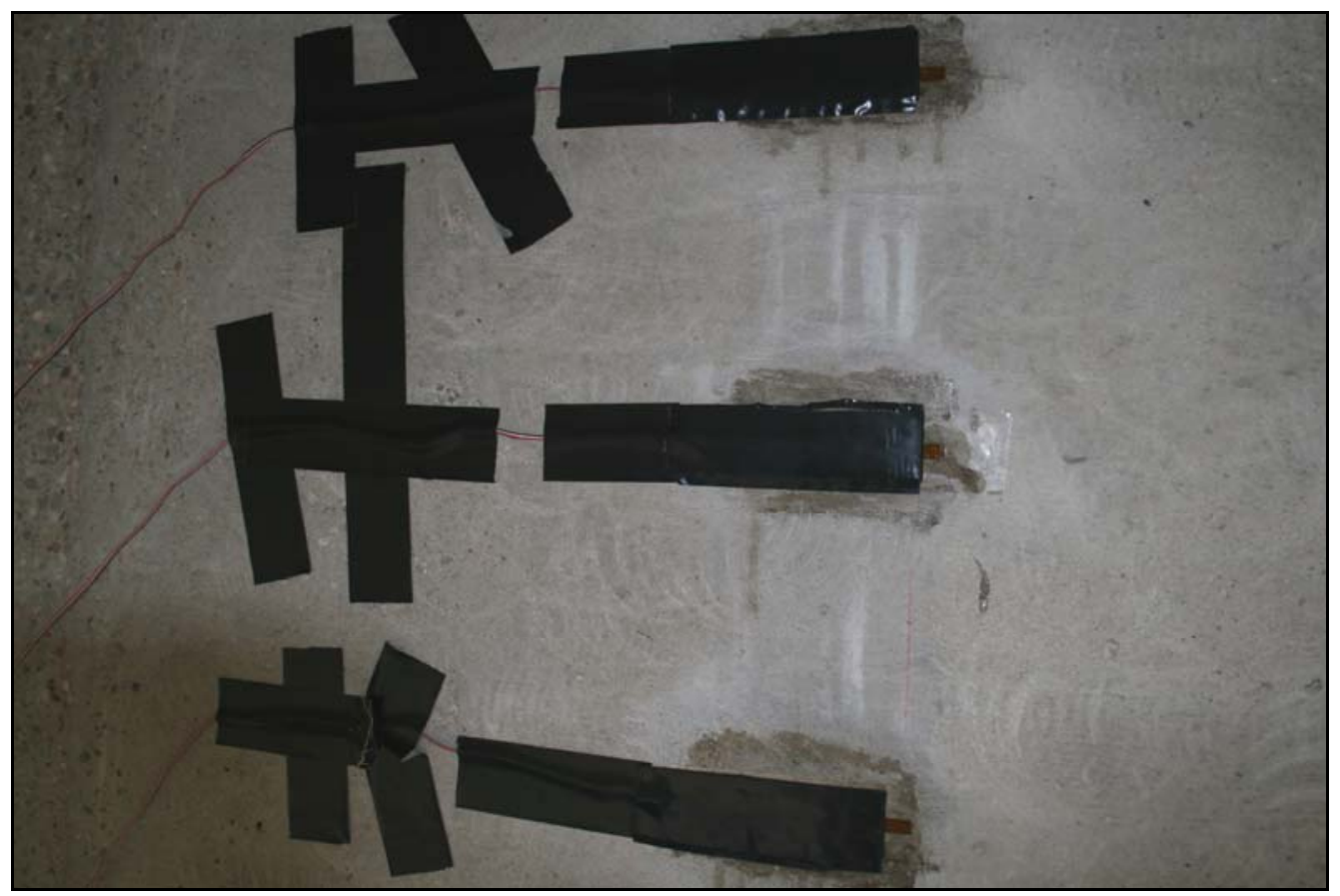

Figure 3.5 Concrete Gage with Barrier E Protective Coating 


\subsubsection{LVDT's}

Six Shaevitz HR 500 LVDTs were placed, one at the bottom-inside face of every girder (see Figure 3.6). The LVDTs had a range of \pm 0.5 inches with a sensitivity of 0.001 inches. The LVDTs were held in place by rubber grip test tube holders that sat on scaffolding, as can be seen from Figure 3.7. Due to the clearing of the creek bed after the repair was completed, scaffolding served as a very convenient tool for both testing preparation and setup; providing a rigid and level surface. The displacements were taken at ten scans per second during the static load tests. Figure 3.8 illustrates this overall setup.

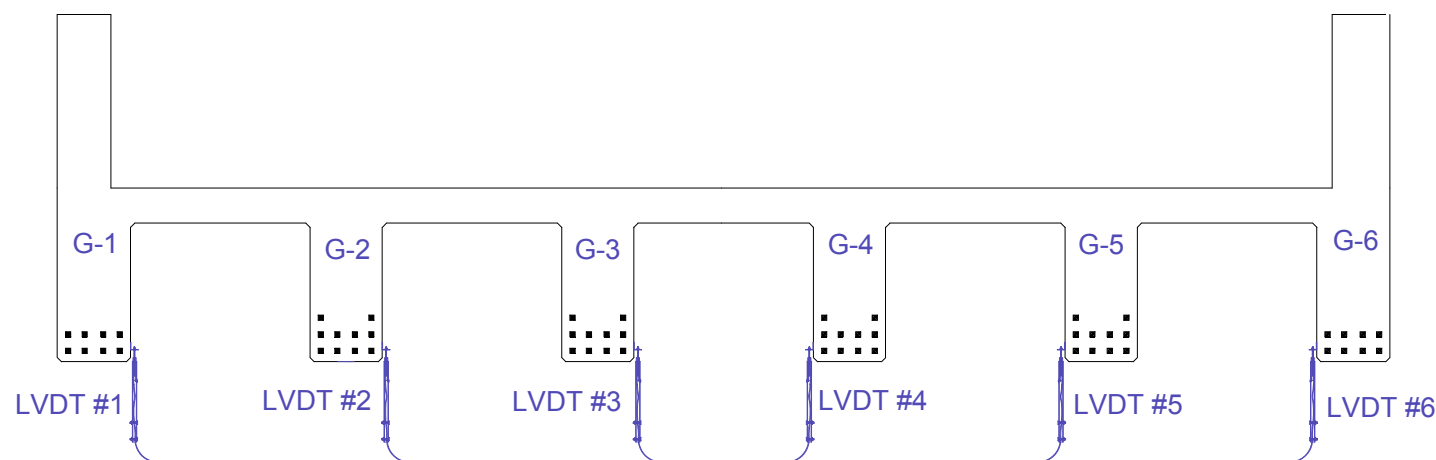

Figure 3.6 Cross-Section View of LVDT Setup

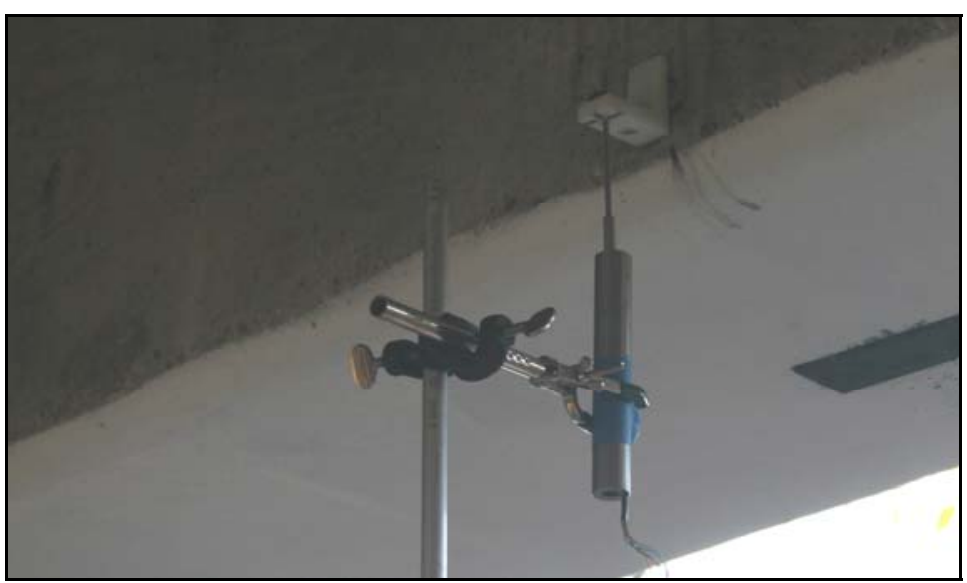

Figure 3.7 LVDT Setup 


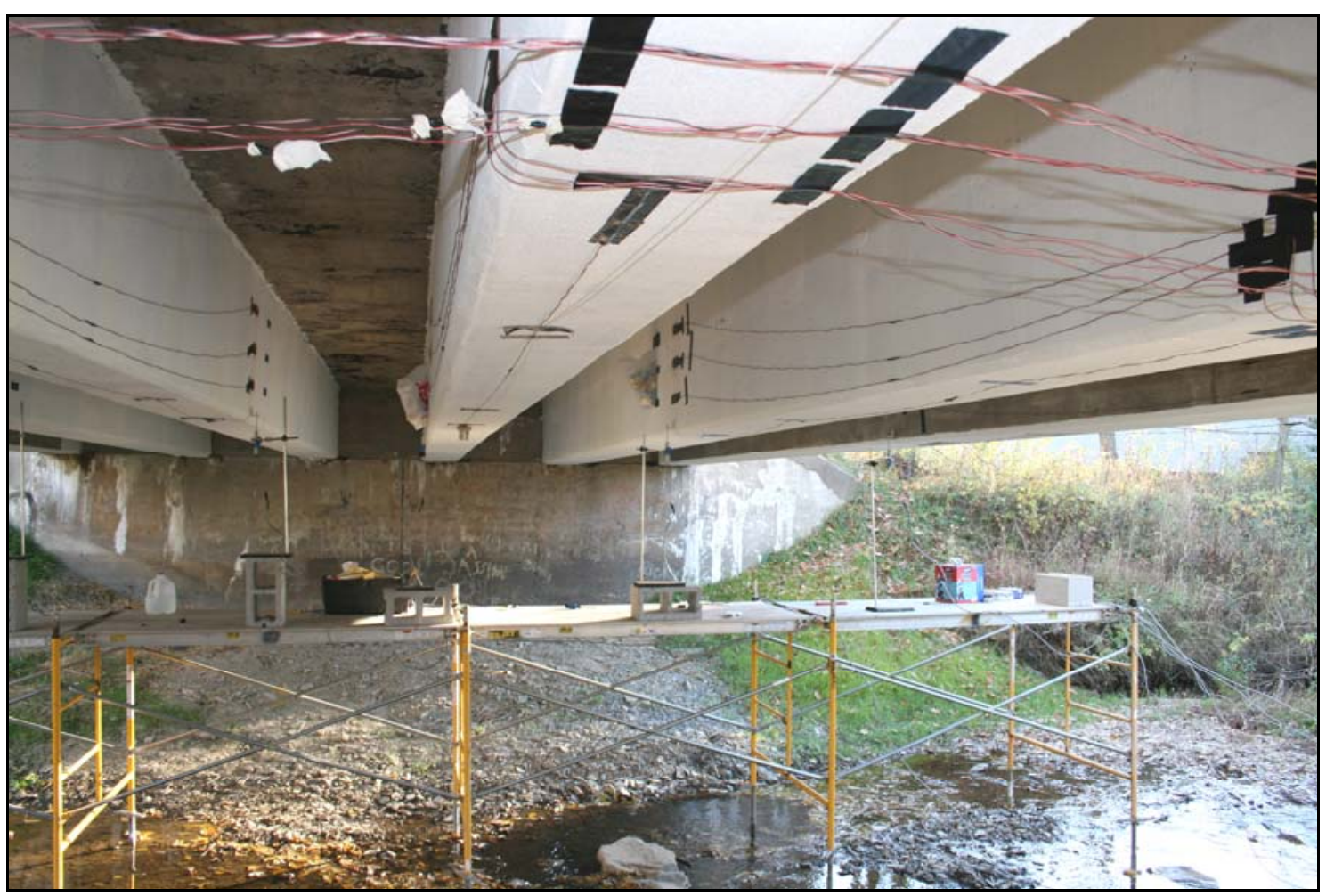

Figure 3.8 Overall Test Setup

\subsubsection{Accelerometer}

A PCB Model 393C accelerometer was used to measure the vibration response of the bridge due to dynamic loading. The accelerometer was placed under the interior Girder \#4 to closely reproduce the testing setup of the un-repaired bridge (see Figure 3.9). The data was collected using a Vishay System 6000 data acquisition system that allowed for using a data collection rate of 10,000 scans per second. Figure 3.10 illustrates the total instrumentation setup. 


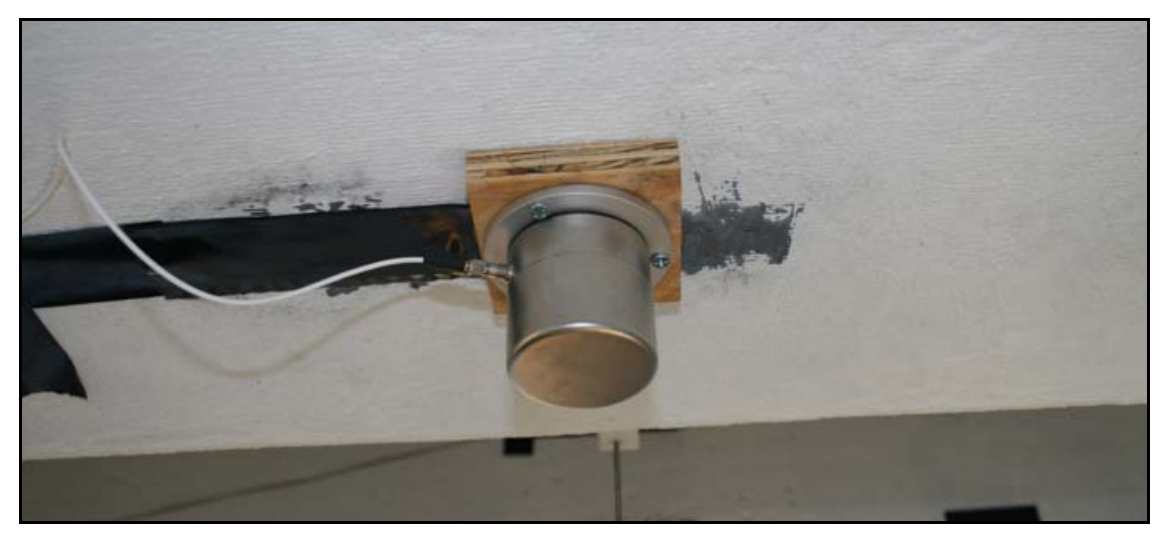

Figure 3.9 PCB 393B Accelerometer Mounted

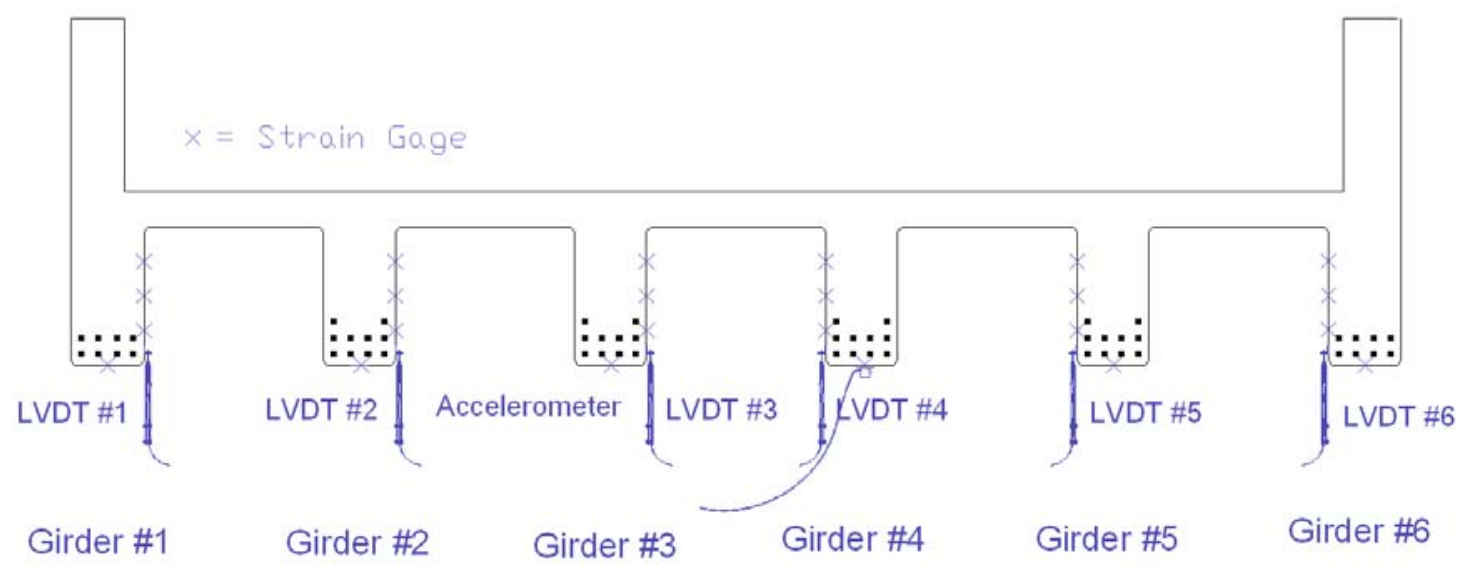

Figure 3.10 Cross-Section View Instrumentation Setup

\subsubsection{Data Acquisition Setup}

All the instruments were connected to the data acquisition system and computer setup at the top of the hill near the north abutment as shown in Figure 3.11. The field setup consisted of three data acquisition systems, two computers, and a battery backup. The two extra data acquisition systems and extra computer were needed for testing of the repaired bridge due to the added sensor channels needed for the strain gages. The data processing was handled by Vishay System 5000 and System 6000 data acquisition 
systems. Strain Smart software version 4.01 produced by Vishay was used to process the data collected during all of the tests.

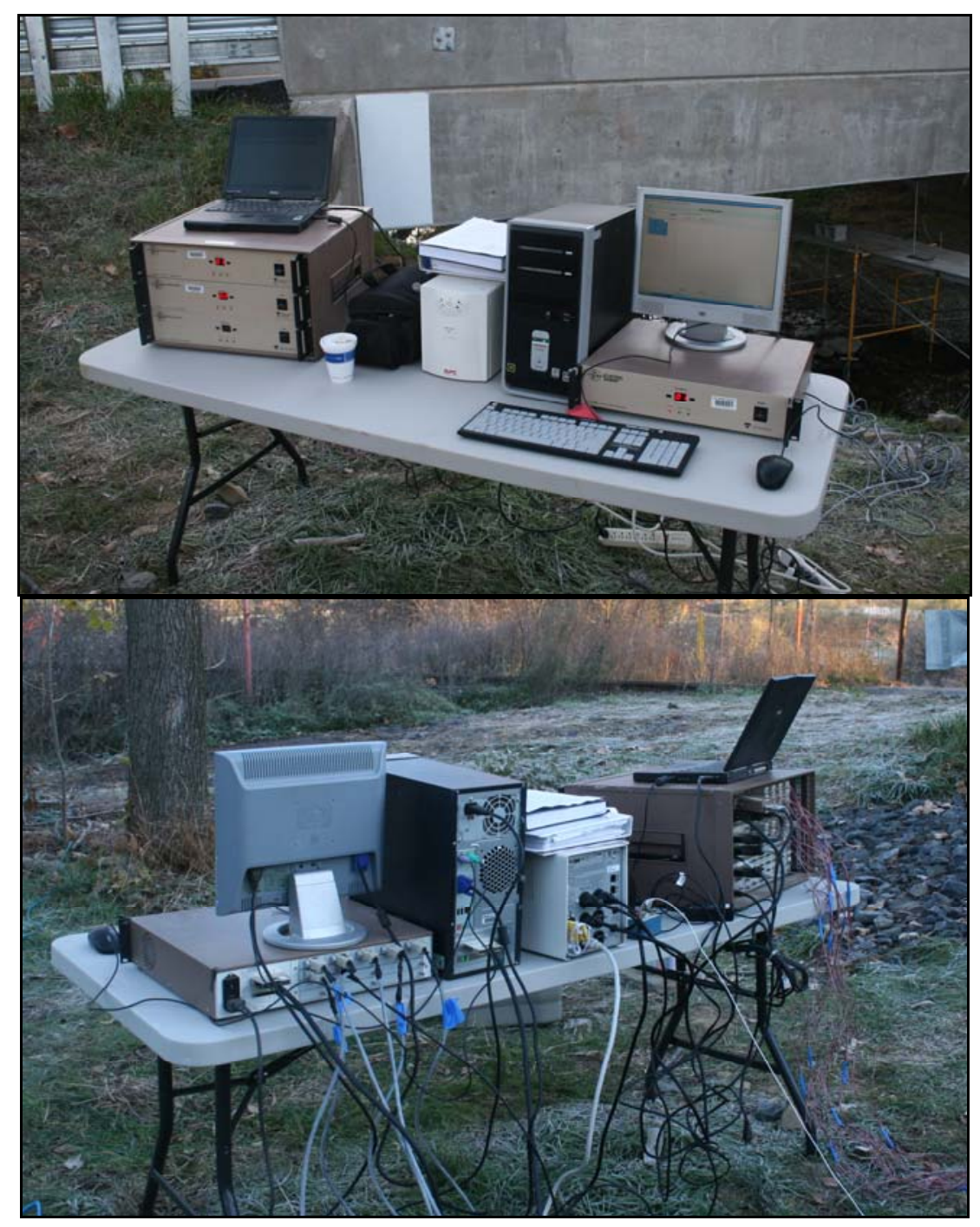

Figure 3.11 Data Acquisition Setup

\subsubsection{Trucks}

Similar to the testing of the un-repaired bridge, PennDOT provided two fully loaded tandem dump trucks for the load test. PennDOT personnel weighed the trucks' individual wheel loads using scales. The loads were then used to calculate the centroid of 
truck loading to define where to line up the trucks on the bridge during testing for maximum load effects. Figure 3.12 and Figure 3.13, respectively, show details for each truck.

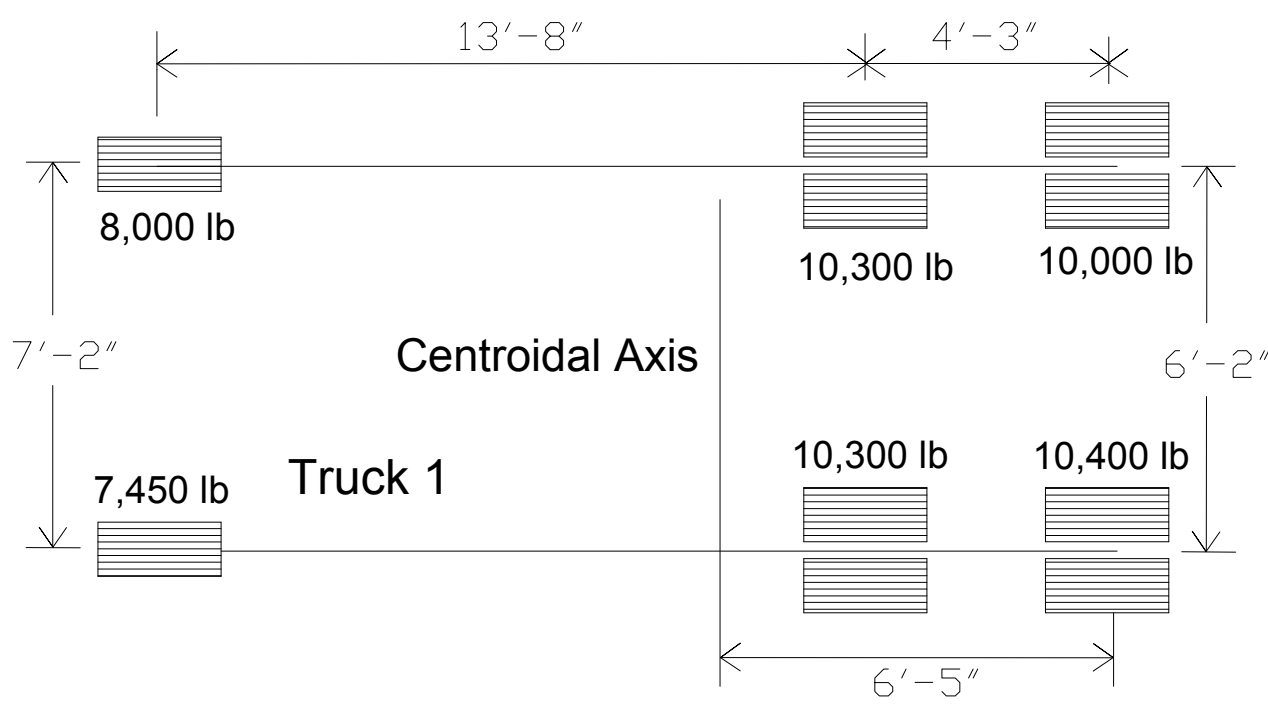

Figure 3.12 Truck 1

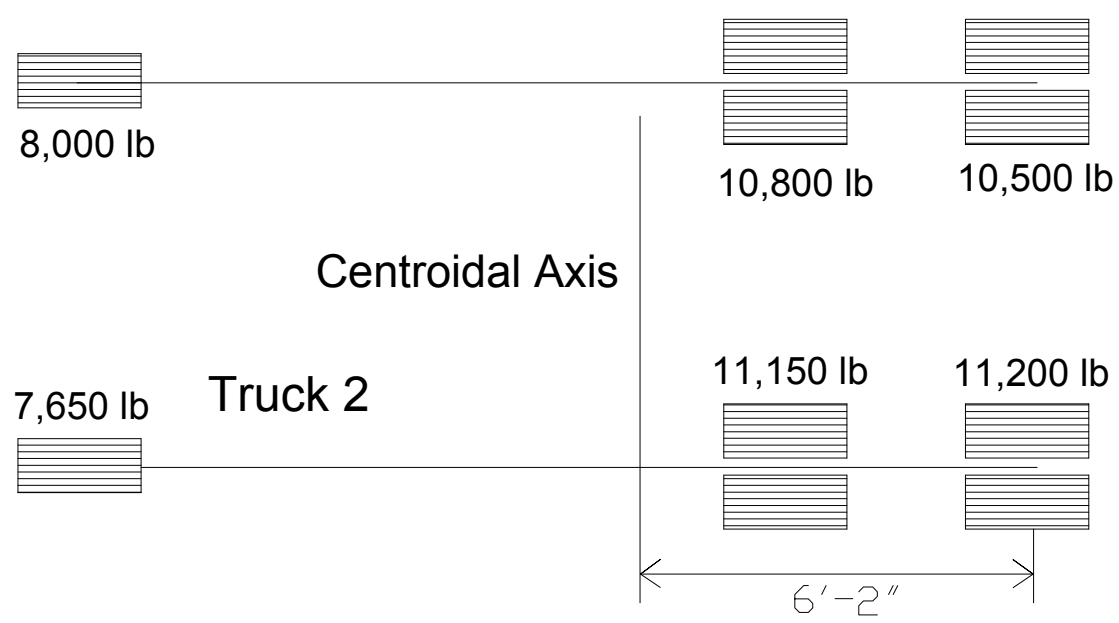

Figure 3.13 Truck 2 


\subsubsection{Static Load Cases}

During testing of the un-repaired bridge, many of the load cases had to be altered due to the dimensions of the bridge and trucks. For comparison purposes, the same load cases with an addition of two more (Load Case \#5 and Load Case \#6) were used in this testing. Load Case \#5 is a mirror load of Load Case \#2-one truck, while Load Case \#6 is a mirror load of Load Case \#4-one truck. The same modified load cases \#1 and \#2 were also used in the repaired bridge testing. The goal of the modified load cases was to have an extreme loading event that could be modeled in FE. The trucks were placed back to back as close as possible over the centerline and straddling girder \#3 for the modified load case $\# 1$, and straddling girder \#4 for the modified load case \#2. There are no AASHTO specifications for the modified load cases. Refer to Table 3-2 for a summary of static load cases and descriptions.

Table 3-2 Summary of Static Load Cases

\begin{tabular}{|c|c|}
\hline Title & Description \\
\hline Load Case \#1 & See Figure 3.14 \\
\hline Load Case \#2 - two truck & See Figure 3.14 \\
\hline Load Case \#2 - one truck & See Figure 3.14 \\
\hline Load Case \#4 - one truck & See Figure 3.14 \\
\hline Load Case \#5 - one truck & Mirror image of Load Case \#2 - one truck \\
\hline Load Case \#6 - one truck & Mirror image of Load Case \#4 - one truck \\
\hline Modified \#1 & See Figure 3.15 \\
\hline Modified \#2 & See Figure 3.15 \\
\hline
\end{tabular}




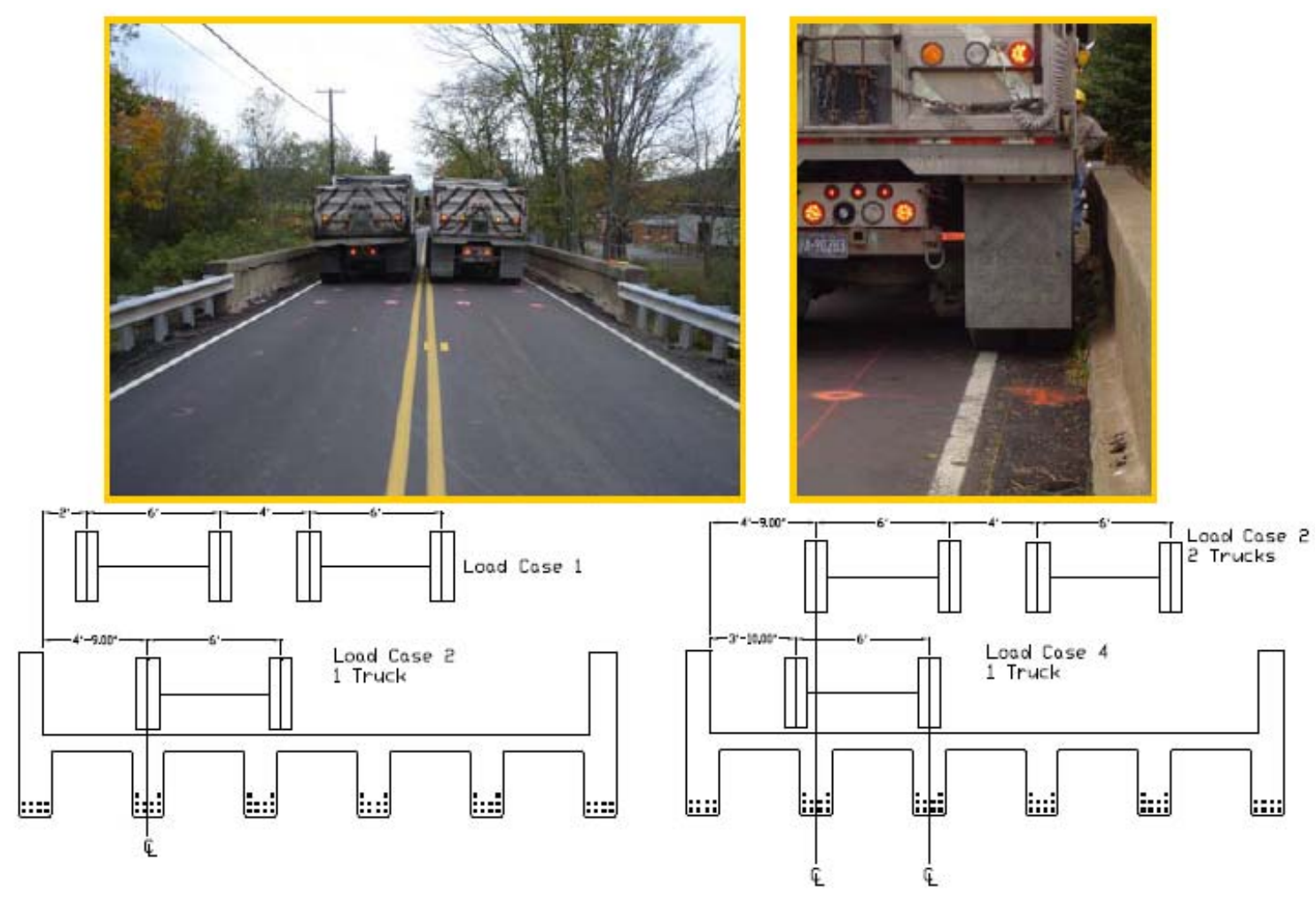

Figure 3.14 Load Cases

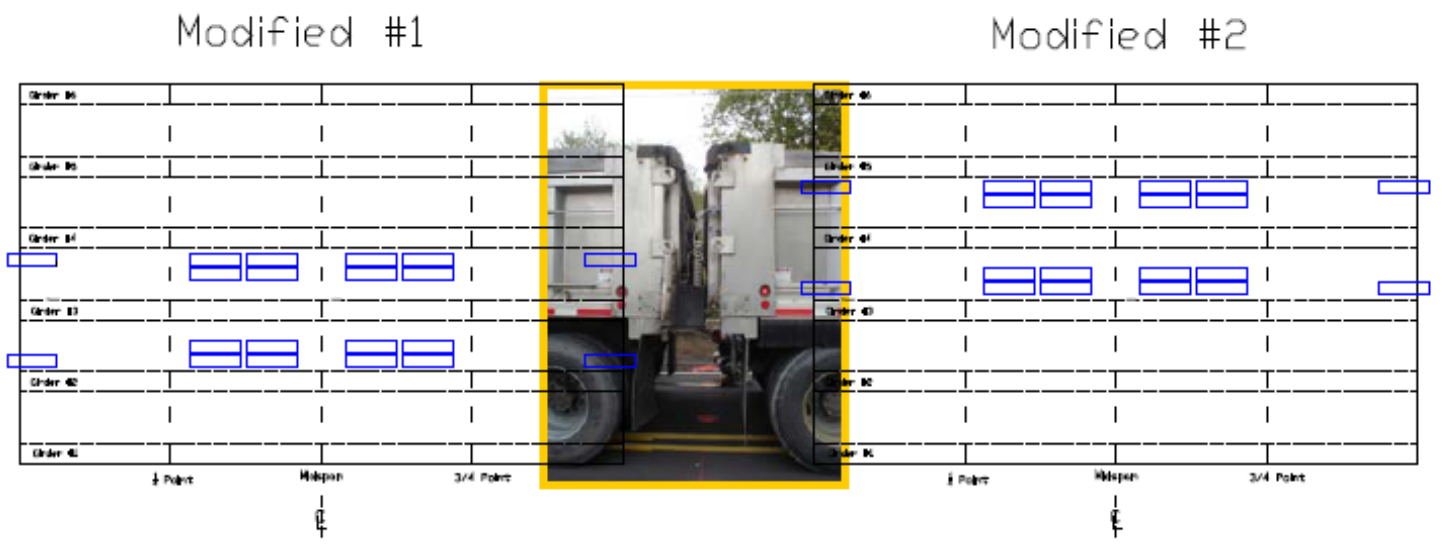

Figure 3.15 Modified Load Cases

The trucks were moved onto the bridge one at a time and the centroid of the trucks were lined up at the quarter, mid, and three-quarter points of the bridge. While continuous data was taken from the initial time the trucks were moved onto the bridge, 30 
to 40 seconds were allowed at each placement to let the bridge dampen itself so that there would be no impact loads recorded in the results.

\subsubsection{Dynamic Load Cases}

For dynamic loading of the un-repaired bridge, six dynamic tests were ran. Three tests used a $2 \times 4$ wood plank that was placed at one end of the bridge to excite the trucks suspension system and therefore excite the bridge under forced vibration. The other three consisted of the truck simply jamming on the brakes around the middle of the bridge at a speed ranging from $30 \mathrm{mph}$ to $50 \mathrm{mph}$. It was concluded that brake jamming tests gave much better results compared to the wood plank tests. Therefore, it was decided to use only the brake jamming tests for dynamic loading on the repaired bridge. This brake jamming test for vibration response was repeated three times. The data was recorded at 10,000 scans per second, which was the limit of the data acquisition system.

\subsubsection{Testing Results}

The load testing deflection results are shown in Figure 3.16 through Figure 3.19 for load cases \#1, \#2 - 1 truck, \#2 - 2 trucks, and \#4. Three of the curves on each figure represent the deflection under each girder when the truck centroid is positioned at quarter, mid, and three-quarter points along the span of the repaired bridge. The other two curves on each figure show the field deflection from the un-repaired bridge and the deflection from the FE model of the repaired bridge. Deflection results for load cases \#5 and \#6 are shown in Figure 3.20 and Figure 3.21. These load cases were not used in the un-repaired bridge testing and, as stated earlier, are mirror loads of load case \#2 - 1 truck and \#4 - 1 truck, respectively. Midspan deflection data from load case \#2 - 1 truck and load case \#4 
- 1 truck are plotted on the same figures to show symmetric stiffness of the repaired bridge. As can be seen from the figures, Girder 1 has nearly the same stiffness as Girder 6, Girder 2 has nearly the same stiffness as Girder 5, and Girder 3 has nearly the same stiffness as Girder 4. This comparison is made easy by flipping the data from load case $\# 2-1$ truck and load case \#4-1 truck as can be seen from the data labels in the graphs. This method was further used in Figure 3.22 in which Modified \#1 and Modified \#2 are compared to confirm symmetric stiffness throughout the repaired bridge. Deflection results for the repaired and un-repaired bridge along with the deflection results from the FE model of the repaired bridge, based on Modified \#1 and \#2, are shown in Figure 3.23 and Figure 3.24, respectively. It is important to note that all deflection values from testing of the un-repaired bridge were scaled up due to the weight difference of the trucks. During testing of the un-repaired bridge, the average of the two truck weights was $51,175 \mathrm{lb}$, whereas during testing of the repaired bridge, the average of the two truck weights was $57,875 \mathrm{lb}$. Based on this difference, a scale factor was used to compare deflection values at the same loading level. This scale factor was used to proportionally increase all un-repaired deflection values as

$$
\text { scale factor }=1+\frac{\text { repaired test weight }- \text { unrepaired test weight }}{\text { unrepaired test weight }}=1.131
$$

It is noted that this method of obtaining comparable values is reasonable for symmetric loading conditions only, since each wheel load is different for the tandem trucks provided. A more accurate analysis can be performed using the FE model to verify the testing data since the FE analysis can include more accurately the individual axel loads and their corresponding locations on the bridge as shown in Section 3.2. As 
illustrated in the aforementioned deflection graphs, no significant changes are observed in the deflections of the un-repaired bridge and repaired bridge, indicating minor change of stiffness from externally bonded FRP strips. Observing the graphs, it is also seen that the deflection results from loading the FE model of the repaired bridge match closely with the field testing results. Although, the FE model does give noticeably less deflection for load case \#1 - 2 trucks and load case \#2 - 2 trucks. The deflection results for load case $\# 1-2$ trucks and load case \#4-1 truck seem to indicate a possible malfunction in LVDT $\# 1$.

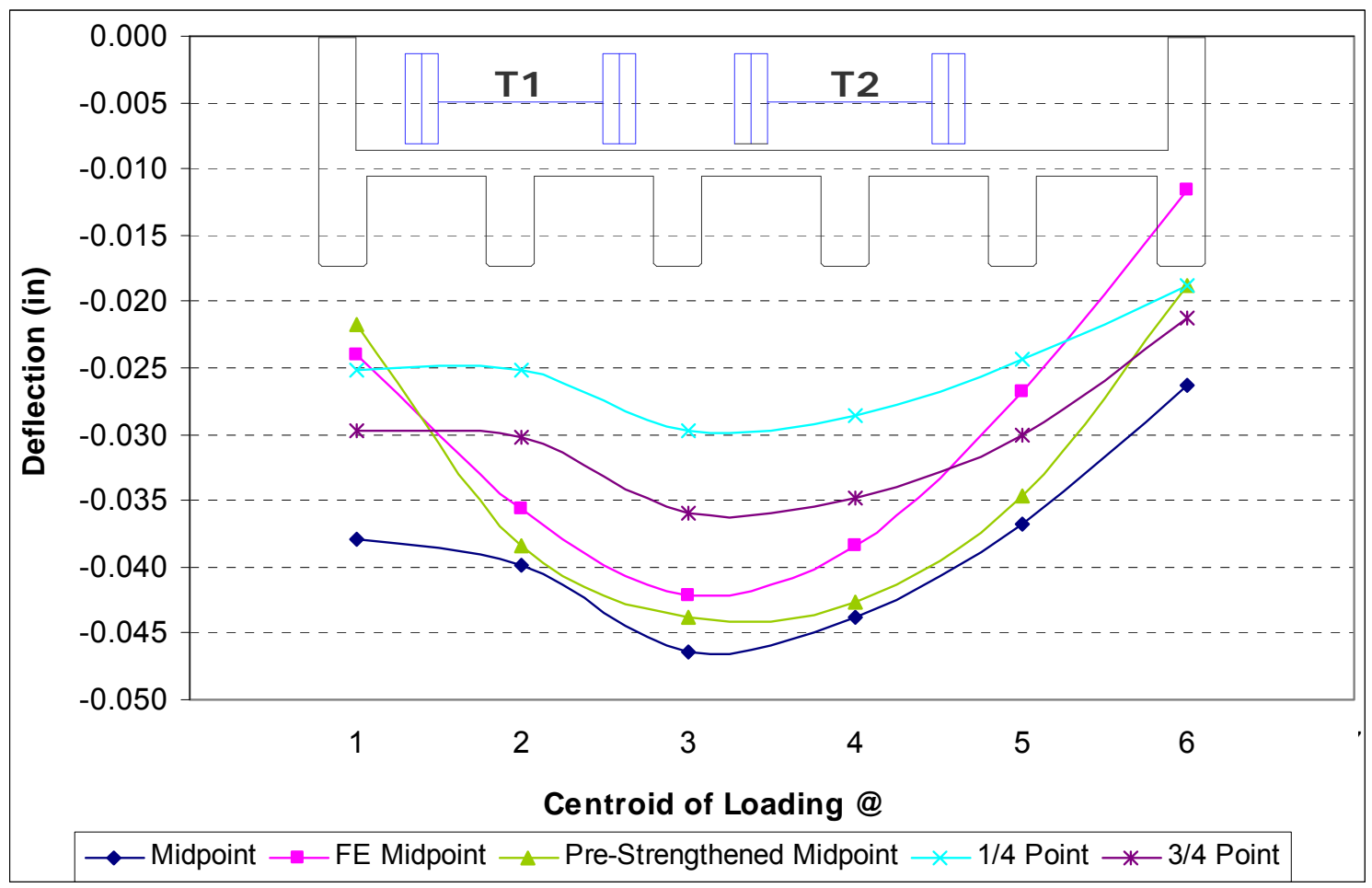

Figure 3.16 Load Case 1 Deflection Results 


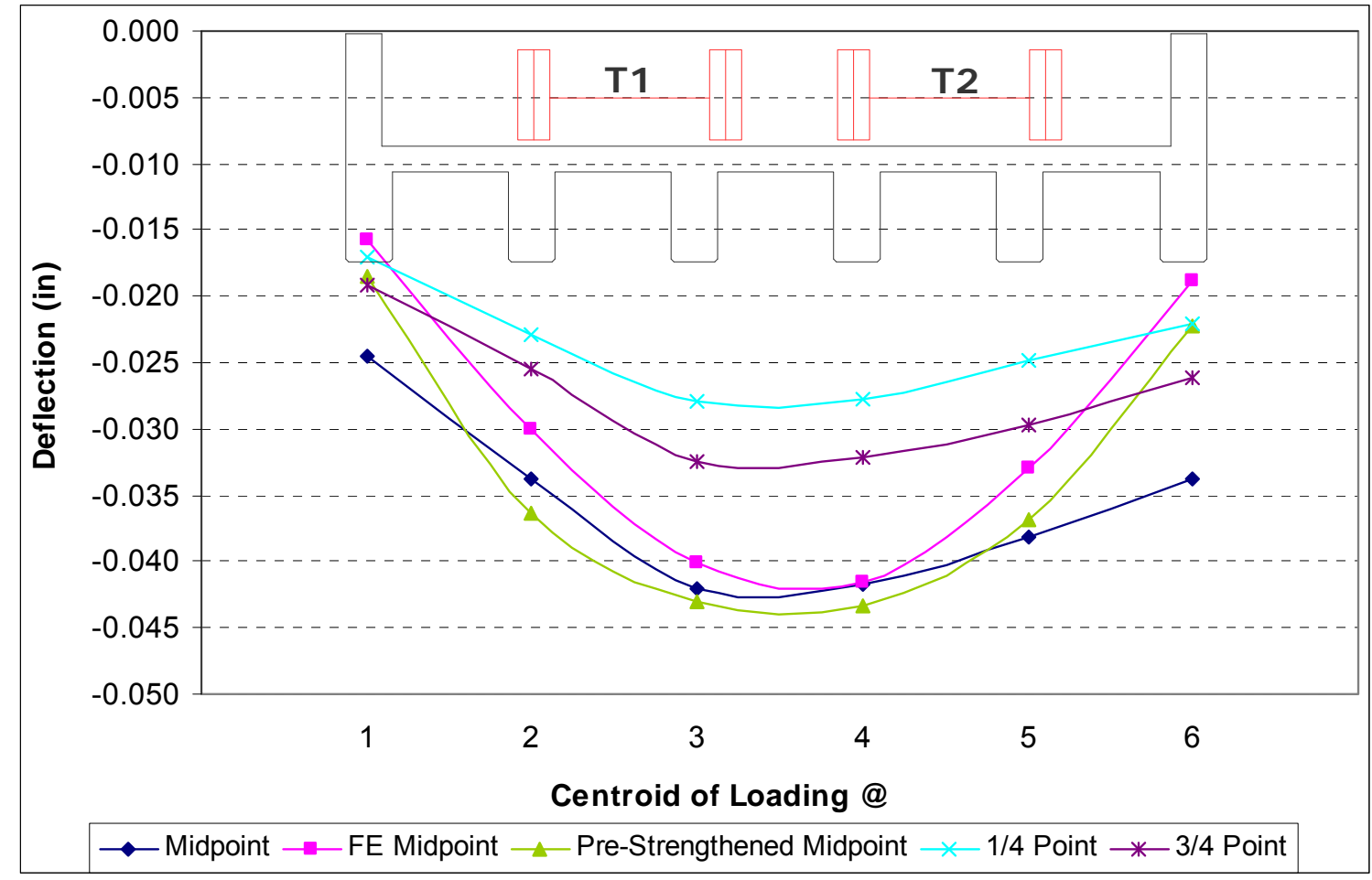

Figure 3.17 Load Case 2-2 Deflection Results

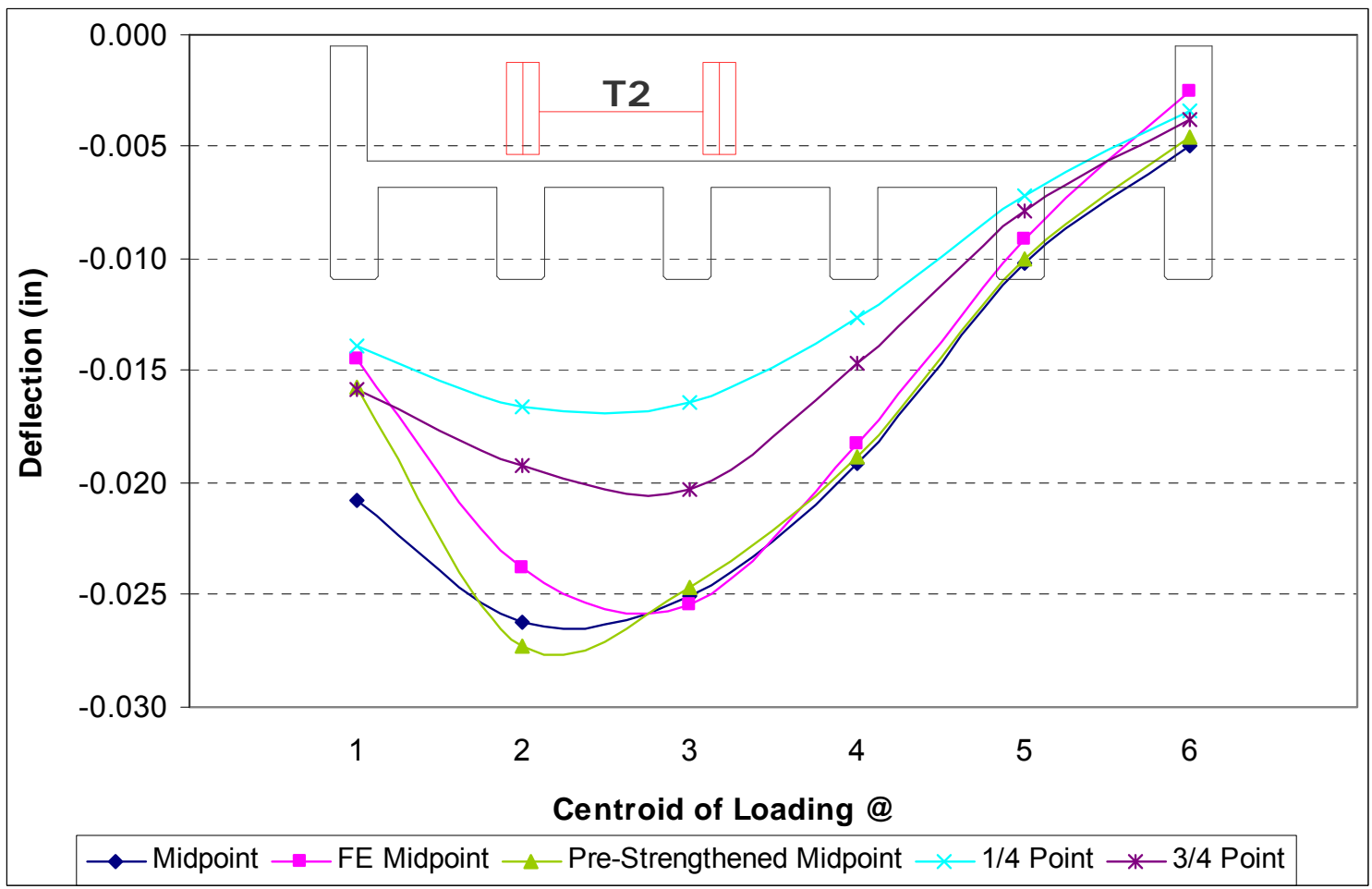

Figure 3.18 Load Case 2-1 Deflection Results 


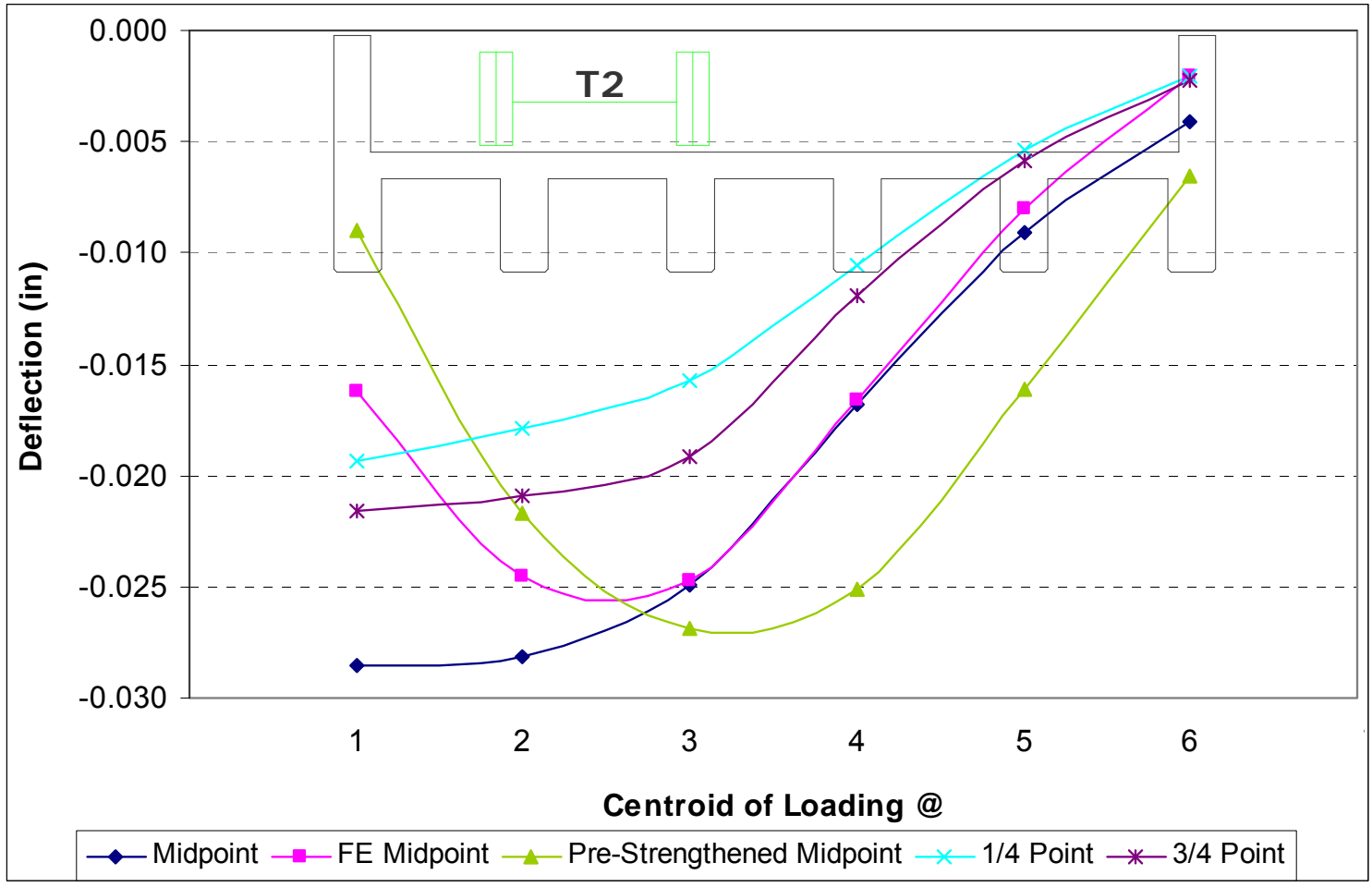

Figure 3.19 Load Case 4 Deflection Results

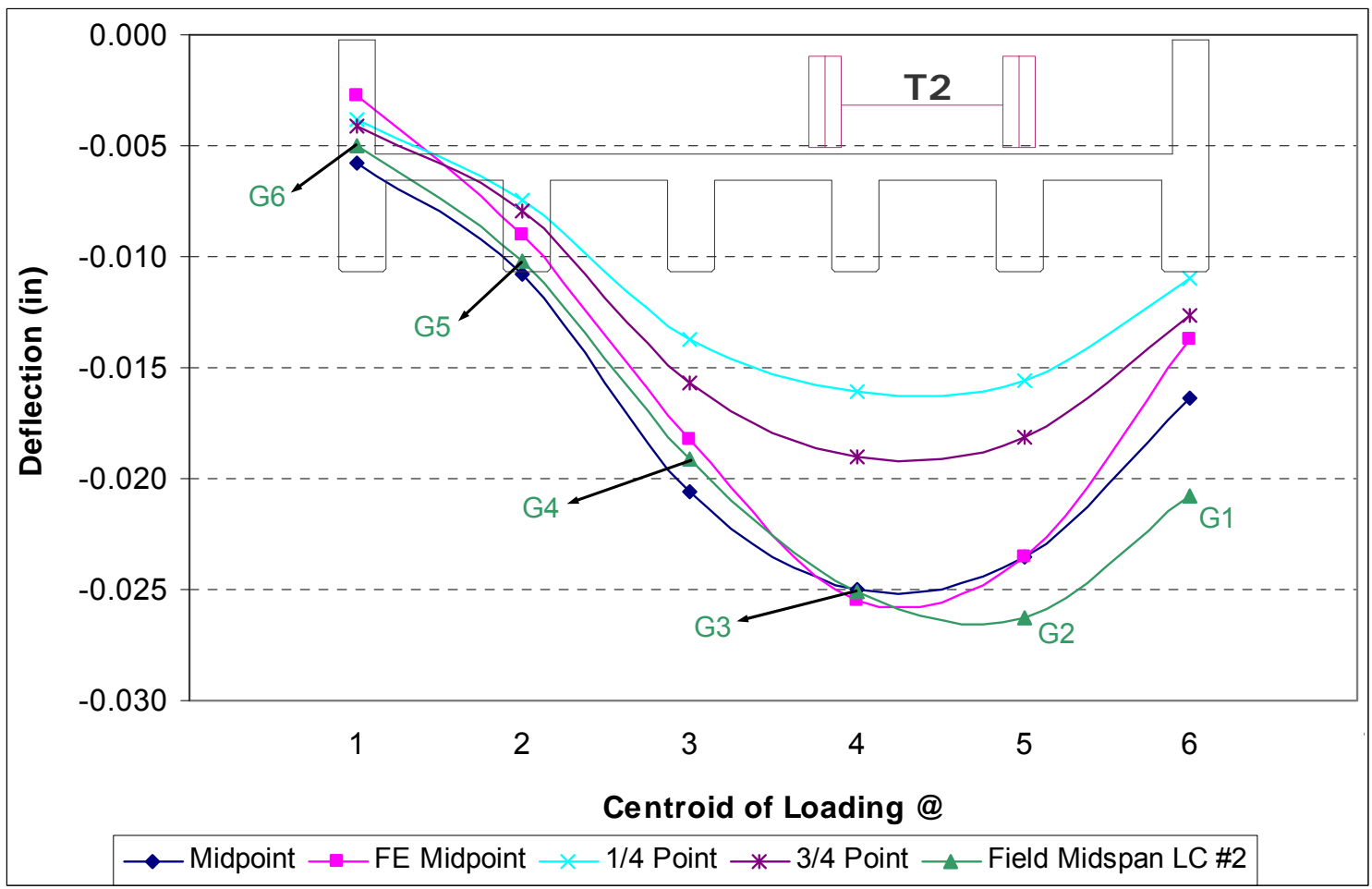

Figure 3.20 Load Case 5 Deflection Results 


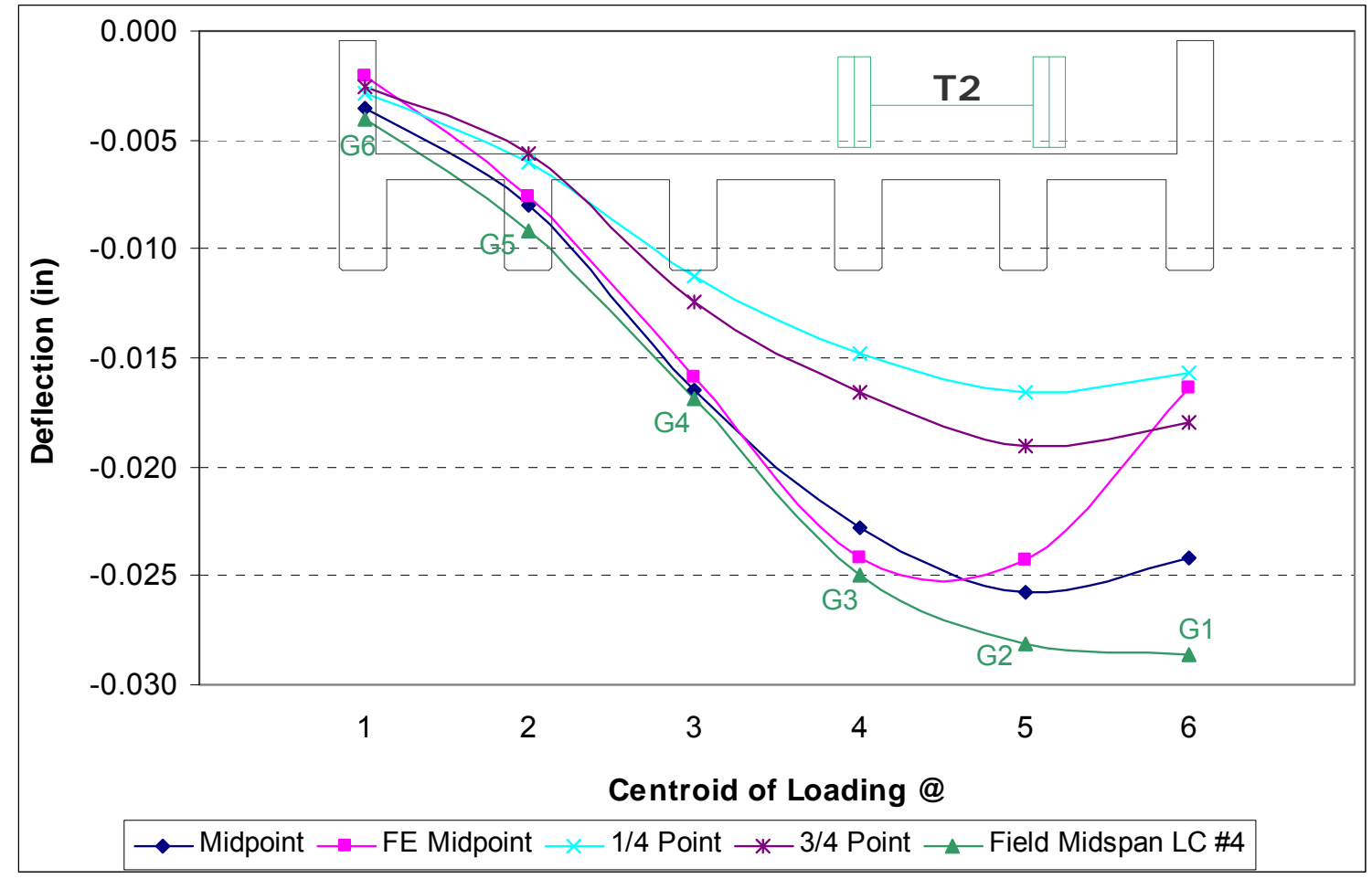

Figure 3.21 Load Case 6 Deflection Results

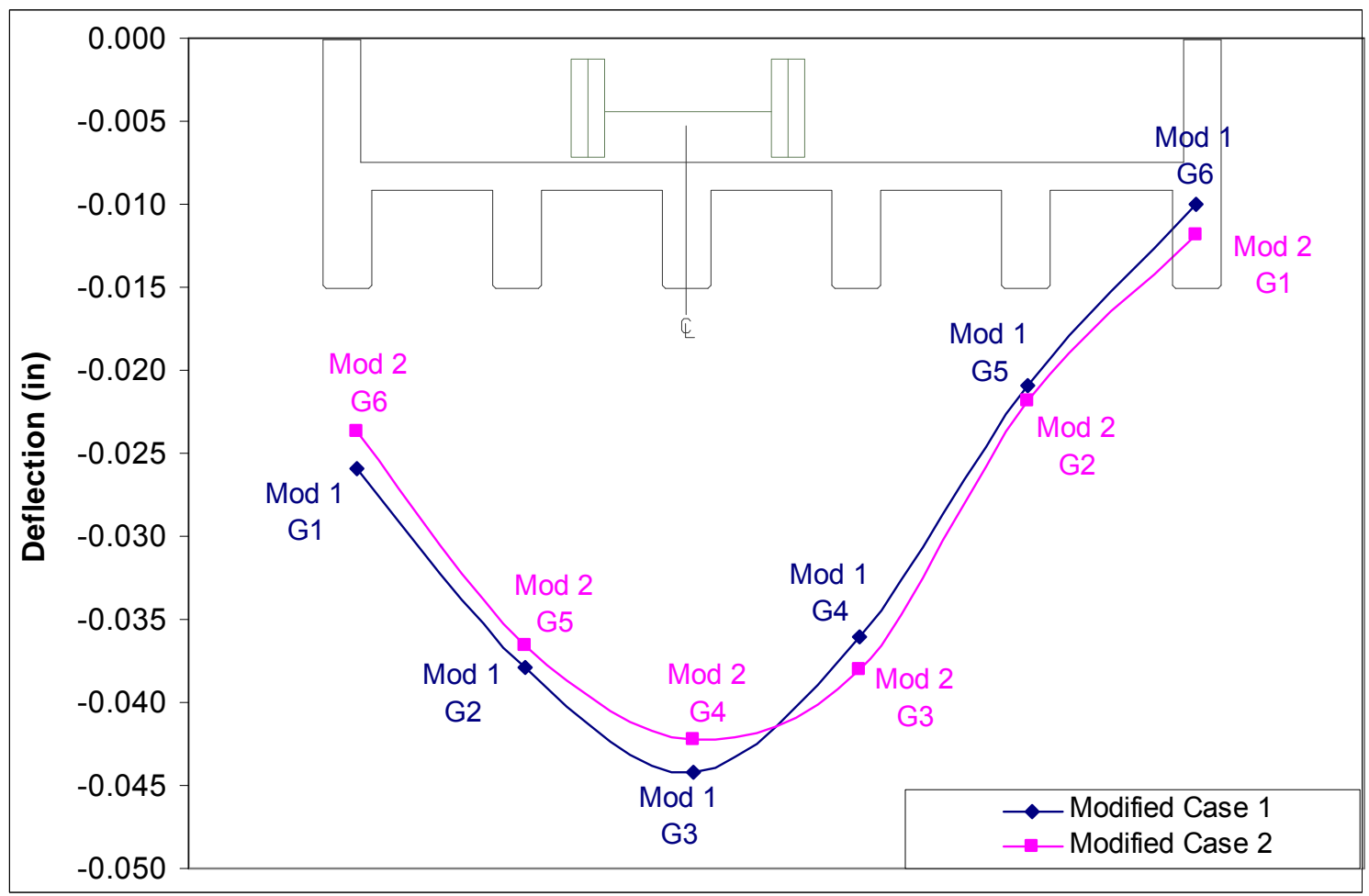

Figure 3.22 Symmetry of Repaired Bridge 


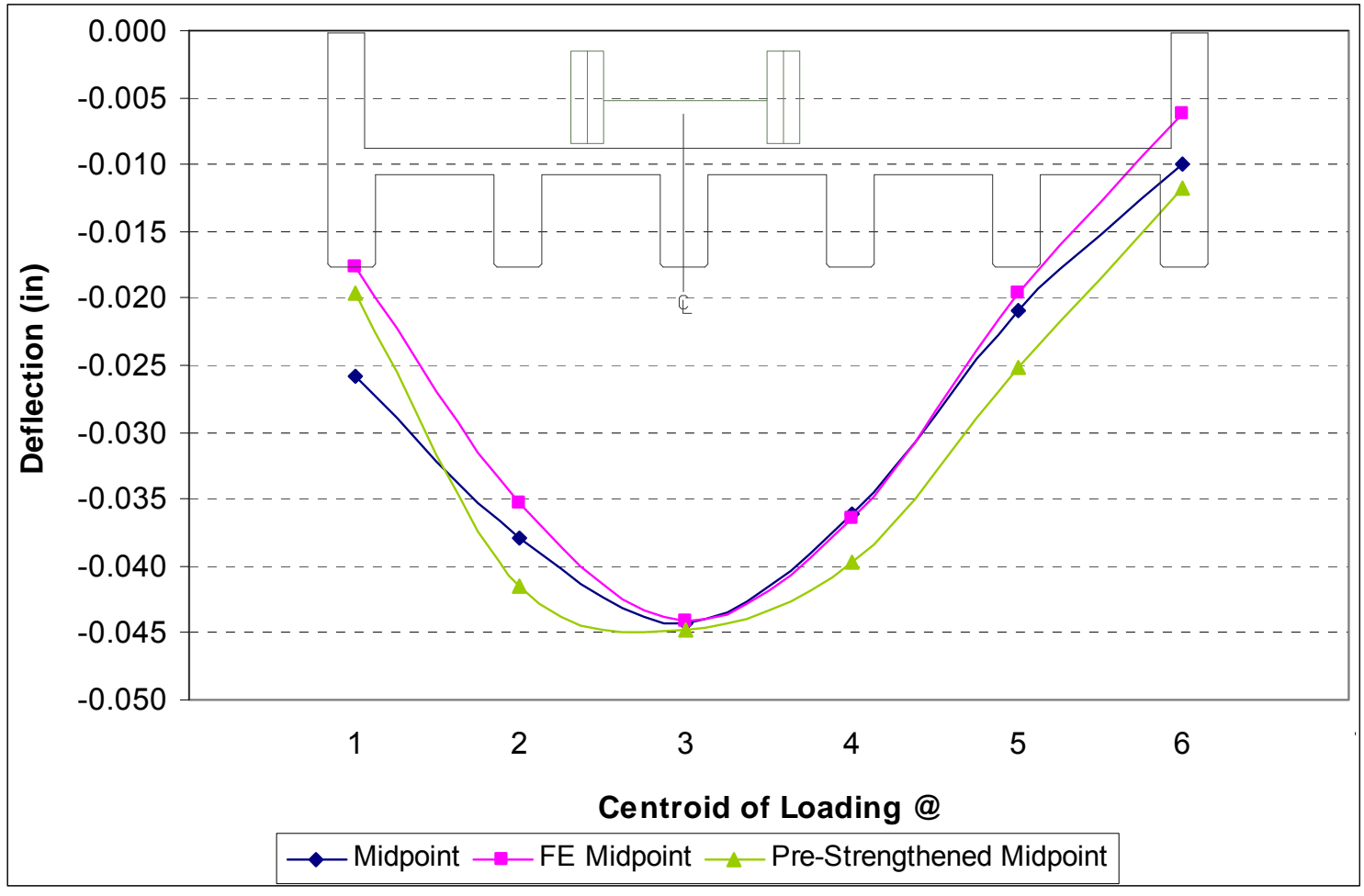

Figure 3.23 Modified 1 Deflection Results

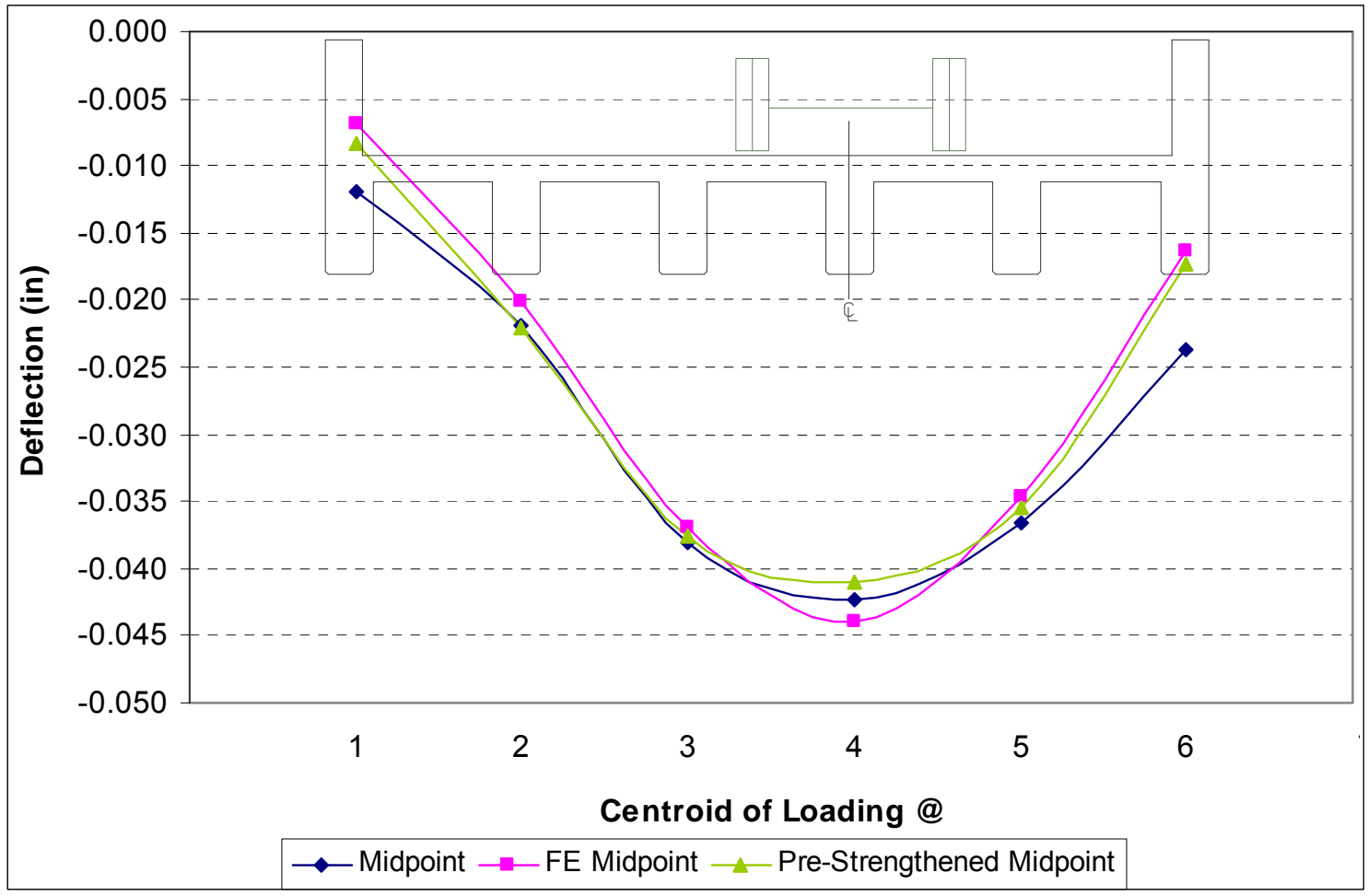

Figure 3.24 Modified 2 Deflection Results 
Figure 3.25 through Figure 3.32 show the strain results of the flexural FRP gages for each load case. Three curves on each figure represent the strains at the bottom face of each girder when the truck centroid is positioned at quarter, mid, and three-quarter points along the span of the bridge. The fourth curve on each figure represents the strain at the bottom of the beams resulting from loading the FE model by placing the truck centroid at the midspan. Similar to the deflection figures, the transverse load placement is also shown in each figure. These figures indicate reasonable strain results with the exception of readings from Girders 2 and 6 . The strain values from the gage on Girder 2 are significantly lower than expected as shown in Figure 3.25 through Figure 3.28. This can indicate a possible malfunction of that gage or poor bond quality. The strain values from the gage on Girder 6 show no relative strain throughout each load case. This, again, may represent a malfunction with that gage.

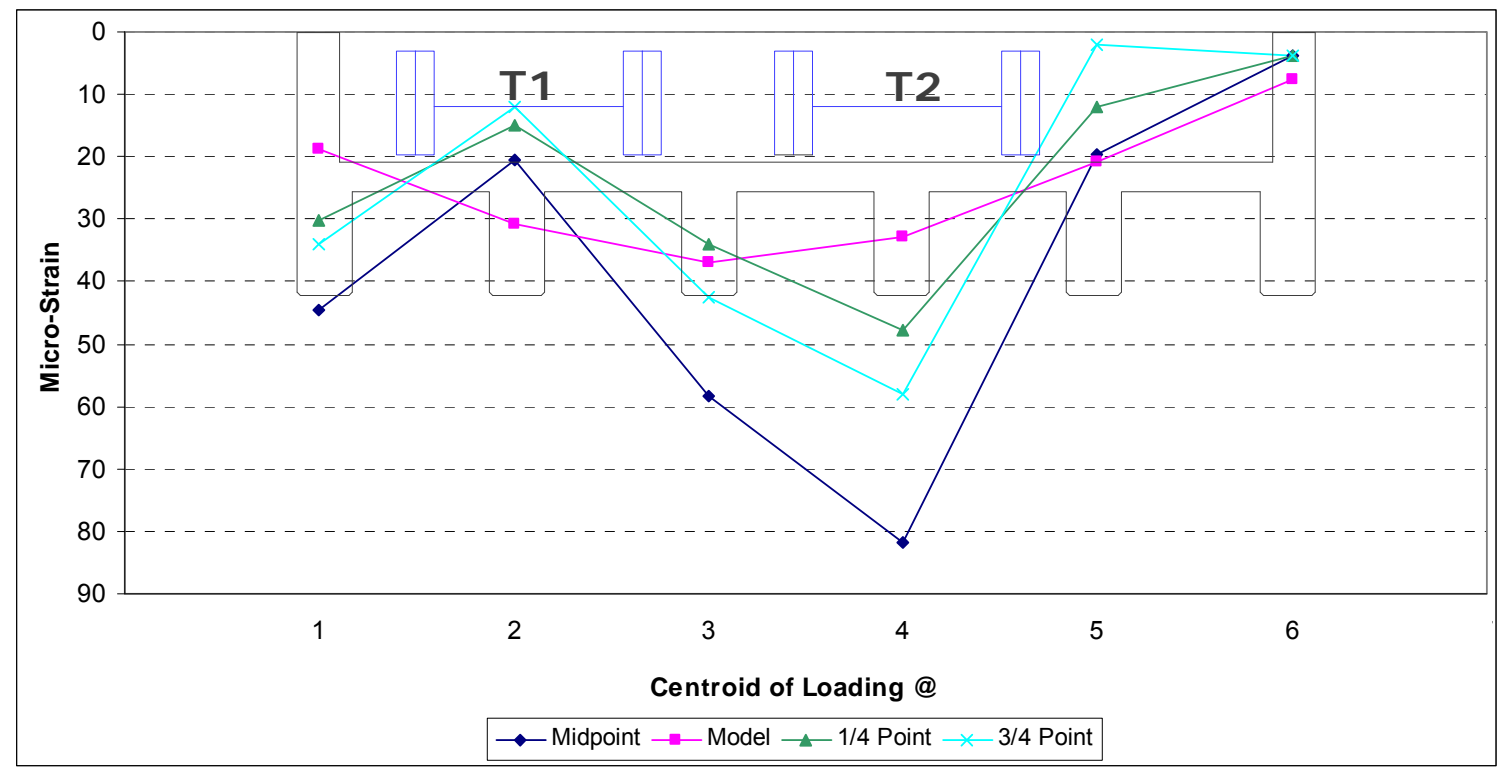

Figure 3.25 Load Case 1 Strain Results 


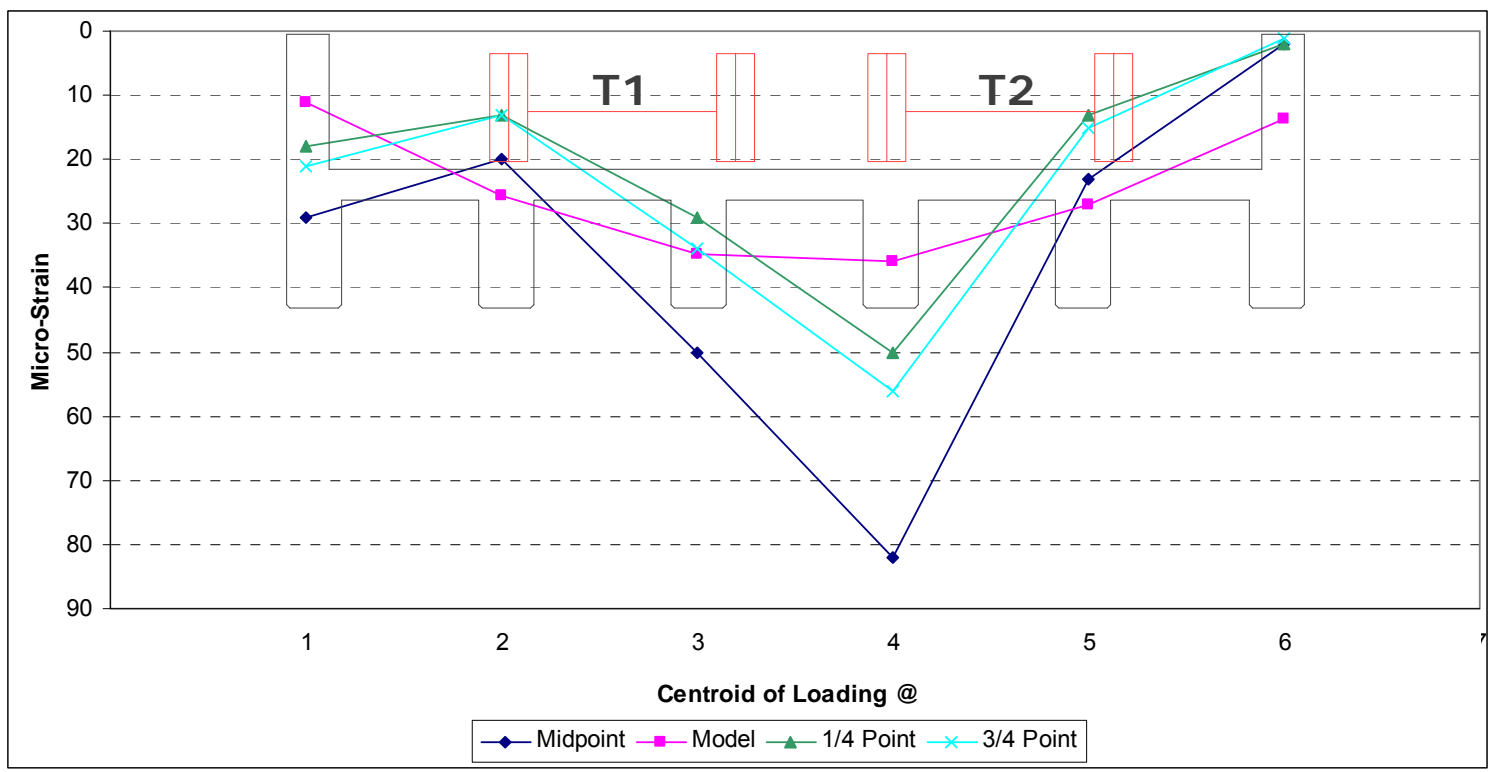

Figure 3.26 Load Case 2-2 Strain Results

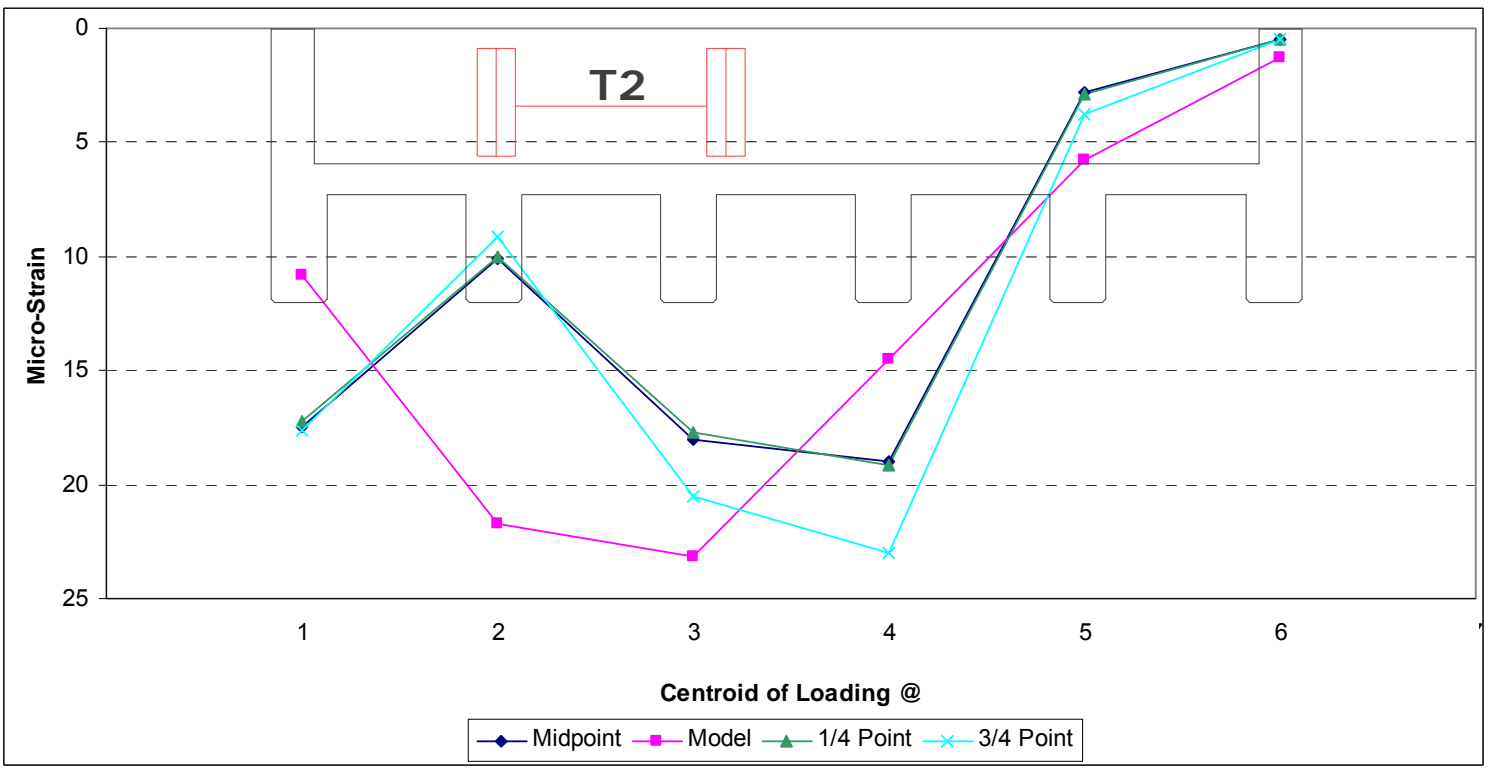

Figure 3.27 Load Case 2-1 Strain Results 


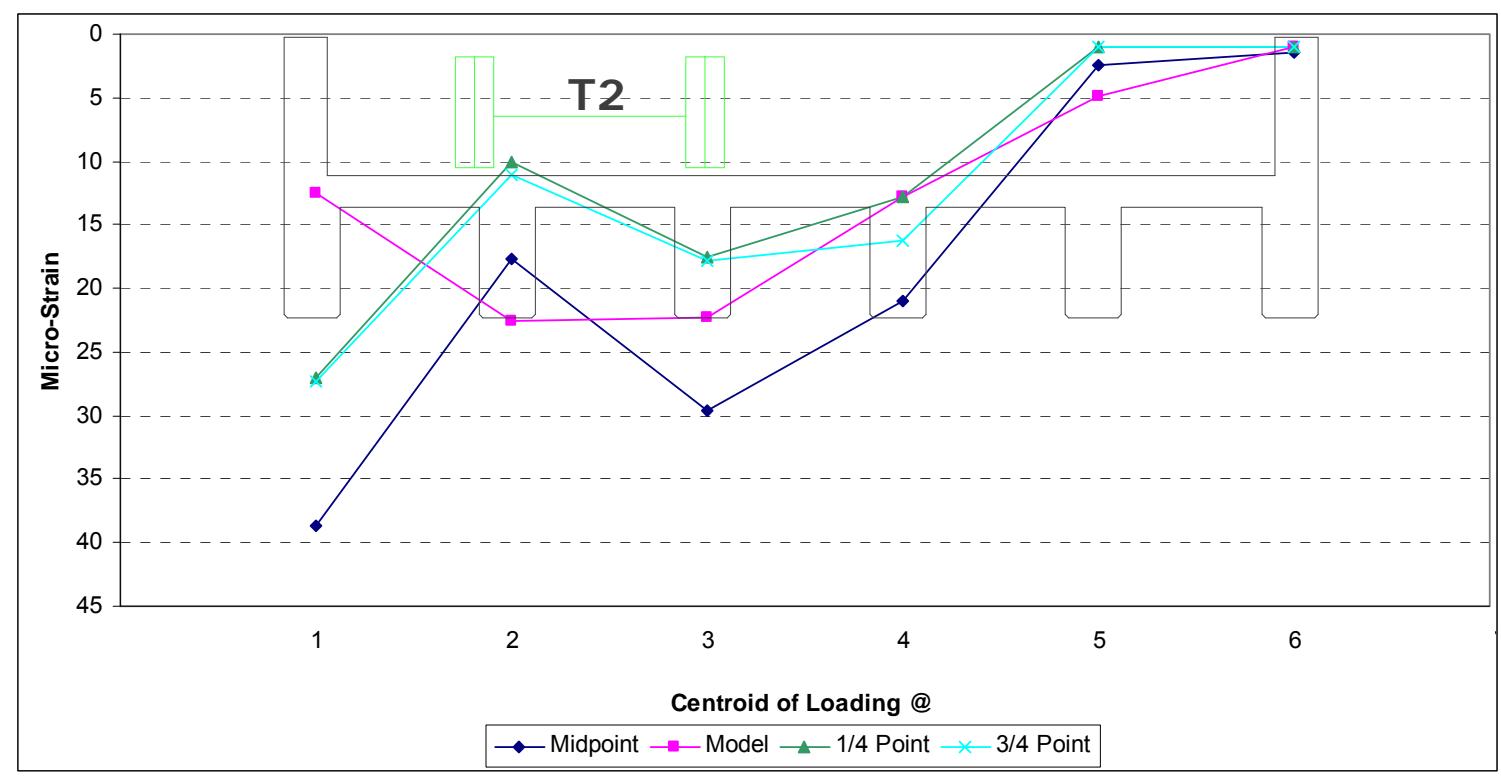

Figure 3.28 Load Case 4 Strain Results

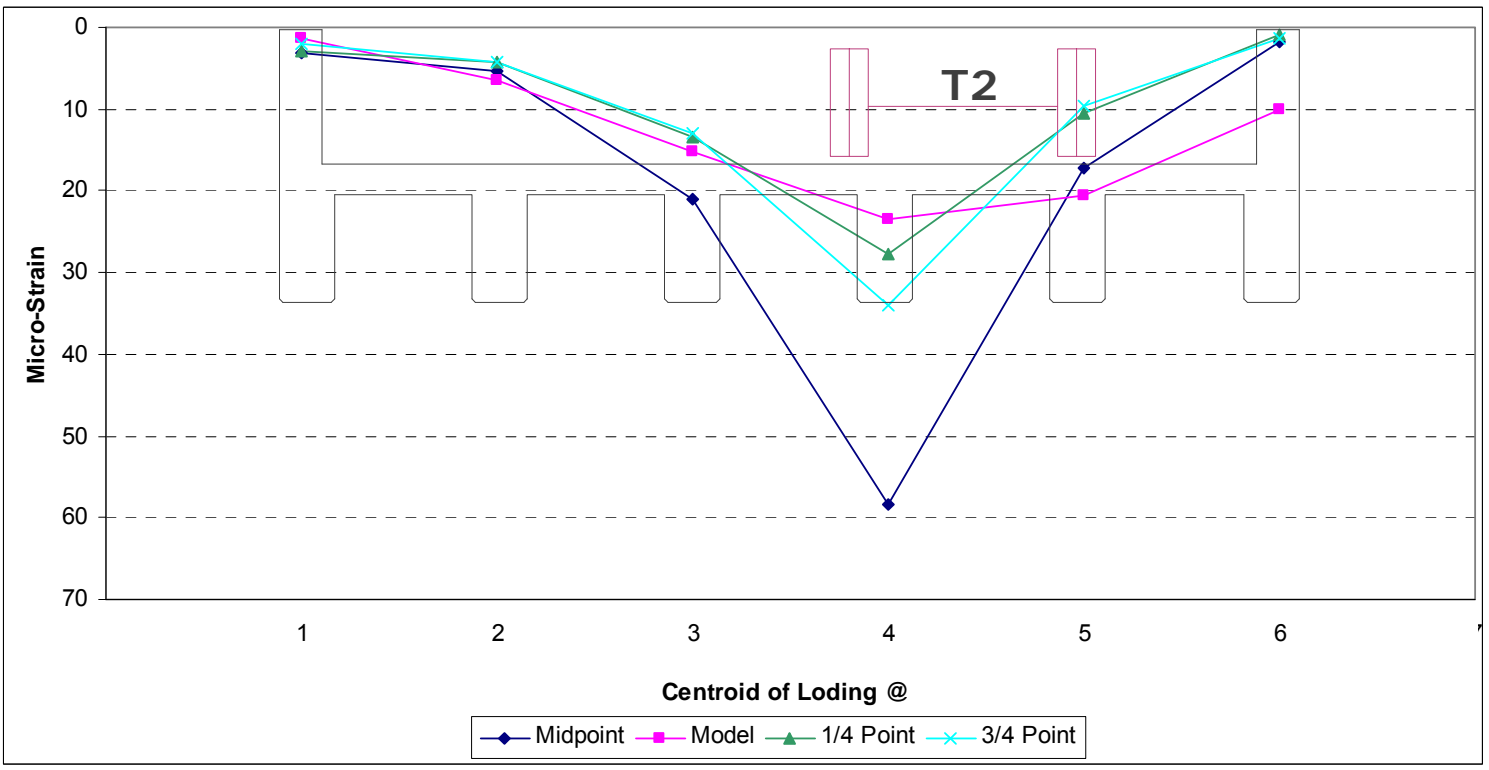

Figure 3.29 Load Case 5 Strain Results 


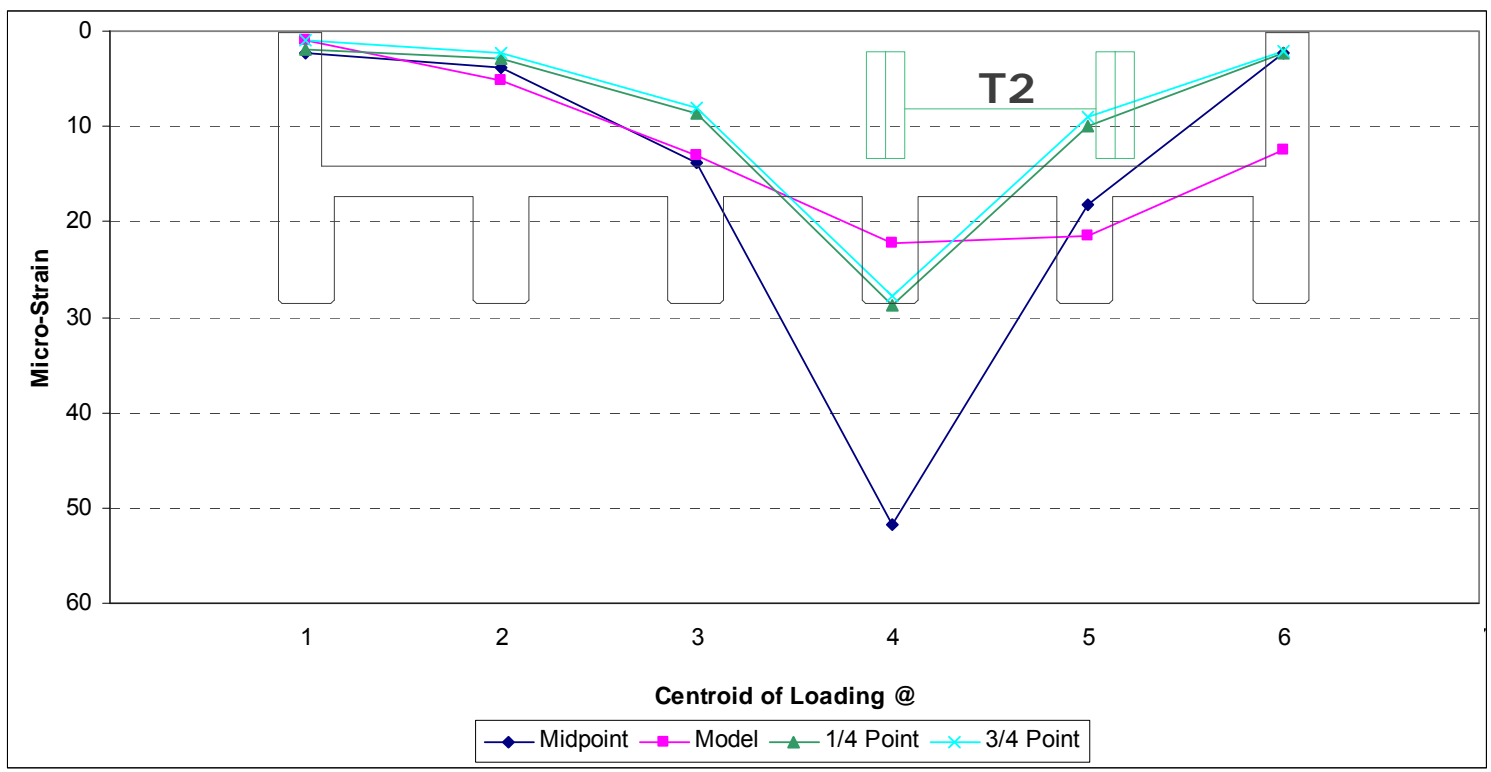

Figure 3.30 Load Case 6 Strain Results

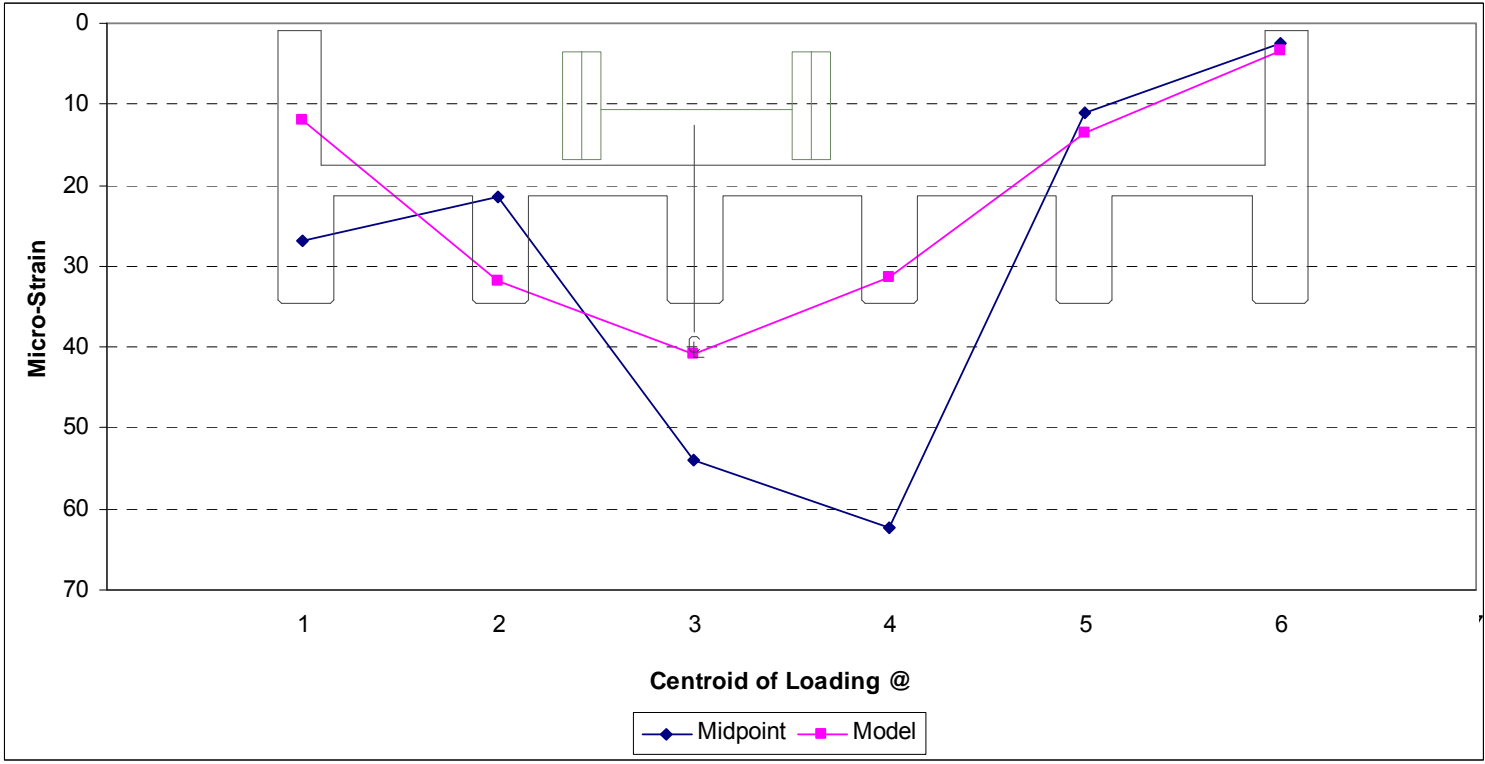

Figure 3.31 Modified 1 Strain Results 


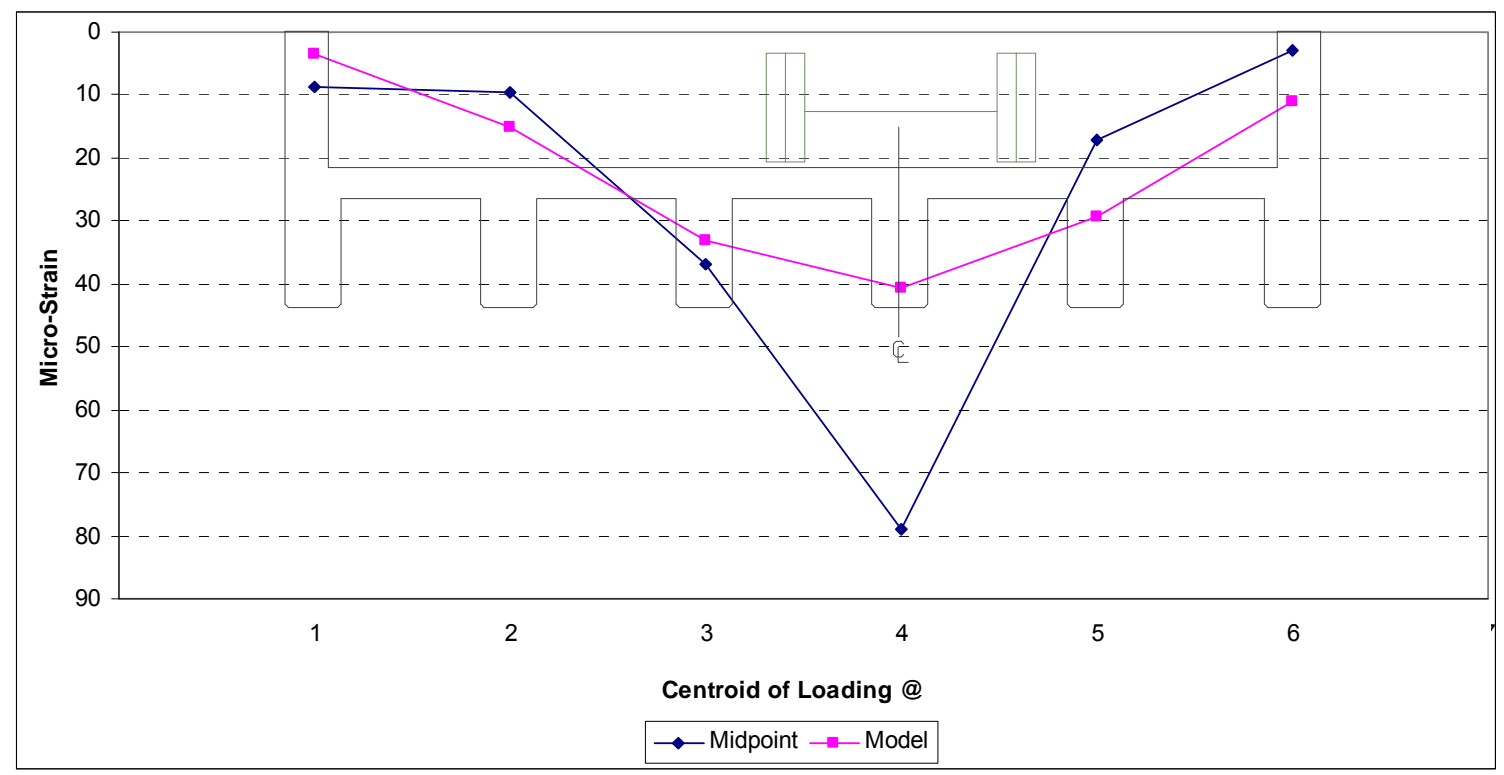

Figure 3.32 Modified 2 Strain Results

Concrete strain gage readings are illustrated in Figure 3.33 through Figure 3.38. One strain distribution diagram is shown for each girder, created from the load case which gave the highest FRP strain reading. Values are presented as micro-strain. The load case used is included in the figure description. As can be seen from these figures, the strain readings on the concrete surface seem to be reasonable and assume an approximate linear distribution. 


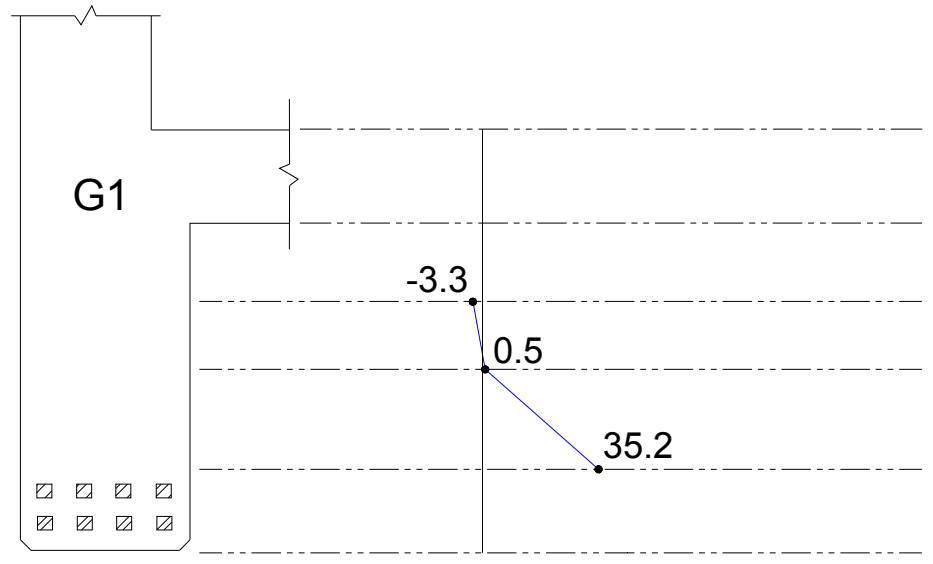

Figure 3.33 Concrete Strain from Load Case \#1 (G1)

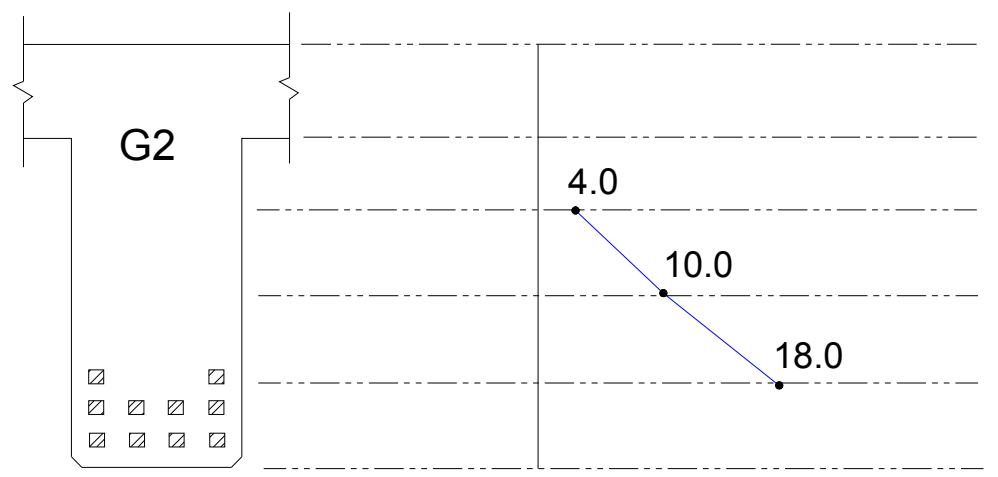

Figure 3.34 Concrete Strain from Modified \#1 (G2)

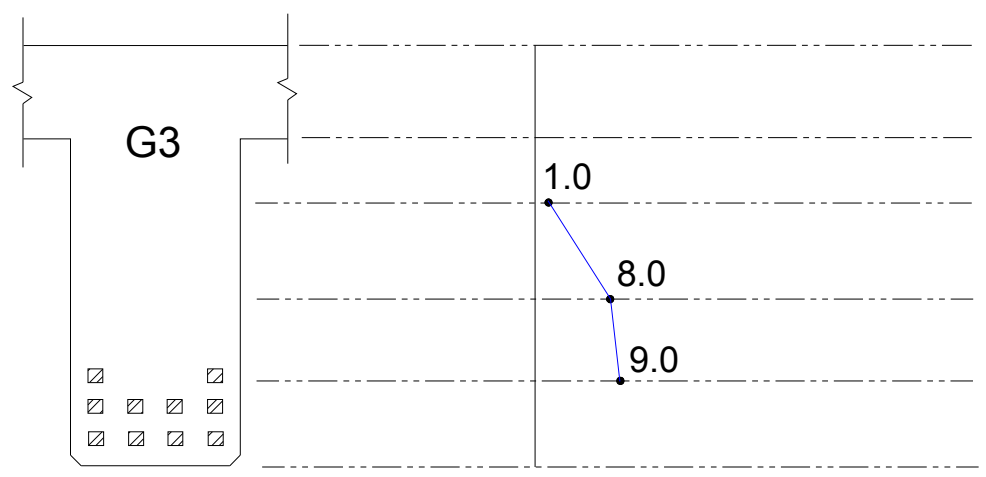

Figure 3.35 Concrete Strain from Modified \#2 (G3) 


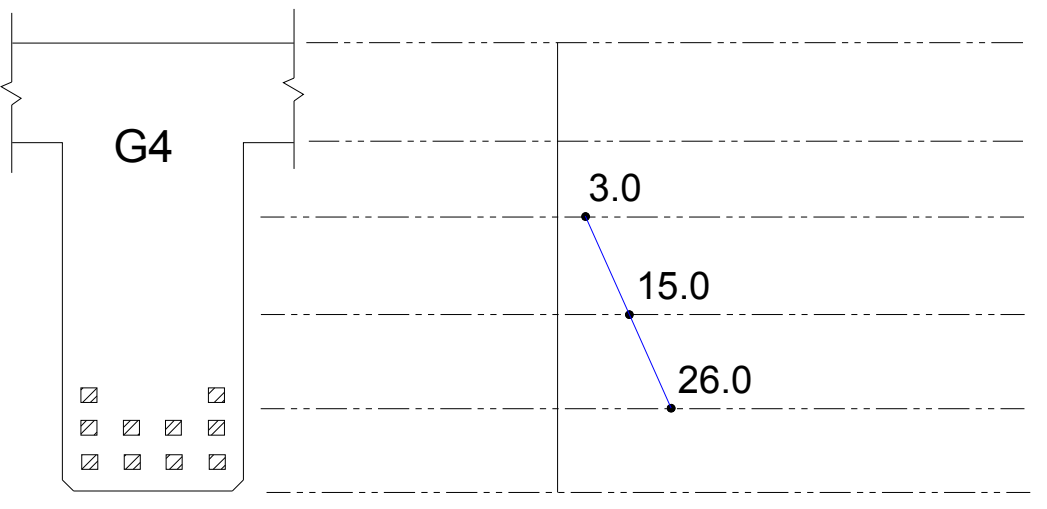

Figure 3.36 Concrete Strain from Load Case \#1 (G4)

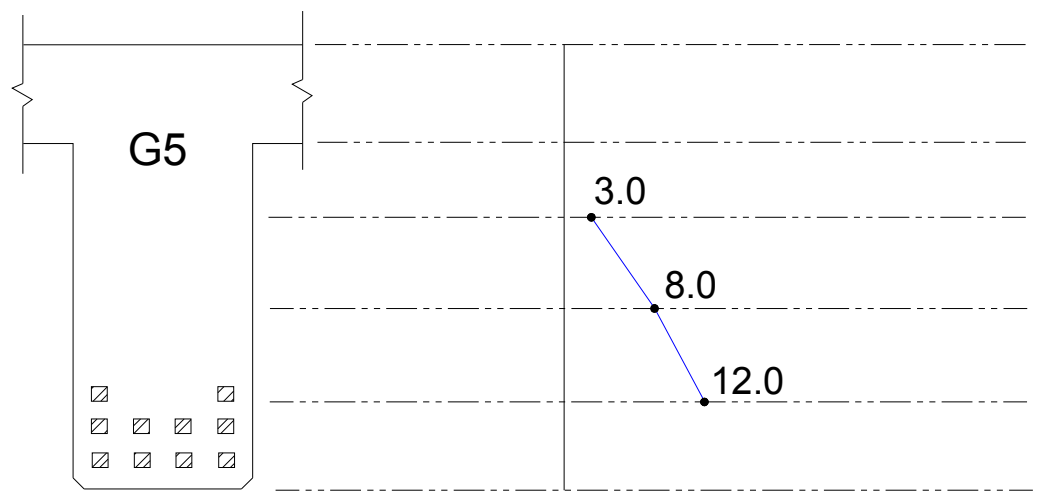

Figure 3.37 Concrete Strain from Load Case \#2-2 (G5)

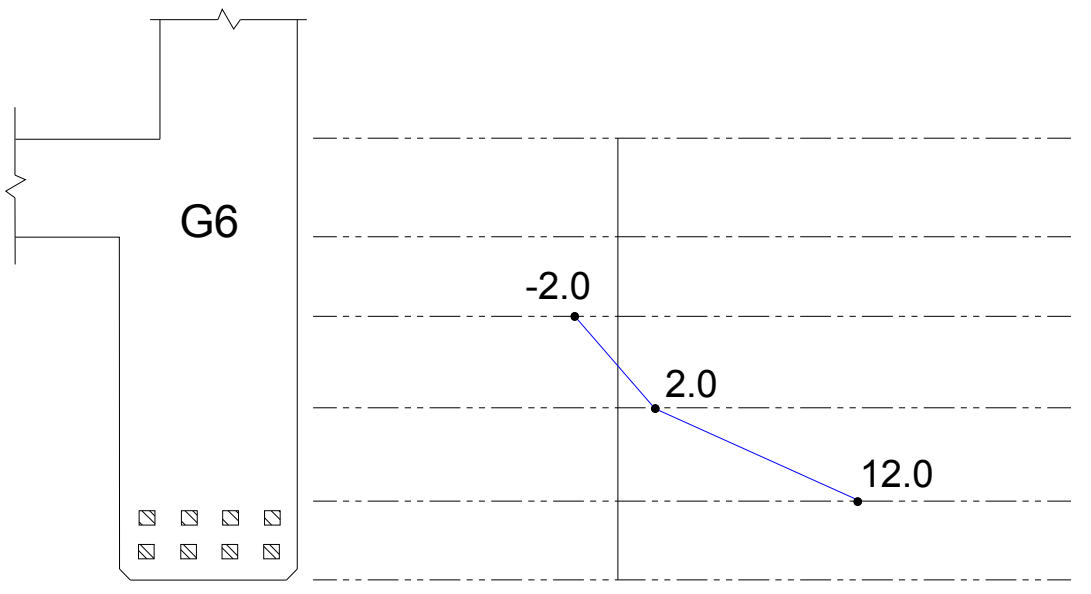

Figure 3.38 Concrete Strain from Modified \#2 (G6) 
A sample natural frequency curve is shown in Figure 3.39. The data was analyzed through a Fast Fourier Transform (FFT) analysis available in the Strain Smart software. The values obtained correlated well with FE results. As seen in Figure 3.39, the field tests showed a first mode frequency of $14.72 \mathrm{~Hz}$. This value is very close to that from testing of the un-repaired bridge, where the first mode frequency was $14.66 \mathrm{~Hz}$. Once again this indicates that the externally bonded FRP strips do not contribute that greatly to the bridge stiffness.

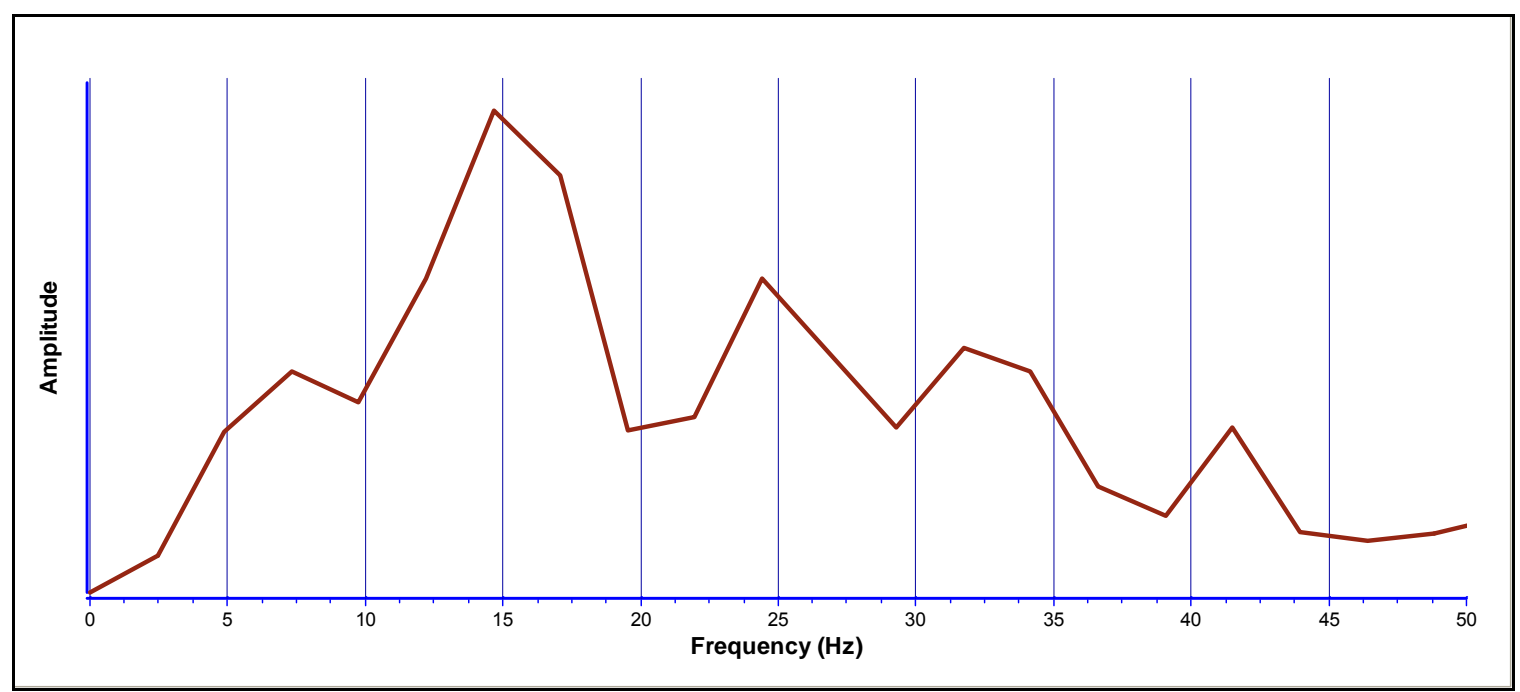

Figure 3.39 Natural Frequency Chart 


\subsection{Finite ELEMENT ANALysis OF REPAIRED BRIDGE}

The information for the FE analysis was obtained from a combination of available design documents provided by PennDOT District 3 and field information obtained from previous tasks. The model was developed in order to: (1) determine current capacities of the repaired bridge, (2) identify critical load conditions for field testing of the structure, and (3) compare predictions with field responses when actual test truck-loads are used. Subsequently, this model was calibrated using the field test results and modified to increase its accuracy. The calibrated model will permit its confident use in evaluating more thoroughly the performance of the strengthened system.

\subsubsection{FE Modeling}

The 8-node linear brick element C3D8R, with reduced integration and hourglass control, was chosen to model the concrete. C3D8R was used for the three-dimensional modeling of concrete with or without reinforcing bars. Three-dimensional linear truss element T3D2 was chosen to model flexural and shear reinforcement in girders, deck, parapets, and curbs. T3D2 was embedded into solid element C3D8R (truss-in-solid) to provide a realistic representation for the reinforcement and the displacements of the reinforcing bar coinciding with that of the concrete (perfect bond between the reinforcing bar and the concrete was assumed). This refined approach to 3D geometric-replica analytical modeling is now practical and enables explicitly simulating every material point of the bridge for an accurate representation of the geometry, the actual behavior mechanisms and existing repair condition. The 2.5 " overlay was also modeled using C3D8R elements and tied to the composite deck. To simplify the modeling, the crosssection of the parapets was assumed to be rectangular with the same height as of the 
actual structure. The FRP strip was modeled using "Element-Based Surface," and the surface based "TIE" constraint was used to couple the FRP strips and concrete surfaces. The details of the reinforcing rebar and FRP system in the model are shown in Figure 3.40 and Figure 3.41. Figure 3.42 shows the meshed finite element model.

Several assumptions were made in modeling. All elements represented linearelastic and isotropic material since the applied load was relatively low with respect to the ultimate load condition. Different concrete compressive strengths were used at different locations. The strength used for the deck was 5,000 psi measured from deck core samples, 6,530 psi for bagging/patching materials based on WVU testing results and results provided by PennDOT. Although AASHTO Manuals for Condition Evaluation of Bridges suggests a value of 2,500 psi for bridges built prior to 1954, a value of 4,000 psi was used for all existing girders based on inspection and consideration of the repair/patching effect. The modulus of elasticity of the concrete was based on compressive strength, according to the standard equation ACI 318-02, Section 8.5.1. The cross-sectional area of rebar was reduced by 20 percent based on the measured dimension of the corroded rebar sample. The concrete Poisson's ratio was set to 0.15 . Different element sizes were used to optimize the model and decrease the computation time. The size chosen for the longitudinal and transverse cross sections allowed for easier and more accurate location of the steel rebar and reduced the number of elements in the "secondary" parts of the model, such as the parapets and the diaphragm beams. Based on the test results of the rebar sample, the modulus of elasticity and the Poisson's ratio for the steel reinforcement were assumed to be $29000 \mathrm{ksi}$ and 0.3 , respectively. The 
orthotropic properties of the FRP strip were based on datasheets provided by the manufacturer as shown in Table 3-3.

The structure was modeled using 126,419 elements and 155,001 nodes. Since the super structure is sitting on and connected to the abutments by 18 anchors at one end and 18 dowels at the other end through the stiff diaphragm beams, pin-pin boundary conditions were chosen to accurately represent the actual restraints at the boundaries. The bridge was vertically, longitudinally, and transversely restrained at 18 nodes corresponding, respectively, to anchor and dowel positions at each end.

Along with the dead load, truck loads were placed on top of the overlay. The same truck loads as used in field testing were placed on the model. In this manner, the results from field testing and the FE model could be compared. These results are shown in Section 3.2.5. In loading the model, wheel loads were assumed as uniformly distributed over an area of $20 \times 10 \mathrm{in}^{2}$, as per AASHTO specifications. The uniform loads were discretized as concentrated forces at the nodes corresponding to the truck wheel foot print, and each force was determined by dividing the total distributed load by the number of nodes. Figure 3.44 illustrates an example loading position on the FE model. Figure 3.45 shows a vertical deformation contour plot of the model and Figure 3.46 shows the in-plane stress view-cut.

For analysis reasons, as detailed in Section 5.2, two lanes were also loaded with an AASHTO HS20 truck loading. The load was positioned at center span and also near the supports; these were determined to be the critical locations for bending and shear respectively. By loading the model in accordance with AASHTO, comparisons could be made between force effects resulting from the accurate FE model and force effects 
resulting from AASHTO standard specifications. The conservative nature of the AASHTO design equations could then be assessed. This correlation between design and analysis is discussed separately in Chapter 5. Table 3-4 shows wheel loads for an AASHTO HS20 truck along with the wheel loads calculated for both tandem trucks used in the load test. Figure 3.43 illustrates the wheel spacing for both the AASHTO HS20 and the PennDOT tandem truck.

Table 3-3 Properties of MBrace CF 130

\begin{tabular}{|c|c|c|}
\hline \multirow{3}{*}{$\begin{array}{c}\text { Physical } \\
\text { Properties }\end{array}$} & Fiber Tensile Strength & $720 \mathrm{ksi}$ \\
\cline { 2 - 3 } & Areal Weight & $0.062 \mathrm{lb} / \mathrm{ft}^{2}$ \\
\cline { 2 - 3 } & Nominal Thickness & $0.0065 \mathrm{in} / \mathrm{ply}$ \\
\hline \multirow{2}{*}{$\begin{array}{c}0^{\circ} \text { Tensile } \\
\text { Properties }\end{array}$} & Ultimate Tensile Strength & $550 \mathrm{ksi}$ \\
\cline { 2 - 3 } & Tensile Modulus & $33000 \mathrm{ksi}$ \\
\cline { 2 - 3 } $90^{\circ}$ Tensile & Ultimate Rupture Strain & $1.67 \%$ \\
\hline \multirow{2}{*}{\begin{tabular}{c} 
Properties \\
\cline { 2 - 3 }
\end{tabular}} & Ultimate Tensile Strength & 0 \\
\cline { 2 - 3 } & Tensile Modulus & $\mathrm{n} / \mathrm{a}$ \\
\cline { 2 - 3 }
\end{tabular}




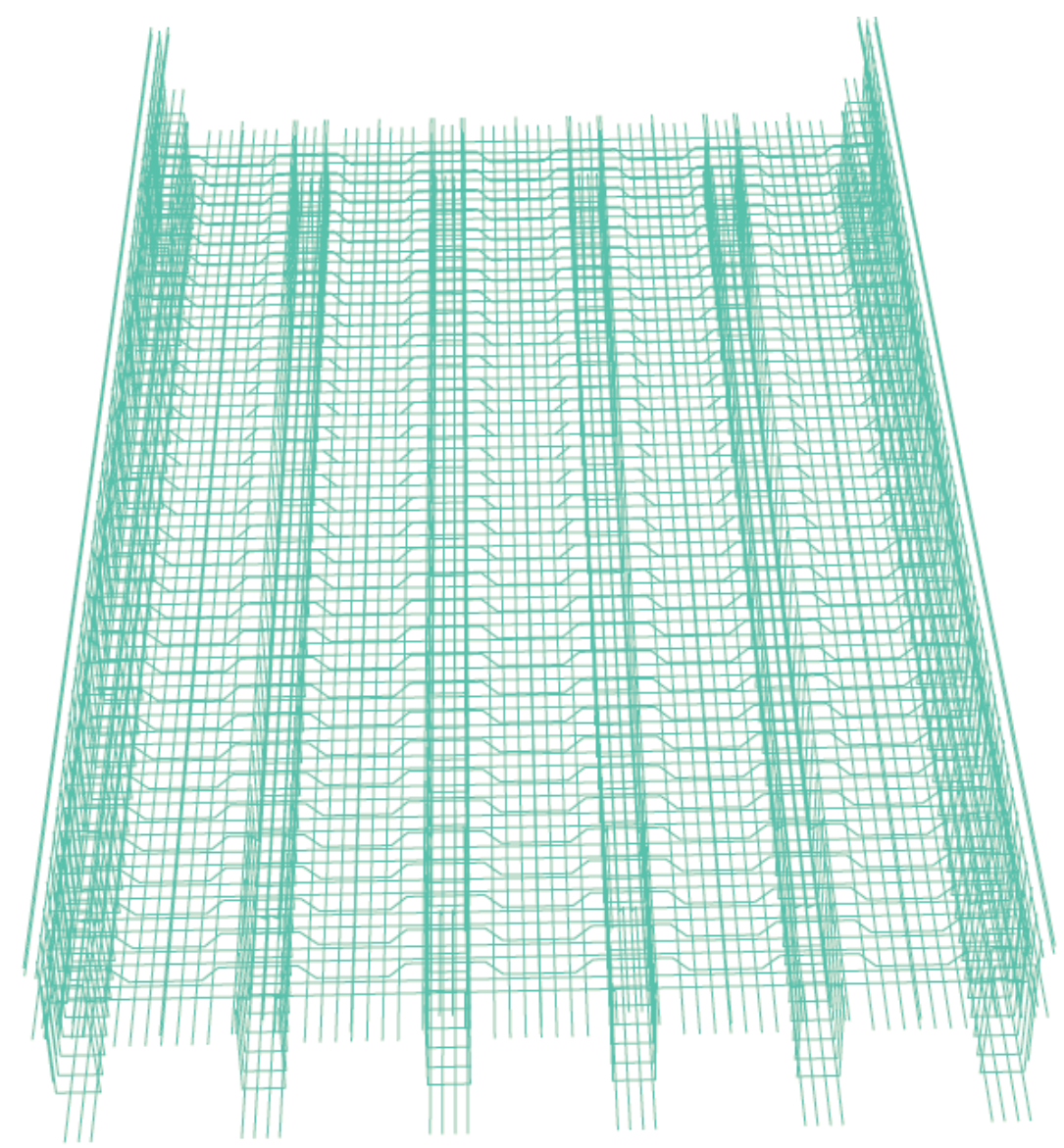

(a) 3D

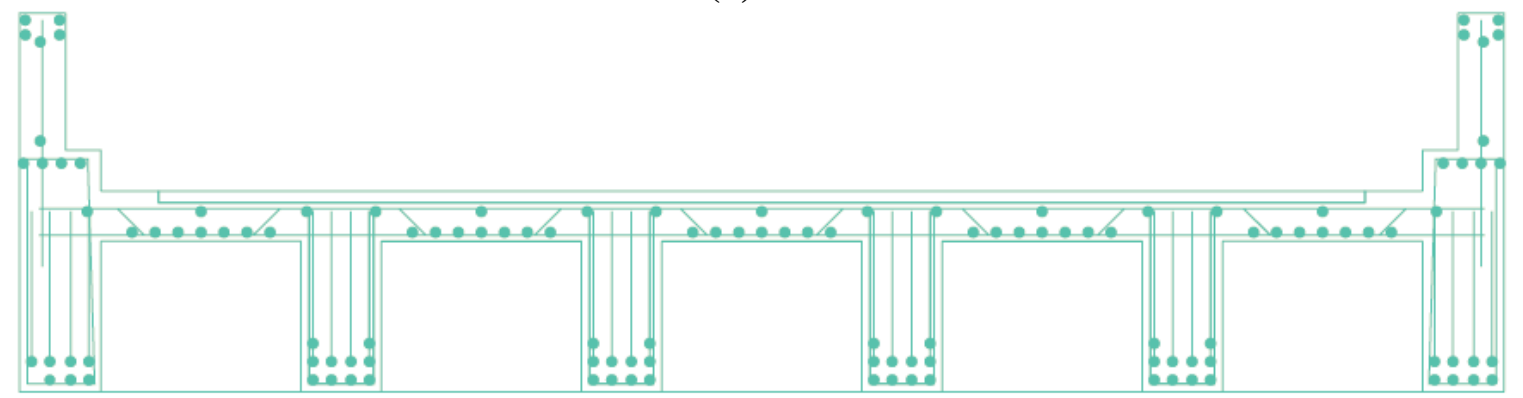

(b) Cross-Section

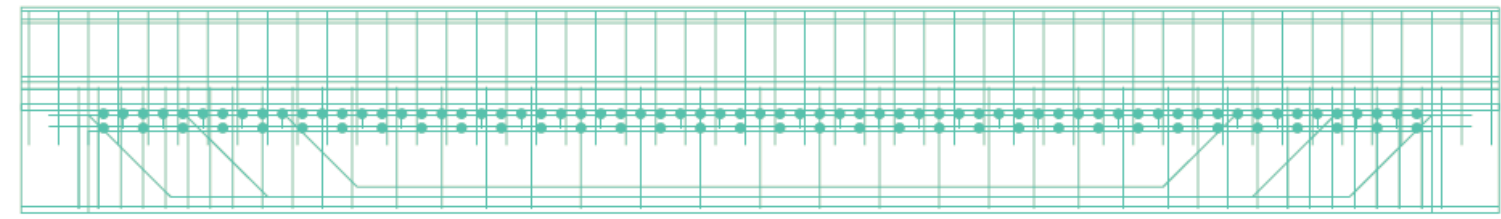

(c) Side View

Figure 3.40 Rebar System of the Model 


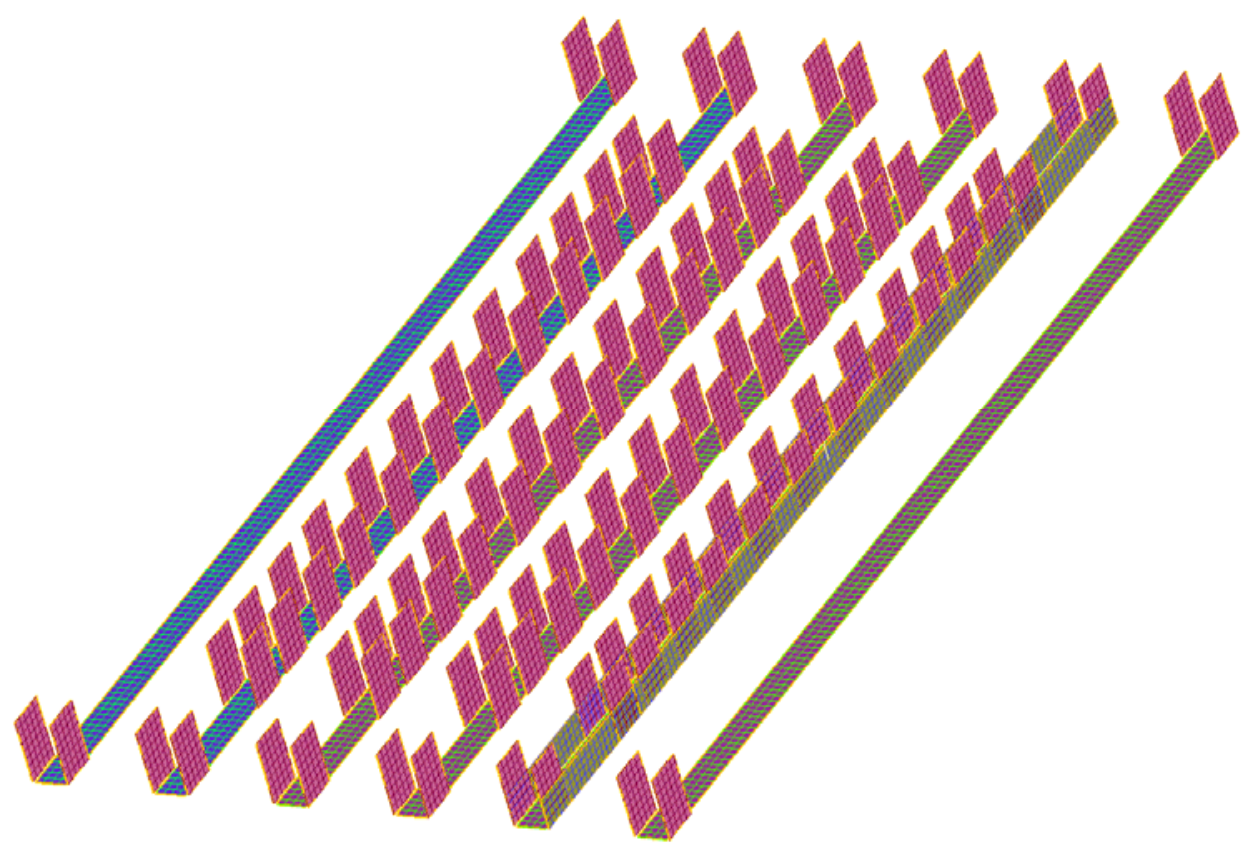

Figure 3.41 Reinforcing FRP System of Model

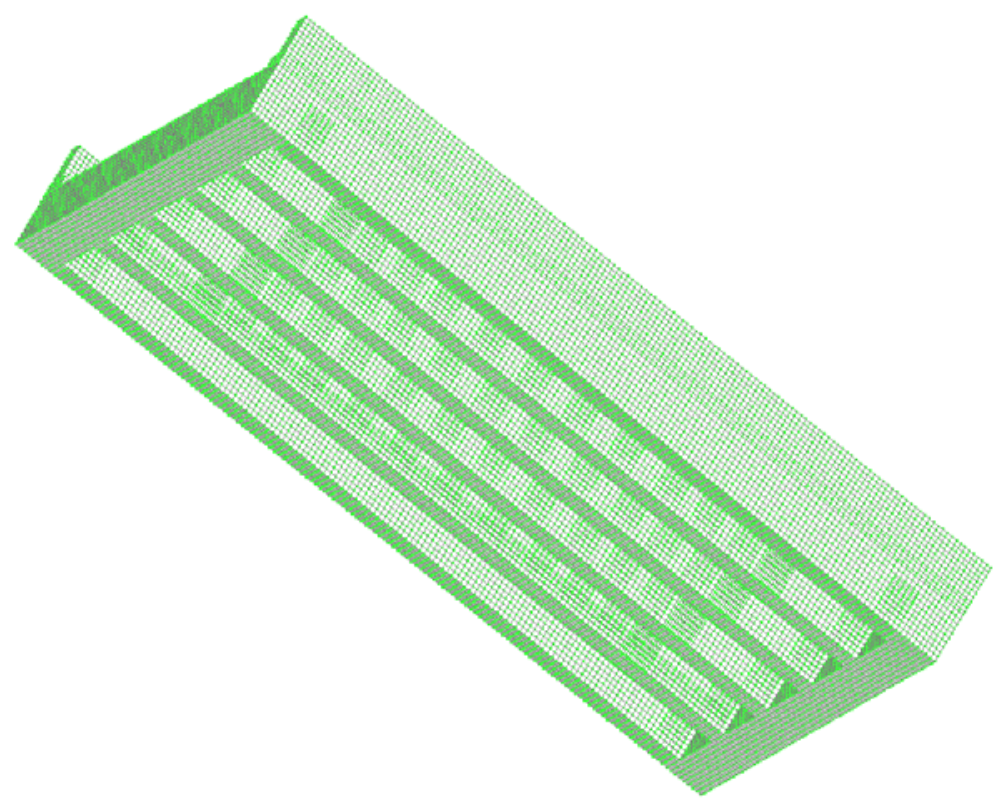

Figure 3.42 Meshed FE Model 
Table 3-4 Wheel Loading (lbs) for AASHTO HS20 and Tandem Trucks

\begin{tabular}{|c|c|c|c|c|c|c|}
\hline & \multicolumn{2}{|c|}{ AASHTO Truck-HS20 } & \multicolumn{2}{c|}{ PennDOT Tandem Truck \#1/\#2 } \\
\hline & Left & Right & Total & Left & Right & Total \\
\hline Front & 4,000 & 4,000 & 8,000 & $7,450 / 7,650$ & $8,000 / 8,000$ & $15,450 / 15,650$ \\
\hline Rear 1 & 16,000 & 16,000 & 32,000 & $10,300 / 11,150$ & $10,300 / 10,800$ & $20,600 / 21,950$ \\
\hline Rear 2 & 16,000 & 16,000 & 32,000 & $10,000 / 11,200$ & $10,400 / 10,500$ & $20,400 / 21,700$ \\
\hline Total & & & $\mathbf{7 2 , 0 0 0}$ & & & $\mathbf{5 6 , 4 5 0 / 5 9 , 3 0 0}$ \\
\hline
\end{tabular}
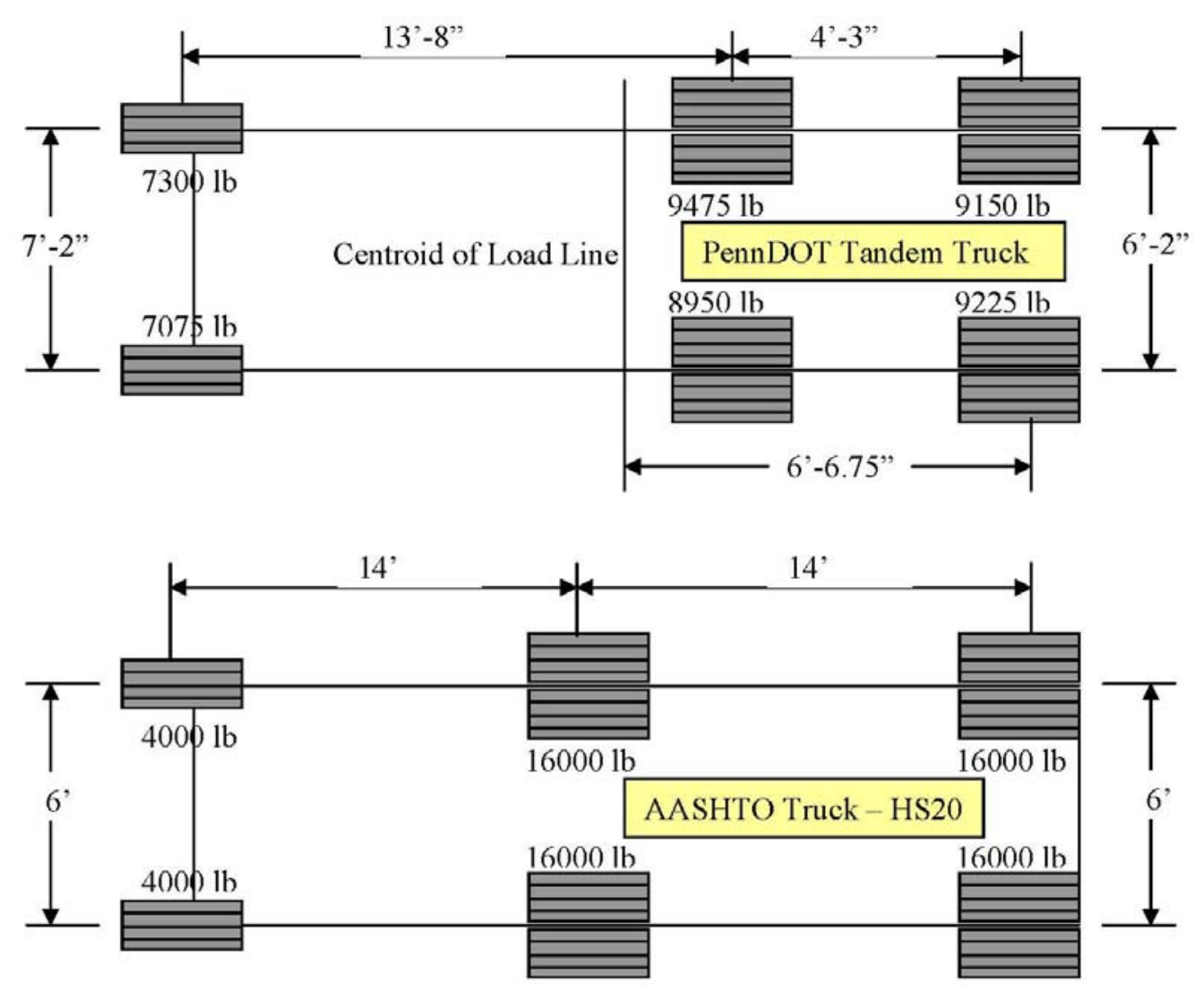

Figure 3.43 Wheel Spacing Comparison 


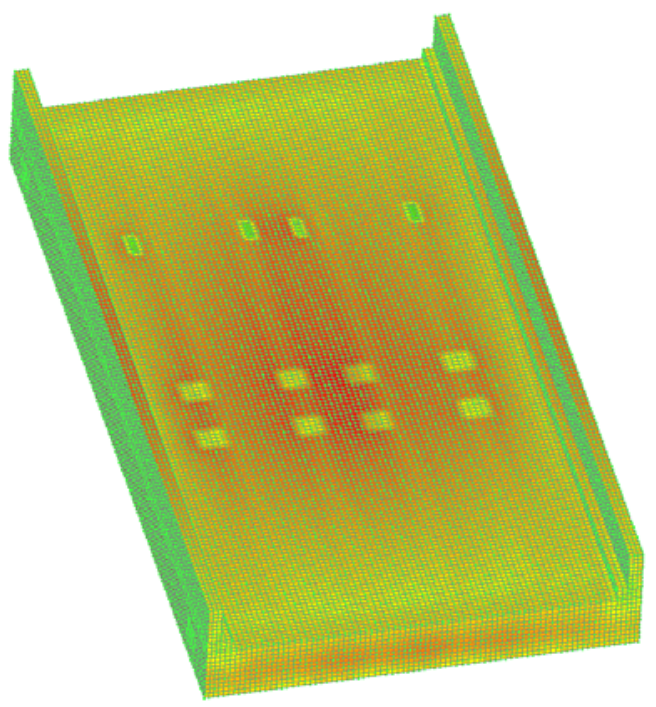

Figure 3.44 Tandem Truck Load Position

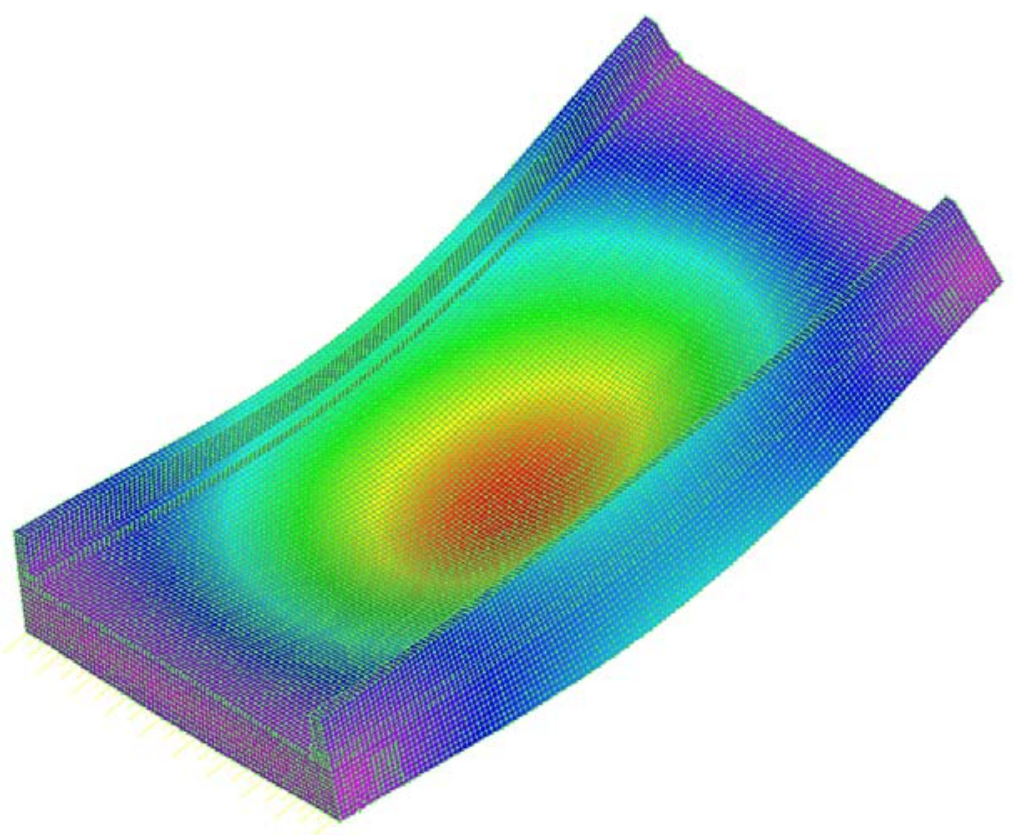

Figure 3.45 Vertical Deformation Contour Plot 


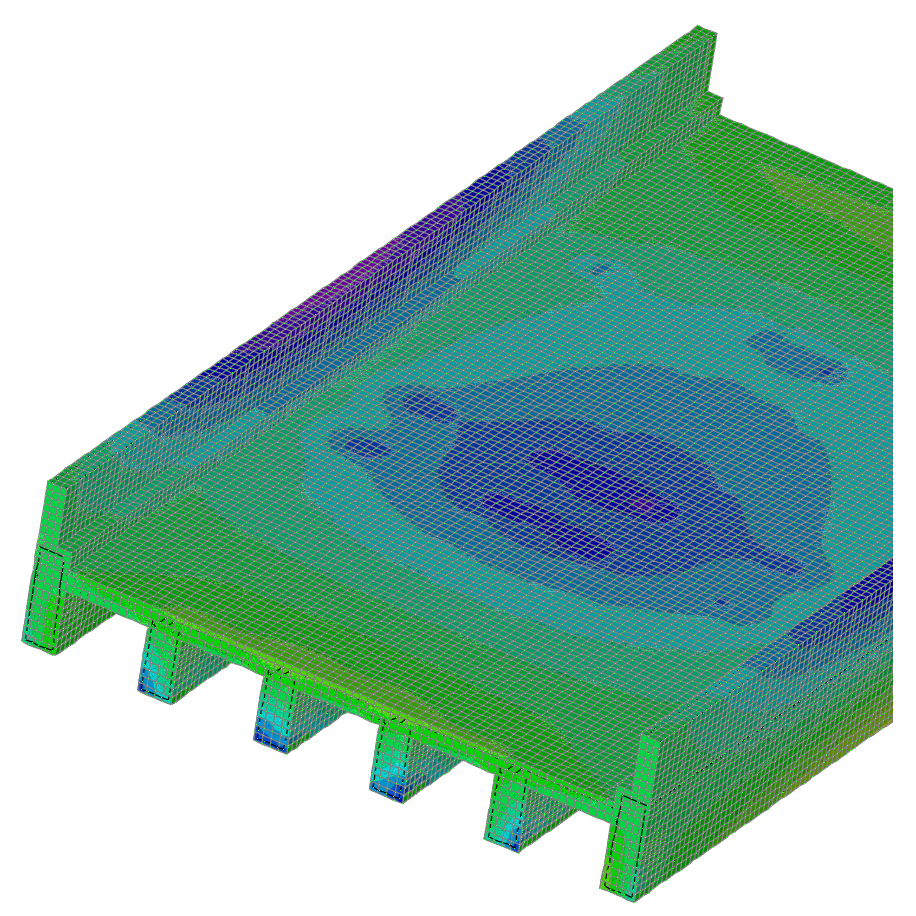

Figure 3.46 In-plane Stress View Cut

\subsubsection{Dynamic Response Analysis}

A dynamic analysis was also performed in order to determine the natural frequency of the bridge. This information will provide verification that the FE model and the actual bridge are yielding the same results and responding to loading in similar fashions. The natural frequencies of the bridge were determined to be 13.44, 16.21, 20.92, 28.49, and 30.61 Hertz for Mode 1, Mode 2, Mode 3, Mode 4, and Mode 5, respectively. The Mode 1 natural frequency from field testing is $14.72 \mathrm{Hertz}$, which is about $9 \%$ higher than the predicted value. Figure 3.47 shows the first three mode shapes. 


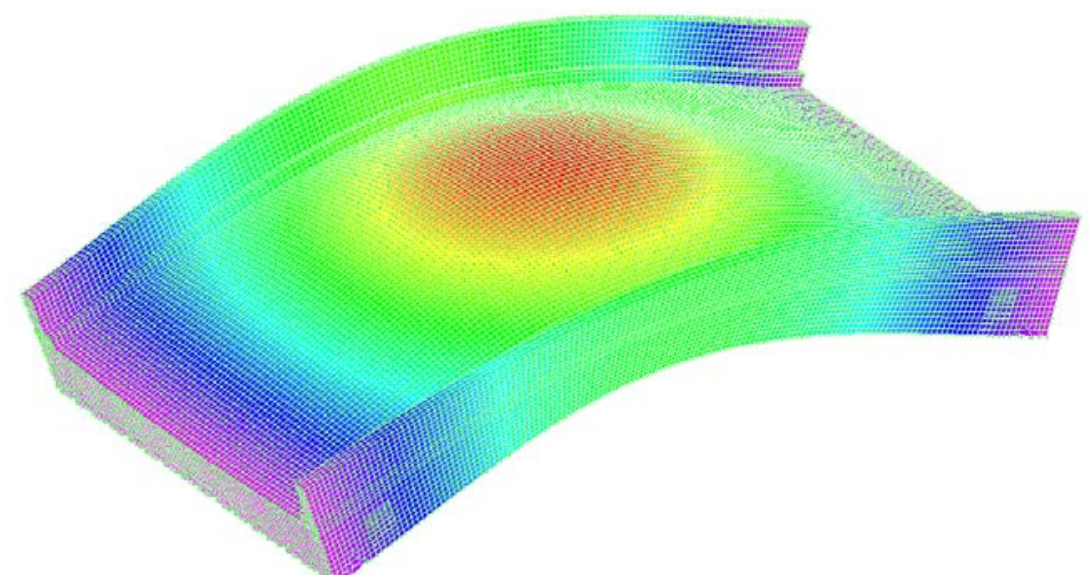

Mode $1-13.44 \mathrm{~Hz}$

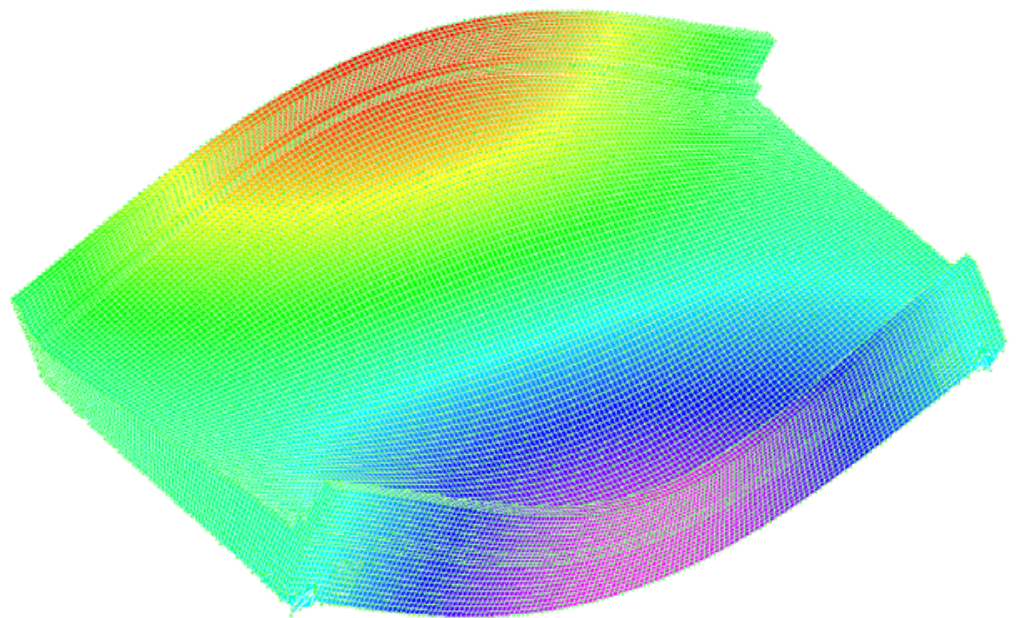

Mode $2-16.21 \mathrm{~Hz}$

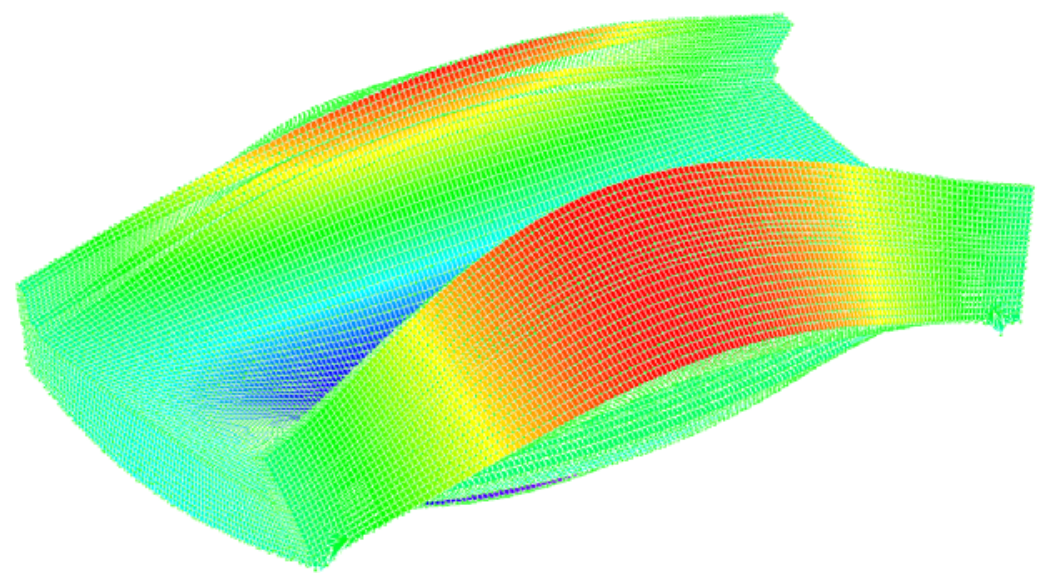

Mode $3-20.92 \mathrm{~Hz}$

Figure 3.47 Mode Shapes and Frequencies 


\section{ChAPTER 4 - Design PRogram}

\subsection{INTRODUCTION}

In Phase II of the project, an extensive analysis and design program was developed in Microsoft Excel. The development of the program was started in an attempt to better understand PennDOT's load rating and analysis program (BAR7). BAR7 is a program that will evaluate many complex factors associated with an existing structure by receiving input from the user. BAR7 then rates the bridge for its capacity to carry the live load safely and to provide useful service.

The program developed in Phase II was expanded to incorporate FRP design based on ACI 440.2R-2002. Reference should be made to Sasher, 2008 for a more in depth review of this program. Although very detailed, the Excel program was not as user friendly as desired. Also, it was concluded that PennDOT's BAR7 would not be replaced by such a program; PennDOT could however benefit from a program stressing key aspects of the FRP design itself.

During the development of the draft design guidelines in PennDOT's DM-4 format, it was desired to develop a design program that could aid the guidelines. The idea was that this program could eventually be linked to BAR7, thereby allowing for the expansion of BAR7 to incorporate FRP rehabilitation of concrete T-Beam bridges. Due to its virtually limitless capabilities and many graphical user interface (GUI) components, MATLAB was used to develop this new program. This chapter presents key points of the program which also serves as a user's manual within the program help menu. 


\subsection{PROGRAM DESCRIPTION}

\subsubsection{General}

For strengthening of simple span, aged concrete T-Beam bridge superstructures, the primary members for strengthening are the beams supporting the deck. For beam strengthening, an increase in moment and shear capacity is the desired result. For this reason, the program is broken down into sections relating to moment and shear. Specifically, there is a tab for: flexural specific input, flexural specific output, shear specific input, shear specific output, and rating factors as indicated in Figure 4.1. Included within the flexural specific input tab are a wide range of input parameters that are used for more than just flexural analyses. These global parameters are incorporated within flexural specific input as an increased organization measure. The user interface is separated into many different panels for various types of input and output data for increased user friendliness and organization as well.

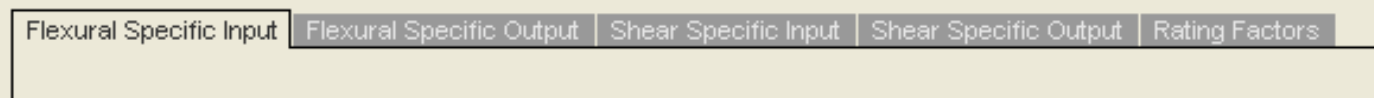

Figure 4.1 Tabbing Organization of Program

Once all input has been accepted by the program, the program presents original capacities, remaining capacities, strengthened capacities, and strengthened design capacities. All relevant detailing aspects and stress checks are provided within the output. All calculations are preformed in accordance with AASHTO, 1996 and ACI 440.2R-08 2008. The program follows U.S. customary units with the units stated in 
parentheses next to the input or output label. The following sections present the details of the various input and output fields of the program.

\subsubsection{Flexural Input}

The flexural input tab invites the user to input a wide range of data as can be seen in Figure 4.2. A drop down menu is presented at the top for beam type selection, in which the user can select from interior and exterior beam. The section is further organized into various input panels where input is accepted relating to: beam dimensions, reinforcing steel details, material properties, loading moments, and flexural FRP layout.

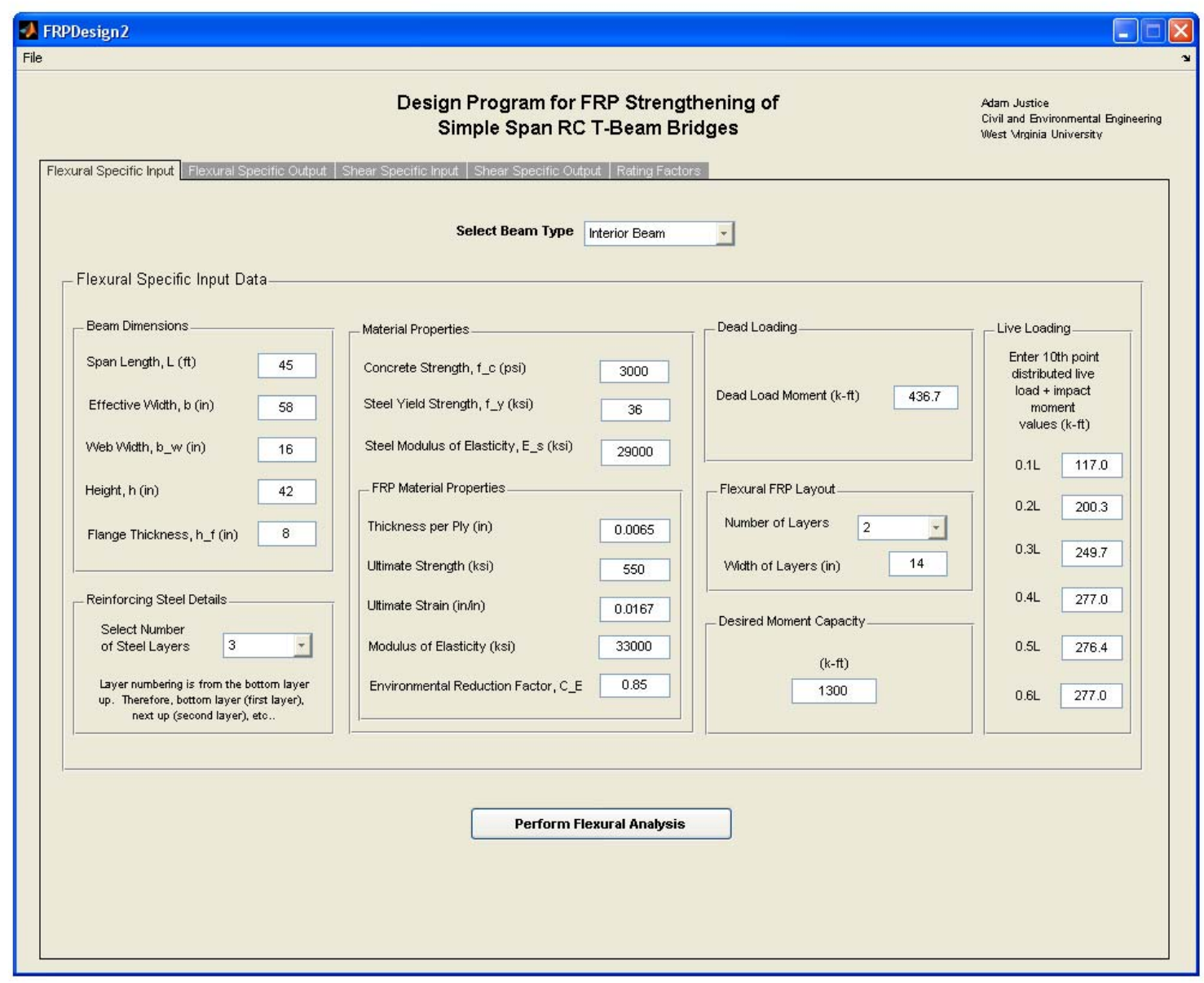

Figure 4.2 Flexural Input Section of Program 


\subsubsection{Beam Dimensions}

The beam dimensioning panel is fairly self explanatory. The user has input fields for span length, flange width, web width, height, and flange thickness. As previously stated, the required units are presented in parentheses next to the input label as illustrated in the top left of Figure 4.2.

\subsubsection{Longitudinal Reinforcement Details}

The reinforcing steel details panel is a very important panel that allows the user the possibility of incorporating many options into the analysis. The panel is separated and enlarged in Figure 4.3 for easier viewing.
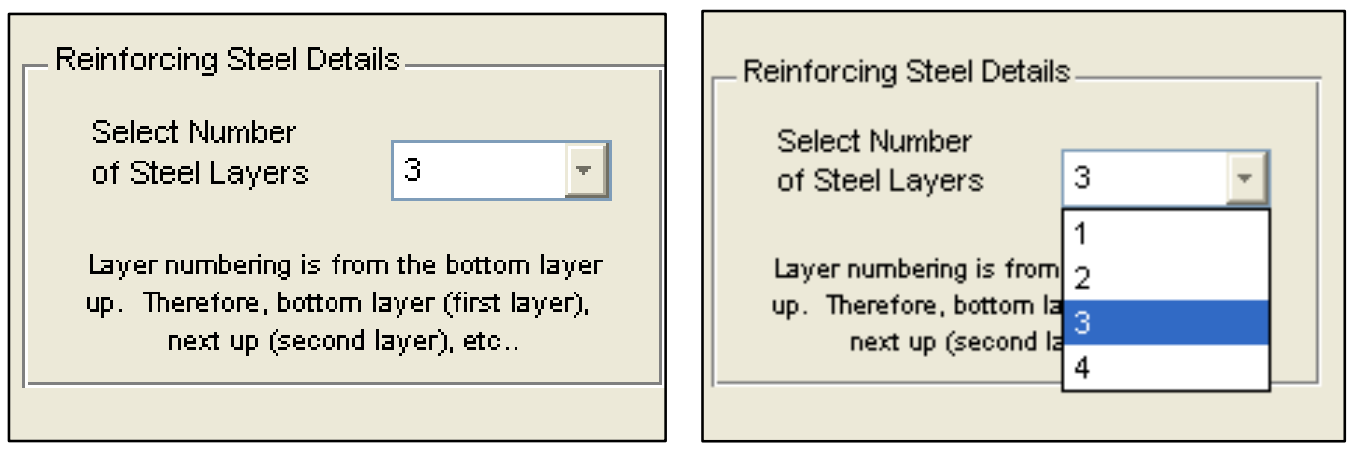

Figure 4.3 Enlarged Flexural Steel Details Panel

As can be seen from Figure 4.3, the drop down menu allows the user to select up to 4 layers of longitudinal steel reinforcement. Based on the selection in this menu, an input dialog box will be presented to the user so that original and existing details for each steel layer can be incorporated into the flexural analysis. This is important so that deterioration assumptions and measures can be used to more accurately assess the existing condition of the structure. Input dialog boxes are presented in Figure 4.4 based on a selection of 2 and 3 steel layers. 


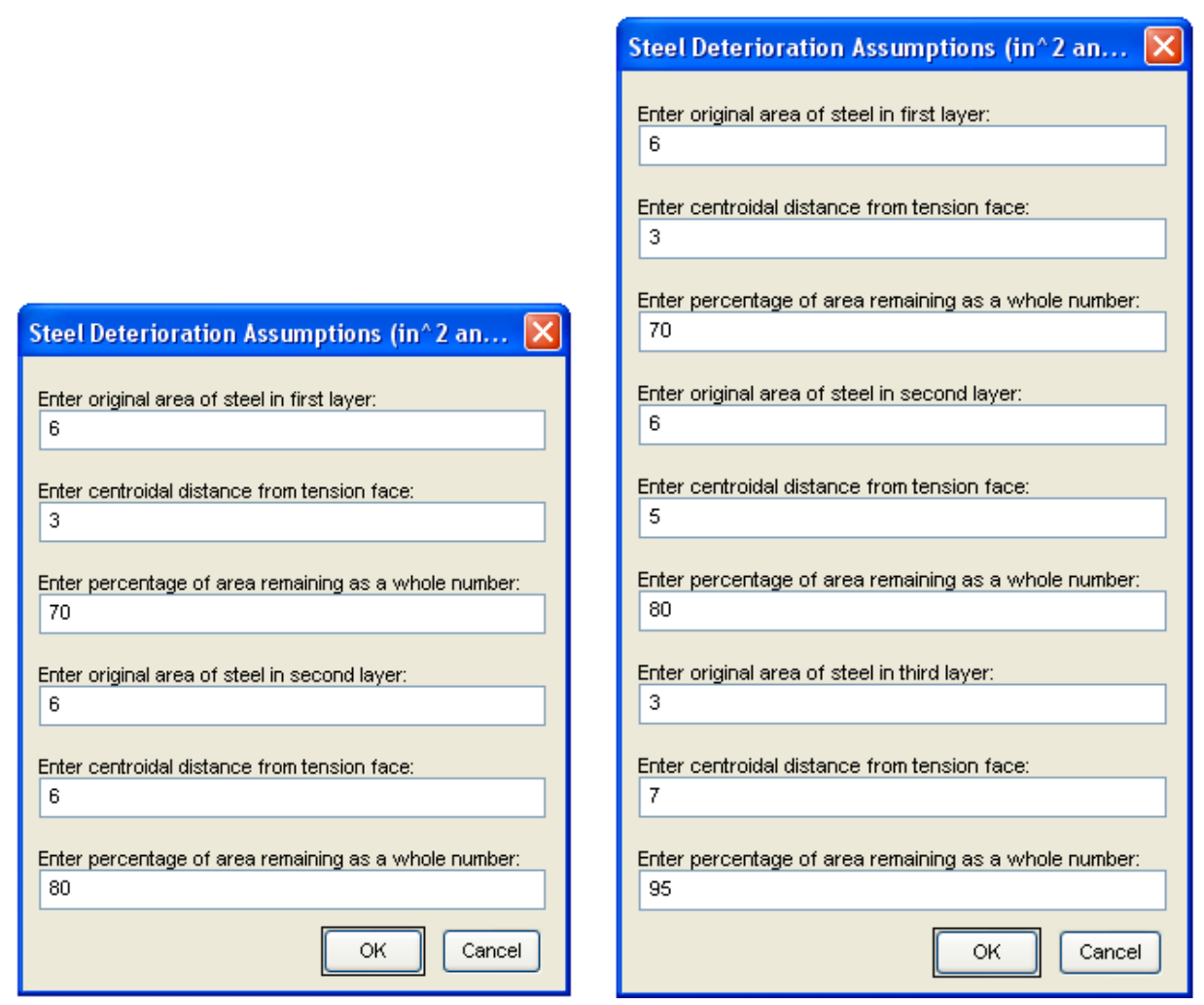

Figure 4.4 Longitudinal Steel Input Dialog Box - 2 and 3 Layers Selected

The same input is required for each layer of steel in the cross-section. More specifically, these input parameters are the following: original area of steel in the layer $\left(\mathrm{in}^{2}\right)$, centroidal distance of steel layer to bottom face of beam (in), and the percentage of steel area remaining in the layer. Based on this input data provided by the user, the program computes the original and the remaining depth to the centroid of all layers of steel from the compression face. These values are then stored and used for various calculations throughout the program. 


\subsubsection{Material Properties}

The material properties panel is divided into general input data for the existing structure and input data corresponding to the FRP strengthening system. FRP material properties should be taken from the system manufacturer's material data sheets. The environmental reduction factor is used to account for long term exposure to environmental conditions. Long term exposure to various environmental conditions can lead to decreases in tensile property values and creep-rupture and fatigue endurance of laminates. As a result, the material properties that are to be used in design should be adjusted to account for the environmental exposure condition. Reduction factors are suggested by ACI for different FRP systems and exposure situations. 0.85 is the environmental reduction factor suggested for exterior exposure such as bridges.

\subsubsection{Loading}

The dead and live load panels illustrated in Figure 4.2 require the maximum bending moments in kip-feet. In bridge analyses, loadings are determined for tenth points of the span length. The maximum dead load moment is taken and the program back calculates to determine the dead load moment corresponding to each tenth point, while the user is asked to input the maximum live load moments for the corresponding tenth points. It should be noted that the live load moments required for input include the impact factor. The program later uses these values to plot the factored moment envelope along the span length.

It is anticipated that this section of the program will be updated to link with PennDOT's BAR7. In this way, BAR7's live load generator can be incorporated and 
allow for the direct input of live load output. Either way, these values can be obtained from BAR7 depending on the user's preference.

\subsubsection{FRP Layout}

Within this particular panel, a drop down menu is accessible allowing for the selection of 1, 2, or 3 layers. These are the flexural FRP layers that are to be applied to the soffit of the beam. ACI requirements state that no more than 3 layers are to be used for these strengthening systems, and as such, the program does not allow for the use of more than 3 .

The use of side bonded FRP for flexural strengthening is also not an applicable action of the program. As stated in the Design Guidelines available in Appendix D, there is much debate and concern over the issue of using continuous side mounted FRP. The concern is that the impervious boundary created by the strengthening system could encase future contaminants and ultimately lead to increased deterioration and loss of structural integrity. Although this technology is relatively new for civil applications such as reinforced concrete retrofitting, and a significant amount of evidence to support this claim is non-existent, the theory is still very plausible. For this reason, and the fact that 3 layers applied to the soffit of a beam is usually more than enough to provide the increase is strength needed, continuously bonded side FRP was not considered in the program.

It is an obvious conclusion that, if the flexural FRP layers are to be applied to the bottom face of the beam and if no continuous side bonded flexural FRP is allowed by the

program, the width of the layers cannot exceed the with of the beam web. To help prevent the use of a layer width that is greater than the beam web width, the program warns the user with an FRP Width Error dialog box as presented in Figure 4.5 if the 
perform flexural analysis button is pressed while the width value currently set is greater than the beam web width.

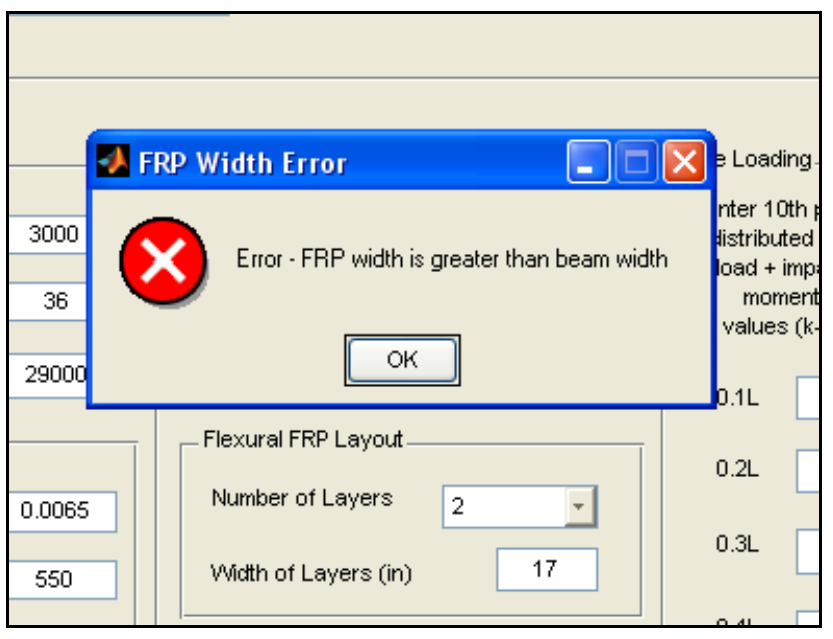

Figure 4.5 FRP Width Error Dialog Box

\subsubsection{Flexural Output}

Figure 4.6 illustrates a before and after shot of the flexural specific output tab. As can be seen, the program gives the original moment capacity, remaining moment capacity, strengthened moment capacity, and the strengthened moment capacity with the design reduction factor applied. The input data used for the example output of Figure 4.6 can be seen in Figure 4.2 along with the reinforcing steel details shown in Figure 4.4 when 3 layers of flexural steel reinforcement has been selected from the steel reinforcement details panel. The output tab presents key information important for design of these strengthening systems, with figures and various intermediate values available upon user selection as detailed in the following sections. 

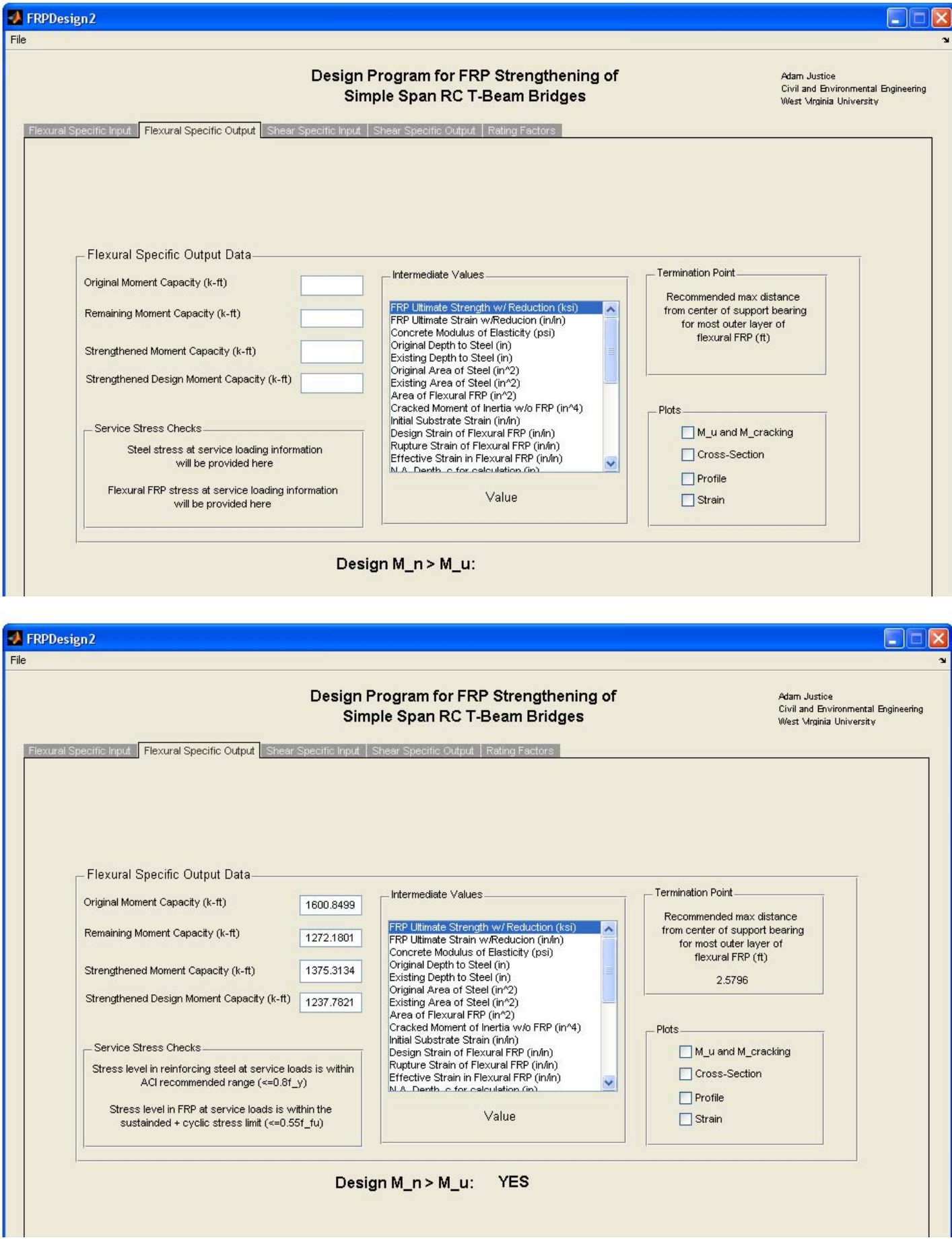

Figure 4.6 Flexural Output Tab 


\subsubsection{Service Stresses}

The service stress checks panel provides service checks as required by ACI 440.2R-08. Prior to the flexural analysis, the panel states the checks that are to be provided as depicted in the lower left region of the panel in Figure 4.6. These stresses are the stresses in the steel and FRP at service loading. As an increased measure of safety, if these stresses are exceeded, the program outputs an extra warning dialog box along with the warnings within the panel itself. The example data used indicates that the service stresses are within the required limits of $80 \%$ of the yield stress for the steel and the sustained plus cyclic stress limit for the FRP, which is $55 \%$ of the ultimate. It must be made clear that the program emphasizes the use of carbon fiber reinforced polymers (CFRP) for concrete T-Beam bridge strengthening and that the sustained plus cyclic stress limit suggested by ACI varies for different fiber types. Namely, 20\% and 30\% are used for glass fiber reinforced polymers (GFRP) and aramid fiber reinforced polymers (AFRP), respectively. These limits are presented in Table $1.6-1$ of the corresponding Design Guidelines developed for the project in Appendix D.

\subsubsection{Intermediate Values}

It is dangerous and irresponsible to perform engineering analyses with computer programs while not knowing what is going on behind the seens and performing calculation checks when felt necessary. If a result seems unreasonable, the user should be able to check the validity of the output. In an effort to not create a program that just blindly presents final results and does not allow for a user to check various values throughout the analysis, an intermediate values panel was created. Due to the large number of values associated with the computations, it was decided to provide this option 
to the user in the form of a list box as can be seen in the central portion of Figure 4.6 and enlarged in Figure 4.7 to save space. Many intermediate values are presented in this list with the value conveniently displayed below the list when selected by the user. All applicable units are presented within the selection list as well. Figure 4.7 illustrates the value presented for the FRP moment strength contribution in $\mathrm{k}-\mathrm{ft}$ resulting from the example data.

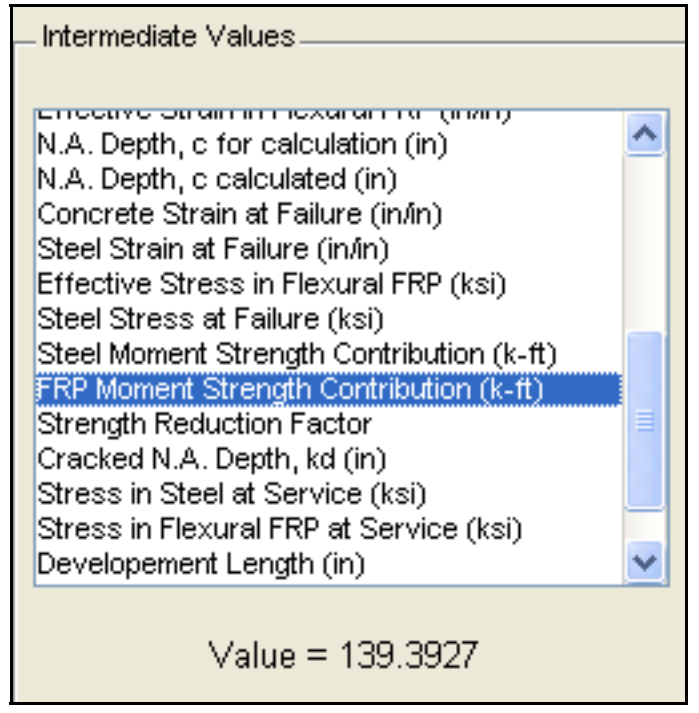

Figure 4.7 Enlarged Intermediate Values Panel

\subsubsection{Termination Point}

The upper right panel of Figure 4.6 is titled the termination point panel. It presents the maximum distance, as determined in accordance with ACI, from the center of support bearing to where the longitudinal progression, extending from the beam midpoint, of the flexural FRP layer or layers is halted. This value is important for detailing of flexural reinforcement as well as shear reinforcement, and as such, is carried over and used in the shear analysis portion of the program. If more than one layer of flexural FRP is used, the termination point corresponds to the termination point for the 
most outer layer. Details for the calculation of the termination point are provided in Section 1.8 of the Design Guidelines. Observing Figure 4.6, a termination point distance of $2.6 \mathrm{ft}$ is given for the example analysis.

\subsubsection{Plots}

As with the intermediate values panel, the plots panel is provided in the form of check boxes to save space and allow for increased organization. Upon checking the desired box, the corresponding plot or figure is presented to the user via a separate window. The presentable plots include: factored moment and cracking moment along the length of the span; generic cross-section with flexural FRP layers; generic elevation view with FRP layers; and the strain through the depth of the cross-section. These plots are illustrated in Figure 4.8 through Figure 4.11 for the example input data of Figure 4.2. The units for the axes of the cross-section diagram are inches while the units for the axes of the elevation view diagram are feet. Figure 4.9 also illustrates one of the many tool tips incorporated into the program. A tool tip is a message that is displayed to the user when the mouse is hovered over an object for a few seconds. In this case, a message can be seen displayed for the termination point reiterating the fact that the termination point is a recommendation from ACI. 


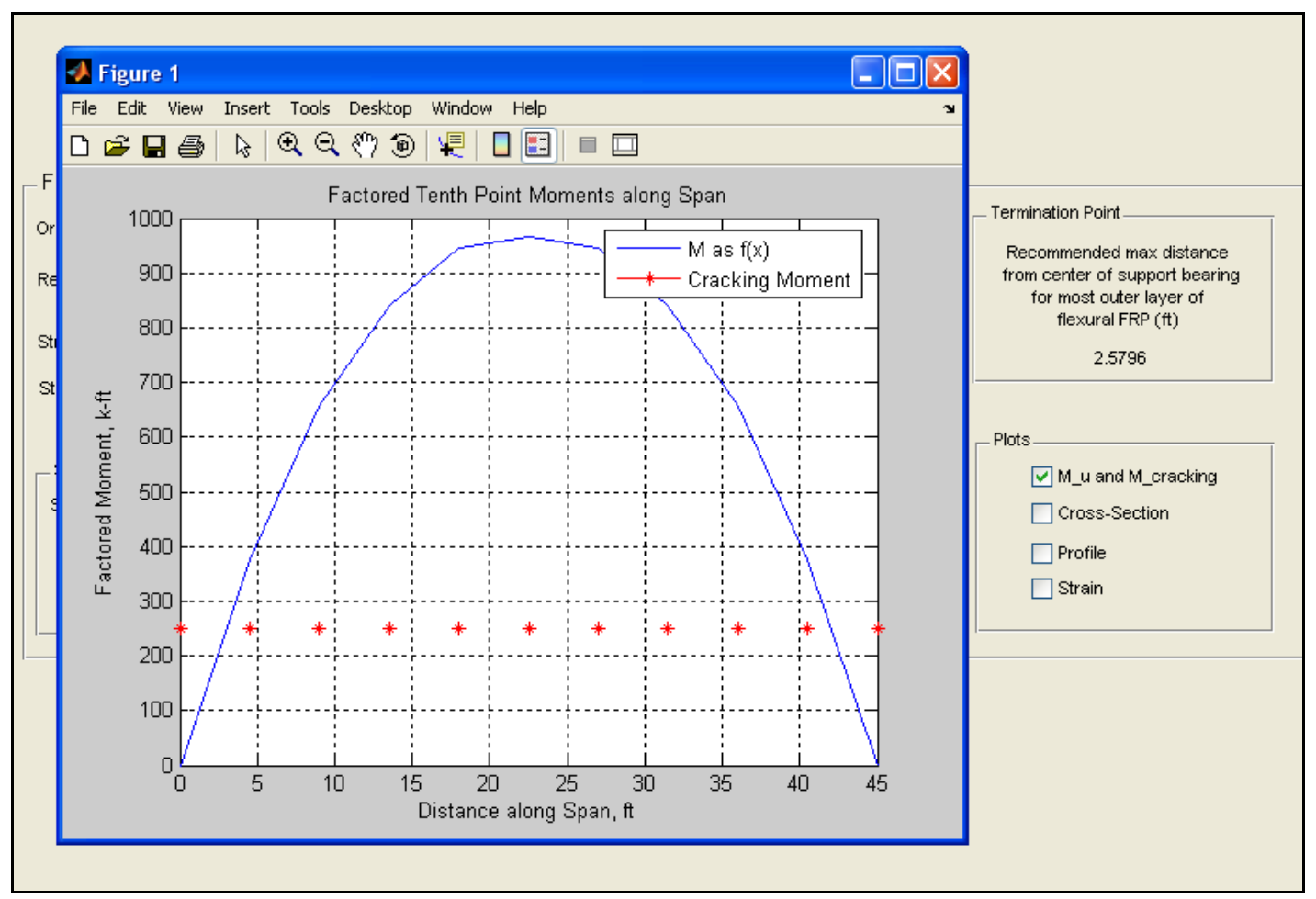

Figure 4.8 Factored Moment and Cracking Moment

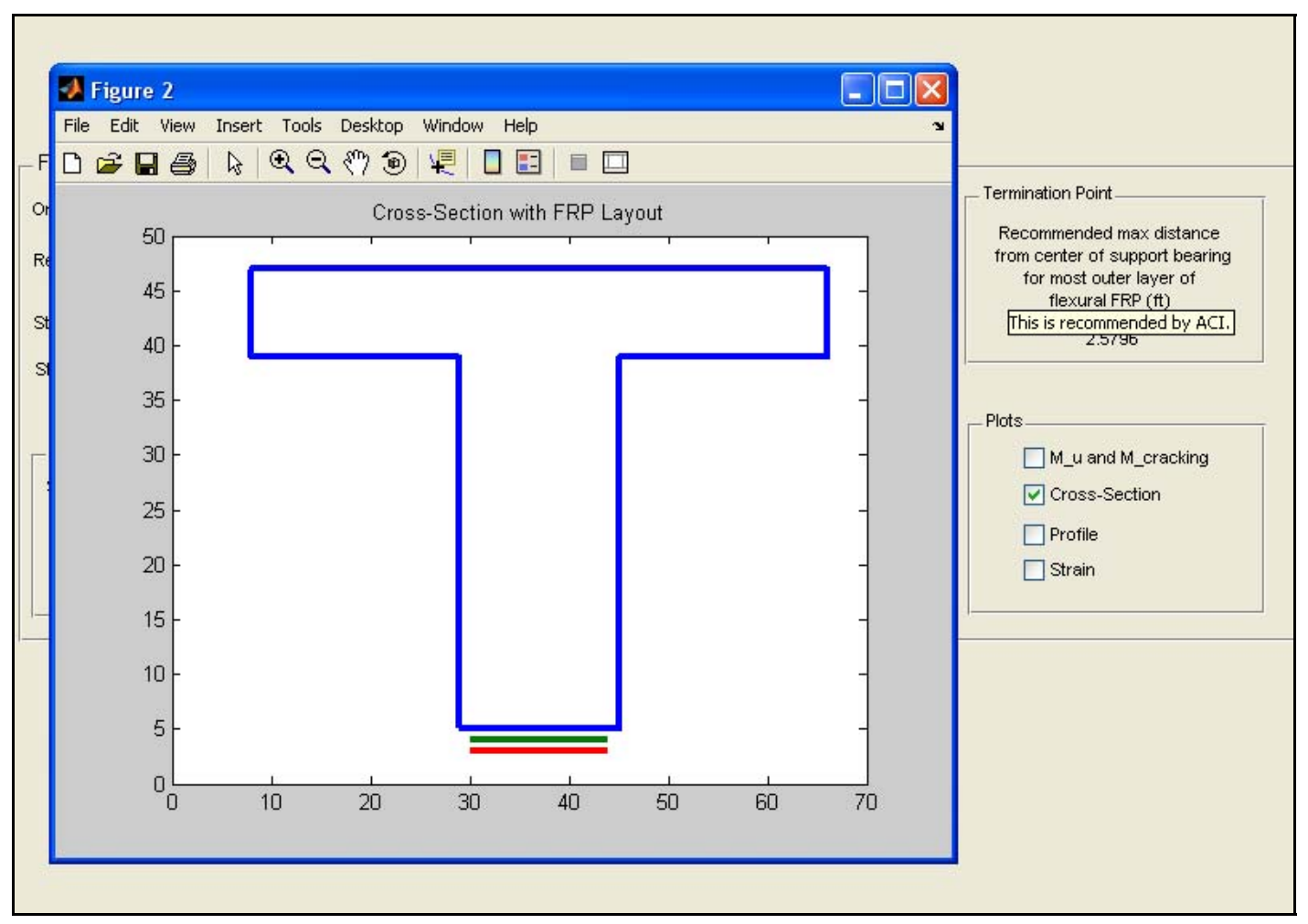

Figure 4.9 Example Cross-Section Diagram 


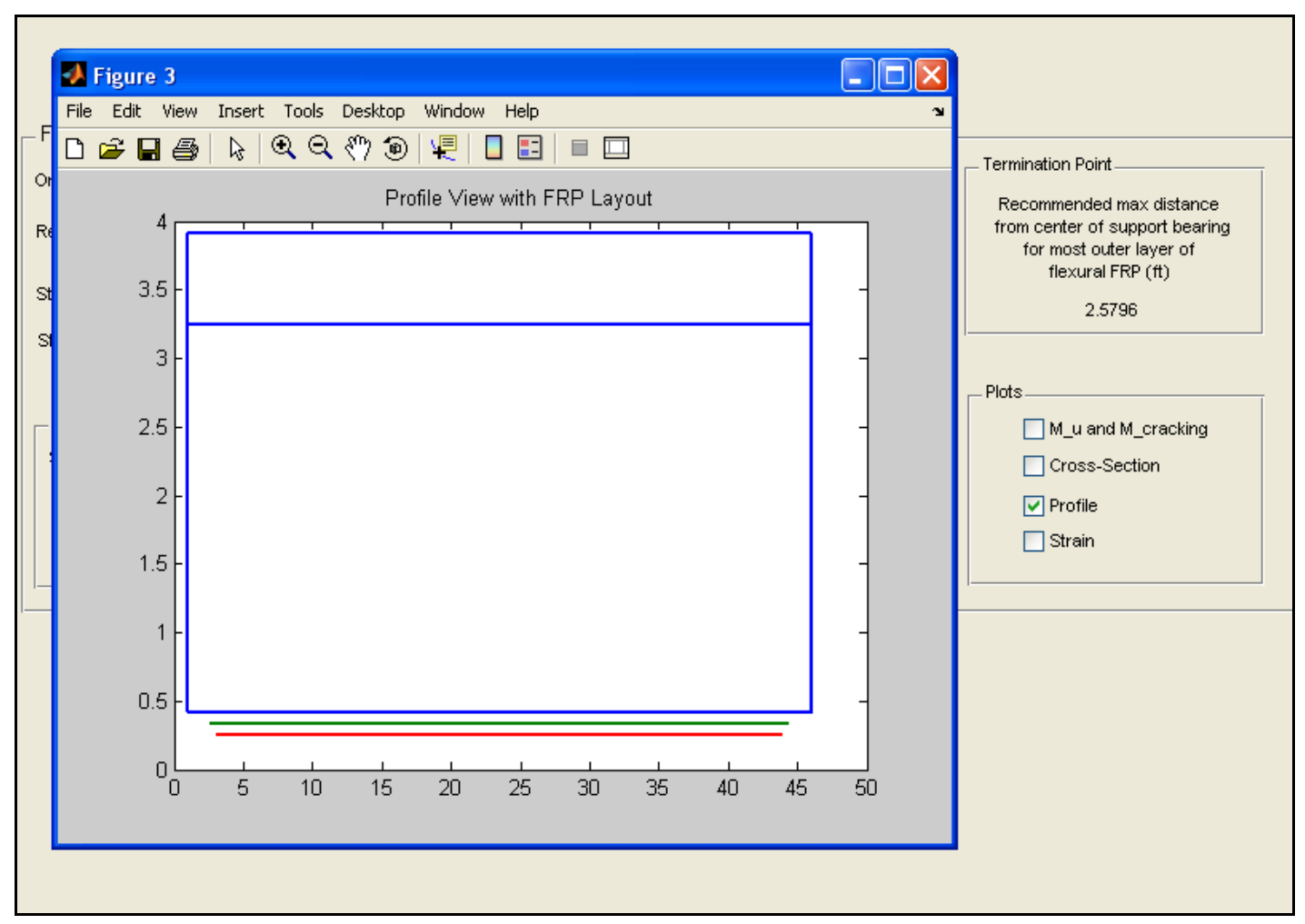

Figure 4.10 Example Elevation Diagram

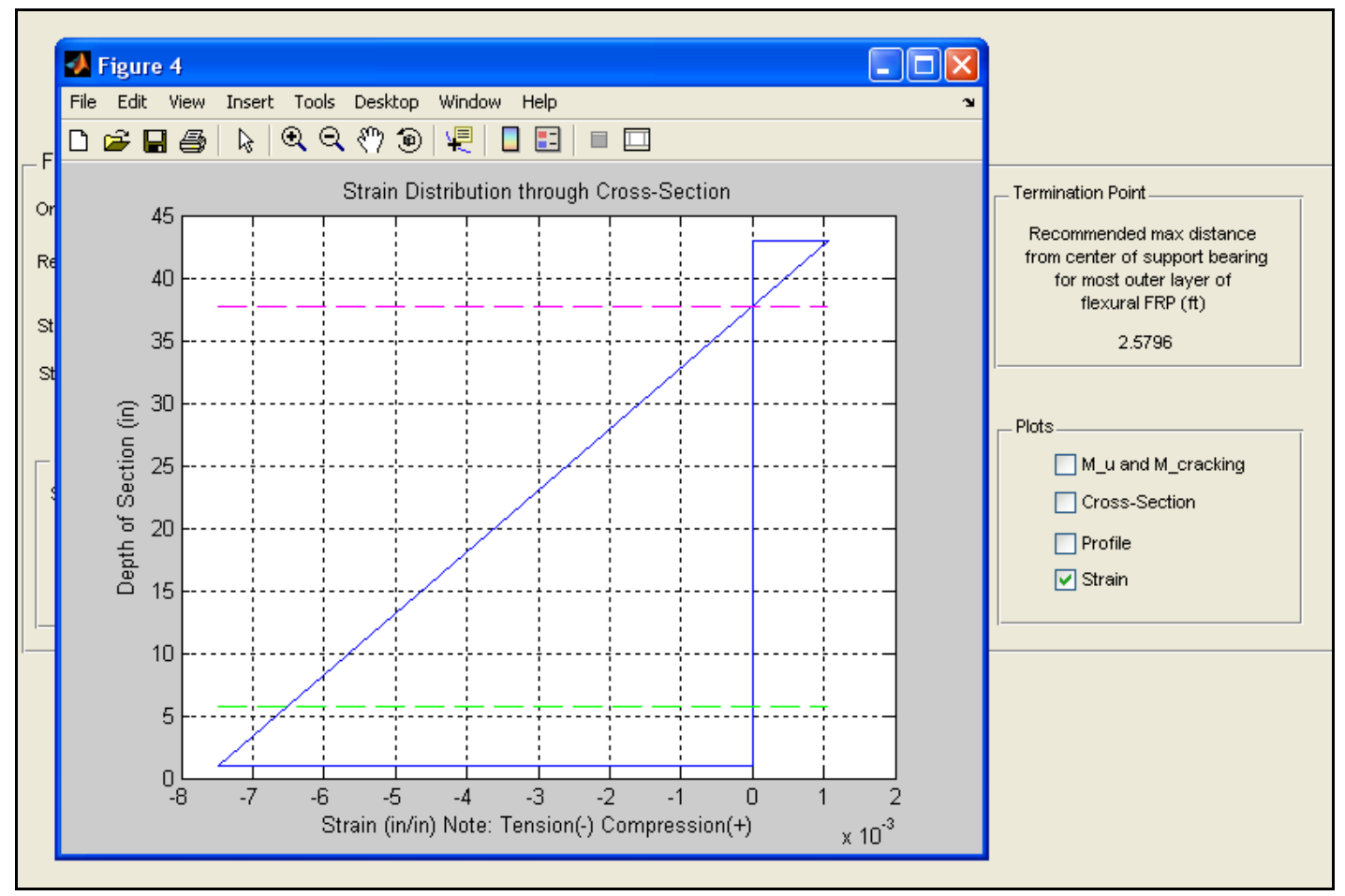

Figure 4.11 Example Cross-Section Strain Plot 


\subsubsection{Shear Input}

Figure 4.12 presents the shear specific input tab of the design program. Like other sections of the program, it is organized by using panels corresponding to different types of input. Input panels for reinforcing steel details, loading, and FRP layout are arranged.

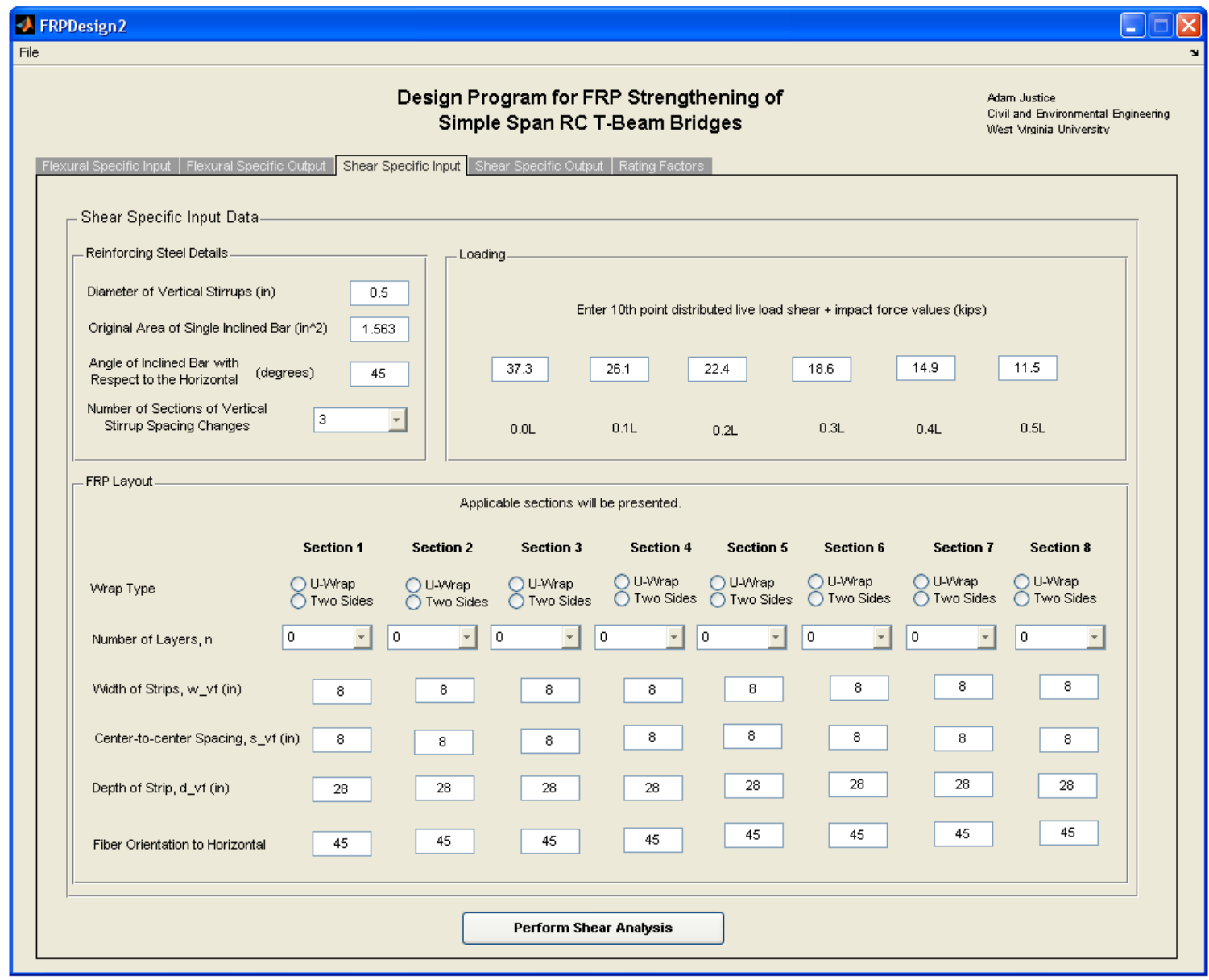

Figure 4.12 Shear Specific Input Section of Program

In designing reinforced concrete beams for shear, the beam is normally broken down into a certain number of sections along the longitudinal length of the member in 
which the center-to-center spacing of stirrups changes for each section. As a result of needed input and output dependence upon the number of shear sections used for analysis, the programming for shear computations presented more complications when compared with programming for flexural computations. These complications are explained further in the following sections when deemed necessary.

\subsubsection{Shear Reinforcement Details}

The shear steel reinforcement details required are similar to that of the flexural input section. With reference to the corresponding panel in Figure 4.12, one can see that the panel requires input for the diameter of vertical stirrups, original area of inclined bars used for shear reinforcement, and the angle of inclined bars with respect to the longitudinal axis of the beam. Required units for the input are presented as well.

A drop down menu is utilized for the user to select the number of sections in which the spacing of vertical stirrups changes. Due to the symmetry of simply supported spans, the shear analysis is performed over half the span length. Therefore, the number of sections selected represents the number of sections for one half the beam span. This detail is clearly defined to the user with the tool tip presented in Figure 4.13. Sections are numbered in ascending order from beam bearing toward beam mid-span.

The menu allows for the selection of any number of shear sections from 2 to 8 . This range was deemed sufficient to account for the majority of design cases. The number of sections selected should come from available drawings and all relevant design records for a particular bridge under investigation. Based on the selection from the drop down menu, a series of input dialog boxes are presented to the user for further data collection. These dialog boxes ask for the following information about each section: 
section distance or length, center-to-center spacing of vertical stirrups, estimate for the percentage of area remaining for vertical stirrups, number of inclined bars effective in section, estimate for the percentage of area remaining for inclined bars, and whether or not severe diagonal cracking is present in section. If the user specifies severe diagonal cracking to be present within a section, the shear strength of the concrete is neglected in computing the total shear capacity for that particular section. Input dialog boxes for the selection of 4 sections in which the vertical stirrup spacing changes are illustrated in Figure 4.14, with one box for sections 1 and 2 and another for sections 3 and 4 .

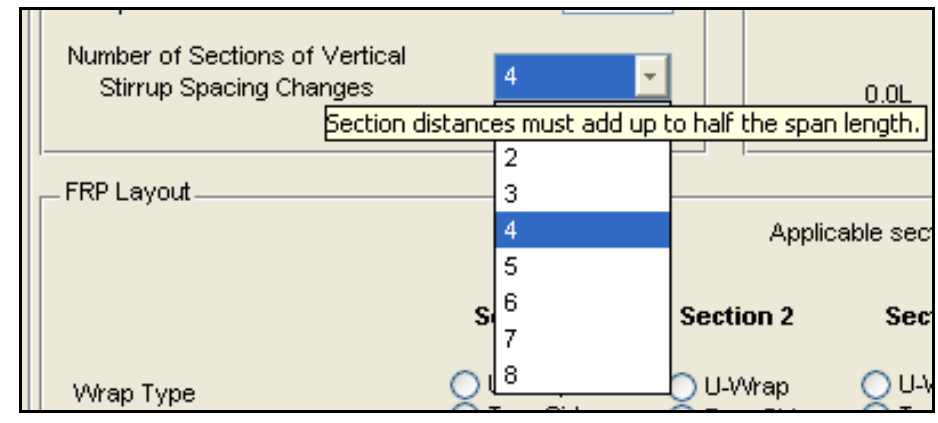

Figure 4.13 Enlarged Shear Sections Selection Menu

Note that section distance and stirrup spacing are required in units of inch as indicated in Figure 4.14. As an increased measure of control for the user, if the perform shear analysis button is pressed and the section distances do not sum up to half the span length, the program presents an error dialog box as depicted in Figure 4.15 before the analysis is performed. 


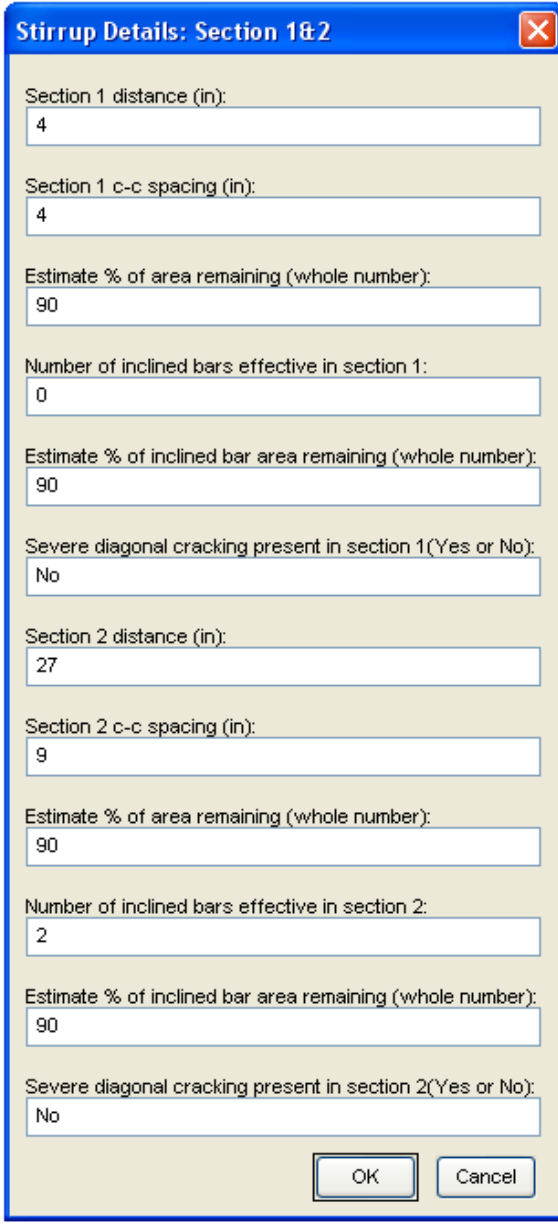

\begin{tabular}{l}
\hline Stirrup Details: Section $3 \mathrm{ft} 4$ \\
Section 3 distance (in): \\
\hline 27 \\
Section 3 c-c spacing (in): \\
\hline 9 \\
Estimate \% of area remaining (whole number): \\
\hline 90 \\
Number of inclined bars effective in section 3: \\
\hline 2 \\
\hline Estimate \% of inclined bar area remaining (whole number): \\
\hline 90 \\
\hline Severe diagonal cracking present in section 3(Yes or No): \\
\hline No \\
\hline Section 4 distance (in): \\
\hline 12 \\
\hline Severe diagonal cracking present in section 4 (Yes or No): \\
\hline Noction 4 c-c spacing (in): \\
\hline 12 \\
\hline 90 \\
\hline
\end{tabular}

Figure 4.14 Input Dialog Boxes for Shear Sections - 4 Sections Selected

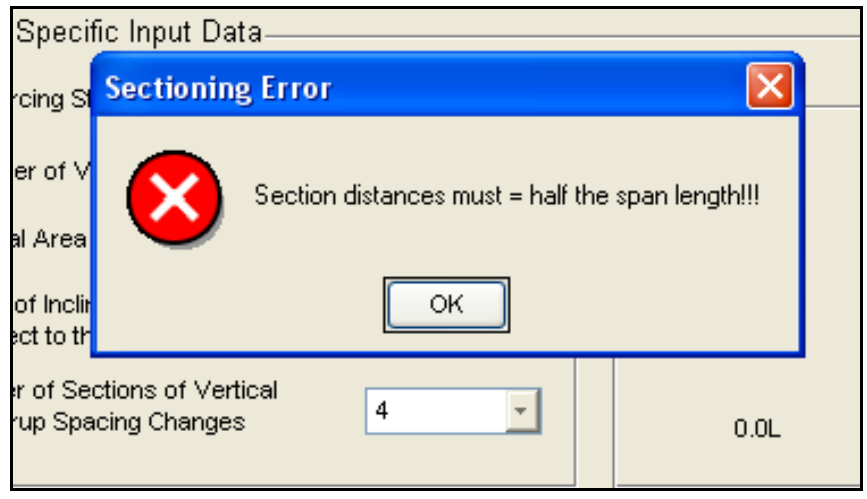

Figure 4.15 Section Distance Error Dialog Box 


\subsubsection{Loading}

The loading panel of the shear input tab is similar to the loading panel of the flexural input tab. The user is required to input the tenth point live load shear values in kips. Like the live load moment input, these values are required to include the impact factor. Employing symmetry, only tenth point values for half the span are needed. The dead load shear values are calculated within the program using the maximum dead load moment which is taken from the flexural input, and therefore, are not required.

\subsubsection{FRP Layout}

The FRP layout panel for shear reinforcement can be seen in Figure 4.12. A different layout for the reinforcement can be applied to each shear section specified in the reinforcing steel details panel. Eight columns are presented in the FRP layout panel to provide required input fields for any number of shear sections. In other words, if eight sections were specified in the drop down menu of the reinforcing steel details panel, eight columns would be provided as indicated in Figure 4.16, with headings of Section 1, Section 2, etc. up to Section 8. Whereas, if only four sections were selected for a beam, the columns for sections 5 through 8 would not be needed and the program would give these column headings as dashed lines indicating that no such section exists. This is illustrated in Figure 4.17. Although not a very important aspect of the program, this small detail can help guide the user through the shear input portion of the program with more clarity. Values placed into sections with dashes as the heading will not cause any errors in the analysis. The values will simply not be used by the program. 


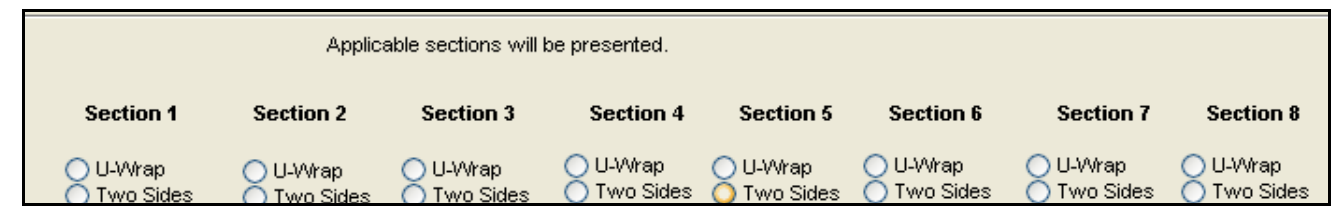

Figure 4.16 FRP Shear Reinforcement for 8 Sections

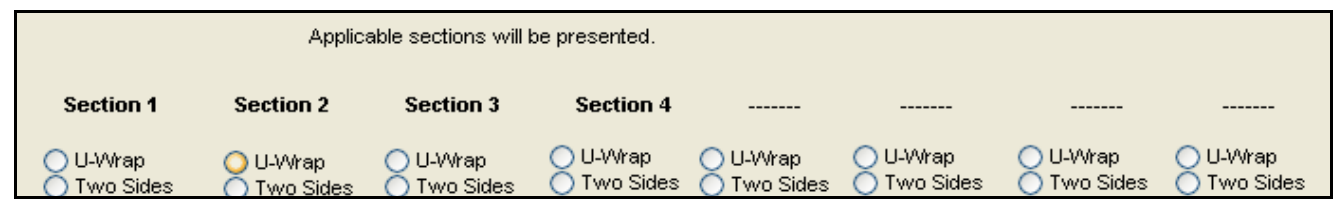

Figure 4.17 FRP Shear Reinforcement for 4 Sections

The first row in the FRP layout panel allows the user to select one of two types of wrapping schemes, U-wrap (also known as three sides wrapped) or two sides (a strip of FRP bonded to each side of the beam web). The most common type is U-wrap, and this is the default wrapping scheme used by the program if no wrapping scheme is selected. Completely wrapping a T-Beam is not applicable, and as such, is not an option for program analysis. Greater detail concerning wrapping schemes for shear reinforcement can be found in Section 1.7.1 of the Design Guidelines.

Drop down menus for selecting the number of layers of shear reinforcement are provided in the second row of the panel. As with flexural input, the user can select up to three layers for the analysis. If zero is selected, then there is simply no FRP applied to that section and the resulting FRP shear strength contribution is zero.

The remaining rows call for various layout dimensions such as: width of strip, center-to-center spacing, depth of strip, and the fiber orientation angle with respect to the longitudinal axis of the member. Reference should be made to Figure $1.7-1$ of the Design Guidelines for an illustration of each of the afore mentioned layout dimensions. 


\subsubsection{Shear Output}

As with much of the input requirements for shear analysis, the shear output format slightly changes depending on the number of shear sections needed. For clarity, shear output tabs with their corresponding input tabs are shown in Figure 4.18 and Figure 4.19 after the perform shear analysis button has been pressed. Figure 4.18 illustrates eight shear sections defined while Figure 4.19 illustrates four shear sections defined. As visible in Figure 4.19, dashed lines are presented for all output fields that are not needed based on the number of shear sections selected.

In the same manner that the flexural output is presented to the user, the shear output presents the following results for each beam section: original capacity, remaining capacity, strengthened capacity, and the strengthened design capacity. All output units are declared in parenthesis along with each component of the GUI.

Separated from the output capacities with a dashed line, reinforcement limit checks and strength checks are listed for each shear section. Reinforcement limits for FRP shear reinforcement are detailed in Section 1.7.7 of the Design Guidelines. If the shear reinforcement limit is exceeded, the program displays "NO GOOD", otherwise, the program displays "OK" as can be seen in Figure 4.18 and Figure 4.19. The same concept is used in displaying whether or not the design strength capacity of the section is greater than or equal to the factored shear force in the section. 

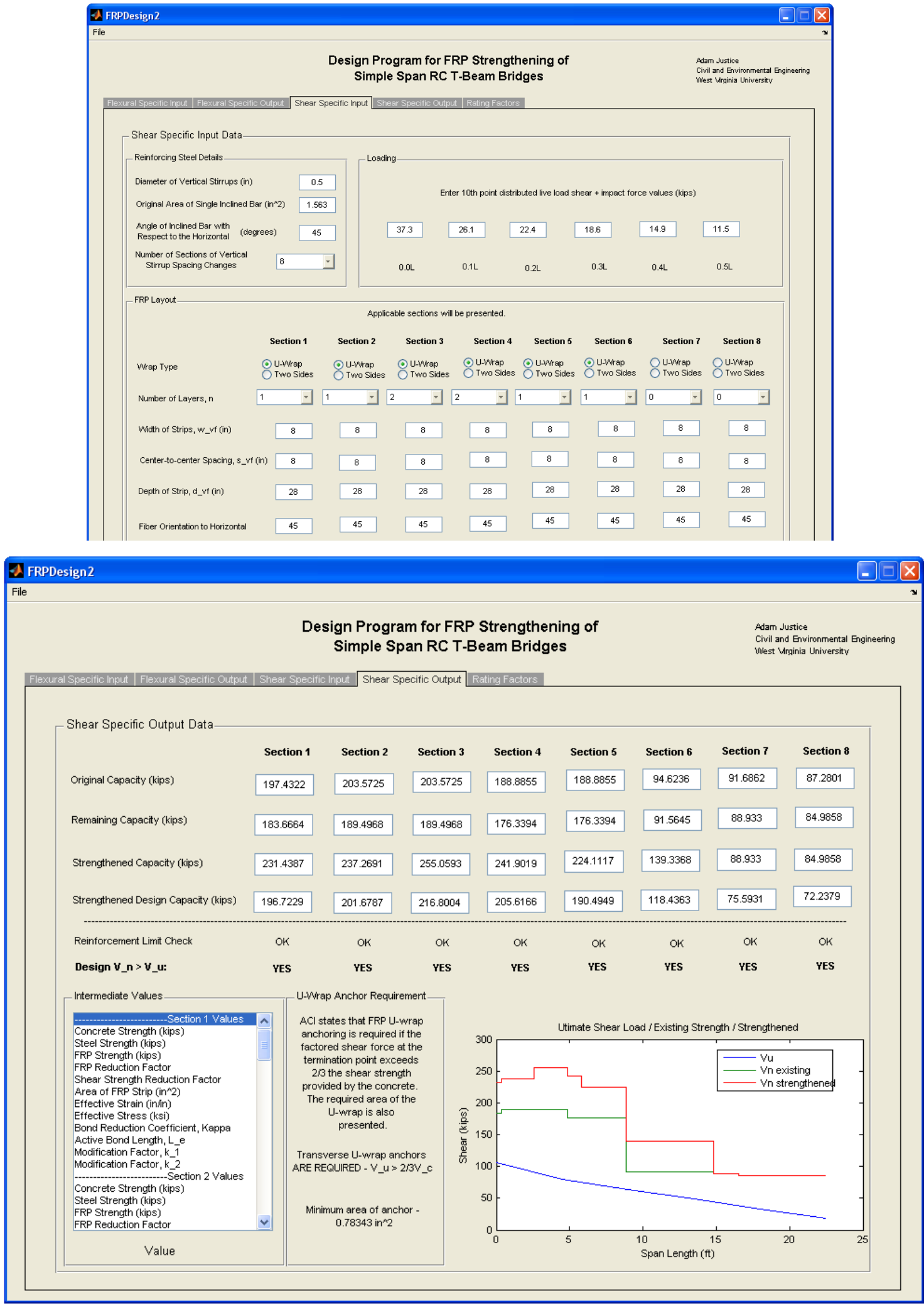

Figure 4.18 Example Shear Output - 8 Shear Sections 

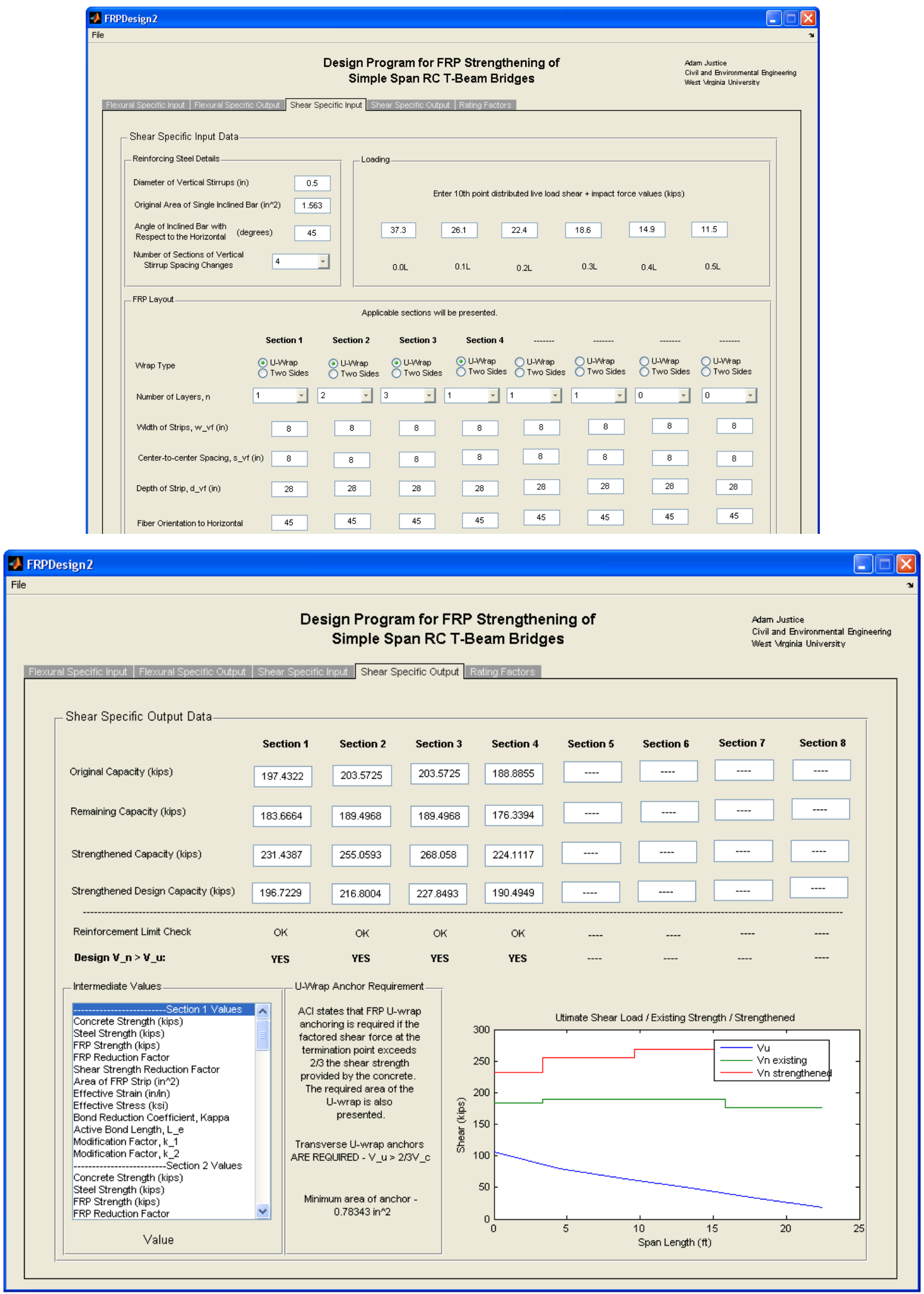

Figure 4.19 Example Shear Output - 4 Shear Sections 


\subsubsection{Intermediate Values}

An intermediate values panel was incorporated into the shear output tab for the same reasons it was used within the flexural output tab. A user should be able to check various intermediate for increased confidence in the analysis results. Shown enlarged in Figure 4.20, the list is much longer due to the fact that it has to be capable of displaying intermediate values for each shear section. As an example, the value displayed when the FRP strength contribution is selected for Section 1 is shown in Figure 4.20. If no FRP has been defined for a shear section in the input tab, the intermediate value list will simply display a value of zero for any selected value that is relative to FRP.

\begin{tabular}{|c|c|}
\hline \multicolumn{2}{|l|}{ Intermediate Values } \\
\hline $\begin{array}{l}\text { Concrete Strength (kips) } \\
\text { Steel Strength (kips) }\end{array}$ & 스 \\
\hline FRP Strength (kips) & \\
\hline $\begin{array}{l}\text { FRP Reduction Factor } \\
\text { Shear Strength Reduction Factor } \\
\text { Area of FRP Strip (in²) } \\
\text { Effective Strain (insin) } \\
\text { Effective Stress (ksi) } \\
\text { Bond Reduction Coefficient, Kappa } \\
\text { Active Bond Length, L_e } \\
\text { Modification Factor, k_1 } \\
\text { Modification Factor, k_2 }\end{array}$ & \\
\hline $\begin{array}{l}\text { Concrete Strength (kips) } \\
\text { Steel Strength (kips) } \\
\text { FRP Strength (kips) } \\
\text { FRP Reduction Factor }\end{array}$ & $\checkmark$ \\
\hline Value $=56.2027$ & \\
\hline
\end{tabular}

\section{Figure 4.20 Enlarged Shear Intermediate Values Panel}

\subsubsection{U-Wrap Anchor Requirement}

U-wrap anchoring is a detailing requirement in accordance with ACI. It is suggested in an effort to prevent FRP end peeling. Section 1.8.2 of the Design 
Guidelines further explains the assumptions and requirements for the prevention of FRP end peeling. In general, ACI states that U-wrap anchoring is required at the termination point if the factored shear force at that point exceeds $2 / 3$ the shear strength provided by the concrete. If anchoring is required, an equation is presented to determine the required area of the U-wrap anchor. This equation is presented in Section 1.8.2 of the Design Guidelines and is used by the program. Basically, the U-wrap anchor requirement panel defines the general requirement, states whether or not anchoring is needed, and determines the minimum area of the anchor if it is needed. This panel can be seen in Figure 4.18 and Figure 4.19.

\subsubsection{Shear Diagram}

The shear output tab provides the user with a shear diagram showing the existing shear capacity, strengthened shear capacity, and the factored shear force along half the span length. This diagram can be seen in the lower right region of Figure 4.18 and Figure 4.19. The existing and strengthened capacities are plotted for each shear section as indicated by the various line steps in the diagram.

With the example input data used in the analysis, it is easy to conclude from the diagram that no FRP is needed for shear strengthening. The ultimate shear force along the span is well below the existing shear capacity provided by each section.

\subsubsection{Rating Factors}

When the flexural and shear analyses have been completed, the program provides a tab detailing load rating factors. It may be desired to design with the intentions of achieving a certain rating factor. The rating factors tab is presented in Figure 4.21. 


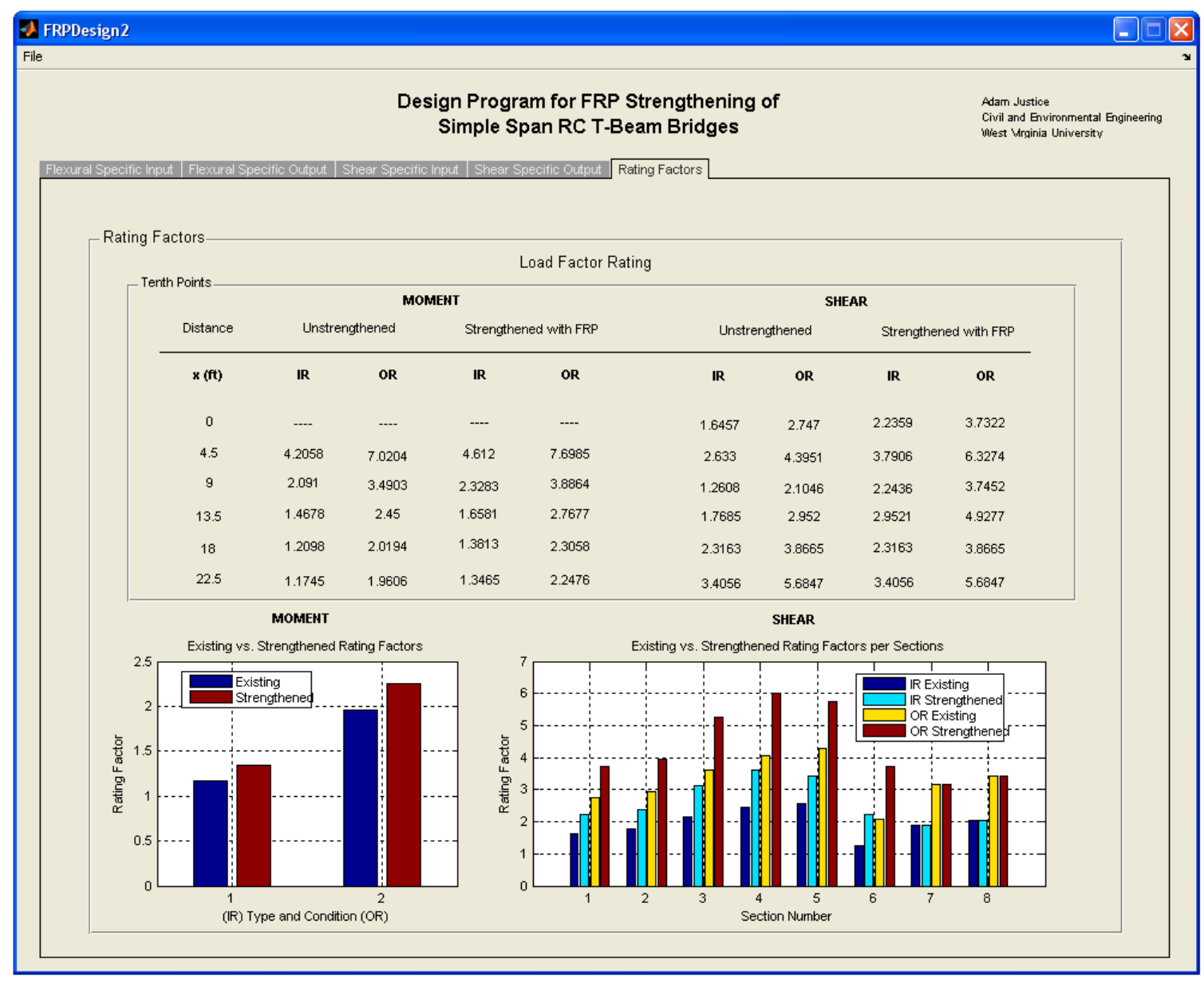

Figure 4.21 Rating Factors Section of Program

Load Factor Rating (LFR) methodology is used for determining the load rating factors. Equation 4-1 presents the LFR equation used. LFR is the agreed upon method by the FHWA for reporting load ratings of bridges on the National Highway System to the National Bridge Inventory database (Sasher, 2008). The load rating factors presented in Figure 4.21 were developed from the example input data of Figure 4.2 and Figure 4.18.

$$
R F=\frac{C-A_{1} D L}{A_{2} L L(1+I)}
$$




$$
\begin{aligned}
& \text { where, } \\
& R F=\text { rating factor } \\
& C=\text { capacity } \\
& A_{1}=\text { factor for dead loads } \\
& D L=\text { dead load force effect } \\
& A_{2}=\text { factor for live loads } \\
& \text { LL=live load force effect } \\
& I=\text { impact factor }
\end{aligned}
$$

As can be seen in Figure 4.21, the Inventory Rating (IR) and Operating Rating (OR) factors are displayed at each tenth point of the span. Exploiting symmetry, only tenth points for half the span are listed. Rating factors for the unstrengthened and strengthened capacities are presented for moment and shear.

To help visualize the significance of the design layout placed by the user, bar charts are provided. A bar chart for moment rating factors is provided in which the governing rating factors, which are normally at the mid-span of the beam, are compared. The bar chart for comparing shear rating factors is section based. In this way, it provides the governing rating factors for each section and not necessarily the tenth points. Therefore, this chart is dependent on the number of shear sections and section dimensions resulting from the shear input tab. This can be more clearly understood by comparing the shear rating factor bar chart of Figure 4.21 with that of Figure 4.22. The rating factors tab of Figure 4.21 resulted from an analysis incorporating eight shear sections, whereas the rating factors tab that produced Figure 4.22 resulted from an analysis incorporating only four shear sections. 


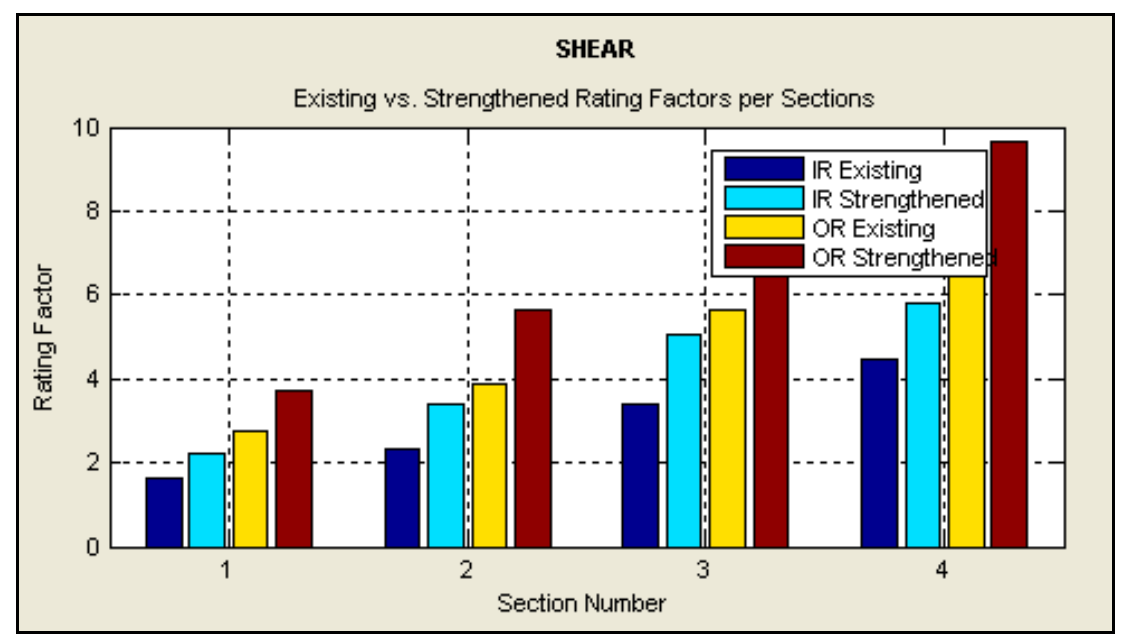

Figure 4.22 Shear Rating Factors - 4 Sections Selected

\subsubsection{Saving and Loading Results}

Analysis results can be saved and loaded with the use of the file menu as seen in Figure 4.23. Also apparent from Figure 4.23, the user's manual can be opened from the file menu as well as exiting the program. Once "Save" has been selected, a "Save the GUI results" dialog box opens asking for the file name as pictured in Figure 4.24. A file can be opened in the same manner with the aid of the "Choose GUI results to load" dialog box of Figure 4.24 .

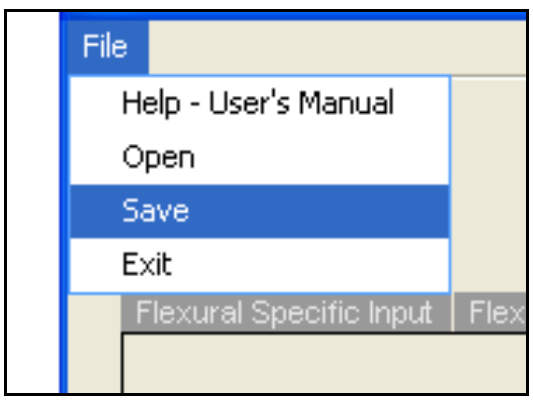

Figure 4.23 File Menu - Save 


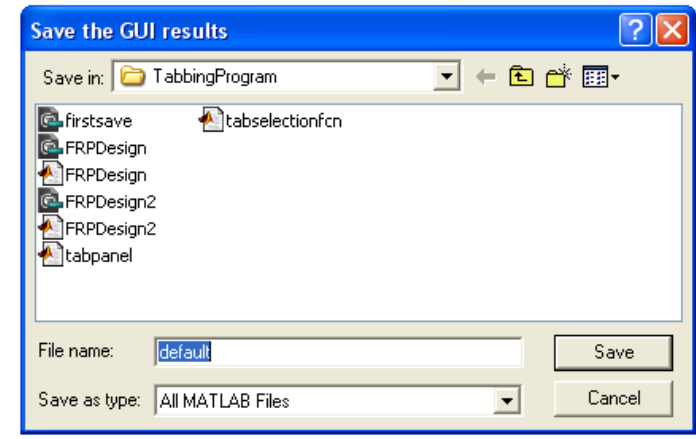

\begin{tabular}{|c|c|c|}
\hline Choose the GUI results to load & & $?$ \\
\hline Look in: $\square$ TabbingProgram & \multicolumn{2}{|c|}{ 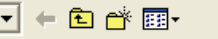 } \\
\hline 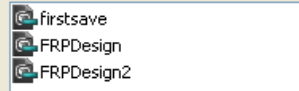 & & \\
\hline File name: & & Open \\
\hline Files of type: Figures ['. ${ }^{x}$ fig) & $=$ & Cancel \\
\hline
\end{tabular}

Figure 4.24 Saved and Load File Name 


\section{CHAPTER 5 - DESIGN AND ANALYSIS CORRELATIONS}

\subsection{INTRODUCTION}

For analysis reasons, two lanes of the FE model were also loaded with an AASHTO HS20 truck loading. The load was positioned at the mid-span and also near the supports; these were determined to be the critical locations for bending and shear respectively. By loading the model in accordance with AASHTO, comparisons could be made between force effects resulting from the accurate FE model and force effects resulting from AASHTO standard specifications. The conservative nature of the AASHTO design equations could then be assessed and correlations between design and analysis could be made. This assessment was made by discussing resulting load rating factors and live load distribution factors as presented within this chapter. Table 3-4 shows wheel loads for an AASHTO HS20 and Figure 3.43 illustrates the wheel spacing as stated previously.

\subsection{MOMENT AND SHEAR ForCE COMPUTATION}

The output from the 3D solid elements and truss elements used in the $\mathrm{FE}$ modeling provides stress profiles, which are used to compute the girder moments. The effective slab width was calculated based on AASHTO specifications.

The normal and shear stresses were integrated to compute the resulting moment and shear force at the section. The maximum moment and shear forces computed from the FE model under live load and dead load for the girders are given in Table 5-1. 
Table 5-1 Maximum Moments and Shear Forces for Girders

\begin{tabular}{|c|c|c|c|c|c|}
\hline & & & HS 20 Truck & Dead Load & $\begin{array}{c}\text { Capacity for } \\
\text { IRF }=1.0\end{array}$ \\
\hline \multirow{2}{*}{$\begin{array}{c}\text { Moment } \\
(\mathrm{k}-\mathrm{ft})\end{array}$} & \multicolumn{2}{|c|}{ Interior Girder } & 143.41 & 247.40 & 726.18 \\
\hline & \multicolumn{2}{|c|}{ Exterior Girder } & 59.06 & 91.25 & 285.24 \\
\hline \multirow{8}{*}{$\begin{array}{l}\text { Shear } \\
\text { (kips) }\end{array}$} & \multirow{4}{*}{$\begin{array}{l}\text { Interior } \\
\text { Girder }\end{array}$} & Section 1 & 27.96 & 28.04 & 115.31 \\
\hline & & Section 5 & 11.08 & 20.53 & 57.95 \\
\hline & & Section 6 & 11.11 & 16.99 & 53.43 \\
\hline & & Section 8 & 7.11 & 7.35 & 29.62 \\
\hline & \multirow{4}{*}{$\begin{array}{c}\text { Exterior } \\
\text { Girder }\end{array}$} & Section 1 & 12.25 & 29.80 & 73.28 \\
\hline & & Section 5 & 4.37 & 16.21 & 33.40 \\
\hline & & Section 6 & 4.29 & 13.40 & 29.52 \\
\hline & & Section 8 & 2.26 & 5.85 & 13.97 \\
\hline
\end{tabular}

\subsection{LOAD RATing FACTOR BASED ON FE MODEL}

Load rating calculations provide a basis for determining the safe load carrying capacity of a bridge. Inventory and operating ratings are required using the Load Factor Method specified in AASHTO Standard specifications. The bridge should be rated at two load levels, the maximum load level called the Operating Rating and a lower load level called the Inventory Rating. The Operating Rating is the maximum permissible load that should be allowed on the bridge. Exceeding this level could damage the bridge. The Inventory Rating is the load level the bridge can carry on a daily basis without damaging the bridge. For comparison, the rating factors are computed using the ultimate force effects calculated from the above described FE model. The Rating Factor $(R F)$ is determined by

$$
R F=\frac{C-A_{1} D}{A_{2} L(1+I)}
$$


where $C$ is the capacity of the member from cross-section analysis, $D$ is the dead load effect on the member, $L$ is the live load effect on the member, $I$ is the impact factor to be used with the live load effect and is taken as 0.3 or $30 \%, A_{l}$ is the factor for dead loads, and $A_{2}$ is the factor for live loads. $A_{1}$ is taken as 1.3 and $A_{2}$ is taken as 2.17 for Inventory Rating or 1.3 for Operating Rating.

It was determined throughout Phase II and III of the project, that in most cases, it shall only be necessary to bring bridge girders up to a minimum Inventory Rating Factor (IRF) of 1.0 as previously stated. This was suggested as a result of the many uncertainties associated with determining a bridge's original capacity. Uncertainties arise due to inaccurate construction drawings or a lack of drawings altogether. Along with inaccurate or missing documentation for these aged concrete T-Beam bridges, it is also considered that many of these bridges were overdesigned due to the less accurate analysis methods used in the past. This assumption of the original structure being overdesigned also lends reason as to why rehabilitating an aged concrete T-Beam bridge to its original capacity may be irrational. As this was concluded, Table 5-1 also presents the required capacity of the interior and exterior girders in order to achieve an IRF of 1.0 based on dead load and live load force effects computed from the FE model.

Using an AASHTO HS-20 truck loading, the maximum shear and maximum moment were listed in Table 5-1. In Table 5-2, rating factors are given for interior and exterior girders based on these dead and live load force effects resulting from the FE analysis. For comparison, the Rating Factors calculated from dead and live load force effects resulting from AASHTO specifications are also presented. The interior and 
exterior girder capacities used in the rating equation are those obtained from the final design calculations.

Table 5-2 Girder Rating Factors

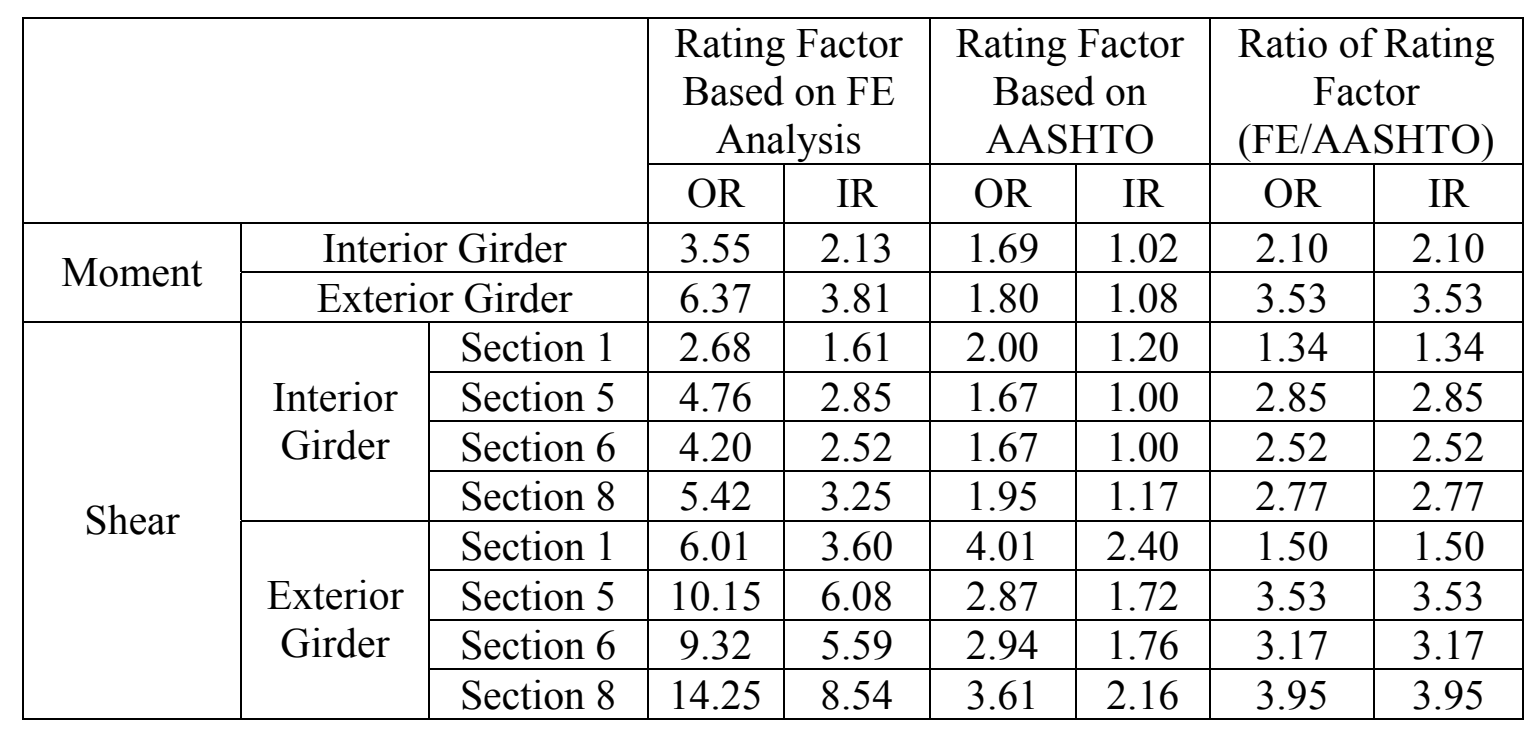

Table 5-2 indicates that the current flexural load capacity rating and shear load capacity rating of the interior girder is at least as much as 2.1 and 1.5 times higher, respectively, than the current load ratings based on AASHTO specifications. Note that the calibrated FE model simulates all of the situations that were identified during field assessment, including the bonding of FRP strips and concrete patching/replacement. This discrepancy is due to the conservatively imprecise nature of the lateral live-load distribution factors that have been recommended in the AASHTO specifications which are discussed in the following section. In the current load capacity rating practice based on AASHTO specifications, an individual beam is taken out as a free-body, idealized as simply-supported, while the continuity of the bridge in the transverse direction is indirectly accounted for by means of axle-load distribution factors. This approach is known to underestimate the plate contributions of the deck. It is expected that the 
differences in modeling assumptions between 3D FE bridge models and 2D AASHTO simplified beam models will lead to different load capacity ratings for the same structure. Support conditions and secondary structural elements also have significant effects on the response of the bridge. The diaphragm beams provide effective rotational restraints and thereby increase bending stiffness at the boundaries, which in turn reduces the critical flexural demand at the mid-span.

Similarly, parapets help distribute the flexural stresses from the mid-span towards the edges by creating very stiff girders at the edges. The AASHTO method incorporates idealized pin-roller boundary conditions, increasing the flexural demand at the mid-span. However, this does not reflect the actual design and measured behavior of the bridge. Lateral and longitudinal movement is restrained with dowels at both ends. In addition, the lateral diaphragm beams restrain the movement of the superstructure. Therefore, the actual boundary conditions do not conform to pin-roller boundary assumptions.

The moment IRF for the un-repaired bridge in accordance with AASHTO was 0.92 and 0.66 for the interior and exterior girder, respectively. Therefore, comparing with the load rating results of the un-repaired bridge, it can be noted that the load rating factors have been increased; illustrating the effectiveness of increasing section capacities using externally bonded FRP strips.

\subsection{LIVE LOAD DISTRIBUTION FACTORS}

The distribution of wheel loads on highway bridges has always been a complicated topic with much research attention. It is one of the key elements in determining the strength and serviceability of a bridge (Nutt et al. 1988). As such, it 
should be considered very important in determining the deteriorated and strengthened load rating capacity of existing structures.

The AASHTO Standard Specifications for Highway Bridges (1996) presented empirical distribution factors from $\mathrm{S} / \mathrm{D}$ formulas where $\mathrm{S}$ was the spacing of adjacent girders and D was a constant dependent on the bridge type. The formulas were for stringers and longitudinal beams and had only gone through minor changes since 1931 (Nutt et al. 1988). In 1985, the National Cooperative Highway Research Program (NCHRP) initiated a project entitled "Distribution of Live Loads on Highway Bridges" in an effort to improve the S/D formulas of the standard specifications. The AASHTOLRFD (AASHTO 1994) live load distribution formulas resulted from that project.

It was found from reviewing the S/D formulas of the 1996 specifications that valid results were being generated for bridges of common geometry (girder spacing about $6 \mathrm{ft}$ and span length about $60 \mathrm{ft}$ ), but they lost accuracy when these parameters were varied (relatively short or long bridges) (Zokaie et al. 2000). Therefore, it was desired to incorporate additional parameters such as span length and stiffness properties in the computation of live load distribution factors. The formulas were developed for several different bridge types and the type considered in the present research is beam-and-slab. Table 5-3 presents the current AASHTO equations for a typical interior girder which resulted from the NCHRP study along with the S/D equation of the Standard Specifications incorporating Load Factor Design (LFD).

Live load distribution factors (LDFs) were determined based on field testing data and FE model data for this research. The following expression as suggested by Eom and Nowak (2001) was used to calculate the LDFs based on testing data. 


$$
L D F=\frac{\varepsilon_{i} w_{i}}{\sum_{j=1}^{k} \varepsilon_{j} w_{j}}
$$

where:

$$
\begin{aligned}
& \varepsilon_{i}=\text { max strain at the bottom of the i'th beam } \\
& w_{i}=\text { the ratio of the section modulus of the i'th beam } \\
& \text { to the section modulus of a typical interior beam } \\
& k=\text { the total number of beams }
\end{aligned}
$$

For the bridge under consideration in this project, all of the beams have approximately the same section modulus, and therefore the expression can be reduced to the following form in which $\mathrm{N}$ is the number of lanes loaded.

$$
L D F=\frac{\varepsilon_{i}}{\sum_{j=1}^{6} \varepsilon_{j}} N
$$

As discussed in Section 3.2.1.1 field testing strain data was recorded with surface bonded foil strain gages. Surface bonded foil gages can be unreliable when performing large scale field testing due to surface defects and difficult surface preparation conditions on site. Deflection readings can typically be considered as a more reliable form of data resulting from such physical testing. Therefore, for a more thorough investigation, deflection data as well as strain data was used to obtain LDFs. The maximum strains were replaced by the maximum deflections in the above equation. This approach shall be deemed applicable when taking into account the very minuscule magnitude of loading when compared to the ultimate capacity of the structure. During the load test, the bridge was well within the linear-elastic range.

In addition to obtaining LDFs from testing data and AASHTO LFD and LRFD design specifications, LDFs were also computed based on multiple regression functions 
(Zou, 2008) developed by using a series solution for stiffened plates as proposed by Salim et al. (2008). An FE parametric study was used to validate the accuracy of the analytical series solution. Based on the results of the FE parametric study performed, and by using the series solution, multiple regression functions for load distribution factors were obtained in terms of non-dimensional variables as reprinted in Table 5-4.

Table 5-3 Comparison of AASHTO Live Load Moment Distribution Factors

\begin{tabular}{|c|c|c|}
\hline AASHTO Specification & Equation & Range \\
\hline $\begin{array}{l}\text { Current LRFD Bridge } \\
\text { Design Specifications }\end{array}$ & $\begin{array}{l}\text { One Design Lane Loaded: } \\
0.06+\left(\frac{S}{14}\right)^{0.4}\left(\frac{S}{L}\right)^{0.3}\left(\frac{K_{g}}{12.0 L t_{s}^{3}}\right)^{0.1} \\
\text { Two or More Design Lanes } \\
\text { Loaded: } \\
0.075+\left(\frac{S}{9.5}\right)^{0.6}\left(\frac{S}{L}\right)^{0.2}\left(\frac{K_{g}}{12.0 L t_{s}^{3}}\right)^{0.1}\end{array}$ & $\begin{array}{l}3.5 \leq S \leq 16.0 \\
4.5 \leq t_{s} \leq 12.0 \\
20 \leq L \leq 240 \\
N_{b} \geq 4 \\
10,000 \leq K_{g} \leq 7,000,000\end{array}$ \\
\hline $\begin{array}{c}\text { Standard Specifications } \\
\text { for Highway Bridges } \\
\text { (LFD-1996) }\end{array}$ & $0.5(\mathrm{~S} / 6)$ & $\begin{array}{l}\text { If S exceeds } 10 \mathrm{ft}-\text { Assume } \\
\text { flooring between stringers to } \\
\text { be simply supported with the } \\
\text { load on the stringer being the } \\
\text { reaction force. }\end{array}$ \\
\hline
\end{tabular}


Table 5-4 Regression Function of Distribution Factors (Zou, 2008)

\begin{tabular}{|c|c|c|}
\hline \multirow{2}{*}{$\begin{array}{c}\text { One } \\
\text { Lane } \\
\text { Loaded }\end{array}$} & $\begin{array}{l}\text { Interior } \\
\text { Girder }\end{array}$ & $D F=1.36 \times\left(\frac{b}{a}\right)^{0.27} \times\left(\frac{t}{a}\right)^{0.11} \times\left(\frac{E I}{D a}\right)^{0.12} \times(N)^{-0.20}$ \\
\hline & $\begin{array}{l}\text { Exterior } \\
\text { Girder }\end{array}$ & $D F=0.16 \times\left(\frac{b}{a}\right)^{0.33} \times\left(\frac{t}{a}\right)^{-0.69} \times\left(\frac{E I}{D a}\right)^{-0.11} \times(N)^{-1.12}$ \\
\hline \multirow{2}{*}{$\begin{array}{c}\text { Two } \\
\text { Lanes } \\
\text { Loaded }\end{array}$} & $\begin{array}{l}\text { Interior } \\
\text { Girder }\end{array}$ & $D F=0.89 \times\left(\frac{b}{a}\right)^{0.95} \times\left(\frac{t}{a}\right)^{-0.49} \times\left(\frac{E I}{D a}\right)^{0.16} \times(N)^{-1.16}$ \\
\hline & $\begin{array}{l}\text { Exterior } \\
\text { Girder }\end{array}$ & $D F=0.005 \times\left(\frac{b}{a}\right)^{1.39} \times\left(\frac{t}{a}\right)^{-1.84} \times\left(\frac{E I}{D a}\right)^{-0.14} \times(N)^{-1.78}$ \\
\hline & & $\begin{array}{l}\text { here } \\
\begin{array}{l}D=\frac{E_{s} t^{3}}{12\left(1-v^{2}\right)} \\
E_{s}=\text { Young's modulus of the slab } \\
v=\text { Poisson's ratio of the slab } \\
t=\text { Thickness of the slab } \\
a=\text { Span length } \\
b=\text { Width of the slab } \\
N=\text { Total number of girders }\end{array}\end{array}$ \\
\hline
\end{tabular}

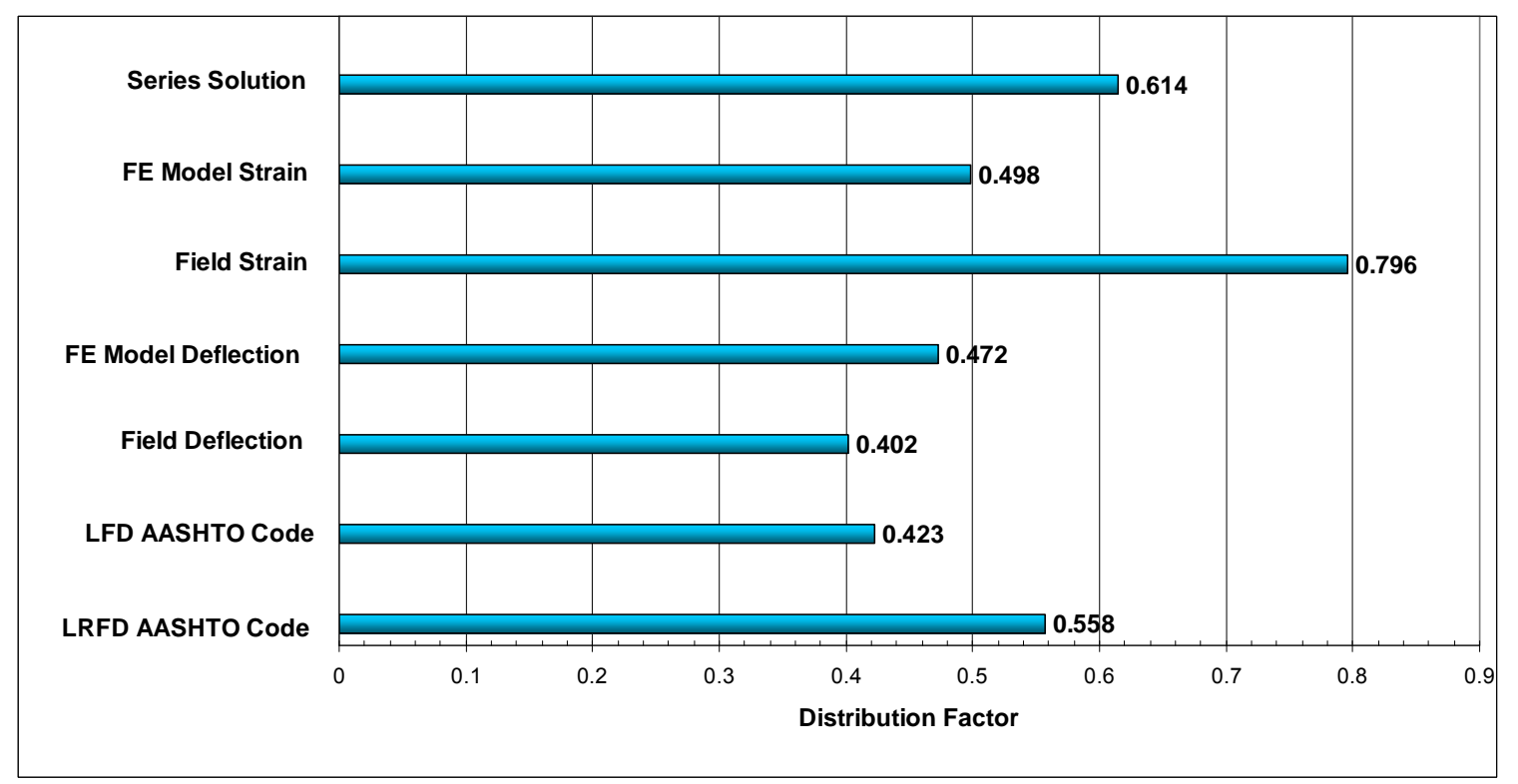

Figure 5.1 Interior Live Load Moment Distribution Factors 


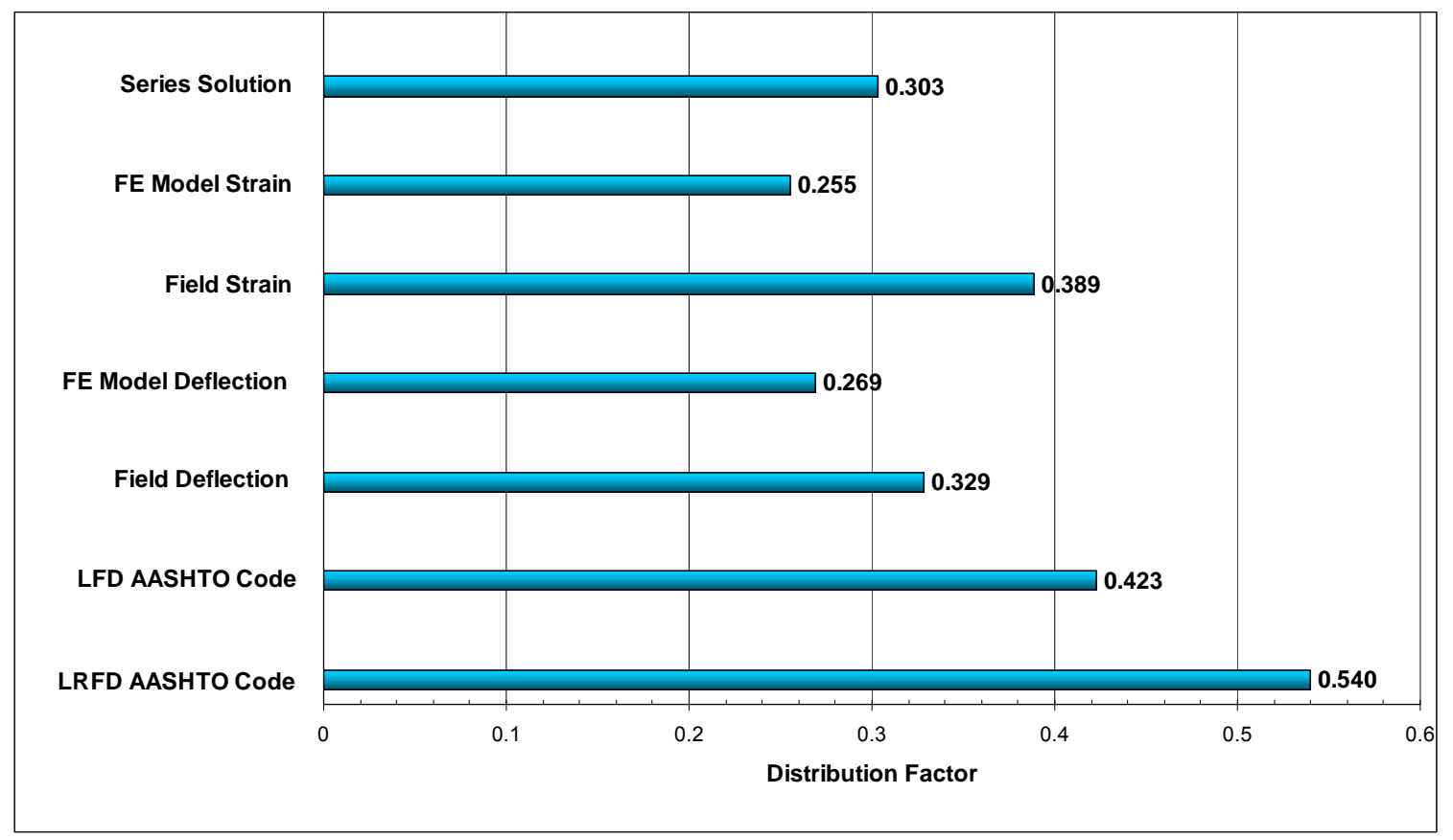

Figure 5.2 Exterior Live Load Moment Distribution Factors

Figure 5.1 and Figure 5.2 present live load moment distribution factors for interior and exterior girders, respectively. As can be seen from the figures, LDFs from the testing data, namely testing data resulting from the calibrated FE model, seem to match more closely with the LDFs resulting from the S/D formulas of the Standard Specifications. This is very much in exception to the LDFs resulting from field strain which, as explained previously, is often inaccurate in large scale field testing of concrete structures.

Although field testing data leads to LDFs more similar in value to the S/D formulas, it can also be seen that for interior girders on this particular bridge, the S/D formula results in a LDF that is under-conservative in relation to field testing data. With this being stated, the more over-conservative LDF resulting from the current AASHTOLRFD equations would be more appropriate for analysis. 
A better comparison of LDFs resulting from AASHTO Standard specifications and AASHTO-LRFD specifications can be made with reference to Figure 5.3. Figure 5.3 presents moment LDFs for typical interior girders of concrete T-Beam bridges while varying the span length and girder spacing. The unitless stiffness term of the AASHTOLRFD equation was kept constant as the value calculated for the geometry and material properties of the demonstration bridge in question. This is an interesting figure to observe considering that PennDOT's Bridge Analysis and Load Rating program (BAR7) has not been updated for use with LRFD/LRFR philosophies. Therefore, it is important to check the adequacy of using AASHTO Standard specifications for determining live load distribution factors for existing concrete bridges as is currently the case in Pennsylvania. Since many of these aged bridges were built to a set of standard drawings and are very similar in geometry, it should be considered desirable to find the existing LDF computation method adequate. Therefore, updating to current AASHTO-LRFD methods may not be deemed necessary for load rating procedures on these existing concrete T-beam bridges. 


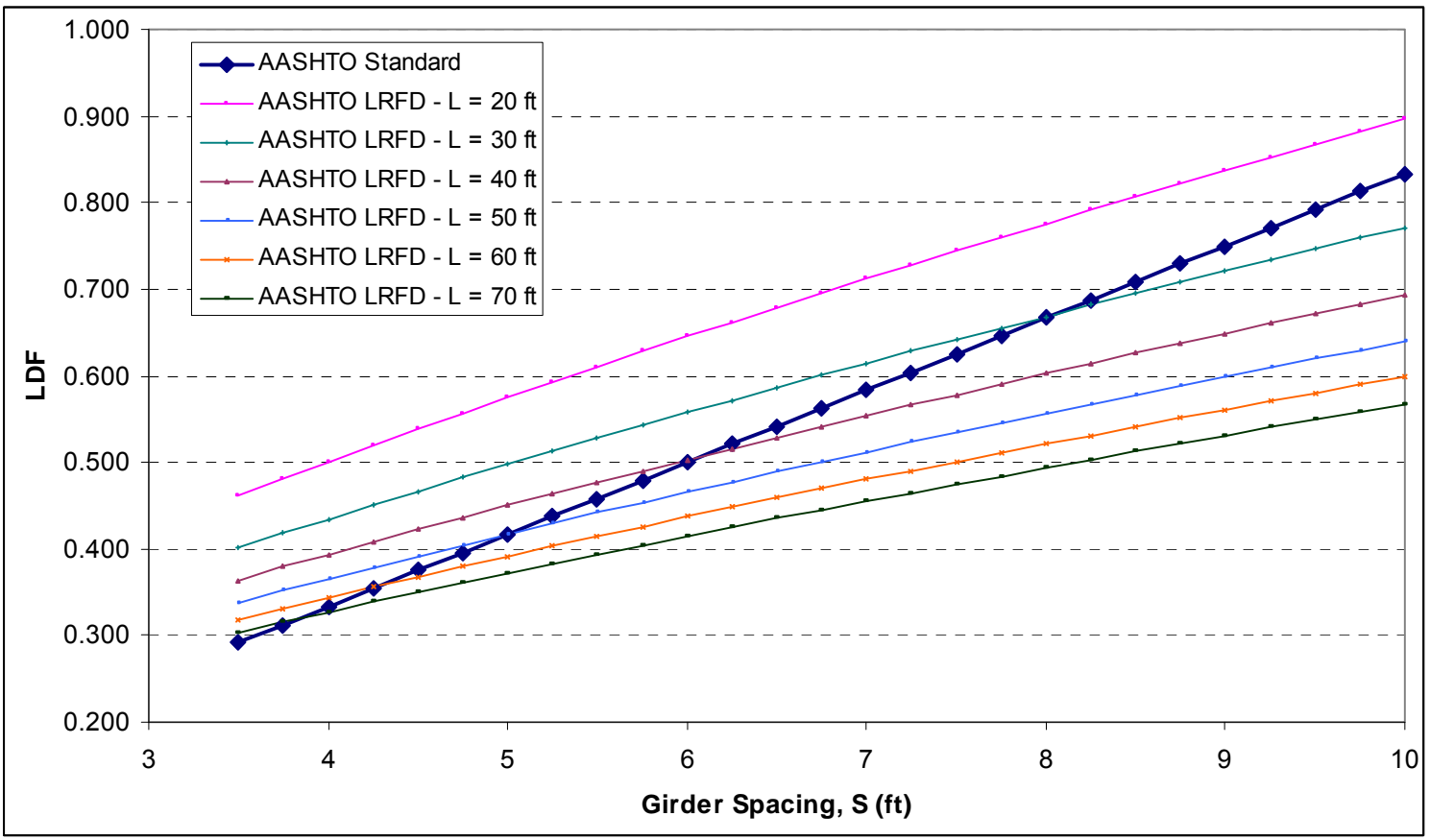

Figure 5.3 Comparison of AASHTO Standard and AASHTO LRFD LDF Values

In general, it can be seen from Figure 5.3 that for relatively common bridges (span length of 40 to $50 \mathrm{ft}$ and girder spacing of 4.5 to $6 \mathrm{ft}$ ), LDFs resulting from the S/D formula are very similar in value to the current LRFD formulas and shall be considered adequate for this range of parameters. More specifically, the following can be concluded about LDFs resulting from the AASHTO Standard specification when compared to the current LRFD specifications:

- $\mathrm{L}=70 \mathrm{ft}-$ Inaccurate for all but relatively close girder spacing $(\mathrm{S} \approx 4 \mathrm{ft})$ and otherwise over-conservative

- $\mathrm{L}=60 \mathrm{ft}-$ Fairly accurate for $4 \mathrm{ft} \leq \mathrm{S} \leq 5 \mathrm{ft}$ and tends to be overconservative for $\mathrm{S}>5 \mathrm{ft}$

- $\mathrm{L}=50 \mathrm{ft}-$ Seems accurate for $4 \mathrm{ft} \leq \mathrm{S} \leq 6 \mathrm{ft}$, under-conservative for $\mathrm{S}<4$ $\mathrm{ft}$, and over-conservative for $\mathrm{S}>6 \mathrm{ft}$ 
- $\mathrm{L}=40 \mathrm{ft}$ - Relatively accurate for $4.5 \mathrm{ft} \leq \mathrm{S} \leq 7.5 \mathrm{ft}$, tends to be underconservative for $\mathrm{S}<4.5 \mathrm{ft}$, and over-conservative for $\mathrm{S}>7.5 \mathrm{ft}$

- $\mathrm{L}=30 \mathrm{ft}-$ Fairly accurate for $7.5 \mathrm{ft} \leq \mathrm{S} \leq 9.5 \mathrm{ft}$ and under-conservative for $\mathrm{S}<7 \mathrm{ft}$

- $\mathrm{L}=20 \mathrm{ft}-$ Under-conservative for all values of $\mathrm{S}$ when comparing with the current LRFD LDF equations 


\section{CHAPTER 6 - QUALITY CONTROL AND ASSURANCE}

\subsection{INTRODUCTION}

The experimental work for Phase III covers all aspects from construction to completion followed by post-strengthening load testing. The WVU research team was able to provide increased quality control (QC) through field visits during the demolition and construction work. Observations and discussions were carried out to ascertain that the highest levels of QC were being achieved. Field visits were also used as a method of exchanging various molds and samples created on site during construction. These samples were tested in WVU research laboratories for quality assurance (QA) measures.

\subsection{Quality Control Assistance}

With respect to QC, WVU researches monitored various stages of construction work including: demolition of deteriorated concrete, concrete repair, FRP installation, and acceptance testing and inspection. Every effort was made to see that all construction work followed existing guidelines such as ACI 440.2R-02 and NCHRP Report 514 as further detailed in the literature review. Observations made through QC assistance, along with reference to existing standards and guidelines, were used to develop the desired construction guidelines proposed in Appendix E. It was concluded during this stage of the work that no repair or rework was needed. 
QC assistance was performed with four field visits occurring during construction work relating to concrete demolition, concrete restoration, repair concrete acceptance testing, and FRP installation.

\subsubsection{Concrete Demolition}

Due to the deteriorated condition of the structure, much of the concrete had to be removed during demolition. The construction guidelines lay out all requirements for concrete removal. Upon the first site visit during construction, the contractors had most of the demolition work completed. Figure 6.1 illustrates concrete removal for the exterior beams.

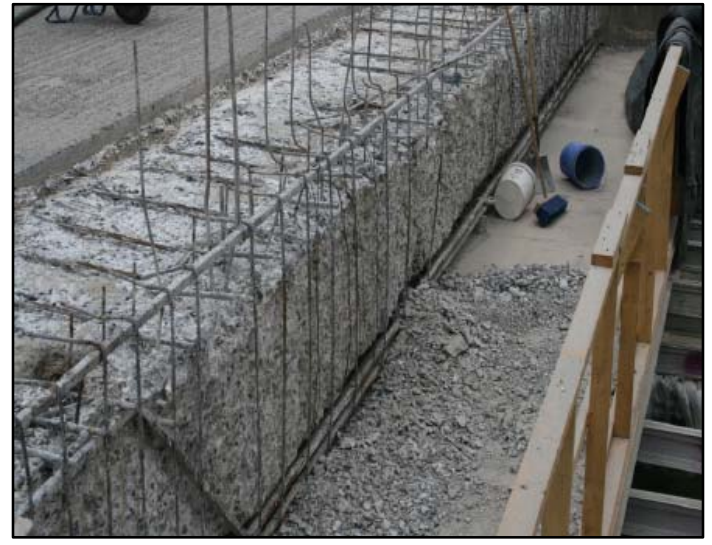

(a)

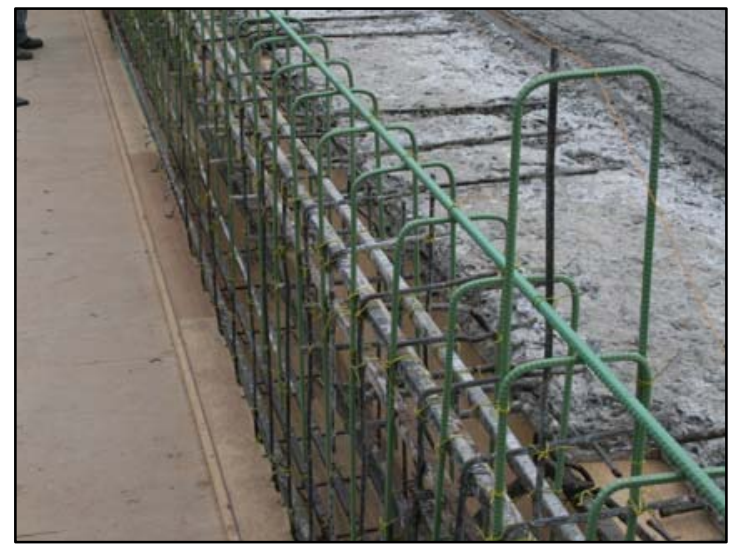

(b)

Figure 6.1 Concrete Demolition - (a) Beam 1 (b) Beam 6

As can be seen from Figure 6.1, complete removal of beam 6 was carried out as compared to the partial removal of beam 1. The amount of cross-section removal for individual beams was decided through the deterioration assessments of Phase II. A surprising discovery was made after completing demolition of beam 6 . Steel reinforcement present in the original design drawings for the bridge, as shown in Appendix F, was found to be missing. Specifically, the two middle longitudinal bars of 
the top layer of reinforcing steel and the vertical stirrups within the central $15 \mathrm{ft}$ of the span were missing.

Figure 6.2 shows the exposed reinforcement for the central portion of beam 6 indicating the two missing longitudinal bars and vertical stirrups. As the cross-section was not completely removed for the other beams, it was assumed that the same amount of reinforcing steel was missing for each beam. The as built longitudinal reinforcement layout along with the general areas of concrete removal for each beam are shown in Figure 6.3. The bridge parapets were also removed and eventually replaced. After some discussion, it was concluded that missing steel reinforcement would be accounted for with the FRP design.

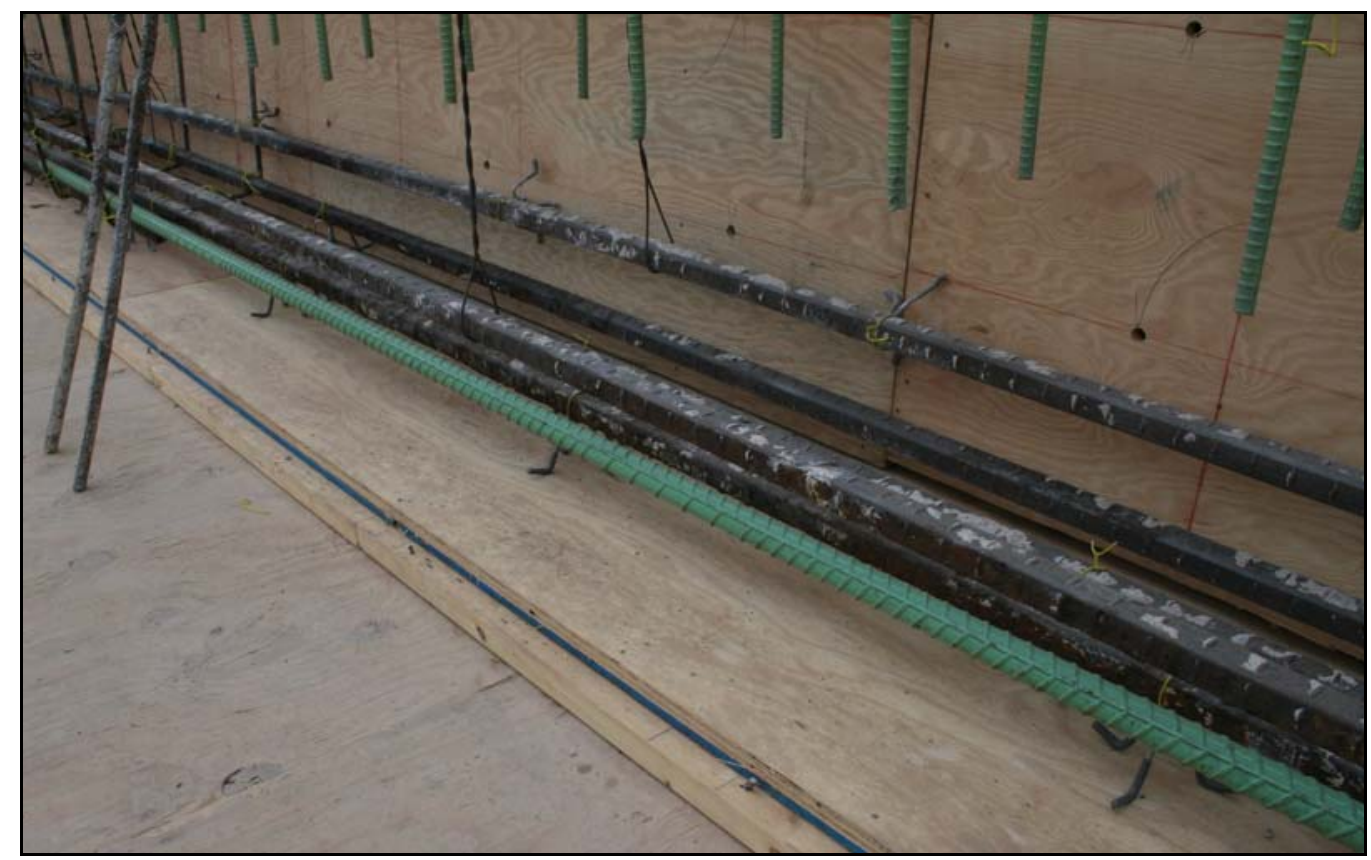

Figure 6.2 Missing Reinforcement Exposed in Beam 6

During the site visit, WVU researchers delivered five prism molds that could later be used to test the quality of repair material. The molds sat on a $6 \times 36$ in. base and were 
6 in. in height. The bottom four inches of the molds contained field simulated concrete that was comparable to the exposed beam concrete of the bridge. In this manner, the top two inches of the molds could be filled with the repair material during restoration of the beam cross-sections. Three of these molds were to have FRP sheets applied during the bridge FRP application process. The purpose for the molds was to later test the quality of bond between the existing concrete and the repair material as well as the quality of bond between the repair material and the FRP. Eighteen cylinder molds were also provided for casting repair material. Twelve of the cylinder molds were $4 \times 8$ in. and six were $6 \times 12$ in.

\subsubsection{Cross-Section Restoration}

As the construction guidelines state, after removal of deteriorated concrete, the newly exposed surface must be properly prepared and new material applied in order to restore the cross-section. Cross-section restoration was the construction work being carried out on the second observational site visit. The restoration process was performed in accordance with ACI 546R and ICRI 03730 as appropriately referenced in the construction guidelines.

Previously indicated in Figure 6.1, beam 6 was to be fully poured and beam 1 had a large portion of the outer perimeter needing poured. Beam 5 suffered from severe conditions of deterioration and as such, replacement of the beam up to the top $10 \mathrm{in}$. was executed. The remaining three beams required patch repairing at various locations along the length of the members. The general areas of concrete restoration observed upon the second site visit can be seen in Figure 6.3. 


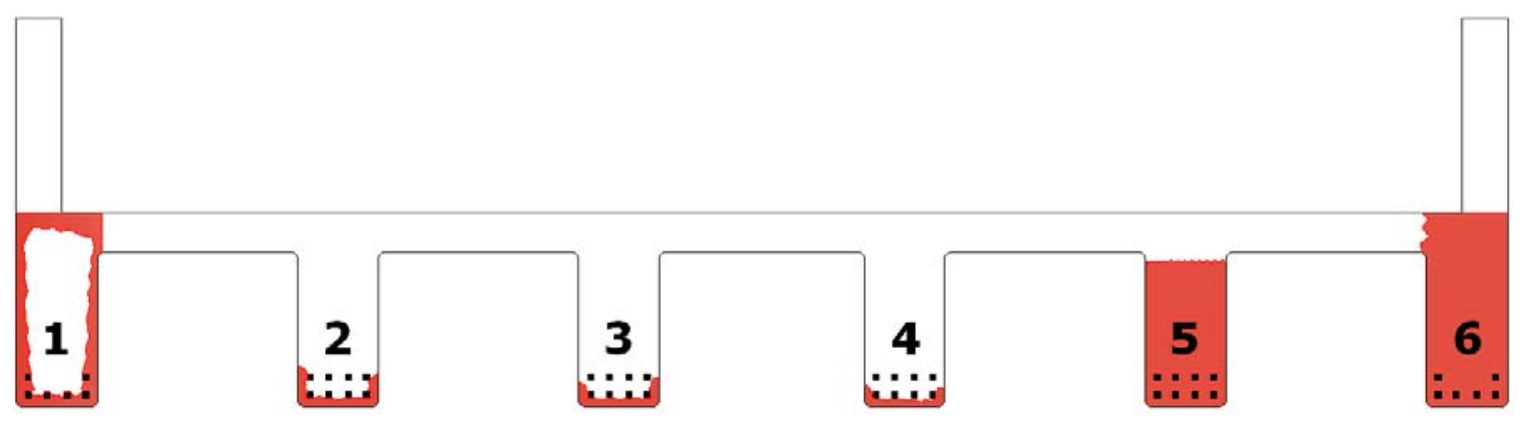

Figure 6.3 Concrete Restoration Area

Two different types of repair material was used for restoring the cross-sections. For the smaller patch area of beams 2,3 , and 4, a bag material was used that could be mixed on site. This was a cement based silica fume modified repair concrete with high durability and strength (BASF Emaco S 66 CI - Flowable Structural-Repair Concrete with Integral Corrosion Inhibitors). For the larger volumes of repair needed for beams 1, 5, and 6, a ready mix concrete was used employing the use of pumps. This repair material was class AAA cement modified concrete.

All repair material was placed with the use of plywood formwork as illustrated in Figure 6.4 and Figure 6.5. As can be seen, the smaller patch areas had formwork with small chutes attached for adequate repair material placement. The repair material was dropped down into these chutes and compacted with rods and mallets impacted along the sides of the plywood. Formwork along beams 5 and 1 are shown in Figure 6.6. 


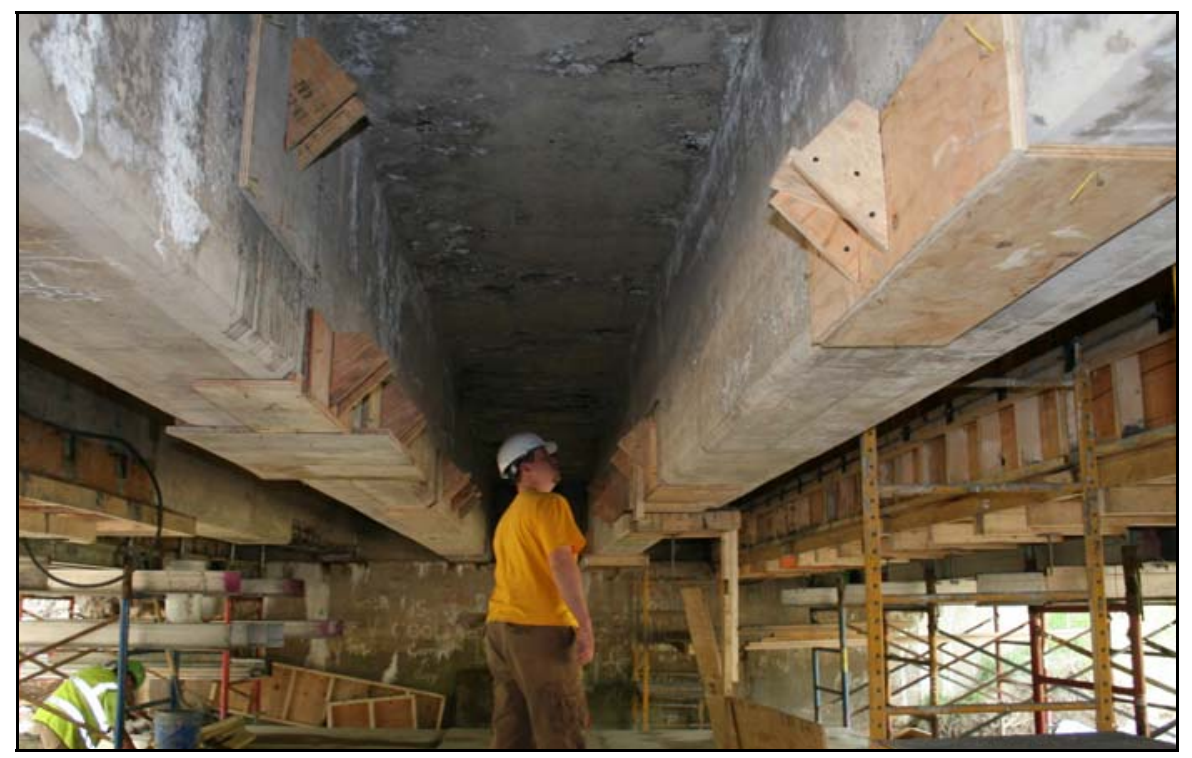

Figure 6.4 Patch Repairing Formwork along Beams 3 \& 4

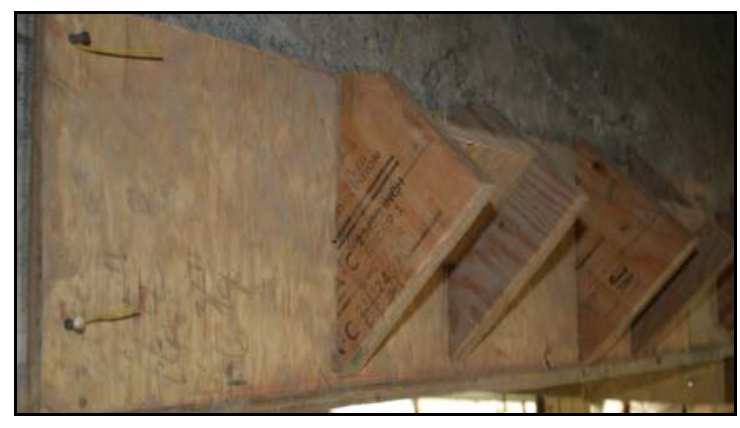

Figure 6.5 Patch Formwork Detail

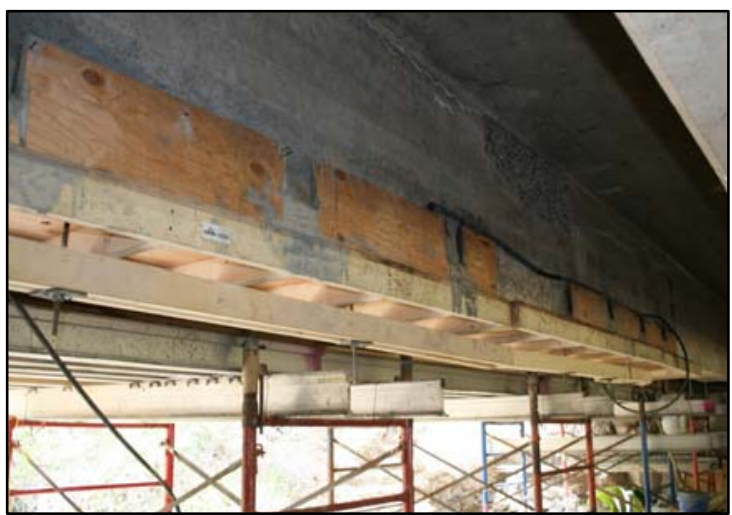

(a)

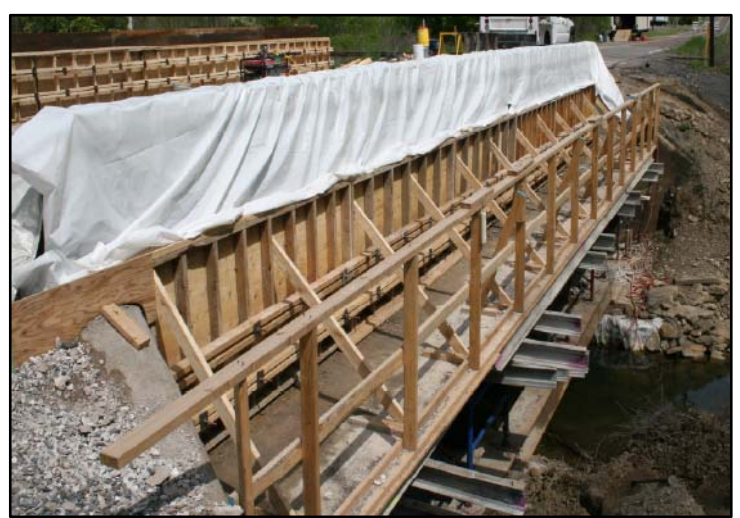

(b)

Figure 6.6 Formwork along (a) Beam 5 \& (b) Beam 1 
The molds delivered in the first site visit were filled with repair material as desired. All molds were cured in the field to match the actual bridge exposure conditions. Two of the prism molds were topped off with the class AAA ready mix material while three were topped off with the BASF bag repairing material. The twelve 4 $\mathrm{x} 8$ in. cylinder molds were filled with bag repairing material and the six $6 \times 12$ in. cylinder molds were filled with the class AAA ready mix material. All molds were to be collected and tested in WVU laboratories as detailed in Section 6.3.

\subsubsection{On-Site Pull-Off Testing}

WVU researchers visited the site a third time to observe pull-off testing on the repair material and to collect samples produced at the site. All pull-off testing was performed in accordance with ASTM C 1583 and ACI 503R standards. Figure 6.7 shows an example area of patched surface as well as the adhesion testing attachment. Table 6-1 presents the results of the field pull-off testing for the patched areas. ACI and ASTM call for a minimum failure stress of 200 psi. Therefore, all testing locations passed as indicated in Table 6-1.

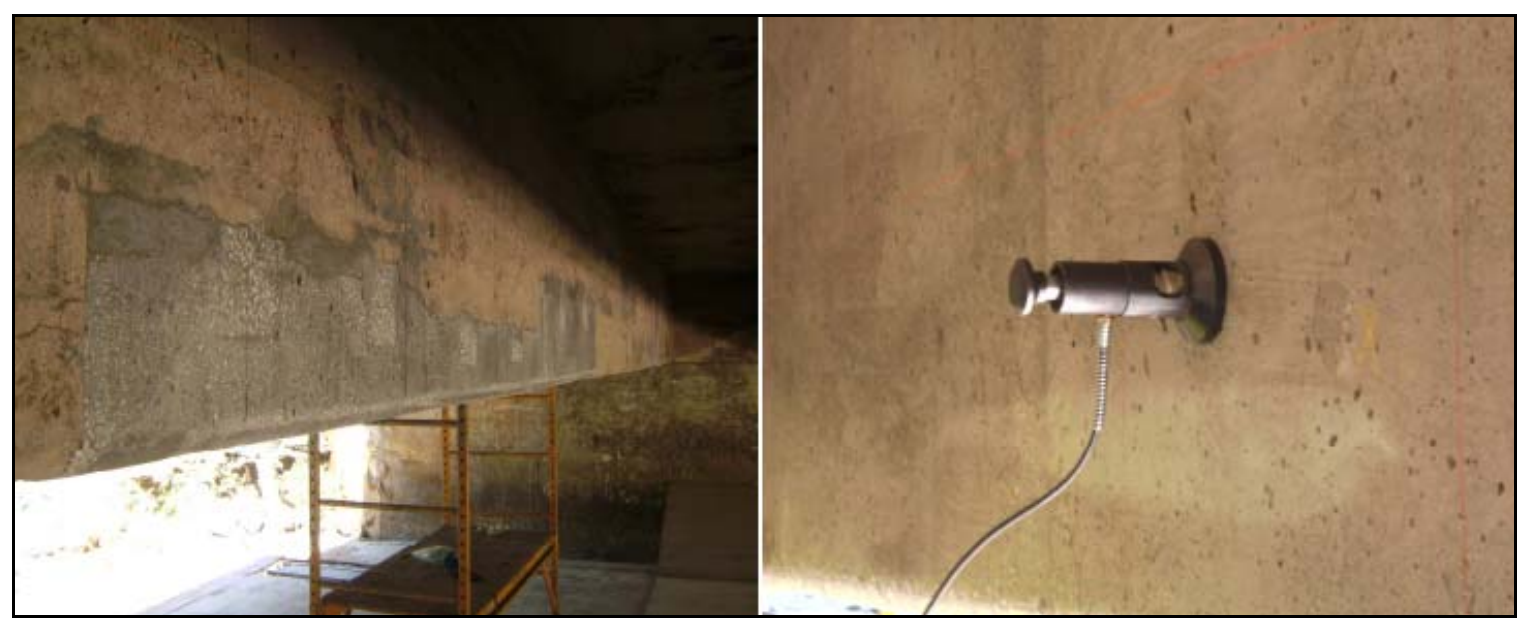

Figure 6.7 Patch Surface \& Adhesion Testing Attachment 
Table 6-1 Field Adhesion Testing Results of Repair Material

\begin{tabular}{|c|c|c|l|c|}
\hline Beam \# & Reading (psi) & Pass/Fail & \multicolumn{1}{|c|}{ Location } & Comment \\
\hline 1 & 442 & PASS & Right face at mid-span & Okay \\
\hline 2 & 294 & PASS & Bottom face at 8 ft. from abutment & Okay \\
\hline 3 & 529 & PASS & Left face at $3 / 4$ span length & Okay \\
\hline 4 & 430 & PASS & Bottom face at far abutment patch & Okay \\
\hline 5 & 325 & PASS & Bottom face at $2 / 3$ span length & Okay \\
\hline 6 & 529 & PASS & Left face at mid-span & Okay \\
\hline
\end{tabular}

\subsubsection{FRP Installation}

The FRP application process had just been completed upon the fourth field visit. The FRP installation process was performed using a wet layup approach as in accordance with Section 1002.4(d)5 of the construction guidelines. In this type of application process, four installment steps are performed. These installment steps, after proper surface preparation and cleaning, are the following: primer application, saturant application, fiber sheet application, and a final layer of saturant for full impregnation of fiber sheeting. For multiply ply installation, the steps are simply repeated. Greater detail concerning the FRP system installation can be obtained with reference to Section 1002.4(d) of the construction guidelines. Table 6-2 displays the FRP wrapping scheme, while the FRP design drawings are presented in Appendix B.

FRP systems subjected to exterior environmental conditions should be protected with some type of protective coating. The strengthening FRP system for the demonstration bridge had a UV light protective coating applied. This protective coating was applied to the FRP surfaces and the concrete surfaces for an overall, more aesthetically pleasing structure. This protective coating was being applied during arrival 
for the fourth site visit as can be seen in Figure 6.8 and Figure 6.9 along with the FRP layout.

Table 6-2 FRP Wrapping Scheme

\begin{tabular}{|c|c|c|c|}
\hline Beam \# & \# of Flexural Plies & $\begin{array}{c}\text { Number of Side } \\
\text { Flexural Plies }\end{array}$ & $\begin{array}{c}\text { Number of FRP } \\
\text { Stirrups }\end{array}$ \\
\hline 1 & 2 & 0 & 2 (as anchors) \\
\hline 2 & 1 & 0 & 14 \\
\hline 3 & 1 & 0 & 14 \\
\hline 4 & 1 & 0 & 14 \\
\hline 5 & 1 & 2 & 14 \\
\hline 6 & 1 & 0 & 2 (as anchors) \\
\hline
\end{tabular}

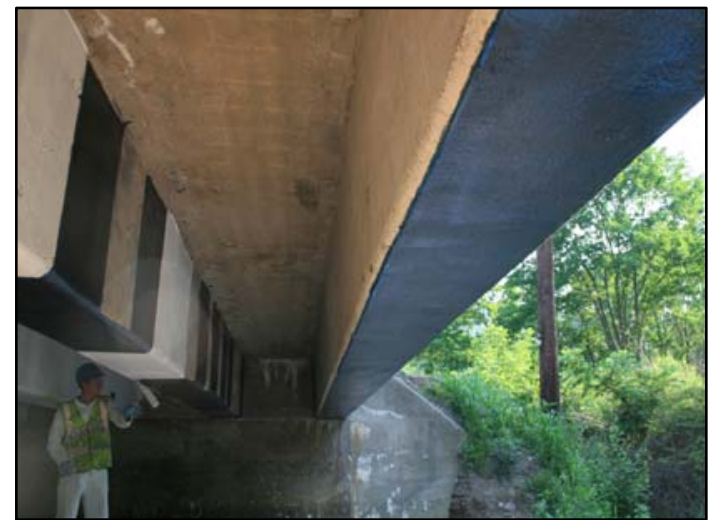

(a)

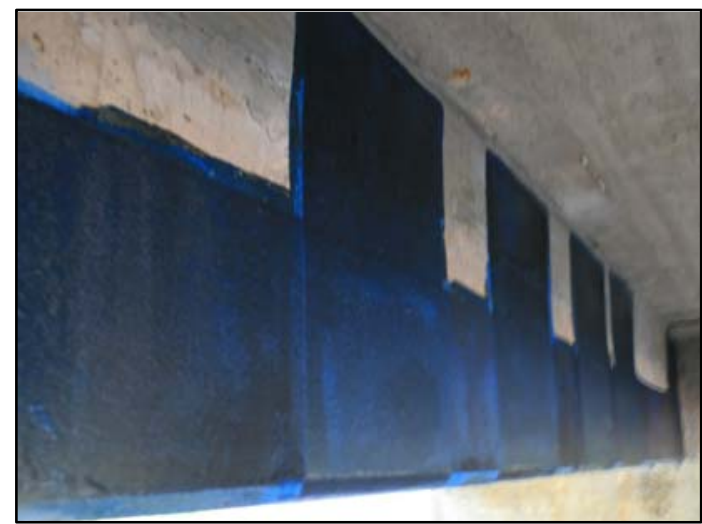

(b)

Figure 6.8 FRP Reinforcement Layout (a) Beam 1 \& (b) Beam 5

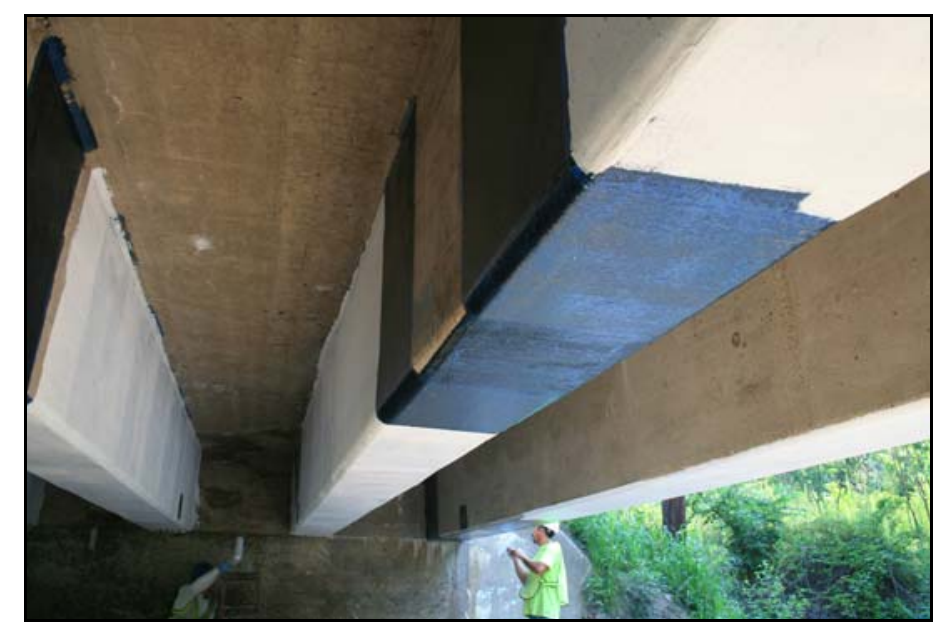

Figure 6.9 FRP Reinforcement Layout for Beams 2 \& 3 
On the same day as the FRP application, three of the concrete test prisms also had FRP installed on the top surface. This was performed so that the prisms could later be transported to WVU laboratories for adhesion testing of the FRP-substrate interface in accordance with ASTM D 4541. The same exact procedure used on the bridge was used for the prisms. The FRP application for the sample prisms is illustrated in Figure 6.10.

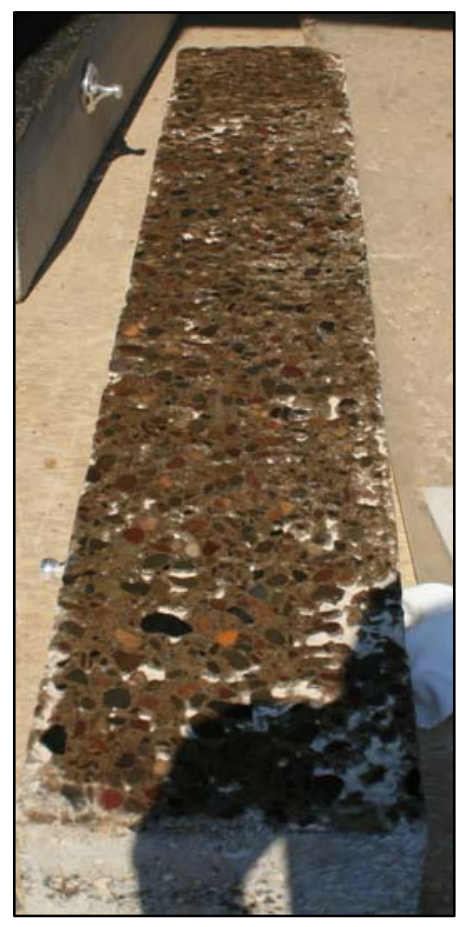

(a)

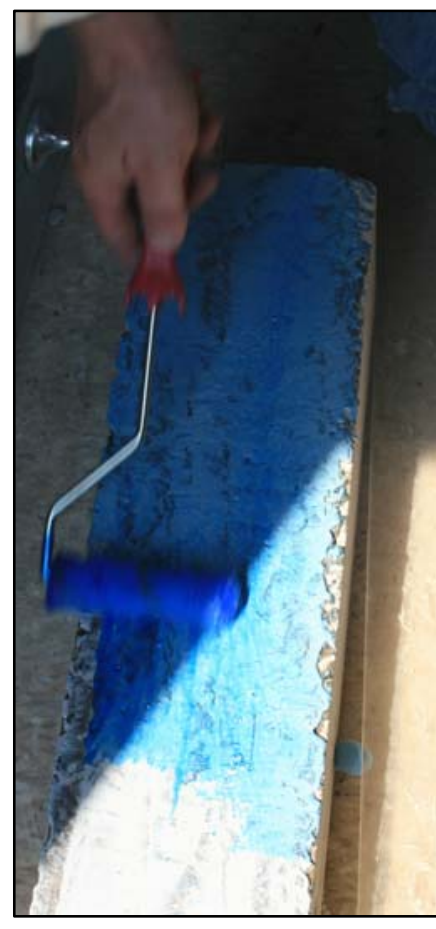

(b)

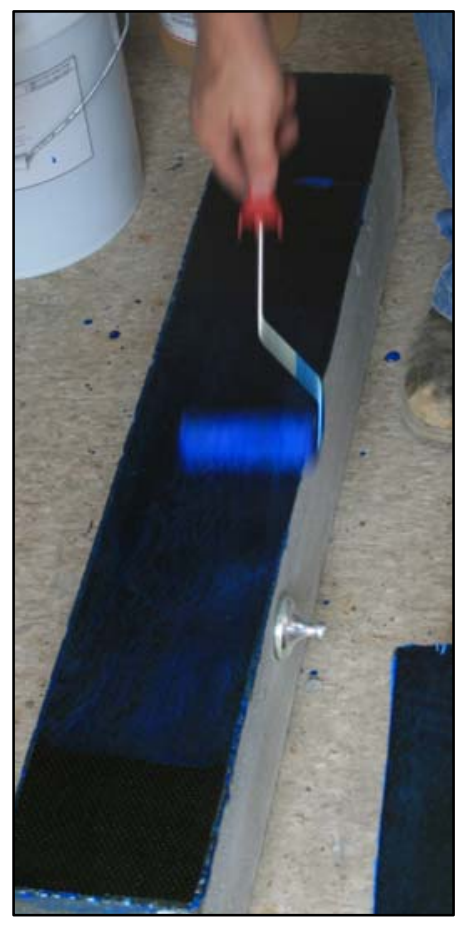

(c)

Figure 6.10 Testing Prism FRP Application (a) Primer (b) Saturant (c) Fiber Sheet

Laminates for tension testing were also produced for later transport to WVU. To develop the sample coupons for tension testing, a square piece of plywood (approximately $15 \times 15$ in.) was used. The plywood was wrapped with plastic to create a non-stick surface for the FRP application. In this manner, flat FRP sheeting could be created and later cut to desired dimensions for tension testing. Figure 6.11 illustrates 
sample preparation. Two plywood panels were used, one with one ply of FRP and the other with two plies of FRP. Details and results of the test are presented in Section 6.3.6.

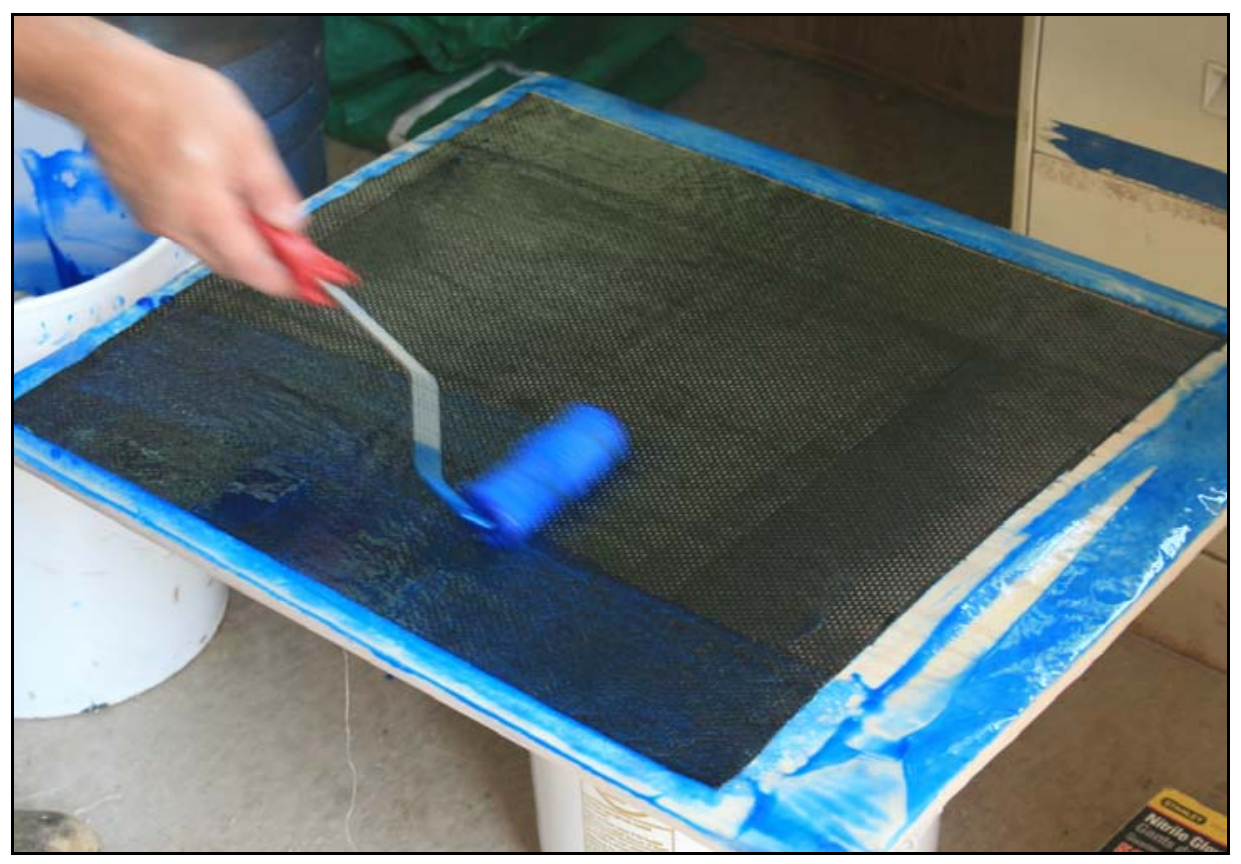

Figure 6.11 FRP Panel Fabrication for Tension Testing

\subsection{Quality Assurance Assistance}

WVU researchers were responsible for QA testing. Compression tests, tensilesplitting tests, FRP coupon tension tests, and pull-off tests were performed. As detailed in the following sections, testing was performed for both the class AAA and bag repairing material. Also, pull-off testing was performed between existing concrete and repair material as well as between repair material and FRP.

\subsubsection{Cylinder Testing of AAA Repair Concrete}

As previously stated, the class AAA repair concrete was used for the full pour of beam 6, partial pour of beam 1, and the majority of beam 5. PennDOT provided 
compressive strength values based on cylinder testing as reported in Table 6-3, based on mean values resulting from two test specimens. WVU researchers conducted further testing of $6 \times 12$ in. cylinders to provide strength and modulus of elasticity values as shown in Table 6-4, based on mean values resulting from three test specimens. Values reported in Table 6-3 and Table 6-4 indicate that the class AAA repair concrete continuously gained strength over time and was able to achieve the standard strength and modulus of elasticity during FRP installation.

Table 6-3 PennDOT Provided Compressive Strength (AAA)

\begin{tabular}{|c|c|c|c|}
\hline \multirow{2}{*}{ Beam \# } & \multicolumn{3}{|c|}{ Compressive Strength (psi) } \\
\cline { 2 - 4 } & 7 Days & 14 Days & 28 Days \\
\hline 1 & - & 4435 & 5555 \\
\hline 5 & - & 4435 & 5555 \\
\hline 6 & 2545 & 5165 & 6395 \\
\hline
\end{tabular}

Table 6-4 WVU Provided Strength and Modulus of Elasticity (AAA)

\begin{tabular}{|c|c|c|c|c|}
\hline \multicolumn{2}{|c|}{ Property } & Result & COV & Standard \\
\hline \multirow{4}{*}{28 Days } & Compressive Strength & $5550 \mathrm{psi}$ & 0.03 & ASTM C 39 \\
\cline { 2 - 5 } & Static Modulus of Elasticity & $4615 \mathrm{ksi}$ & 0.032 & ASTM C 469 \\
\cline { 2 - 5 } & Dynamic Modulus of Elasticity & $5920 \mathrm{ksi}$ & 0.025 & ASTM C 215 \\
\cline { 2 - 5 } & Unit Weight & $141.1 \mathrm{lb} / \mathrm{ft}^{3}$ & - & ASTM C 642 \\
\hline 90 Days & Compressive Strength & $6530 \mathrm{psi}$ & - & - \\
\hline
\end{tabular}

\subsubsection{Cylinder Testing of Bag Repair Material}

The bag repairing material, as detailed in Section 6.2.2, was used for repairing the cross-sections of beams 2, 3, 4, and part of 5. WVU researchers performed compression 
testing and splitting-tensile testing on $4 \times 8$ in. cylinders of this repair material as illustrated in Figure 6.12.

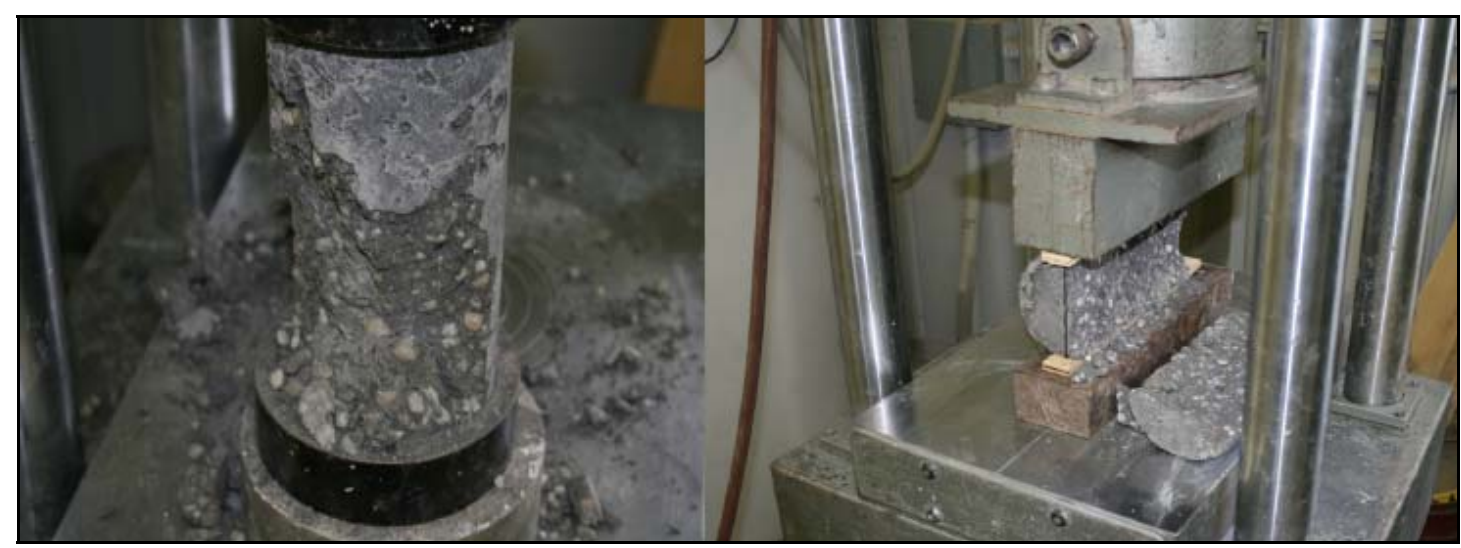

(a)

(b)

Figure 6.12 Bag Material Cylinder Tests (a) Compression (b) Splitting-Tensile

Seen in Table 6-5, the repair material did not gain much strength between 56 and 90 days. This is very reasonable considering that the material is classified as high early strength. Testing at 56 days was performed since this was approximately the number of days that passed after cross-section restoration and before FRP installation.

Table 6-5 Bag Repairing Material Testing Results

\begin{tabular}{|c|c|c|c|c|}
\hline \multicolumn{2}{|c|}{ Test } & Result & COV & Standard \\
\hline \multirow{2}{*}{ 56 Days } & Compression & $9250 \mathrm{psi}$ & 0.08 & ASTM C 39 \\
\cline { 2 - 5 } & Splitting-Tensile & $595 \mathrm{psi}$ & 0.05 & ASTM C 496 \\
\hline \multirow{2}{*}{ 90 Days } & Compression & $9500 \mathrm{psi}$ & 0.04 & ASTM C 39 \\
\hline
\end{tabular}

It should be noted that the values reported in Table 6-5 are the mean values from tests of three specimens. Also, it can be easily concluded that the bag repairing material reached a compressive strength at 90 days that is about $45 \%$ higher than that of the class AAA repair material. 


\subsubsection{Bond Strength between Old and New Concrete}

The pull-off testing to assess the bond strength between old and new concrete was performed in accordance with ASTM C 1583 and ACI 503R Appendix A. For this type of pull-off test, a core that is $2 \mathrm{in.} \mathrm{in} \mathrm{diameter} \mathrm{is} \mathrm{drilled} \mathrm{into} \mathrm{the} \mathrm{concrete,} \mathrm{reaching} \mathrm{a} \mathrm{depth}$ just below the underlying substrate. Once the core is drilled, a metal disk is mounted to the top with epoxy adhesive. The adhesive is allowed 48 hours to cure properly. The schematics of the test are illustrated in Figure 6.13, while the core drill setup is shown in Figure 6.14(a).

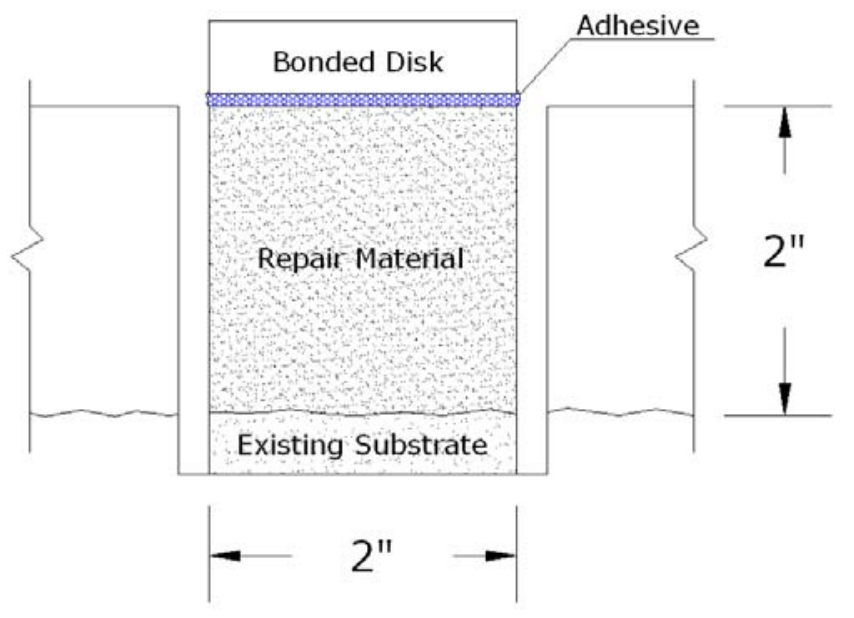

Figure 6.13 Schematics of Pull-Off Test for Material Interface

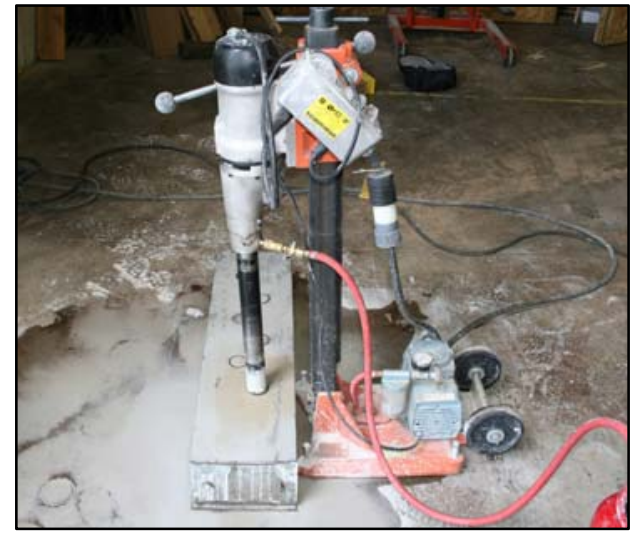

(a)

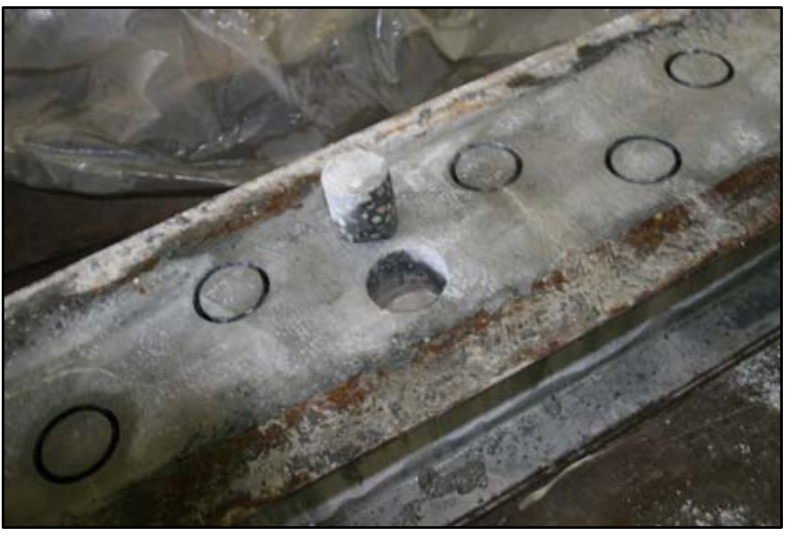

(b)

Figure 6.14 Concrete Pull-Off Test (a) Drill Setup (b) Tested Core 
Once the epoxy is properly cured and the disk is mounted securely, the pull-off tester is attached and tension force is applied until the concrete ruptures, releasing the core. A Proceq Dyna pull-off tester Z16 was used, as shown in Figure 6.15. The force causing failure is recorded and the stress is then computed, while the nature of the failure is noted. As stated in ASTM C 1583, failure can occur within the substrate, at the concrete/overlay interface, within the repair material, or within the epoxy/overlay interface. An example tested core, with failure in the substrate, is shown in Figure 6.14(b). About eight locations were tested for each prism.

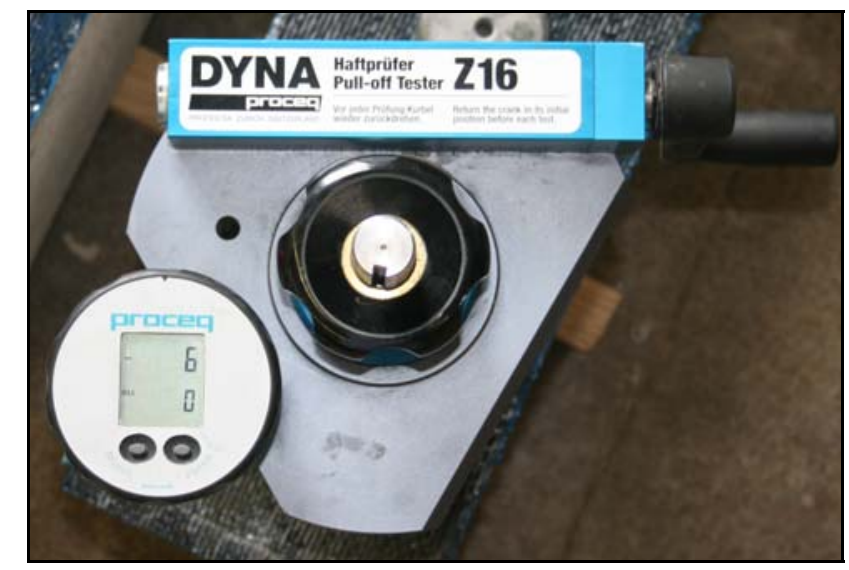

Figure 6.15 Dyna Z16 Pull-Off Tester

To obtain an assessment of the early bond strength, several cores for the class AAA repair material were tested only 14 days after casting ( 7 days field curing and 7 days lab curing). For these early tests, the bond strength range was found to be between 45 and 110 psi, indicating a moderate rate of strength gain. Four tests were conducted close to the FRP installation day; and the strength values obtained were in the range of 315 to 480 psi. With the exclusion of one case being in the repair overlay, the failure for all cases was within substrate or substrate/overlay interface. From theses tests, it was 
concluded that the bond strength between existing concrete and class AAA repair material was adequate.

A prism incorporating an overlay with the BASF bag repairing material as detailed in Section 6.2.2 was tested for bond strength at a time close to FRP installation. Seven cores were tested on this prism. With the exception of two cores failing within the repair material overlay, failure within the substrate and substrate/overlay interface was observed. Failure strengths between 120 and 395 psi were recorded. With these strength values and those obtained in the field, it was concluded that the bond strength between existing concrete and the BASF bag repairing material was adequate.

The adhesion pull-off testing conducted in the field as discussed in Section 6.2.3, resulted in strength values between 294 and 529 psi. It should be noted that this type of pull-off testing is different than lab testing, as no cores are drilled. Therefore, the quality of the surface of the repair material is assessed by measuring the tensile strength adjacent to the surface. It should be logically assumed that this type of testing would result in higher strength values due to radial stresses developed around the circular contact area with the testing apparatus.

\subsubsection{Prism Rebound Hammer Tests}

Rebound hammer tests were conducted on prisms consisting of class AAA and BASF bag repairing material to assess surface quality. The tests were performed in accordance with ASTM C 805. In this test, a consistent amount of energy is used to impact, with a steel hammer, a steel plunger that is in contact with the concrete surface. The rebound distance of the hammer is measured in $\mathrm{mm} .97$ readings were taken for each prism. It was concluded that the bag material had a superior surface hardness over 
the class AAA material as can be seen in Table 6-6. Both materials achieved an adequate surface hardness which was suitable for FRP installation.

Table 6-6 Rebound Hammer Test Results

\begin{tabular}{|c|c|c|c|}
\hline Repair Material & Mean & Median & COV \\
\hline Class AAA & 32 & 34 & 0.12 \\
\hline BASF Emaco S 66 & 36 & 38 & 0.10 \\
\hline
\end{tabular}

\subsubsection{Bond Strength between Concrete and FRP}

Three prisms received externally bonded FRP. Two prisms had an overlay composed of BASF bag material while one prism had an overlay composed of class AAA repair material. One of the prisms with bag material had a 2-ply FRP layer bonded while the rest of the prisms only had a 1-ply FRP layer bonded. Pull-off testing was performed on the bonded FRP layers in accordance with ASTM D 4541. The testing procedure is very similar to the pull-off testing procedure of ASTM C 1583 as discussed in Section 6.3.3 for the bond strength of concrete repair material. The same core drill was used with a 2 in. diameter drill bit. The difference being that, instead of cutting to a depth of at least 2 inches, a depth of just below the FRP level and slightly into the concrete substrate was attained. This area and depth of cutting is illustrated in Figure 6.16(a). The metal disks are then attached and the epoxy is allowed to cure in the same manner as detailed in Section 6.3.3. Attached disks are presented in Figure 6.16(b). The same pull-off tester of Figure 6.15 was used as well. Again, dividing the failure force by the disk/FRP contact area, the failure stress is determined. The ultimate stress and failure type were recorded.

During FRP installation on the bridge, various locations were selected for placing small FRP patches for pull-off testing. Testing of these patch areas was performed after 
approximately the same number of days that passed leading to the prism pull-off testing.

Results and details of the field testing for FRP bond strength are presented in Table 6-7.

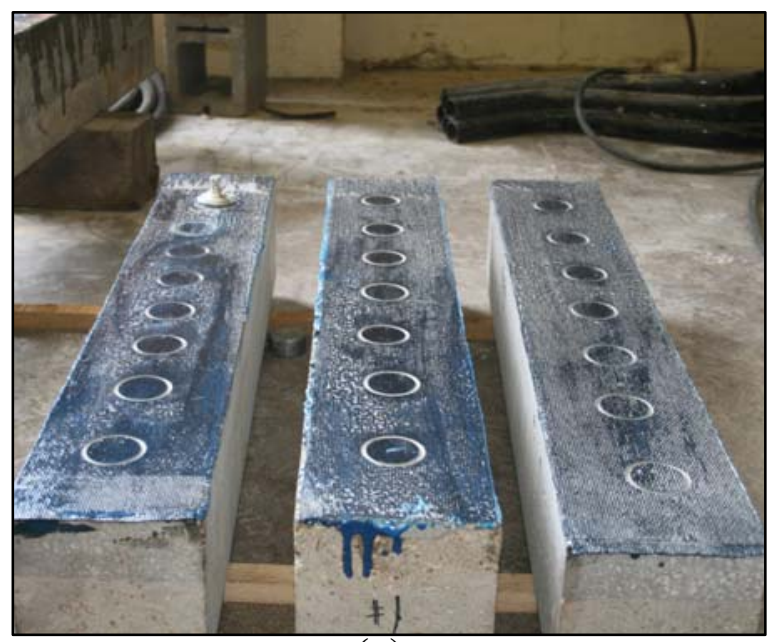

(a)

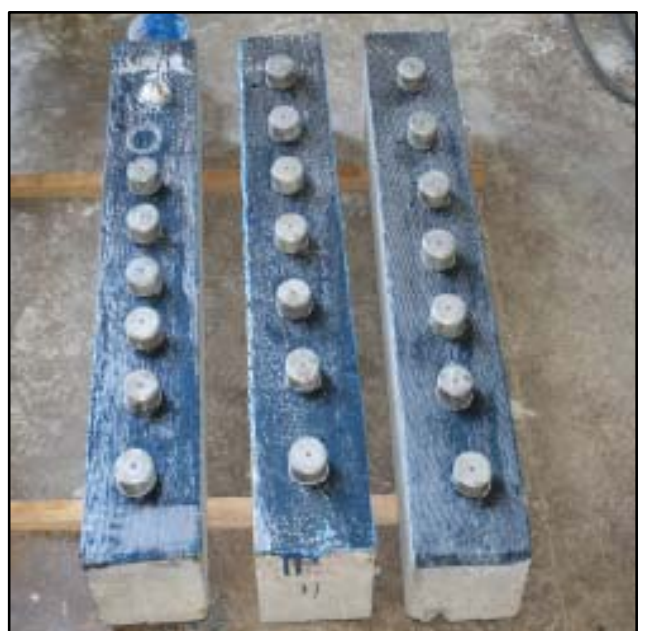

(b)

Figure 6.16 Pull-Off Testing Preparation (a) Cutting (b) Attached Disks

Table 6-7 FRP Bond Strength of Field Testing

\begin{tabular}{|c|c|c|l|c|}
\hline Beam \# & $\begin{array}{c}\text { Reading } \\
\text { (psi) }\end{array}$ & Pass/Fail & \multicolumn{1}{|c|}{ Location } & Comment \\
\hline 1 & 319 & PASS & $\begin{array}{l}\text { Right vertical face, 65" from north } \\
\text { abutment, 5" from soffit }\end{array}$ & Okay \\
\hline 2 & 401 & PASS & $\begin{array}{l}\text { Right vertical face, 54" from north } \\
\text { abutment, 5" from soffit }\end{array}$ & Okay \\
\hline 3 & 421 & PASS & $\begin{array}{l}\text { Left vertical face, 53" from north } \\
\text { abutment, 6" from soffit }\end{array}$ & Okay \\
\hline 4 & 544 & PASS & $\begin{array}{l}\text { Right vertical face, 49" from north } \\
\text { abutment, 5" from soffit }\end{array}$ & Okay \\
\hline 5 & 441 & PASS & $\begin{array}{l}\text { Right vertical face, 49” from north } \\
\text { abutment, 20" from soffit }\end{array}$ & Okay \\
\hline 6 & - & - & $\begin{array}{l}\text { Right vertical face, 68" from north } \\
\text { abutment, 6" from soffit }\end{array}$ & $\begin{array}{c}\text { Gauge } \\
\text { Malfunction }\end{array}$ \\
\hline
\end{tabular}

In accordance with ACI 440.2R-08, the failure stress for bond strength between externally bonded FRP and concrete substrate shall not be less than 200 psi. Pull-off testing results for FRP bond strength of prism samples are presented as follows: 
- Single Ply FRP Layer and Class AAA Repair Material

Seven pull-off tests were conducted with a mean value of 600 psi and a $\mathrm{COV}$ of 0.12 . One failure occurred in the epoxy/FRP interface while the rest failed as desired, cohesive failure within the concrete substrate as shown in Figure 6.17(b). This indicated a strong bond between repair material and FRP.

- Single Ply FRP Layer and BASF Bag Repair Material

Seven pull-off tests were conducted with a mean value of 740 psi and a $\mathrm{COV}$ of 0.10 . One failure occurred in the epoxy/FRP interface while the rest demonstrated a cohesive failure within the concrete substrate.

- Double Ply FRP Layer and BASF Bag Repair Material Seven pull-off tests were conducted with a mean value of $810 \mathrm{psi}$ and a $\mathrm{COV}$ of 0.05 . Five of the tests demonstrated complete cohesive failure within the concrete substrate while two demonstrated roughly $90 \%$ failure within the concrete substrate and 10\% failure between FRP plies.

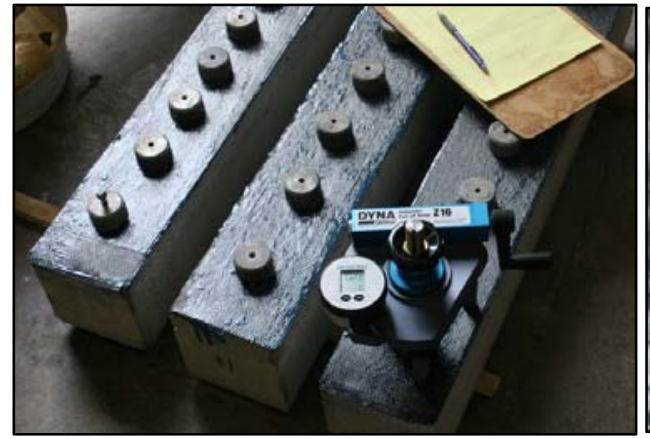

(a)

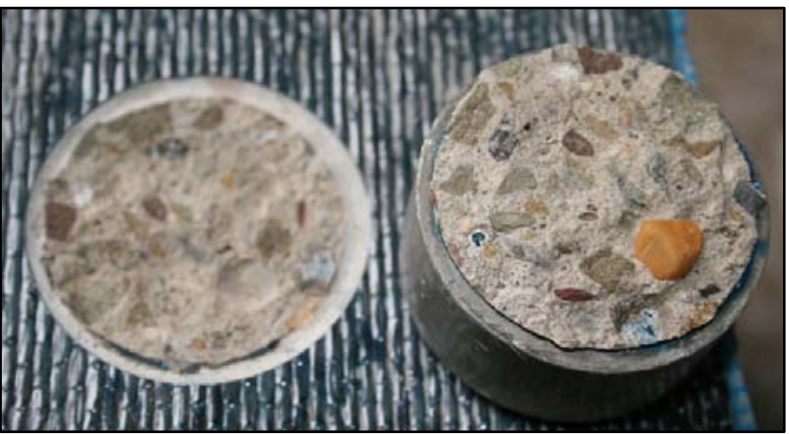

(b)

Figure 6.17 FRP Pull-Off Test (a) Mounted Tester (b) Cohesive Failure 
The results suggest that the bag material was able to achieve greater bond strength with the FRP, with the bond strength for the double ply being the greatest. Also, the double ply FRP pull-off testing results seemed to be less varied as indicated by the covariance measurement.

As shown in Table 6-7, pull-off testing results on the bridge were between 319 and 544 psi. It should be noted that all of the field tests were performed on single ply patches of FRP and the underlying substrate could have been class AAA repair material, BASF bag repair material, or old concrete. The test patch on beam 6 consisted of two layers, but the gage malfunctioned and no reading could be obtained. Other than this, all tests passed.

\subsubsection{Tension Testing of FRP Coupon Samples}

The two FRP laminates created in the field as discussed in Section 6.2.4 were cut into strips 1 in. wide and 12 in. long for direct tension testing in accordance with ASTM D 3039. Five strips were cut and tested for each FRP laminate. As previously stated, one laminate was single ply while the other laminate was double ply. Therefore, testing was performed with five single ply coupons and five double ply coupons.

An MTS 810 Material Testing System equipped with hydraulic wedge grips was used to apply tension force at a rate of $1,000 \mathrm{lbs} / \mathrm{min}$ until FRP rupture. To adequately grip the FRP strips, aluminum end tabs were created and bonded to the ends of the strips (two for each strip end). This allowed for even load transfer. The tabs were $1 \times 4$ in. and had been roughen for increased grip. The tabs were pressure bonded to the ends of the FRP strips for 48 hours to allow for proper curing. The testing setup is shown in Figure 6.18 . 


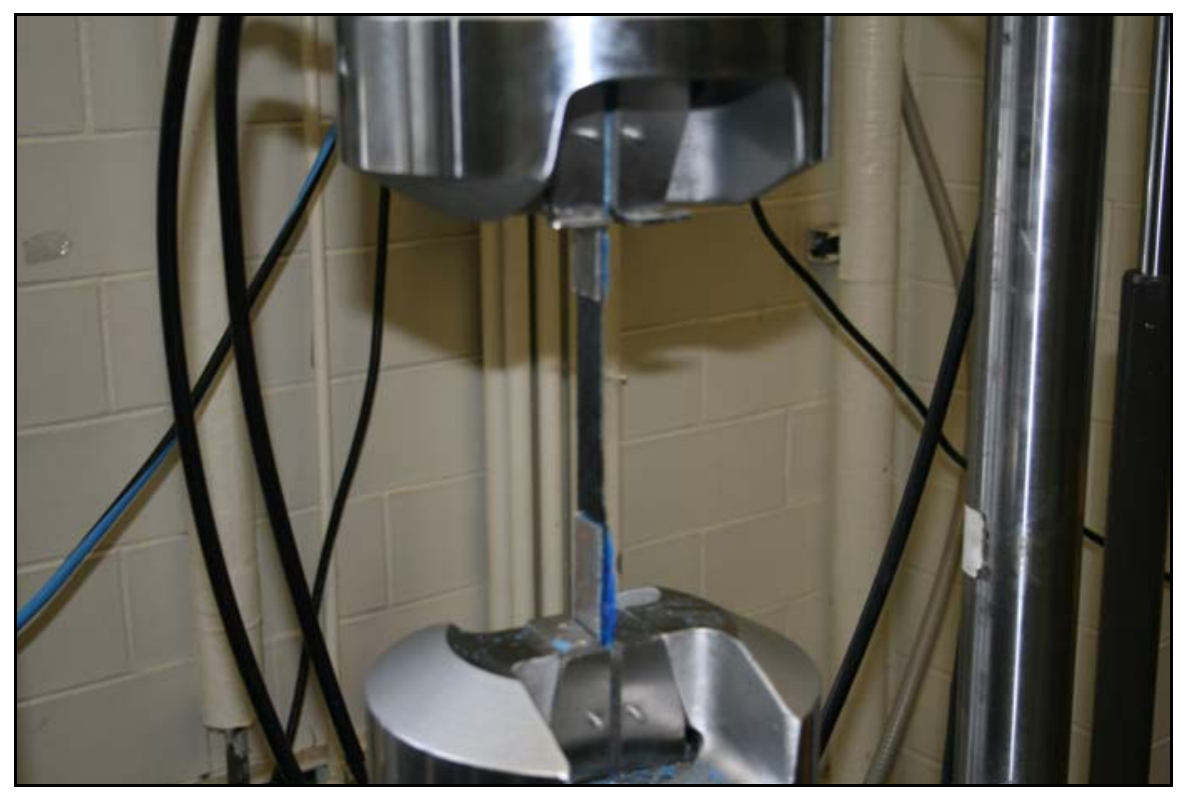

Figure 6.18 FRP Coupon Tension Test Setup

The tensile test results for the single ply coupons are shown in Figure 6.19 while the results for the double ply coupons are shown in Figure 6.20. For the single ply samples, the mean tensile strength was found to be $115 \mathrm{ksi}$ with a COV of 0.10 and an average thickness of 0.03 inches. Whereas, for the double ply samples, the mean tensile strength was found to be $142 \mathrm{ksi}$ with a COV of 0.07 and an average thickness of 0.051 inches.

The ultimate tensile strength of the double ply coupons is greater, owing to the measured thickness being slightly less than that obtained by doubling the thickness of the single ply samples. The ultimate elongation is greater for the double ply coupons as well, indicating no change, or very little change, in stiffness for the two laminates. The stress vs. elongation graphs show the nearly linear-elastic behavior and brittle failure of FRP as should be expected. 


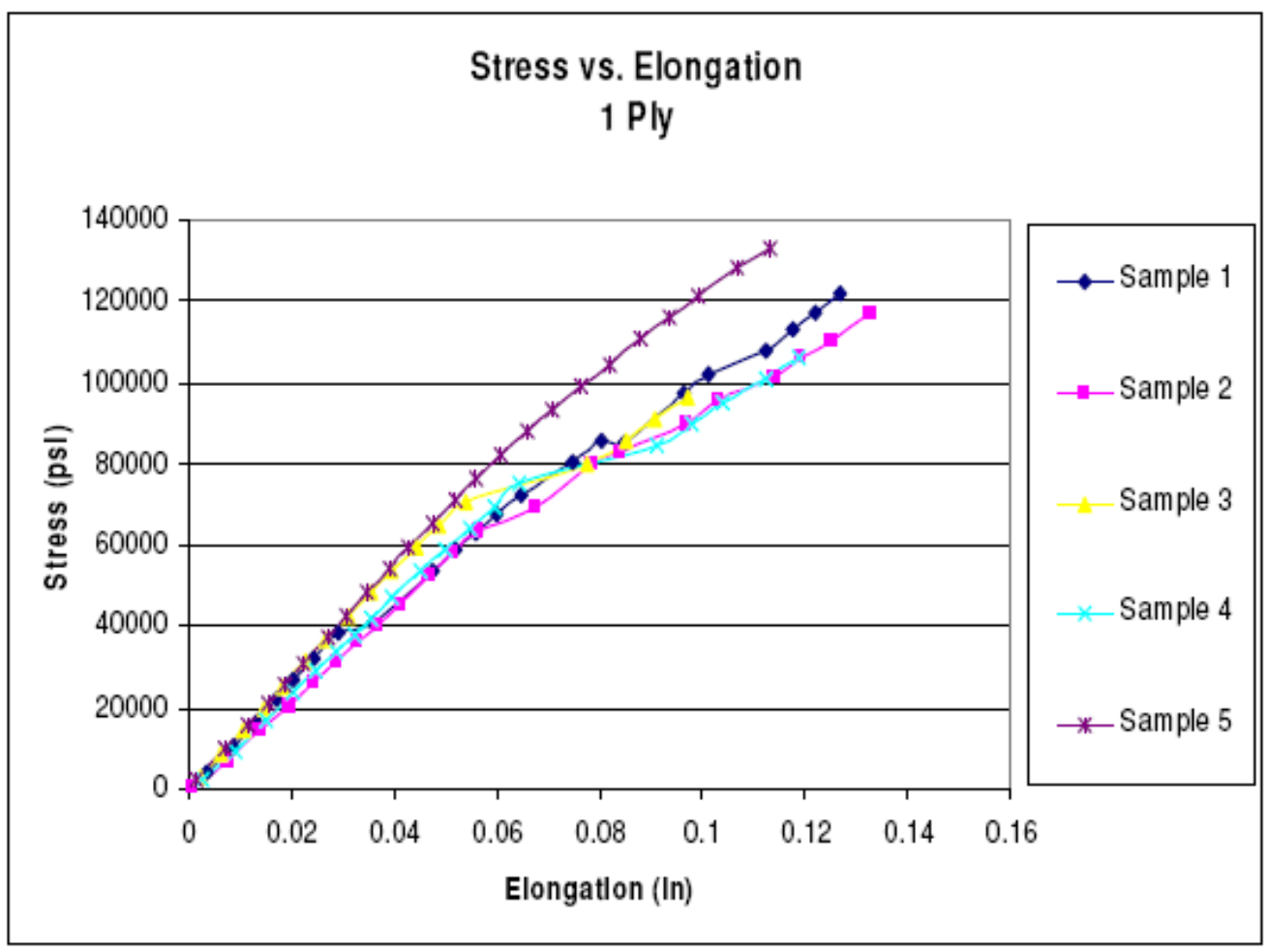

Figure 6.19 1-Ply Tension Coupon Samples

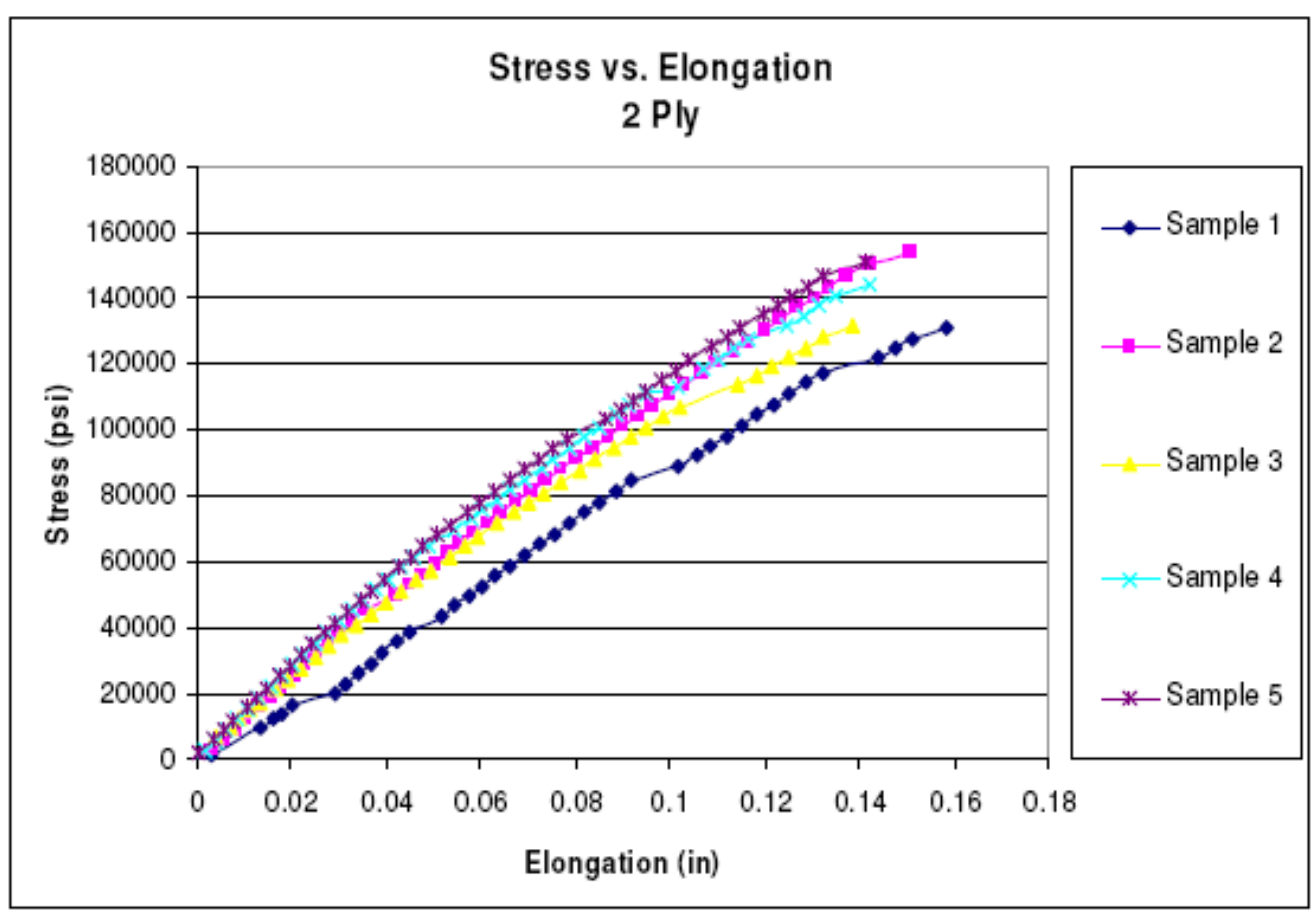

Figure 6.20 2-Ply Tension Coupon Samples 


\section{CHAPTER 7 - CONCLUSIONS}

\subsection{INTRODUCTION}

As previously stated, much of the research presented within this thesis results from Phase III of a three-phase project with PennDOT-D3. Phase III involved construction quality assessment and post-strengthening evaluation for concrete T-Beam bridge \#49-4012-0250-1032 near Sunbury, Pennsylvania. With Phase III work concluded, all supporting documents were submitted to PennDOT-D3 as required. It is intended that PennDOT-D3 can incorporate an effective and economical FRP rehabilitation program for its large number of deteriorated concrete T-Beam bridges.

A broad range of work was performed and incorporated into this thesis in order to arrive at its completion. Such work included: (1) reviewing all previous project tasks and literature along with a collection of case studies incorporating the use of externally bonded FRP for structural strengthening and rehabilitation (Chapter 2); (2) structural evaluation of PennDOT bridge \#49-4012-0250-1032 after FRP strengthening via physical load testing and FE model load testing along with relevant discussions concerning current

design methodology as opposed to more accurate analysis results from FE modeling (Chapter 3 \& 5); (3) development of a user friendly FRP strengthening design program that is capable of providing detailed structural analysis results by allowing the user to specify key deterioration parameters after proper field inspection (Chapter 4); (4) performing regular site visits to observe and gather material specimens for testing to ensure that the highest possible quality of work was being achieved (Chapter 6); and the 
development of design, construction, and testing guidelines for implementation into future work carried out by PennDOT-D3.

Various details and results are presented within each chapter of this thesis. This chapter further recaps these details and results. Throughout the work, various concerns and recommendations for future work have been noted and are also presented.

\subsection{LOAD TESTING AND FE MODELING}

An FE model constructed by a separate research team member, as stated earlier, was calibrated using field test results and modified as needed to increase its accuracy. The proper construction of the model was made possible by incorporating the as-built drawings and by using field information. FE model verification though comparison with field testing data allowed for its confident use in analyzing the strengthened structure.

Deflection readings from load testing indicated a very slight to no decrease in deflection when comparing the un-strengthened bridge to the strengthened bridge. This signifies that the FRP strengthening system has very minimal or no impact on the stiffness of the structure as a whole. No apparent change in stiffness was also concluded through the FE model and dynamic analysis. This conclusion is very reasonable when considering the very minimal amount of space consumed by the externally bonded FRP strips and the corresponding minimal increase in the moment of inertia for the section.

It was concluded through FE model analyses, as it has been discovered in similar research, that current design methods can be over-conservative. This over-conservative nature of design methods arises from the simplistic approaches taken. The standard 2-D girder-line-analysis used by AASHTO does not consider secondary mechanism of restraint as previously described. Also, its simplistic approach does not always 
accurately consider the deck's contribution to primary element capacities. This deck contribution is accounted for in design via live load distribution factors (LDFs) as previously described. Several methods for obtaining LDFs were compared for this demonstration bridge. As well as comparing LDFs, LDFs resulting from AASHTO Standard specifications (LFD methodology) and LDFs resulting from current AASHTO specifications (LRFD methodology) were evaluated for aged concrete T-Beam bridges in particular. With this evaluation, it was concluded that for relatively common bridges (span length of 40 to $50 \mathrm{ft}$ and girder spacing of 4.5 to $6 \mathrm{ft}$ ) LDFs resulting from the AASHTO Standard S/D formula shall be deemed adequate. This is a desired conclusion considering that the current structural analysis methods used for rating bridges in Pennsylvania have not been updated to incorporate LRFR methodologies. Therefore, PennDOT's current method for obtaining LDFs for rating is simply the S/D formula of the AASHTO Standard specifications and may not need to be updated for implementing and FRP repair program for aged concrete T-Beam bridges.

\subsection{Design Program}

The design program created within this research can be a very helpful tool for the implementation of an economical FRP rehabilitation program for PennDOT-D3. PennDOT's current load rating program (BAR7) can be applied to a wide range of bridge types and is not limited to simple span concrete T-Beam bridges. Although BAR7 has fewer limitations when considering all bridge types, it does have more limitations when considering the implementation of an FRP strengthening program specifically for its large number of concrete T-Beam bridges. A BAR7 analysis does not allow the user to specify different amounts of reinforcing steel corrosion in different sections of the bridge. 
The demonstration bridge of this project exhibited excessive amounts of corrosion near the drain pipes, with some of the vertical stirrups corroded completely through. This loss of shear resistance needs to be accounted for to provide a more safe and reliable load rating analysis and FRP design. The FRP design program created in this research was developed specifically for concrete T-Beam bridges and allows the user to specify varying corrosion levels per section. The developed design program also allows for

flexural steel loss variation within beams. The pre- and post-strengthened capacities and load rating factors are a direct result of the program analysis. This can allow a designer to design with the goal of achieving a specified load rating factor as discussed previously. The load rating method used in the design program follows LFR methodology and as concluded through this research, shall be deemed adequate for common geometries of concrete T-Beam bridges. In this manner, the design program can be incorporated into a much needed rehabilitation plan for only concrete T-Beam bridges and provide economical savings, as well as time savings, of vast proportions.

\subsection{Quality Control AND Assurance}

Based on the method developed and refined during Phase III of the project, the candidate bridge was chosen as a Level -1 bridge to demonstrate the effectiveness of externally bonded FRP for strengthening. All removal and restoration of deteriorated concrete was observed for adequacy with respect to standard documentation (ACI 440.2R-02, NCHRP Report 514). Specimen testing was performed in accordance with ACI and ASTM standards. All construction complications and discoveries were noted. This includes the discovery that the bridge reinforcement layout did not match the original design layout. During the construction of the bridge, several of the flexural 
reinforcement bars and vertical stirrups were omitted as opposed to the original design drawings. All of the supporting knowledge gained through this stage of the work was used to develop the design and construction guidelines as presented in Appendix D and E, respectively.

\subsection{RECOMMENDATIONS AND FUTURE WORK}

This research wraps up a three-phase project with PennDOT-D3 in order to initiate an economical and technically effective FRP rehabilitation program for concrete T-Beam bridges. The following recommendations are applicable to interested researchers in the continued development of effective FRP strengthening protocol for aged concrete T-Beam bridges.

1. Use heavier loading vehicles for testing and design. The readings from field load testing of the bridge were very minute and did not allow for the best possible insight to structural analysis concepts. Bridges set to be demolished and replaced should even be considered for instrumentation and load tested to failure if possible. This will allow for researchers to gain more knowledge and exploit the full structural responses of the FRP-concrete system. Also, as the standard design methodology has changed from LFD to LRFD, the standard design load has also changed. The HL-93 truck or tandem loading is the standard design load for LRFD. Incorporating the use of these heavier design loads for strengthening may offset future repair and rehabilitation since legal highway vehicle loads have increased over the years.

2. Apply externally bonded FRP to the deck. It was observed on multiple occasions throughout this project that the underside of the deck displayed regions of serious deterioration. Although not logically of great concern in the selected bridge due 
to the relatively close spaced beams with respect to beam geometry, the underside of the deck should be considered for strengthening in future projects. Corrosion on the underside of decks can lead to decreased strength and stiffness, thereby decreasing the deck's effectiveness in load transfer and decreasing its contribution to the T-Beam capacity. This, in some instances, can cause the live load distribution factors obtained through standard equations to be under-conservative and unsafe.

3. Determine true as-built conditions though effective field inspection incorporating minimal destructive testing along with all applicable non-destructive testing. As the as-built conditions for the demonstration bridge of this project differed from that shown in the original design drawings, it is very reasonable to assume that this is the case with similar bridges in the state. Researchers should use all appropriate test methods to determine the real conditions of a bridge so that proper structural analysis can be performed.

4. The use of more and different types of strain gages. As it is previously discussed, concrete surface bonded strain gages have a high probability of being inaccurate due to surface irregularities and environmental conditions. It is recommended to use embedded strain gages and gages mounted to reinforcing steel. In this manner, the readings can be more reliable and a more accurate assessment of the FRP contribution to strength can be made by directly looking into the change in reinforcing steel strain before and after FRP application under repeated loading.

5. Continued long-term evaluation of FRP-concrete system to ensure its effectiveness. Since FRP strengthening techniques have quickly become acceptable as a means of strengthening concrete structures, it is imperative that continued research be 
conducted to evaluate its long-term performance. Proper non-destructive testing methods and periodic load testing should be performed on such rehabilitation projects. For WVU researchers, PennDOT bridge \#49-4012-0250-1032 should be used as an educational tool to assess the time-dependent effectiveness of the FRP system. As a basis, several load tests could be conducted over the next 10-20 years to determine any loss of structural capacity, with supplementary non-destructive testing performed to determine the reason for any such losses.

6. Increase capabilities of developed FRP design program. The user friendly FRP strengthening design program can be built upon to increase its capabilities. Currently, the program accepts loading input from the user. The program could be updated to incorporate its own live load generator based on a specified design truck loading. As an alternative, the design program could be integrated with PennDOT's BAR7 program. In this manner, the program could simply take loading output from BAR7 and use it as loading input. Updated or not, the program should be incorporated into PennDOT's concrete T-Beam FRP rehabilitation program.

7. Over-use of FRP and future deterioration. During construction, flexural FRP was placed on beam 5 as a continuous wrap. There is no known research incorporating this type of continuous wrap for flexural strengthening. Researchers have expressed concern with this type of FRP layout. There is concern that, due to the impervious nature of the FRP material, a trough like structure will be formed and potentially trap future contaminants thereby increasing corrosion rates. There is also concern with the continuous U-wrap and FRP stirrup interaction. Along with these concerns, the design procedure for such a flexural wrapping scheme is not standard. The 
strain gradient throughout the depth of the side flexural reinforcement needs to be accounted for in design. This approach should be verified with lab-scale testing.

Another related research topic is the use of chloride extraction techniques with FRP strengthened beams. Currently, researchers at WVU are performing Electrochemical Chloride Extraction (ECE) on lab-scale beams repaired with externally bonded FRP similar to that of PennDOT bridge \#49-4012-0250-1032. This is a new and important research topic considering the fact that future corrosion due to environmental factors and winter maintenance is inevitable. Can chloride extraction techniques be successfully employed on bridge members reinforced with externally bonded FRP?

8. $\quad$ Researching aged bridges that have been set for demolition. In previous research on deteriorated concrete T-Beam bridges, full bridge field testing has been performed followed by testing of bridge girders extracted during demolition. Interestingly, girder responses when part of the entire structure and girder responses when extracted to be a single girder have been compared. This same approach can be insightful for researching externally bonded FRP for strengthening. In this manner, full instrumentation and testing of a bridge set for demolition can be performed. Following full bridge testing, a selected girder can be extracted and tested again. Considering crosssection repair and FRP strengthening as two separate phases, this extracted girder shall then be repaired in accordance with standard specifications and strengthened with externally bonded FRP strips. Instrumentation and duplicate load testing can be performed after repair and also after FRP strengthening. Data resulting from the four different tests can be analyzed to fully evaluate and deduce structural aspects of the following: the entire deteriorated structure, the extracted deteriorated beam, the extracted 
beam after cross-section repair, and the beam after adding externally bonded FRP to the repaired cross-section. The evaluation can be enhanced by performing finite element modeling and analysis of the testing procedures. With this type of study, direct and accurate discussions can be made concerning: distribution of live load, secondary bridge members and their resulting contribution in resisting forces, change in structural response due to cross-section repair, and change in structural response due to strengthening with externally bonded FRP strips. With the repair and strengthening complete, the extracted bridge girder can be maintained in a desired location with mild to harsh environmental conditions in order to reproduce field conditions. The long-term performance of the repair and strengthening system can be monitored by periodic visual inspection, load testing, and non-destructive testing. The execution of this type of experiment can lead to a comprehensive understanding of aged concrete bridge repair and strengthening along with the long-term performance of such repair and strengthening. 


\section{REFERENCES}

AASHTO, "Manual for Condition Evaluation of Bridges," $2^{\text {nd }}$ Edition, pp 49-72, 1994.

AASHTO, "Standard Specifications for Highway Bridges," $16^{\text {th }}$ Edition, 760 pp., 1996.

ABAQUS/Standard User's Manual, Version 6.5, Hibbitt, Karlsson, and Sorensen, Inc., Pawtucket, RI, 2005.

ACI Concrete Repair Manual

ACI 318-08 (2008), Building Code Requirements for Structural Concrete and Commentary (318R-08), American Concrete Institute, Farmington Hills, MI.

ACI 440.2R-08. Guide for the Design and Construction of Externally Bonded FRP Systems for Strengthening Concrete Structures. Farmington Hills, MI: American Concrete Institute, 2008.

ACI 440R-07 (2007). Report on Fiber-Reinforced Polymer (FRP) Reinforced for Concrete Structures. American Concrete Institute.

Alkhrdaji, T. and A. Nanni, "Surface Bonded FRP Reinforcement for Strengthening/Repair of Structural Reinforced Concrete," Proc., ICRI-NRCC Workshop, Baltimore, MD, Oct 30, 1999, 19 pp.

Alkhrdaji, Tarek, Antonio Nanni, Genda Chen, and Michael Barker. Destructive and Non-Destructive Testing of Bridge J857 Phelps County, Missouri- Volume I: Strengthening and Testing to Failure of Bridge Decks. University of MissouriRolla. Center for Infrastructure Engineering Studies, 1999.

Ball, Ryan. Experimental Analysis of Composite Reinforced Concrete Beams Thesis. Ohio University, 1998. Athens, OH: Ohio University, 1998.

Blok, J., and Brown, J. (2009). "Load-induced debonding of FRP composites applied to reinforced concrete." SPIE, Vol. 7299, Q-1 - Q-9.

Bonfiglioli, Barbara, Giovanni Pascale, and Sonia Martinez De Mingo. "Dynamic Testing of Reinforced Concrete Beams Damaged and Repaired with Fiber Reinforced Polymer Sheets." Journal of Materials in Civil Engineering 16 (2004): 400-406.

Bousselham, A., and Chaallal, O., 2006, "Behavior of Reinforced Concrete T-Beams Strengthened in Shear with Carbon Fiber-Reinforced Polymer-An Experimental Study," ACI Structural Journal, V. 103, No. 3, May-June, pp. 339-347. 
Brayack, Daniel A. Technical and Economic Effectiveness for Repair with FRP of Concrete T-Beam Bridges: Case Study for PennDOT-District 3. Thesis. West Virginia Univ., 2006. Morgantown, WV: West Virginia University, 2006.

Catbas, F N., S K. Ciloglu, O Hasancebi, J S. Popovics, and A E. Aktan. Re-Qualification of Aged Reinforced Concrete T-Beam Bridges in Pennsylvania. Drexel University. Drexel Intelligent Infrastructure Institute, 2003.

Catbas, Necati, Korhan Ciloglu, Arda Celebioglu, and Emin Aktan. Fleet Health Monitoring of Large Populations: Aged Concrete T-Beam Bridge in Pennsylvania. Drexel University. Drexel Intelligent Infrastructure Institute, 2001.

Corvaglia, P., Galietti, U., Largo, A., Nenna, S., and Spagnolo, L. (2007). "Feasibility of different thermal analysis of FRP-reinforced concrete." CETMA Consortium, Brindisi, Italy

Davalos, Julio F., Chunfu Lin, Indrajit Ray, Karl E. Barth, George Parish, and William C. Sasher. A Comprehensive Program for Repair with External FRP of Concrete TBeam Bridges in Pennsylvania DOT - USA. West Virginia University. Morgantown, WV: West Virginia University, 2007.

Davalos, Julio F., Chunfu Lin, Karl E. Barth, Indrajit Ray, William C. Sasher, and George Parish. "Material/Structural Evaluation and FRP Retrofit Design of a Concrete T-Beam Bridge." American Concrete Institute (2007).

Davalos, Julio F., Karl E. Barth, Indrajit Ray, Chunfu Lin, and Daniel A. Brayack. District 3-0 Investigation of Fiber-Wrap Technology for Bridge Repair and Rehabilitation (Phase-I). West Virginia University. Morgantown, WV: West Virginia University, 2006.

Davalos, Julio F., Karl E. Barth, Indrajit Ray, Chunfu Lin, William C. Sasher, and George Parish. District 3-0 Investigation of Fiber Wrap Technology for Bridge Repair \& Rehabilitation-Phase 2. West Virginia University. Morgantown, WV: West Virginia University, 2007.

Davalos, Julio F., Karl E. Barth, Indrajit Ray, Chunfu Lin, Adam L. Justice, and Matt D. Anderson. District 3-0 Investigation of Fiber-Wrap Technology for Bridge Repair and Rehabilitation (Phase-3). Morgantown, WV: West Virginia University, 2008.

Deniaud, C., and Cheng, J. J. R., 2003, "Reinforced Concrete T-Beams Strengthened in Shear with Fiber Reinforced Polymer Sheets," Journal of Composites in Construction, ASCE, V. 7, No. 4, pp. 302-310.

Eom, J. and Nowak., A. S. (2001) "Live Load Distribution for Steel Girder Bridges," ASCE Journal of Bridge Engineering, Vol. 6, No. 6, November/December, pp. 489-497. 
Funakawa, I.; Shimono, K.; Watanabe, T.; Asada, S.; and Ushijima, S., 1997, "Experimental Study on Shear Strengthening with Continuous Fiber Reinforcement Sheet and Methyl Methacrylate Resion," Third International Symposium on Non-Metallic (FRP) Reinforcement for Concrete Structures (FRPRCS-3), V. 1, Japan Concrete Institute, Tokyo, Japan, pp. 475-482.

Green, M.; Bisby, L.; Beaudoin, Y.; and Labossiere, P., 1998, "Effects of Freeze-Thaw Action on the Bond of FRP Sheets to Concrete," Proceedings of the First International Conference on Durability of Composites for Construction, Sherbrooke, QC, Canada, Oct., pp. 179-190.

Hag-Elsafi, Osman, Jonathan Kunin, Sreenivas Alampalli, and Timothy Conway. New York. Transportation Research and Development Bureau. New York State Department of Transportation. Strengthening of Route 378 Bridge Over Wynantskill Creek in New York Using FRP Laminates. New York: New York State Department of Transportation, 2001.

Khalifa, A.; Alkhrdaji, T.; Nanni, A.; and Lansburg, S., 1999, “Anchorage of SurfaceMounted FRP Reinforcement," Concrete International, V. 21, No. 10, Oct., pp. 49-54.

Lopez, Alexis, and Antonio Nanni. "Composite Strengthening Technologies." Concrete International (2006): 74-80.

Malek, A.; Saadatmanesh, H.; and Ehsani, M., 1998, "Prediction of Failure Load of R/C Beams Strengthened with FRP Plate Due to Stress Concentrations at the Plate End," ACI Structural Journal, V. 95, No. 1, Jan.-Feb., pp. 142-152.

Mayo, R., Nanni, A., Gold, W. and Barker, M., "Strengthening of Bridge G270 with Externally-Bonded CFRP Reinforcement," SP-188, American Concrete Institute, Proc., $4^{\text {th }}$ International Symposium on FRP for Reinforcement of Concrete Structures (FRPRCS4), Baltimore, MD, Nov. 1999, pp.429-440.

Nutt, R. V., Schamber, R. A., \& Zokaie, T. (1988). NCHRP 12-26: Distribution of Wheel Loads on Highway Bridges. Final Report for National Cooperative Highway Research Program.

Okeil, A. M.; Bingol, Y.; and Alkhrdaji, T., 2007, “Analyzing Model Uncertainties for Concrete Beams Flexurally Strengthened with FRP Laminates," Proceedings of the Transportation Research Board 86th Annual Meeting, Jan. 21-25, 2007, Washington, DC, 15 pp. (CD-ROM)

Parish, George C. CFRP Repair of Concrete Beams Aged by Accelerated Corrosion. Thesis. West Virginia Univ., 2008. Morgantown, WV: West Virginia University, 2008 
Pellegrino, C., and Modena, C., 2002, "Fiber Reinforced Polymer Shear Strengthening of Reinforced Concrete Beams with Transverse Steel Reinforcement," Journal of Composites in Construction, ASCE, V. 6, No. 2, pp. 104-111.

Priestley, M.; Seible, F.; and Calvi, G., 1996, Seismic Design and Retrofit of Bridges, John Wiley and Sons, New York, 704 pp.

Quattlebaum, J.; Harries, K. A.; and Petrou, M. F., 2005, "Comparison of Three CFRP Flexural Retrofit Systems Under Monotonic and Fatigue Loads," Journal of Bridge Engineering, ASCE, V. 10, No. 6, pp. 731-740.

Roberts, T. M., and Haji-Kazemi, H., 1989, "Theoretical Study of the Behavior of Reinforced Concrete Beams Strengthened by Externally Bonded Steel Plates," Proceedings of the Institute of Civil Engineers, Part 2, V. 87, No. 9344, pp. 39-55.

Salim, H.A., J.F. Davalos, H.V.S. Gangarao, and P.R. Raju (1995), “An Approximate Series Solution for Design of Deck-and-Stringer Bridges", International Journal for Engineering Analysis and Design, Vol. 2, pp. 15-31.

Sargand, Shad M., and Ryan Ball. Special Students Study: Experimental Analysis of Composite Reinforced Bridge - Field Study. Diss. Ohio Univ., 2000.

Sasher, William C. Testing, Assessment and FRP Strengthening of Concrete T-Beam Bridges in Pennsylvania. Thesis. West Virginia Univ., 2008. Morgantown, WV: West Virginia University, 2008

Soudki, K. A., and Green, M. F., 1997, "Freeze-Thaw Response of CFRP Wrapped Concrete," Concrete International, V. 19, No. 8, Aug., pp. 64-67.

Triantafillou, T. C., 1998a, "Shear Strengthening of Reinforced Concrete Beams Using Epoxy-Bonded FRP Composites," ACI Structural Journal, V. 95, No. 2, Mar.Apr., pp. 107-115.

University of Missouri-Rolla. Preservation of Missouri Transportation Infrastructures; Validation of FRP Composite Technology Through Field Testing; Strengthening of Bridge P-0962 Vol. II: Master Design. Rolla, MO: University of Missouri-Rolla, 2004.

Valluzzi, M.R., Grinzato, E., and Pellegrino, C. (2009). "IR thermography for interface analysis of FRP laminates externally bonded to RC beams." Materials and Structures, 42, 25-34

Zokaie, T. (2000) "AASHTO-LRFD Live Load Distribution Specifications," ASCE Journal of Bridge Engineering, Vol. 5, No. 2, May, pp. 131-138.

Zou, Bin. Design Guidelines for FRP Honeycomb Sandwich Bridge Deck. Dissertation. West Virginia Univ., 2008. Morgantown, WV: West Virginia University, 2008. 
APPENDIX A: ORIGINAL BRIDGE DRAWINGS 


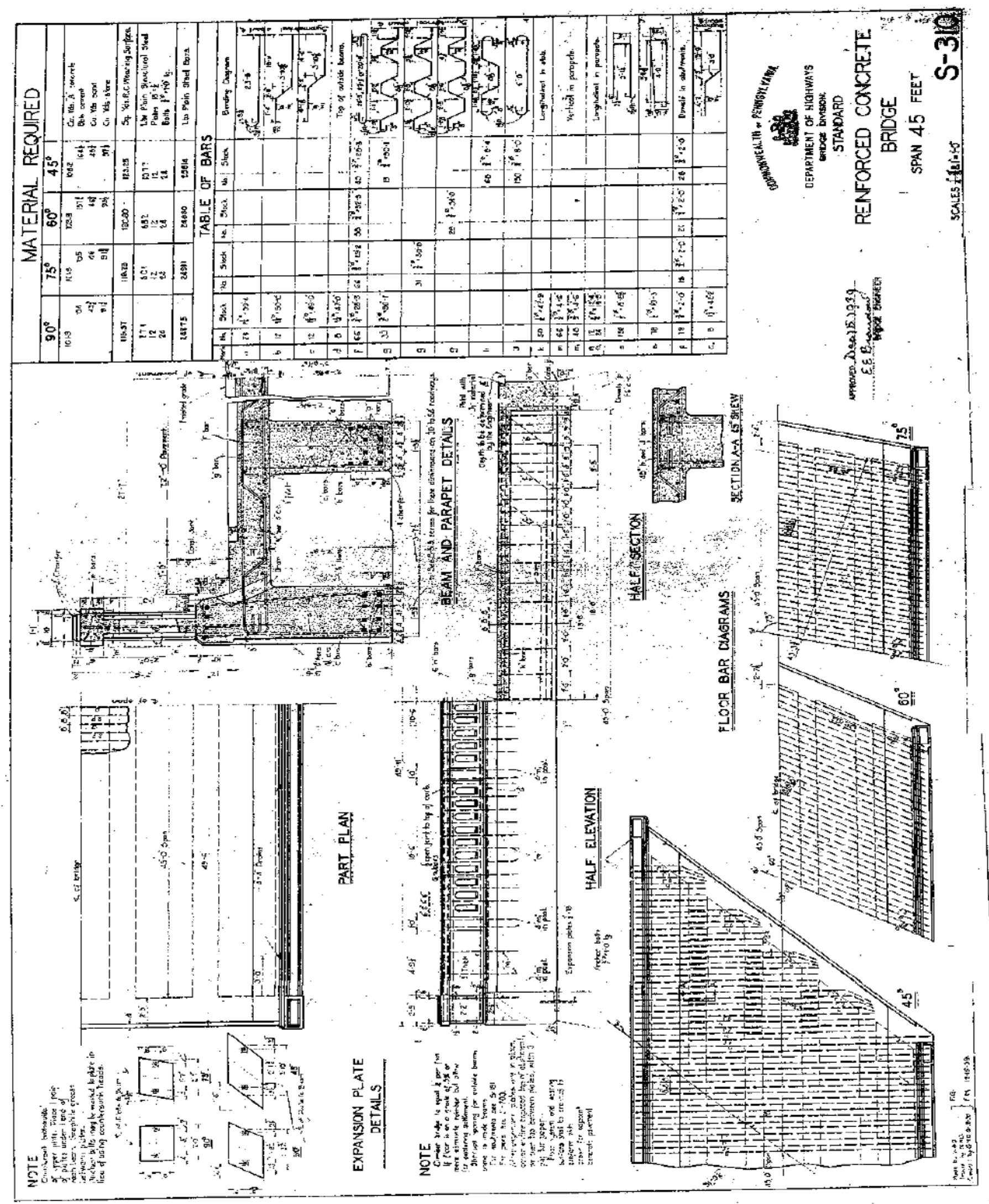




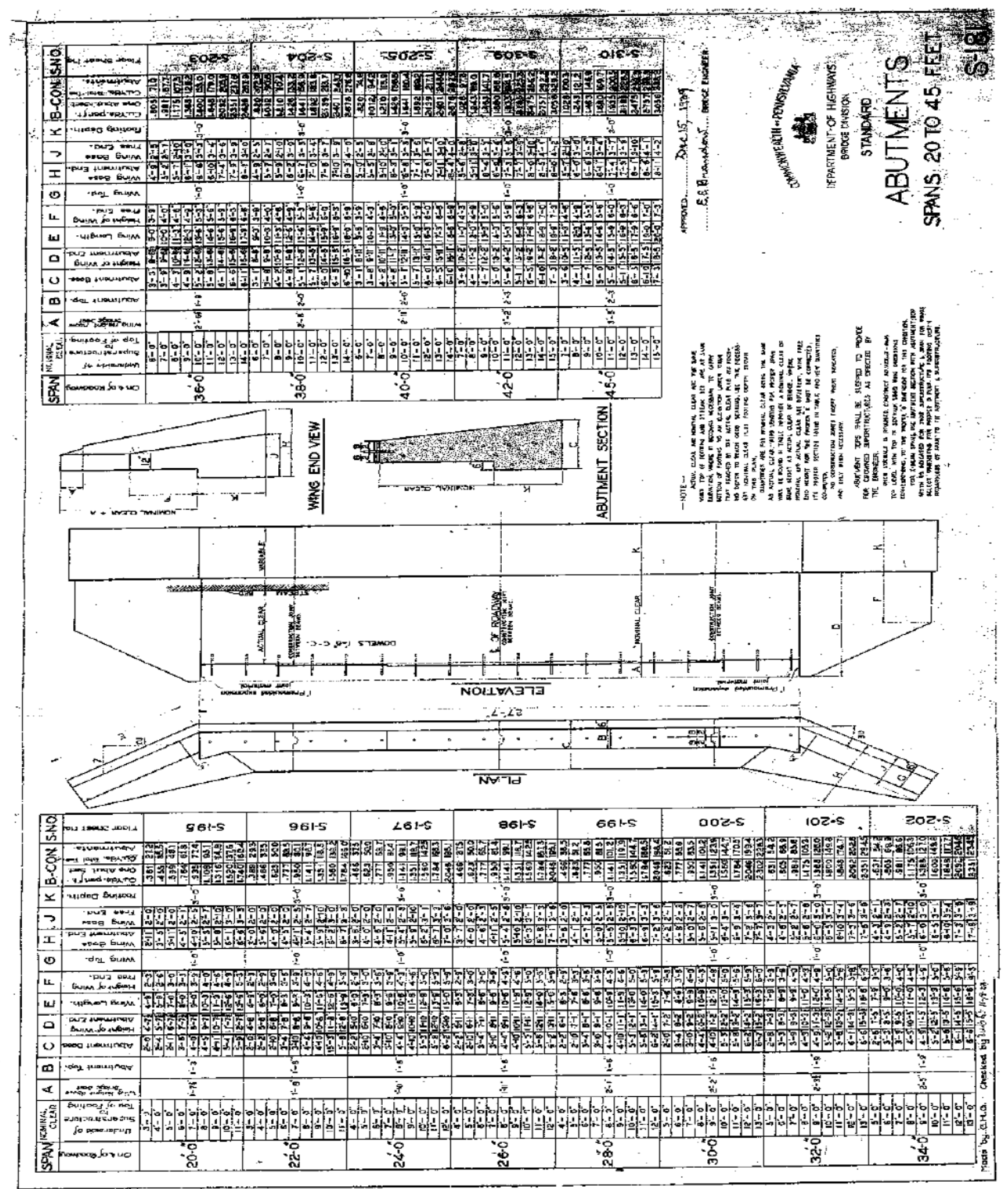


APPENDIX B： FRP DESIGN LAYOUT 

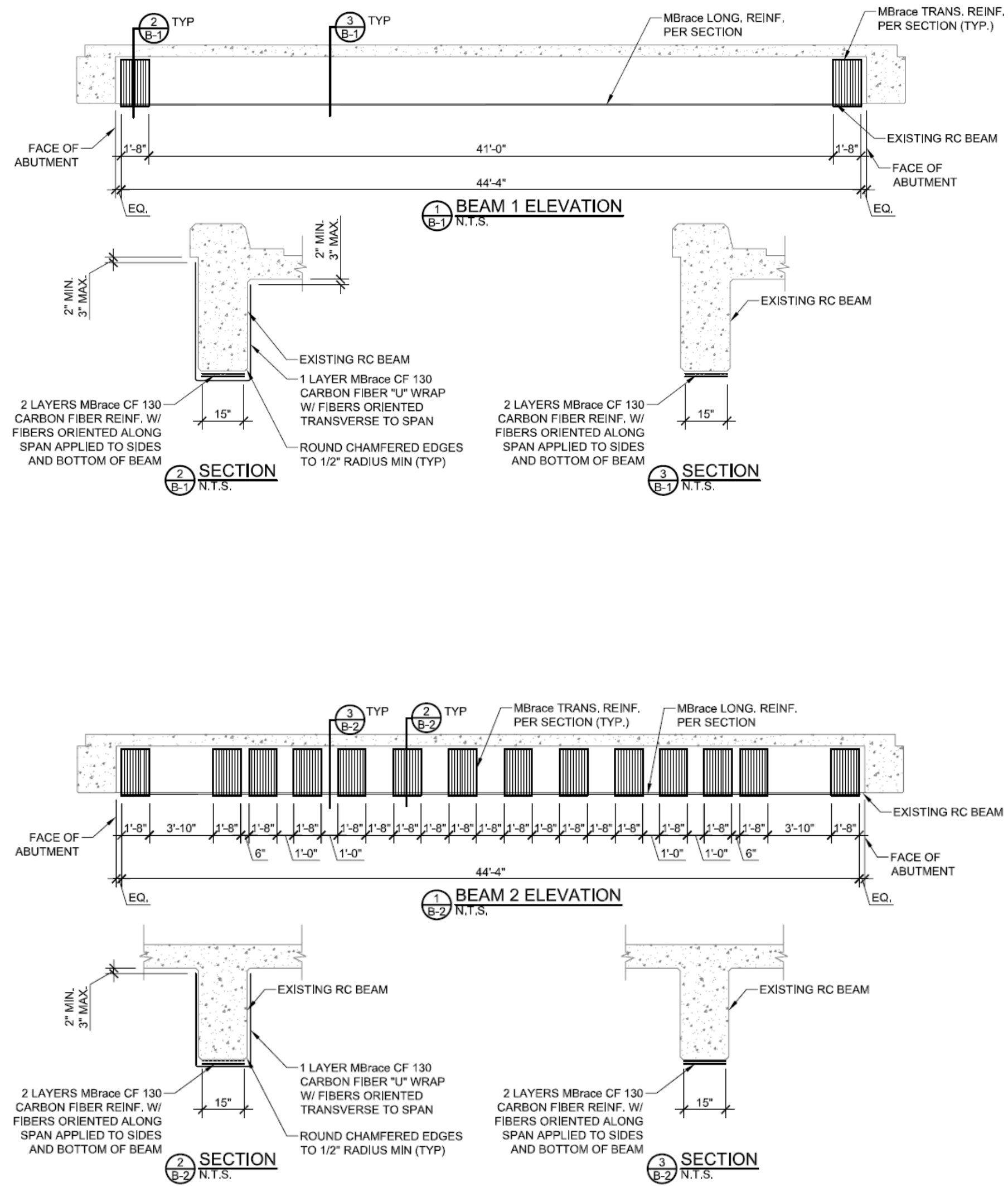

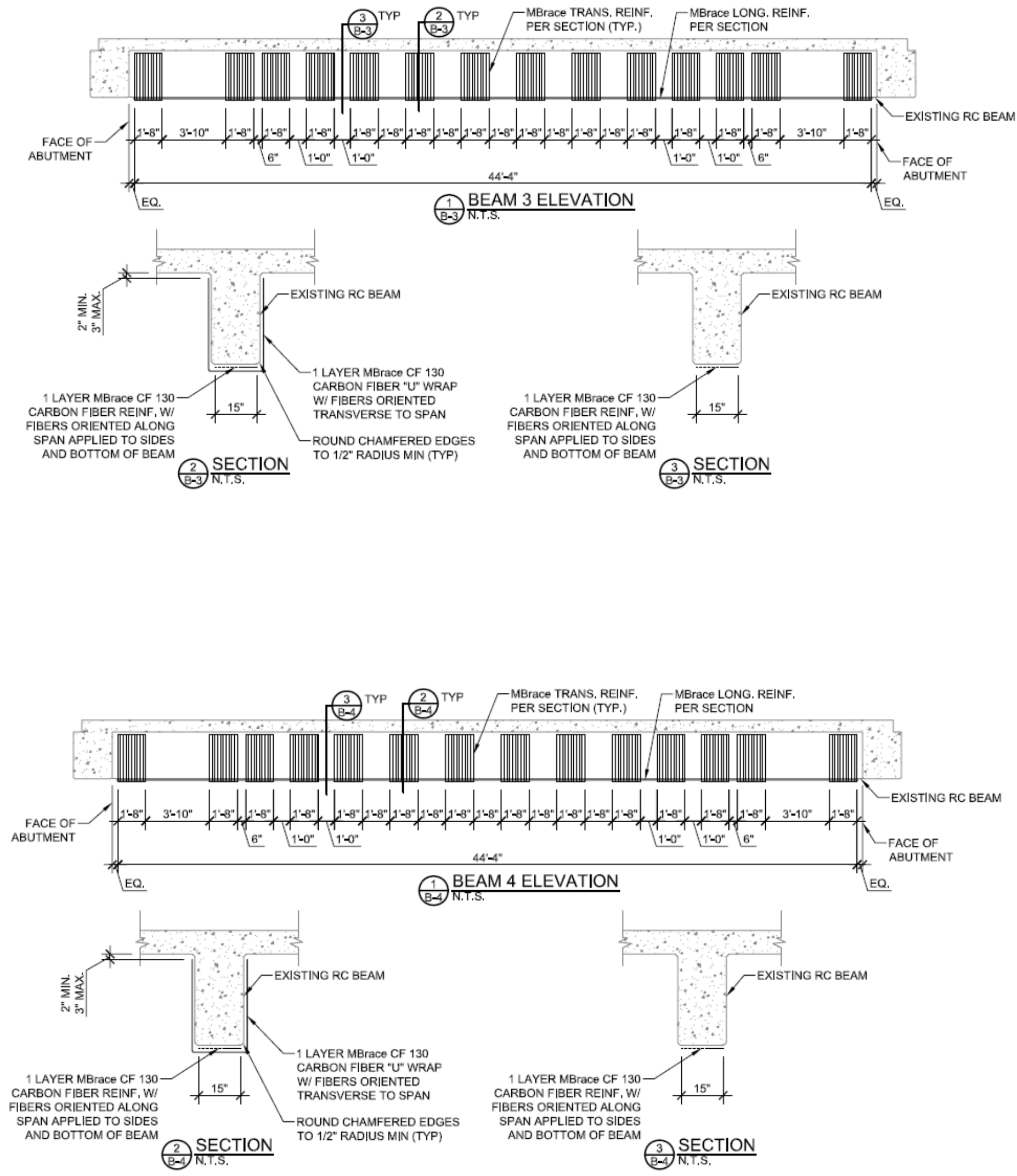

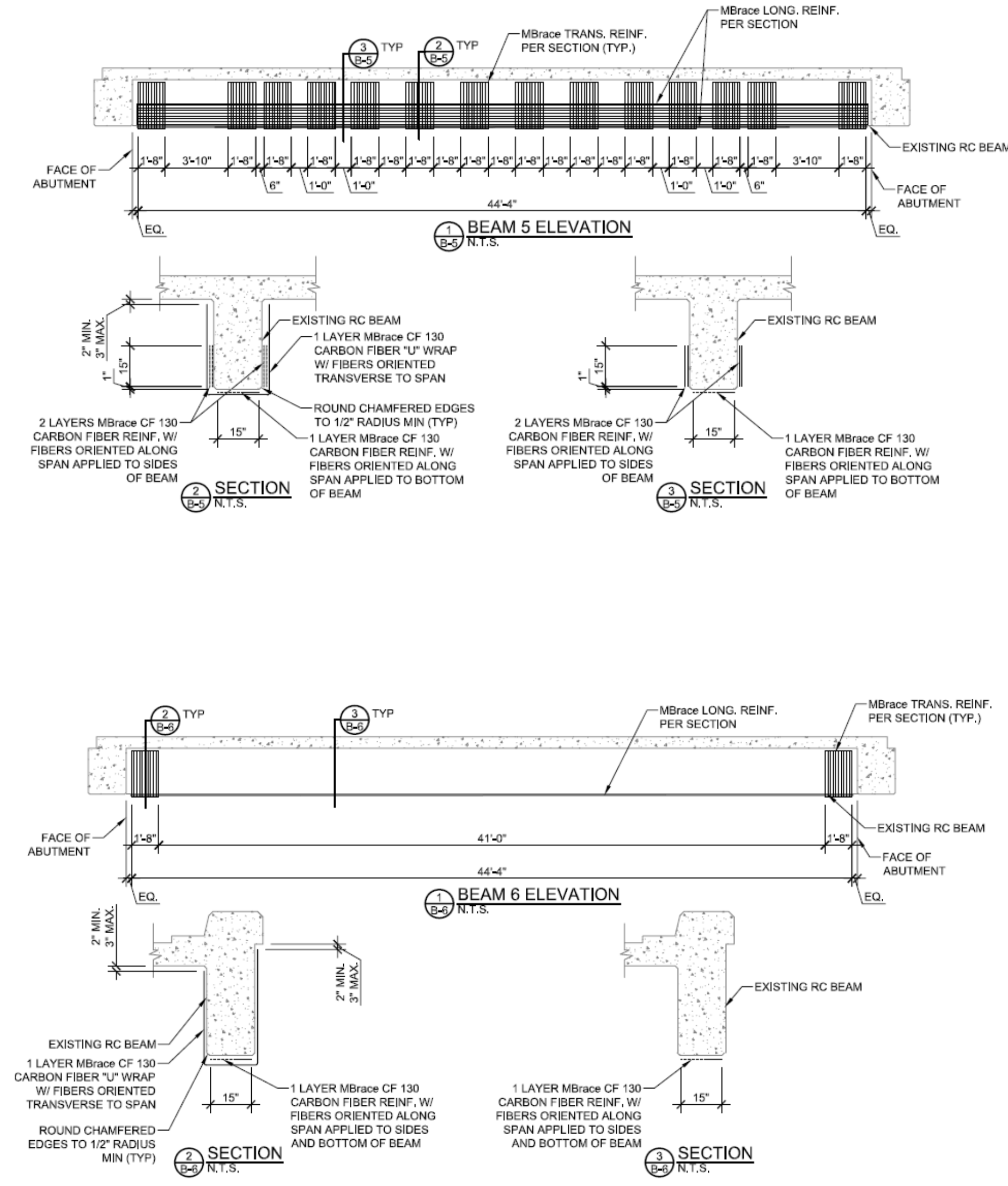


\section{ApPendix C: Project Selection Forms}




\begin{tabular}{|c|c|}
\hline \multicolumn{2}{|c|}{$\begin{array}{c}\text { Form for Assessing the Suitability of a Concrete T-Beam Bridge for Repair with } \\
\text { FRP } \\
\text { (Based on Bridge Classification) }\end{array}$} \\
\hline Scoring Category (weight percentage) & Score \\
\hline $\begin{array}{l}\text { 1. Photographic Indication of Damage } \\
(40 \%)\end{array}$ & 6.67 \\
\hline 2. Age $(10 \%)$ & 10 \\
\hline 3. Span Length (6\%) & 10 \\
\hline 4. ADT \& ADTT $(10 \% \& 10 \%)$ & $10 \& 10$ \\
\hline 5. Functional Class of Highway $(12 \%)$ & 10 \\
\hline 6. Bridge Capacity Appraisal (12\%) & 10 \\
\hline Total Weighted Score & $86.68 \%$ \\
\hline
\end{tabular}

\section{Instructions:}

1. A score shall be assigned for each category.

2. The score column on the right contains drop down menus that offer the score values recommended for bridge classification.

3. Select the appropriate score for each category from the drop down menus.

4. After the scores have been chosen, right click the total weighted score field and click update field. The total weighted score will be calculated based on the individual scores chosen. Based on this score, a class rating will be assigned.

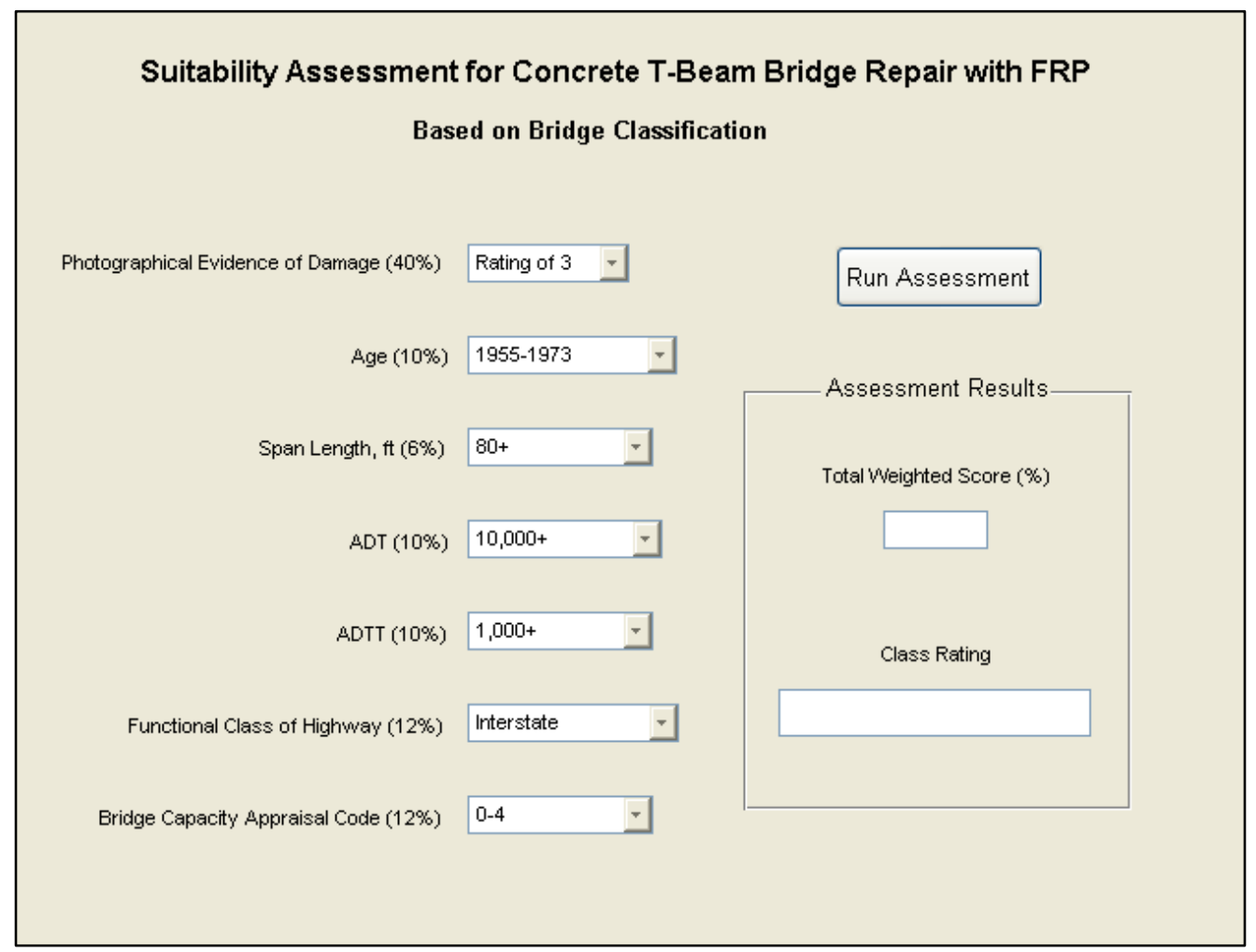


APPENDIX D: DESIGN GUIDELINES 


\section{PENNSYLVANIA DEPARTMENT OF TRANSPORTATION DESIGN MANUAL}

PART 4

PART B: DESIGN SPECIFICATIONS

\section{SECTION 1 - FRP STRENGTHENING DESIGN \\ $\underline{\text { SECTION } 1 \text { - TABLE OF CONTENTS }}$}

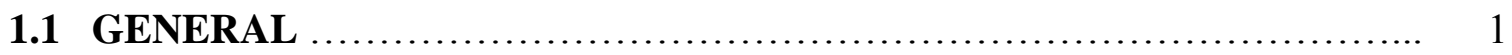

1.2 DEFINITIONS …..................................................... 1

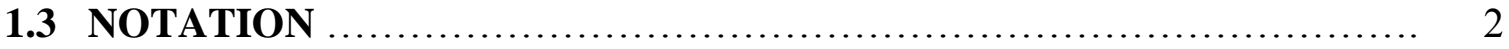

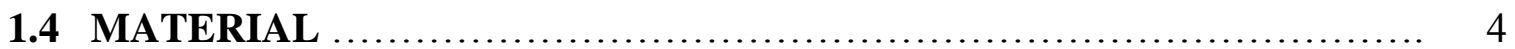

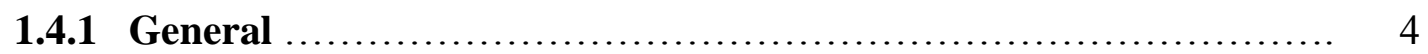

1.4.2 Concrete ......................................................... 4

1.4.3 FRP System ....................................................... 4

1.4.3.1 FIBERS .............................................. 5

1.4.3.2 RESINS .............................................. 5

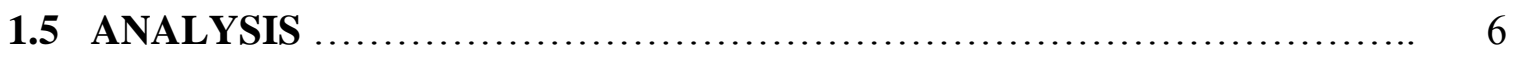

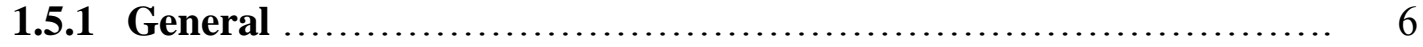

1.5.2 Concrete Material Properties .......................................................... 6

1.5.3 FRP System Material Properties ................................ 6

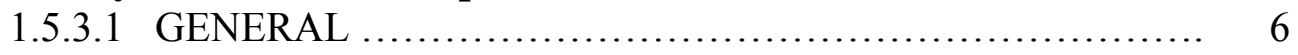

1.5.3.2 EXPANSION AND CONTRACTION ..................... 7

1.5.3.3 TENSILE AND COMPRESSIVE BEHAVIOR ................ 7

1.5.3.4 DESIGN MATERIAL PROPERTIES ........................ 8

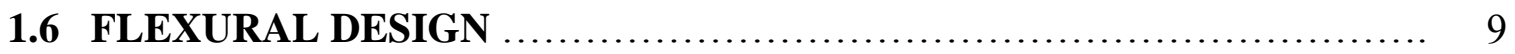

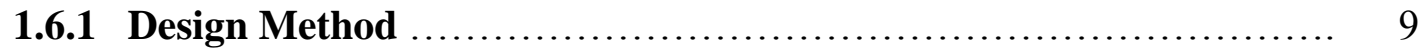

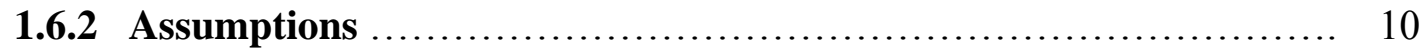

1.6.3 Strengthening Limits ............................................. 11

1.6.4 Flexural Strengthening ............................................. 11

1.6.4.1 NOMINAL STRENGTH ................................ 12

1.6.4.2 INITIAL SUBSTRATE STRAIN ........................... 12

1.6.4.3 FRP REINFORCEMENT STRAIN AND STRESS ............ 14

1.6.4.4 SERVICEABILITY ........................................ 15

1.6.4.5 CREEP-RUPTURE AND FATIGUE ........................ 15

1.6.4.6 FAILURE MODES .................................... 16

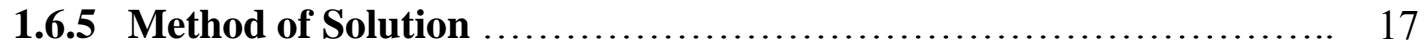

1.6.6 Tension Reinforcement Steel Only in Strengthened Section .......... 21 


\subsubsection{STRESS BLOCK DEPTH LESS THAN FLANGE}

THICKNESS

1.6.6.2 STRESS BLOCK DEPTH GREATER THAN FLANGE THICKNESS

1.6.7 Side Bonded FRP Laminates for Flexural Strengthening ............. 24

1.6.8 Stress in Reinforcing Steel Under Service Loads .................... 25

1.6.9 Stress in FRP Under Service Loads ............................... 25

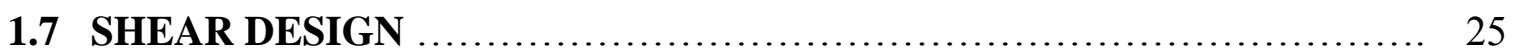

1.7.1 Wrapping Schemes .............................................. 26

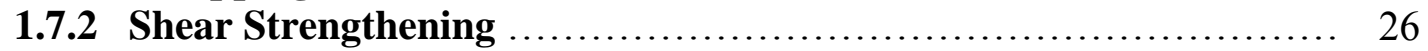

1.7.3 Concrete and Steel Shear Strength Contribution .................... 27

1.7.4 FRP Shear Strength Contribution ............................... 28

1.7.5 Effective Strain in FRP Shear Reinforcement ....................... 29

1.7.5.1 SECTIONS COMPLETELY WRAPPED .................... 29

1.7.5.2 SECTIONS NOT COMPLETELY WRAPPED ............... 29

1.7.6 Spacing Limits ................................................... 31

1.7.7 Reinforcement Limits ......................................... 31

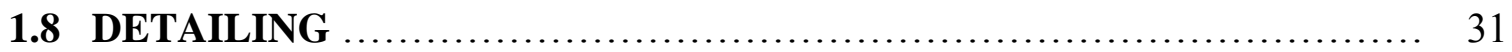

1.8.1 General Detailing Concerns .................................... 31

1.8.2 Prevention of FRP End Peeling ................................ 32

1.8.3 Development Length ........................................... 33

1.8.4 Laps and Splices ................................................ 34

1.9 EXAMPLE DESIGN PROBLEMS _.................................. 34

1.9.1 Flexural Strengthening of a Reinforced Concrete T-Beam with FRP Laminates ............................................. 34

1.9.2 Shear Strengthening of an Interior Reinforced Concrete T-Beam ... 42 


\subsection{GENERAL}

These design specifications are recommended for the repair of reinforced concrete Tbeam bridges using FRP. Sections 1.2 through 1.5 present general material and analysis considerations. Sections 1.6 through 1.8 lay out the design procedures. Prestressed components are not discussed in this document.

\subsection{DEFINITIONS}

AFRP - Aramid fiber-reinforced polymer.

CFRP - Carbon fiber-reinforced polymer (includes graphite fiber-reinforced polymer).

Creep-rupture - The gradual, time-dependent reduction of tensile strength due to continuous loading that leads to failure of the section.

Debonding - A separation at the interface between the substrate and the adherent material.

Delamination - A separation along a plane parallel to the surface, as in the separation of the layers of the FRP laminate from each other.

Epoxy - A thermosetting polymer that is the reaction product of epoxy resin and an amino hardener (see also Epoxy resin).

Epoxy Resin - A class of organic chemical-bonding system used in the preparation of special coating or adhesives for concrete and as binders in epoxy-resin mortars and concretes.

Fiber-reinforced Polymer (FRP) - A general term for a composite material that consists of a polymer matrix reinforced with cloth, mat, strands, or any other fiber form.

GFRP - Glass fiber-reinforced polymer.

Inside Corner - Corner such as that found on the inside of hollow rectangular members.

Outside Corner - Corner such as that found on the outside of a hollow rectangular member.

Ply - A single layer of fabric or mat; multiple plies, when molded together, make up the laminate.

Resin - Polymeric material that is rigid or semi rigid at room temperature, usually with a melting point or glass transition temperature above room temperature. 
Sheet, FRP - A dry, flexible ply used in wet lay-up FRP systems. Unidirectional FRP sheets consist of continuous fibers aligned in one direction and held together in-plane to create a ply of finite width and length. Fabrics are also referred to as sheets.

\subsection{NOTATION}

a $=$ depth of equivalent stress block, in.

$\mathrm{a}_{\mathrm{b}}=$ depth of equivalent rectangular stress block for balanced strain conditions, in.

$\mathrm{A}_{\mathrm{f}}=$ area of external FRP reinforcement, $\mathrm{nt}_{\mathrm{f}} \mathrm{W}_{\mathrm{f}}, \mathrm{in}^{2}$

$A_{\mathrm{fv}}=$ area of FRP shear reinforcement with spacing $\mathrm{s}$, in $^{2}$

$\mathrm{A}_{\mathrm{s}} \quad=$ area of steel tension reinforcement, in ${ }^{2}$

$\mathrm{A}_{\mathrm{s}} \mathrm{s}_{\mathrm{S}}=$ area of compression steel reinforcement, in ${ }^{2}$

$\mathrm{b} \quad=$ width of compression face of member, in.

$b_{\mathrm{w}}=$ web width, in.

c = distance from extreme compression fiber to neutral axis, in.

$\mathrm{C}_{\mathrm{E}}=$ environmental reduction factor

$\mathrm{d}=$ distance form extreme compression fiber to centroid of tension reinforcement, in.

d' = distance form extreme compression fiber to centroid of compression reinforcement, in.

$\mathrm{d}_{\mathrm{c}}=$ distance measured from extreme tension fiber to center of the closest bar or wire in inches. For calculation purposes, the thickness of clear concrete cover used to compute $d_{c}$ shall not be taken greater than 2 inches.

$\mathrm{d}_{\mathrm{f}}=$ distance form the extreme compression fiber to centroid of FRP reinforcement, in.

$\mathrm{d}_{\mathrm{fv}}=$ depth of FRP shear reinforcement, in.

$\mathrm{d}_{\mathrm{L}}=$ distance form the extreme compression fiber to the top of the lateral FRP plies, in.

$\mathrm{E}_{\mathrm{f}} \quad=$ tensile modulus of elasticity of FRP, psi

$\mathrm{E}_{\mathrm{c}} \quad=$ modulus of elasticity of concrete, $\mathrm{psi}$

$\mathrm{f}_{\mathrm{c}} \quad=$ specified compressive strength of concrete, psi

$\mathrm{f}_{\mathrm{f}} \quad=$ stress level in the FRP reinforcement, psi

$\mathrm{f}_{\mathrm{f}, \mathrm{s}} \quad=$ stress level in the FRP caused by a moment within the elastic range of the member, psi

$\mathrm{f}_{\mathrm{fe}} \quad=$ effective stress in the FRP; stress level attained at section failure, psi

$\mathrm{f}_{\mathrm{fu}}^{*}=$ ultimate tensile strength of the FRP material as reported by the manufacturer, psi

$\mathrm{f}_{\mathrm{fu}} \quad=$ design ultimate tensile strength of FRP, psi

$\mathrm{f}_{\mathrm{r}} \quad=$ modulus of rupture of concrete, $\mathrm{psi}$

$\mathrm{f}_{\mathrm{s}} \mathrm{s}=$ stress in compression reinforcement, $\mathrm{psi}$

$\mathrm{f}_{\mathrm{s}} \quad=$ tensile stress in nonprestressed steel reinforcement, psi

$\mathrm{f}_{\mathrm{s}, \mathrm{s}}=$ stress level in nonprestressed steel reinforcement at service loads, psi

$\mathrm{f}_{\mathrm{y}} \quad=$ specified yield strength of reinforcement, psi

$\mathrm{h}_{\mathrm{f}} \quad=$ compression flange thickness of $\mathrm{T}-$ sections, in.

$\mathrm{I}_{\mathrm{e}} \quad=$ effective moment of inertia for computation of deflection, in $^{4}$ 
$\mathrm{I}_{\mathrm{g}}=$ moment of inertia of the gross concrete section about the centroidal axis, neglecting reinforcement, in ${ }^{4}$

$\mathrm{k} \quad=$ ratio of the depth of the neutral axis to the reinforcement depth measured on the same side of the neutral axis

$\mathrm{k}_{1} \quad=$ modification factor applied to $\kappa_{\mathrm{v}}$ to account for the concrete strength

$\mathrm{k}_{2}=$ modification factor applied to $\kappa_{\mathrm{v}}$ to account for the wrapping scheme

$\mathrm{L}_{\mathrm{e}} \quad=$ active bond length of FRP laminate, in.

$\mathrm{M}_{\mathrm{a}}=$ maximum moment in member at stage for which deflection is being computed

$\mathrm{M}_{\mathrm{cr}}=$ cracking moment

$\mathrm{M}_{\mathrm{n}}$ = nominal moment strength of a section

$\mathrm{M}_{\mathrm{s}}=$ moment within the elastic range of the member, in-lb

$\mathrm{M}_{\mathrm{u}}=$ factored moment at the section under consideration

$\mathrm{n} \quad=$ number of plies of the FRP reinforcement

$\mathrm{n}_{\mathrm{f}} \quad=$ modular ratio of FRP to concrete

$\mathrm{n}_{\mathrm{s}} \quad=$ modular ratio of steel to concrete

$\mathrm{R}_{\mathrm{n}} \quad=$ nominal strength of a member

$\mathrm{S}_{\mathrm{DL}}=$ dead load effects

$\mathrm{s}_{\mathrm{f}} \quad=$ center-to-center spacing of FRP shear reinforcement, in.

$\mathrm{S}_{\mathrm{LL}}=$ live load effects

$\mathrm{t}_{\mathrm{f}} \quad=$ nominal thickness of one ply of the FRP reinforcement, in.

$\mathrm{V}_{\mathrm{c}}=$ nominal shear strength provided by the concrete with steel flexural reinforcement, $\mathrm{lb}$

$\mathrm{V}_{\mathrm{f}} \quad=$ nominal shear strength provided by the FRP stirrups, $1 \mathrm{~b}$

$\mathrm{V}_{\mathrm{n}} \quad=$ nominal shear strength, $\mathrm{lb}$

$\mathrm{V}_{\mathrm{s}} \quad=$ nominal shear strength provided by the steel stirrups, $\mathrm{lb}$

$\mathrm{V}_{\mathrm{u}}=$ factored shear force at the section under consideration

$\mathrm{w}_{\mathrm{f}} \quad=$ width of FRP reinforcing plies, in.

$\mathrm{y}_{\mathrm{t}}=$ distance form the centroidal axis of the gross section, neglecting reinforcement, to extreme fiber in tension

$\alpha \quad=$ angle between inclined shear reinforcement and longitudinal axis of the member

$\alpha_{\mathrm{L}}=$ longitudinal coefficient of thermal expansion, in $/ \mathrm{in} /{ }^{\circ} \mathrm{F}$

$\beta_{1} \quad=$ ratio of depth of equivalent compression zone to depth from extreme compression fiber to the neutral axis

$\varepsilon_{\mathrm{bi}}=$ strain level in the concrete substrate at the time of the FRP installation, in/in

$\varepsilon_{\mathrm{cu}}=$ maximum usable compressive strain of concrete, in/in

$\varepsilon_{\mathrm{fe}} \quad=$ effective strain level in FRP reinforcement; strain level attained at section failure, in/in

$\varepsilon_{\mathrm{fu}}=$ design rupture strain of FRP reinforcement, in/in

$\varepsilon_{\mathrm{fu}}^{*}=$ ultimate rupture strain of the FRP reinforcement, in/in

$\varepsilon_{\mathrm{s}} \quad=$ strain level in the nonprestressed tension steel reinforcement, in/in

$\varepsilon_{\mathrm{s}}^{\prime}=$ strain level in the compression steel reinforcement, in/in

$\Phi=$ strength reduction factor

$\gamma=$ multiplier for $\mathrm{f}^{\prime}{ }_{\mathrm{c}}$ to determine the intensity of an equivalent rectangular stress distribution for concrete

$\kappa_{\mathrm{m}} \quad=$ bond-dependent coefficient for flexure

$\kappa_{\mathrm{V}} \quad=$ bond-dependent coefficient for shear 
$\rho_{\mathrm{f}} \quad=$ FRP reinforcement ratio

$\rho_{\mathrm{s}} \quad=$ steel reinforcement ratio

$\Psi_{\mathrm{f}} \quad=$ additional FRP strength reduction factor

\subsection{MATERIAL}

\subsubsection{General}

Materials to be considered in designing an FRP system for strengthening reinforced concrete components consist of the concrete, whether it be the existing or the replacement material, and all materials comprising the FRP system.

\subsubsection{Concrete}

\section{C1.4.2}

The substrate material for the application of the proposed FRP system should be of sound quality such that the FRP system will be allowed to perform as intended. The substrate material shall be prepared in a way that conforms to ICRI 03730 and/or the construction specifications.

\subsubsection{FRP System}

\section{C1.4.3}

Materials comprising the FRP repair system include fibers and all resins such as primers, putties, saturants, and adhesives. Brief descriptions of these FRP materials are given in Sections 1.4.3.1 - 1.4.3.5. The design engineer should consult with the FRP system manufacturer for more detailed aspects of these materials and the importance of these aspects in design.

The plans should include type of fiber, type of resin, tensile strength, $f_{\text {fu }}$, modulus of elasticity, $\mathrm{E}_{\mathrm{f}}$, and ultimate strain, $\varepsilon_{\mathrm{fu}}$. FRP reinforcement shall conform to the specifications of ACI 440.3R-04.

In order for the FRP system to achieve its design objectives, it is imperative that a clean and sound substrate is prepared. Important considerations to consider are the quality and strength of the patch material, as well as its bond with the existing concrete.

All constituent materials used in FRP systems have been developed for the strengthening of structural concrete members through material and structural testing. The characteristics of an FRP material are greatly influenced by aspects such as fiber volume, type of fiber, type of resin, fiber orientation, and quality control during the manufacture process.

The most widely used forms of FRP system include wet layup, precured, and near-surface mounted (NSM) systems. 


\subsubsection{FIBERS}

FRP systems commonly incorporate the use of continuous glass, aramid, and carbon fibers. Fibers provide the FRP system with its strength and stiffness. ACI 440R can be referenced for a more detailed discussion of fibers.

\subsubsection{RESINS}

An extensive range of polymeric resins are used with FRP systems. These resins include primers, saturants, adhesives, and putty fillers as described herein. Frequently used resin types such as epoxy, vinyl esters, and polyesters have been formulated for use in many different environments.

Primer - Primer penetrates the surface of the substrate concrete and provides an improved bond for the saturating adhesive.

Saturants - Saturants are used to impregnate the fibers so as to provide a shear load path for the effective transfer of load between fibers. The saturant is also used as the adhesive for wet layup systems and as a result provides the shear load path between the concrete and the FRP.

Adhesive - Adhesives are used for bonding precured FRP laminates and NSM systems. A shear load path is created. Adhesives are also used if it is necessary to bond multiple layers of precured FRP laminates.

Putty fillers - The use of putty is necessary to fill small surface voids in the concrete substrate and to provide a smooth surface for the FRP system.

\section{C1.4.3.2}

Resins are broken into two broad categories: thermoset and thermoplastic. Thermoplastic resins are normally solid in their initial form and may be shaped or molded while in a heated semi-fluid state. Thermosetting resins are closer to a liquid form in their initial state and are more commonly used in the composites industry. Thermosetting resins are cured with a catalyst, heat, or a combination of the two. Once formed, they cannot be reshaped. The softening of a cured resin can be determined by the measurement of a heat distortion temperature and a glass transition temperature. Epoxy, vinyl esters, and polyesters are common types of thermosetting resins used. For a more informative discussion on various types of resins, refer to ACI 440R. 


\subsection{ANALYSIS}

\subsubsection{General}

In order to design an FRP system to achieve a desired capacity, the existing capacity of the member considered needs to be determined in accordance with acceptable engineering principals. A load rating analysis may be used to assess the existing and desired structural capacity. The increase in structural capacity can be determined with the goal of reaching a desirable load rating factor. With an existing and required capacity established, the FRP strengthening system can be designed.

A realistic representation of the bridge's material strength and geometric properties is necessary to accurately determine the bridge's existing structural capacity. If available, documentation of the original material properties and any drawings should be used. In absence of original documentation, material strength values are suggested by AASHTO for unknown material properties in the Manual for Condition Evaluation of Bridges in accordance with the year a structure was built. As a more reliable alternative, AASHTO guidelines allow for the use of experimental values when available.

\subsubsection{Concrete Material Properties}

For all relevant material properties for concrete structures refer to Article 5.4.

\subsubsection{FRP System Material Properties}

\subsubsection{GENERAL}

Relevant material properties are presented in this section. Included, is a section for thermal expansion, general tensile and compressive behavior, and design material properties.

\section{C1.5.1}

The repair process should be analyzed in an effort to achieve the most efficient design possible. FRP composite strengthening systems shall be designed to increase the flexural capacity, shear capacity, axial capacity, and ductility, or any combination thereof.

It has been found that there are several failure modes controlling the ultimate strength in concrete beams strengthened with FRP laminates. These failure modes consist of the following:

- Crushing of the concrete in compression before yielding of the reinforcing steel;

- Yielding of the steel in tension which is followed by rupture of the FRP laminate;

- Yielding of the steel in tension which is followed by concrete crushing;

- Delamination of the concrete cover due to shear or tension; and

- FRP debonding from the concrete substrate

\section{C1.5.3.1}

Factors such as loading history and duration, temperature, and moisture affect the properties of FRP material. The physical and mechanical properties discussed are the most relevant for concrete structure rehabilitation. 


\subsubsection{EXPANSION AND CONTRACTION}

The manufacturer shall supply the coefficient of thermal expansion and contraction. Typical values for coefficients of thermal expansion for FRP materials are presented in ACI 440.2R-08 and are reprinted in Table $1.5-1$.

Table 1.5 - 1 - Typical Coefficients of Thermal Expansion for FRP Materials

\begin{tabular}{|c|c|c|c|}
\hline \multirow{2}{*}{ Direction } & \multicolumn{3}{|c|}{$\begin{array}{c}\text { Coefficient of thermal expansion, } \times 10^{-6} /{ }^{\circ} \mathrm{F} \\
\left(\times 10^{-6} /{ }^{\circ} \mathrm{C}\right)\end{array}$} \\
\cline { 2 - 4 } & GFRP & CFRP & AFRP \\
\hline $\begin{array}{c}\text { Longitudinal, } \\
\alpha_{\mathrm{L}}\end{array}$ & $\begin{array}{c}3.3 \text { to } 5.6 \\
(6 \text { to } 10)\end{array}$ & $\begin{array}{c}-0.6 \text { to } 0 \\
(-1 \text { to } 0)\end{array}$ & $\begin{array}{c}-3.3 \text { to }-1.1 \\
(-6 \text { to }-2)\end{array}$ \\
\hline $\begin{array}{c}\text { Transverse, } \\
\text { aL }\end{array}$ & $\begin{array}{c}10.4 \text { to } \\
12.6 \\
(19 \text { to } 23)\end{array}$ & $\begin{array}{c}12 \text { to } 27 \\
(22 \text { to } 50)\end{array}$ & $\begin{array}{c}33 \text { to } 44 \\
(60 \text { to } 80)\end{array}$ \\
\hline
\end{tabular}

Note that negative values of coefficients of thermal expansion indicate that the material contracts with increased temperature and expands with decreased temperatures.

\subsubsection{TENSILE AND COMPRESSIVE BEHAVIOR}

With respect to mechanical properties, the tensile behavior of FRP materials should be very well understood. Under direct tension, unidirectional FRP materials do not display any yielding before rupture. Therefore, FRP consisting of one type of fiber will exhibit a linear elastic stress-strain relationship until failure. This results in a sudden and brittle failure which should be avoided in design.

Insufficient testing has been performed to permit the use of externally bonded FRP systems for compression reinforcement. Compression strength of externally bonded FRP shall be omitted in design.

\section{C1.5.3.2}

Unidirectional FRP materials have differing coefficients of thermal expansion in the longitudinal and transverse directions. Thermal expansion properties will depend on the types of fiber, resin, and volume fraction of fiber.

Often, thermal expansion properties of the fiber and polymer constituents will vary and be different from that of concrete. Polymers used in FRP strengthening systems normally have coefficients of thermal expansion nearly five times that of concrete. It has been shown (Motavalli et al. 1997; Soudki and Green 1997; Green et al. 1998) that although there are great thermal expansion differences in materials, the effect is not significant for small ranges of temperature change, within $\pm 50{ }^{\circ} \mathrm{F}$ $\left( \pm 28^{\circ} \mathrm{C}\right)$.

\section{C1.5.3.3}

The fiber in an FRP system is the main load-carrying material. Therefore, the tensile strength and stiffness of a system are strongly dependant on fiber type, fiber orientation, and fiber quantity. Due to this significant role of fibers, FRP system properties are often reported based on net-fiber area. Alternatively, and used with precured systems, properties can be reported based on grosslaminate area.

Mechanical properties of FRP systems should be based on testing of laminate samples with known fiber content. The FRP system manufacturer shall supply the tensile properties of any particular FRP system. 


\subsubsection{DESIGN MATERIAL PROPERTIES}

Material properties reported by manufacturers, such as the ultimate tensile strength, should typically be considered as initial properties; as they do not account for long term exposure to environmental conditions. Long term exposure to various environmental conditions can lead to decreases in tensile property values and creep-rupture and fatigue endurance of laminates. As a result, the material properties that are to be used in design should be adjusted to account for the environmental exposure condition. Equations (1-1) through (1-3) should be used to obtain tensile properties to be used in all design equations.

$$
\begin{aligned}
& f_{f u}=C_{E} f_{f u}^{*} \\
& \varepsilon_{f u}=C_{E} \varepsilon_{f u}{ }^{*} \\
& E_{f}=\frac{f_{f u}}{\varepsilon_{f u}}
\end{aligned}
$$

Table 1.5 - 2 - Environmental Reduction Factors for Various FRP Systems and Exposure Conditions

\begin{tabular}{|c|c|c|}
\hline \multirow{2}{*}{$\begin{array}{c}\text { Exposure } \\
\text { Conditions }\end{array}$} & $\begin{array}{c}\text { Fiber and } \\
\text { Resin Type }\end{array}$ & $\begin{array}{c}\text { Environmental } \\
\text { Reduction } \\
\text { Factor } \mathrm{C}_{\mathrm{E}}\end{array}$ \\
\hline \multirow{2}{*}{$\begin{array}{c}\text { Interior } \\
\text { Exposure }\end{array}$} & Carbon/epoxy & 0.95 \\
\cline { 2 - 3 } & Glass/epoxy & 0.75 \\
\cline { 2 - 3 } & Aramid/epoxy & 0.85 \\
\hline $\begin{array}{c}\text { Exterior } \\
\text { Exposure } \\
\text { (bridges, piers, } \\
\text { and unenclosed } \\
\text { parking } \\
\text { garages) }\end{array}$ & Carbon/epoxy & 0.85 \\
\cline { 2 - 3 } & Glass/epoxy & 0.65 \\
\hline $\begin{array}{c}\text { Aggressive } \\
\text { Environment } \\
\text { (chemical } \\
\text { plants and } \\
\text { waste water }\end{array}$ & Aramid/epoxy & 0.75 \\
\cline { 2 - 3 } & Garbon/epoxy & 0.85 \\
\cline { 2 - 3 } & Aramid/epoxy & 0.50 \\
\hline
\end{tabular}

\section{C1.5.3.4}

Due to the linear elastic nature until failure for unidirectional FRP materials, Hooke's law can simply be used to determine the design modulus of elasticity. Due to the use of the same reduction factor, the modulus is typically unaffected by environmental conditions.

Test data for the durability of FRP systems with and without protective coatings can be obtained from the manufacturer of the FRP system when and if they become available. 
treatment plants)

$\mathrm{C}_{\mathrm{E}}$ is the reduction factor and can be found from Table $1.5-2$. The reduction factor can be altered to reflect the use of protective coatings only if it has been demonstrated through testing that the coating reduces the effects of environmental exposure and the coating is maintained throughout the life of the FRP system.

\subsection{FLEXURAL DESIGN}

\subsubsection{Design Method}

1.6.1.1 - FRP strengthening systems should be designed to withstand tensile forces while maintaining strain compatibility between the FRP and the concrete substrate.

1.6.1.2 - FRP systems should not be relied on to withstand compression forces, although it is acceptable to introduce compression forces to an FRP strengthening system due to moment reversals and points of contra-flexure.

1.6.1.3 - Limit-states design principles are used that set acceptable levels of safety for the occurrence of both serviceability limit states and ultimate limit states.

1.6.1.4 - In evaluating the nominal strength of a member, the possible failure modes and corresponding strains and stresses in each material should be assessed.

1.6.1.5 - Engineering principles such as modular ratios and transformed sections can be used when evaluating the serviceability of a member.

\subsubsection{6 - ACI 318-08 strength and} serviceability requirements should be adhered to along with implementing additional reduction factors to the FRP contribution.

\section{C1.6.1}

Strain compatibility should be satisfied in the design method, meaning that the strain across the depth of the section follows a linear distribution as illustrated in Figure 1.6-1. The calculation procedure should consider the governing mode of failure and satisfy force equilibrium.

Transformed sections incorporating the use of modular ratios for the evaluation of serviceability provides a way to visualize and organize the calculations. The method consists of transforming the cross section of a composite beam into an equivalent cross section of an imaginary beam that is composed of only one material.

The additional reduction factor that is implemented for the FRP contribution is presented in Section 1.6.4.1. It helps to account for the varying failure modes experimentally seen for FRP strengthened members and improves the reliability of the strength prediction. The reduction factor was developed based on experimentally calibrated statistical properties of the flexural strength (Okeil et al. 2007). 


\subsubsection{Assumptions}

As with any design, assumptions are made in order to decrease the computational efforts down to a practical matter. This section presents the assumptions used in FRP strengthening design.

1.6.2.1 - Calculations are based on actual dimensions, material properties, and arrangement and type of internal reinforcement for the existing member that is to be strengthened.

1.6.2.2 - The maximum usable compressive strain in the concrete is 0.003 .

1.6.2.3 - The strains in the concrete and reinforcement are directly proportional to their distances from the neutral axis of the member.

1.6.2.4 - Tensile strength of concrete is neglected.

1.6.2.5 - Shear deformation within the adhesive layer is neglected noting that the adhesive layer is very thin with only slight variations in thickness.

1.6.2.6 - There is no relative slip between the concrete and the externally bonded composites.

1.6.2.7 - FRP reinforcement has a linear elastic stress-strain relationship to failure.

1.6.2.8 - The concrete compressive stress/strain distribution can be taken as any shape that results in strength predictions within agreement of testing data. Most often, a rectangular stress/strain block will be used.

1.6.2.9 - The parameters $\alpha_{1}$ and $\beta_{1}$ are used to define a rectangular stress block equivalent to the nonlinear distribution of concrete stress.

\section{C1.6.2}

Much of the assumptions are necessary for the sake of computational ease and do not perfectly portray the exact fundamental behavior of FRP flexural reinforcement. Although the assumptions are not completely accurate, the computed flexural strength of a strengthened member will not be significantly affected. 
$\alpha_{1}$ and $\beta_{1}$ should be taken as the values associated with the Whitney stress block, where $\alpha_{1}$ is equal to 0.85 and $\beta_{1}$ can be taken as 0.85 for $\mathrm{f}_{\mathrm{c}}{ }^{\prime} \leq 4,000 \mathrm{psi} ; 0.80$ for $\mathrm{f}_{\mathrm{c}}{ }^{\prime}=5,000$ psi ; 0.75 for $f_{c}{ }^{\prime} \leq 6,000$ psi $; 0.70$ for $f_{c}{ }^{\prime} \leq$ 7,000 psi ; 0.65 for $\mathrm{f}_{\mathrm{c}} \geq 8,000$ psi. Note that this approach will give good results if concrete crushing is the controlling mode of failure. If FRP rupture, cover delamination, or FRP debonding is the mode of failure, the approach will still yield reasonably accurate results.

\subsubsection{Strengthening Limits}

Strengthening limits should be imposed to guard against collapse of the structure if failure of the FRP system would occur due to damage, vandalism, or any other causes.

1.6.3.1 - The existing strength of the structure should be adequate to resist a level load as given by equation (1-4).

$$
\left(\Phi R_{n}\right)_{\text {existing }} \geq\left(1.1 S_{D L}+0.75 S_{L L}\right)_{\text {new }}
$$

1.6.3.2 - If the member to be strengthened has a high likelihood of being subjected to a live load that is present for a sustained period of time, a live load factor of 1.0 should be used in equation (1-4) instead of 0.75 .

1.6.3.3 - All members of a structure should be adequate to withstand the anticipated increase in loads that is associated with the strengthened members.

\subsubsection{Flexural Strengthening}

Flexural strengthening is achieved by bonding FRP reinforcement to the tension face of flexural members. The FRP is bonded so that the fibers are oriented along the longitudinal length of the member. Strength increases of up to $40 \%$ are reasonable when strengthening limits are imposed.

\section{C1.6.3}

Careful consideration should be given to strengthening limits. It is possible to obtain an accurate evaluation of existing dead loads on a structure, and therefore, a number close to unity, such as 1.1, is used for the dead load factor. As reported in ACI 440.2R-08 and taken from ASCE 7-05, a live load factor of 0.75 is incorporated to exceed the statistical mean of annual maximum live load factors set at 0.5 .

Examples where a live load factor of 1.0 may be used instead of 0.75 can include any area along a bridge that may be used as a heavy storage area for any period of time.

Special care should be taken to see that all components of the structure can withstand the anticipated future loading. Increasing primary member capacities without a full analysis of remaining components can prove disastrous. 


\subsubsection{NOMINAL STRENGTH}

1.6.4.1.1 - The strength design approach is used. This requires that the design flexural strength (nominal flexural strength, $M_{n}$ multiplied by a reduction factor, $\Phi)$ exceeds it required factored moment $\left(\mathrm{M}_{\mathrm{u}}\right)$ as indicated in equation (1-5).

$\Phi M_{n} \geq M_{u}$

1.6.4.1.2 - To maintain an adequate degree of ductility, the strain level in the steel at the ultimate limit state should be checked. The strength reduction factor, $\Phi$ should be determined with reference to this strain level by using equation (1-6). $\quad \varepsilon_{t}$ is the net tensile strain in the extreme tension steel at nominal strength.

$\Phi=\left\{\begin{array}{c}0.90 \text { for } \varepsilon_{t} \geq 0.005 \\ 0.65+\frac{0.25\left(\varepsilon_{t}-\varepsilon_{s y}\right)}{0.005-\varepsilon_{s y}} \quad \text { for } \varepsilon_{s y}<\varepsilon_{t}<0.005 \\ 0.65 \text { for } \varepsilon_{t} \leq \varepsilon_{s y}\end{array}\right.$

1.6.4.1.3 - An additional reduction factor $\psi_{\mathrm{f}}$ is applied to the FRP strength contribution. The recommended value of $\psi_{\mathrm{f}}$ is 0.85 .

\subsubsection{INITIAL SUBSTRATE STRAIN}

The substrate to which the FRP reinforcement is to be bonded will have an already existing strain due to self-weight and any sustained loads that may be present. These strains should be excluded from the strain in the FRP. An elastic analysis, considering all loads on the structure during application, can be used to determine the initial strain level on the bonded substrate $\left(\varepsilon_{\mathrm{bi}}\right)$ for a given member. The elastic analysis should be based on cracked section properties.

\section{C1.6.4.1}

Load factors in correspondence with ACI 318-05 are used in calculating the factored moment, $\mathrm{M}_{\mathrm{u}}$.

Using externally bonded FRP to strengthen concrete members will often result in a reduction of the original ductility. Significant losses in ductility should be carefully evaluated. Adequate ductility should be maintained through careful consideration of strain levels in the reinforcing steel. The strain level in the steel, $\varepsilon_{t}$, should be at least 0.005 in order for adequate ductility to be achieved. This is in accordance with the definition of a tension-controlled section as specified in ACI 318-05. Equation (1-6) is represented graphically in Figure C1.6-1.

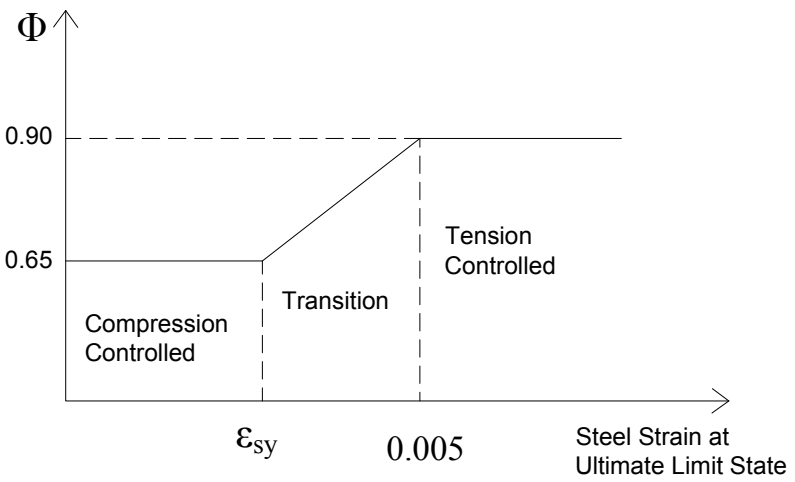

Figure C1.6-1 - Graphical Representation of Strength Reduction Factor

\section{C1.6.4.2}

The elastic analysis approach used based on cracked section properties neglects any contribution of tension-zone concrete to the stiffness of the cross section. The moment of inertia of the cracked section, $\mathrm{I}_{\mathrm{cr}}$, shall be determined from the basic principles of mechanics.

With reference to Figure $\mathrm{C} 1.6-2$ and the accompanying discussion, the determination of the cracked section moment of inertia, $\mathrm{I}_{\mathrm{cr}}$, and therefore the initial substrate strain, $\varepsilon_{\mathrm{bi}}$, can be made. 


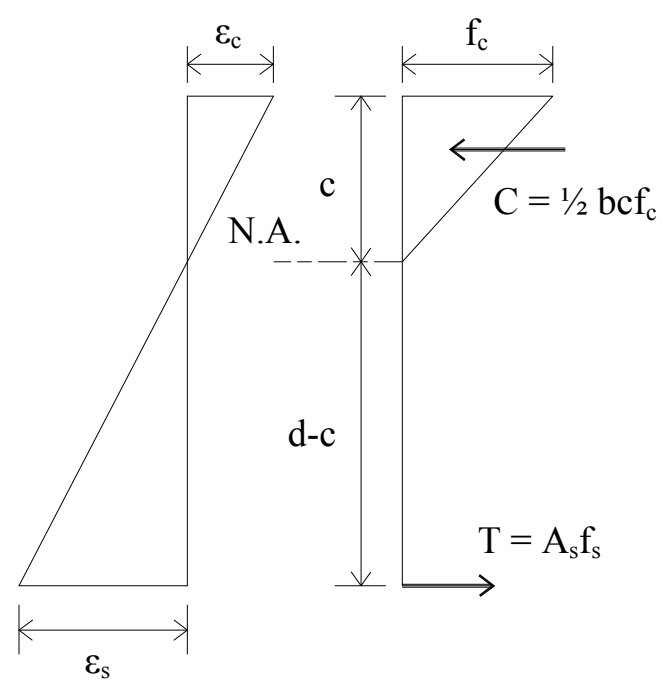

Figure C1.6-2 - Elastic Strain and Stress Across a Cracked RC Section

Horizontal force equilibrium should be used to calculate the moment of inertia.

$$
\begin{gathered}
A_{s} f_{s}=\frac{1}{2} b c f_{c} \\
f_{s}=E_{s} \varepsilon_{s} \\
f_{c}=E_{c} \varepsilon_{c}
\end{gathered}
$$

Therefore, force equilibrium can be rewritten as follows:

$$
A_{s} E_{s} \varepsilon_{s}=\frac{b c}{2} E_{c} \varepsilon_{c}
$$

By using similar triangles, we can obtain

$$
\frac{\varepsilon_{c}}{c}=\frac{\varepsilon_{s}}{d-c} \Rightarrow \varepsilon_{s}=\varepsilon_{c}\left(\frac{d}{c}-1\right)
$$

And therefore force equilibrium may be written as follows:

$$
A_{s} E_{s} \varepsilon_{c}\left(\frac{d}{c}-1\right)=\frac{b c}{2} E_{c} \varepsilon_{c} \Rightarrow \frac{A_{s} E_{s}}{E_{c}}\left(\frac{d}{c}-1\right)=\frac{b c}{2}
$$


Replacing the modular ratio, $\mathrm{E}_{\mathrm{s}} / \mathrm{E}_{\mathrm{c}}$, with $\mathrm{n}$, the force equilibrium equation can further be written as,

$$
\frac{b c^{2}}{2}+n A_{s} c-n A_{s} d=0
$$

The quadratic equation can then be solved to determine the location of the neutral axis, c. Once $\mathrm{c}$ is found, the moment of inertia and the initial substrate strain can be found from the following two equations. It should be noted that the equation for the moment of inertia is in general for rectangular sections. Therefore, in a T-beam analysis, if the value $\mathrm{c}$ is found to be greater than the flange thickness, the equation should be altered slightly to account for the changing value of $b$ as the concrete compression zone changes from flange to web.

$$
\begin{gathered}
I_{c r}=\frac{b c^{3}}{3}+n A_{s}(d-c)^{2} \\
\varepsilon_{b i}=\frac{M_{D L}(h-c)}{I_{c r} E_{c}}
\end{gathered}
$$

\subsubsection{FRP REINFORCEMENT STRAIN} AND STRESS

1.6.4.3.1 - The strain level in the FRP reinforcement at the ultimate limit state must be determined. FRP materials are linear elastic until failure and therefore the strain will directly dictate the stress level developed.

1.6.4.3.2 - The maximum strain level developed within the FRP will be that which occurs during concrete crushing, FRP rupture, or FRP debonding. This effective strain level can be determined from equation (1-7).

\section{C1.6.4.3}

$\varepsilon_{f d}$ in Equation (1-7) is the strain level at which debonding will occur and is determined in accordance with Section 1.6.4.6.4. Therefore, if the second expression in Equation (1-7) governs, FRP debonding will be the failure mode, otherwise if the first expression governs; concrete crushing would be in the failure mode. If it is found that FRP does control the failure of the section, the concrete strain at failure, $\varepsilon_{c}$, may be less than 0.003 and can be calculated using similar triangles as presented in Equation (1-13). 
$\varepsilon_{f e}=\varepsilon_{c u}\left(\frac{d_{f}-c}{c}\right)-\varepsilon_{b i} \leq \varepsilon_{f d}$

1.6.4.3.3 - The maximum stress level developed within the FRP at failure can be found from the corresponding strain level. Equation (1-8) can be used to determine this effective stress level.

$f_{f e}=E_{f} \varepsilon_{f e}$

\subsubsection{SERVICEABILITY}

1.6.4.4.1 - The serviceability of a bridge member under service loads should satisfy AASHTO specifications. The transformedsection analysis can be used to assess the FRP external reinforcement on the serviceability of a member.

1.6.4.4.2 - The existing internal steel reinforcement should be prevented from yielding under service loads in order to avoid inelastic deformations of reinforced concrete members.

1.6.4.4.3 - The stress in the internal steel under service loads should be limited to $80 \%$ of its yield strength as shown in equation (1-9).

1.6.4.4.4 - The compressive stress in the concrete under service loading should be limited to $45 \%$ of the compressive strength as shown in equation (1-10).

$f_{s, s} \leq 0.80 f_{y}$

$f_{c, s} \leq 0.45 f_{c}^{\prime}$

\subsubsection{CREEP-RUPTURE AND FATIGUE STRESS}

Creep-rupture of the FRP reinforcement under sustained stresses and fatigue failure of the FRP due to cyclic stresses should be of

C1.6.4.4

The procedure for applying a transformedsection analysis is presented in Section C1.6.4.2.

\section{C1.6.4.5}

Creep-rupture is a type of failure in which a material is subjected to a constant load for such a time period known as the endurance 
great concern. The stress levels associated with these stress conditions, if present, should be checked. This section presents information to avoid these types of failure.

1.6.4.5.1 - To avoid failure of an FRP reinforced member due to creep-rupture and fatigue of the FRP, stress limits are imposed on the FRP reinforcement.

1.6.4.5.2 - The stress level in the FRP reinforcement can be found using an elastic analysis incorporating an applied moment due to all sustained loads plus the maximum moment induced in a fatigue loading cycle.

1.6.4.5.3 - The sustained stress should be limited as expressed by equation (1-11), where values of sustained plus cyclic stress limits are given in Table $1.6-1$.

$f_{f, s} \leq$ sustained plus cyclic stress limit

Table 1.6 - 1 - Sustained plus Cyclic Service Load Stress

$\begin{array}{cccc}\text { Stress Type } & \text { GFRP } & \begin{array}{c}\text { Fiber Type } \\ \text { AFRP }\end{array} & \text { CFRP } \\ \begin{array}{c}\text { Sustained plus } \\ \text { cyclic stress limit }\end{array} & 0.20 f_{f u} & 0.30 f_{f u} & 0.55 f_{f u}\end{array}$

\subsubsection{FAILURE MODES}

1.6.4.6.1 - The controlling failure mode will govern the strength of a section. For a section strengthened with FRP, the following flexural failure modes, as listed in by ACI 440, should be investigated:

- Crushing of the concrete before yielding of the reinforcing steel

- Yielding of the steel in tension followed by rupture of the FRP time. It is when this endurance time has been reached, that the material can suddenly fail. Harsh environmental conditions, such as high temperatures, ultraviolet-radiation, and freeze thaw cycles, may decrease this endurance time. The most common type of FRP used for concrete rehabilitation, CFRP, is the most resistant to creep-rupture failure. The strength of the FRP is available for nonsustained loads if the sustained stress is kept below the creeprupture stress limit.

As with creep-rupture, CFRP is the least susceptible to fatigue failure as well. With CFRP, an endurance limit of 60 to $70 \%$ of the initial static ultimate strength can be expected. This is in part due to the fact that CFRP is fairly unaltered by the moisture and temperature exposures of concrete structures unless environmental degradation of the fiber/resin interface is extensive.

\section{C1.6.4.6}

The best fit coefficient of 0.083 in Equation (1-12) was developed by ACI Committee 440. The development resulted after assessing a significant data set of flexural beam tests focusing on FRP debonding failure. The reliability of Equation (1-12) to accurately portray FRP contribution to flexural strength is considered by imposing an additional strength reduction factor for FRP, $\psi_{\mathrm{f}}$, as introduced in Section 1.6.4.1. 
laminate

- Yielding of the steel in tension followed by concrete crushing

- Shear/tension delamination of the concrete cover

- Debonding of the FRP from the concrete substrate

1.6.4.6.2 - Rupture of the externally bonded FRP is assumed to occur if the strain in the FRP reaches its design rupture strain $\left(\varepsilon_{\mathrm{f}}=\varepsilon_{\mathrm{fu}}\right)$ before the concrete reaches its maximum usable strain $\left(\varepsilon_{\mathrm{c}}=\varepsilon_{\mathrm{cu}}=0.003\right)$.

1.6.4.6.3 - If the force within the FRP is too great to be sustained by the concrete substrate, cover delamination or FRP debonding can occur.

1.6.4.6.4 - To prevent the occurrence of a debonding failure mode, the effective strain developed within the FRP should be limited to the strain level at which debonding can occur, $\varepsilon_{f d}$. This limitation is defined in equation (112).

$\varepsilon_{f d}=0.083 \sqrt{\frac{f_{c}^{\prime}}{n E_{f} t_{f}}} \leq 0.9 \varepsilon_{f u}$ in in.-lb units

$\varepsilon_{f d}=0.41 \sqrt{\frac{f_{c}^{\prime}}{n E_{f} t_{f}}} \leq 0.9 \varepsilon_{f u} \quad$ in SI units

In equation (1-12), $\mathrm{n}$ is the number of plies at the location along the length of the member where the flexural strength is being computed.

\subsubsection{Method of Solution}

Strain compatibility and force equilibrium should be satisfied when calculating the ultimate strength of a member reinforced with externally bonded composites. The calculation procedure should also consider the governing
It is possible to improve the bond behavior in comparison to that determined by Equation (1-12) by use of transverse clamping as per procedure presented in Section 1.8.2. 
mode of failure. More than one calculation procedure can be derived to meet these conditions. A trial-and-error method is presented in this section.

In the trial-and-error procedure, an assumed depth to the neutral axis $\mathrm{c}$ is selected. Then, the strain level in each material is calculated using strain compatibility. With this strain, the corresponding stress levels are calculated and force equilibrium is checked. It these internal force resultants do not equilibrate, the neutral axis depth $\mathrm{c}$ is revised and the procedure is repeated.

\subsubsection{STEP 1 - Preliminary Calculations}

Before the trial-and-error procedure can be performed, some preliminary calculations need to be performed to obtain required information. These preliminary calculations include the following:

- Calculate FRP system design material properties using the provisions of Article 1.5.3.4.

- $f_{f u}=C_{E} f_{f u}^{*}$

- $\varepsilon_{f u}=C_{E} \varepsilon_{f u}{ }^{*}$

- Determine properties of the concrete, the existing reinforcing steel, and FRP.

- Concrete $-\beta_{1}$ (Article 1.6.2.9), $\mathrm{E}_{\mathrm{c}}$ $\left(57,000 \sqrt{f_{c}^{\prime}}\right)$

- Area of reinforcing steel $-\mathrm{A}_{\mathrm{s}}$

- Area of external bonded FRP reinforcement - $\mathrm{A}_{\mathrm{f}}$

- Determine the initial substrate strain as explained in Article 1.6.4.2.

- Determine the design strain of the FRP system accounting for debonding failure using equation (1-12). Least value controls. 
$\varepsilon_{f d}=0.083 \sqrt{\frac{f_{c}^{\prime}}{n E_{f} t_{f}}} \leq 0.9 \varepsilon_{f u} \quad$ in in.-lb units

$\varepsilon_{f d}=0.41 \sqrt{\frac{f_{c}^{\prime}}{n E_{f} t_{f}}} \leq 0.9 \varepsilon_{f u} \quad$ in SI units

1.6.5.2 STEP 2 - Estimate the depth to the neutral axis, $\mathrm{c}$

A reasonable first estimate can be taken as $0.20 \mathrm{~d}$.

1.6.5.3 STEP 3 - Calculate material strains

- Effective strain level in the FRP equation (1-7)

$\varepsilon_{f e}=\varepsilon_{c u}\left(\frac{d_{f}-c}{c}\right)-\varepsilon_{b i} \leq \varepsilon_{f d}$

The controlling term in equation (1-7) signifies the controlling failure mode. If the first term controls, concrete crushing is the controlling failure mode; whereas if the second term controls, FRP rupture or debonding is the controlling failure mode.

If concrete crushing controls, the concrete strain is the maximum usable strain at 0.003 . Otherwise, FRP failure controls and the concrete strain may be found using similar triangles as set in equation (1-13).

$\varepsilon_{c}=\left(\varepsilon_{f e}+\varepsilon_{b i}\right)\left(\frac{c}{d_{f}-c}\right)$

- Strain in the existing reinforcing steel

This strain level can be found based off the strain level found in the FRP reinforcement using strain compatibility. Equation (1-14) provides this strain. 


$$
\varepsilon_{s}=\left(\varepsilon_{f e}+\varepsilon_{b i}\right)\left(\frac{d-c}{d_{f}-c}\right)
$$

1.6.5.4 STEP 4 - Calculate stresses in the reinforcing steel and FRP

Equation (1-8) of Article 1.6.4.3.3 can be used to find the effective stress in the FRP reinforcement.

$$
f_{f e}=E_{f} \mathcal{E}_{f e}
$$

Equation (1-15) can be used to calculate the stress in the reinforcing steel.

$f_{s}=E_{s} \varepsilon_{s} \leq f_{y}$

1.6.5.5 STEP 5 - Determine internal force resultants and check equilibrium

For T-beam analysis, two cases can occur. The depth of the rectangular stress block can be less than the flange thickness, in which the analysis is performed in the same manner as with a rectangular section. If the depth of the rectangular stress block (a) is greater than the flange thickness, the analysis has to account for it and hence, different equations are derived. In the following sections, equations are presented for each case that may be encountered. If force equilibrium is not satisfied for a given case, a different $\mathrm{c}$ value will be chosen and STEP 2 through STEP 5 should be repeated until force equilibrium is achieved.

1.6.5.6 STEP 6 - Compute nominal moment strength, $M_{n}$

With convergence on the correct neutral axis depth from STEP 5, the nominal moment strength can be calculated. As with the force 
equilibrium check, the equations used for the nominal moment strength are dependent on the analysis situation. These equations are presented in the following sections for each situation to be considered.

\subsubsection{Tension Reinforcement Steel Only in Strengthened Section}

\subsubsection{DEPTH OF STESS BLOCK IS LESS THAN FLANGE THICKNESS}

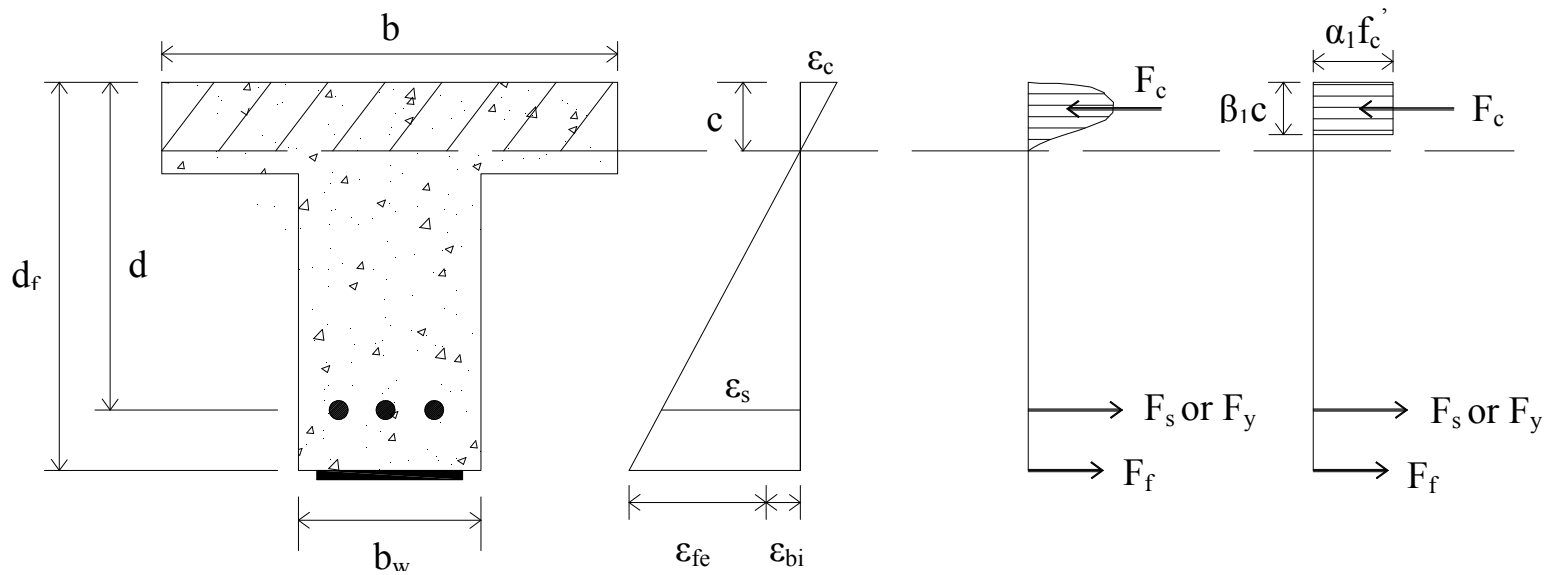

Figure 1.6 - 1 - Internal Strain and Stress Distribution at Ultimate Limit State $\left(\beta_{1} \mathrm{c}<\mathrm{h}_{\mathrm{f}}\right)$

1.6.6.1.1 This analysis is performed as if it were a rectangular section. Equation (1-16) may be used to check force equilibrium.

$$
c=\frac{A_{s} f_{s}+A_{f} f_{f e}}{\alpha_{1} f_{c}^{\prime} \beta_{1} b}
$$

The depth to the neutral axis is found by simultaneous satisfying equations (1-7), (1-8), (1-14), (1-15), and (1-16).

1.6.6.1.2 With the value of c known, the design moment strength can be determined using equation (1-17). 
$\Phi M_{n}=\Phi\left[\begin{array}{l}A_{s} f_{s}\left(d-\frac{\beta_{1} c}{2}\right)+ \\ \psi_{f} A_{f} f_{f e}\left(d_{f}-\frac{\beta_{1} c}{2}\right)\end{array}\right]$

1.6.6.1.3 Service condition properties are determined using a cracked section analysis as illustrated in Figure $1.6-2$. The neutral axis depth at service loads, $\mathrm{kd}$, can be calculated using equation (1-18).

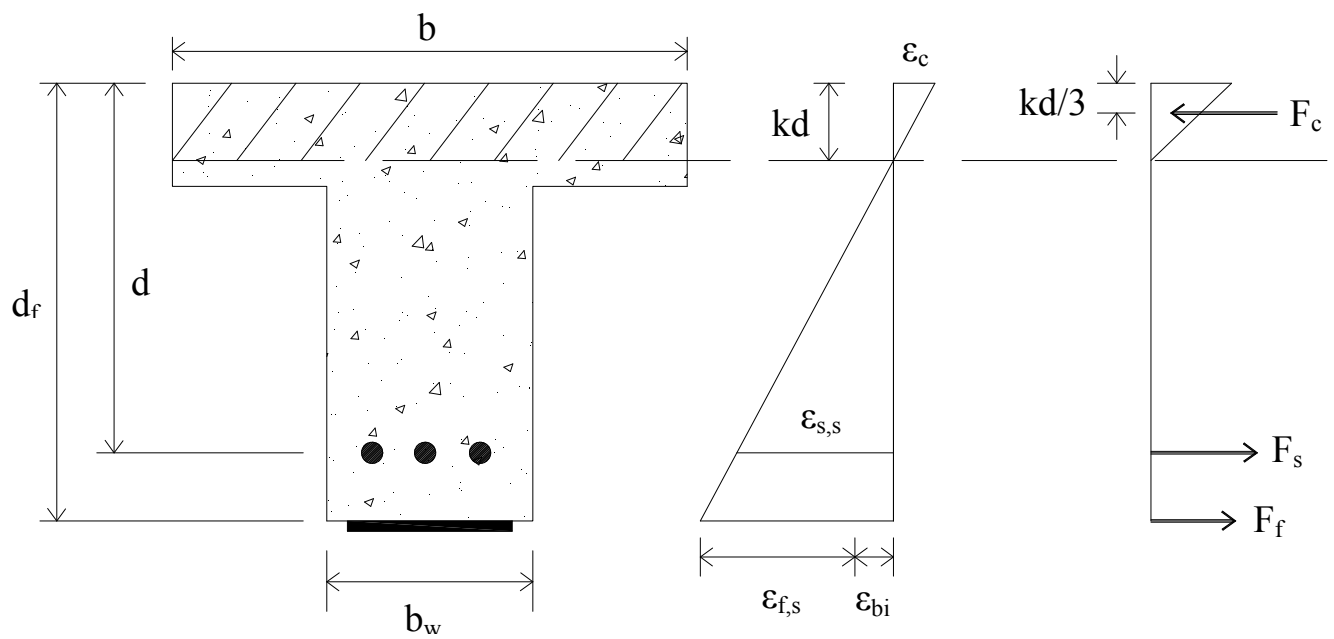

Figure 1.6 - 2 - Elastic Strain and Stress Distribution

$k=\sqrt{\left(2 n_{s} \rho_{s}+2 n_{f} \rho_{f} \frac{d_{f}}{d} \rho_{s}+n_{f} \rho_{f}\right)^{2}+}-\left(n_{s} \rho_{s}+n_{f} \rho_{f}\right)$

1.6.6.1.4 Equation (1-19) may be used to calculate the cracked moment of inertia, $\mathrm{I}_{\mathrm{cr}}$, of the section.

$I_{c r}=\frac{b(k d)^{3}}{3}+n_{s} A_{s}(d-k d)^{2}+n_{f} A_{f}\left(d_{f}-k d\right)^{2}$ 


\subsubsection{DEPTH OF STRESS BLOCK IS} GREATER THAN FLANGE THICKNESS

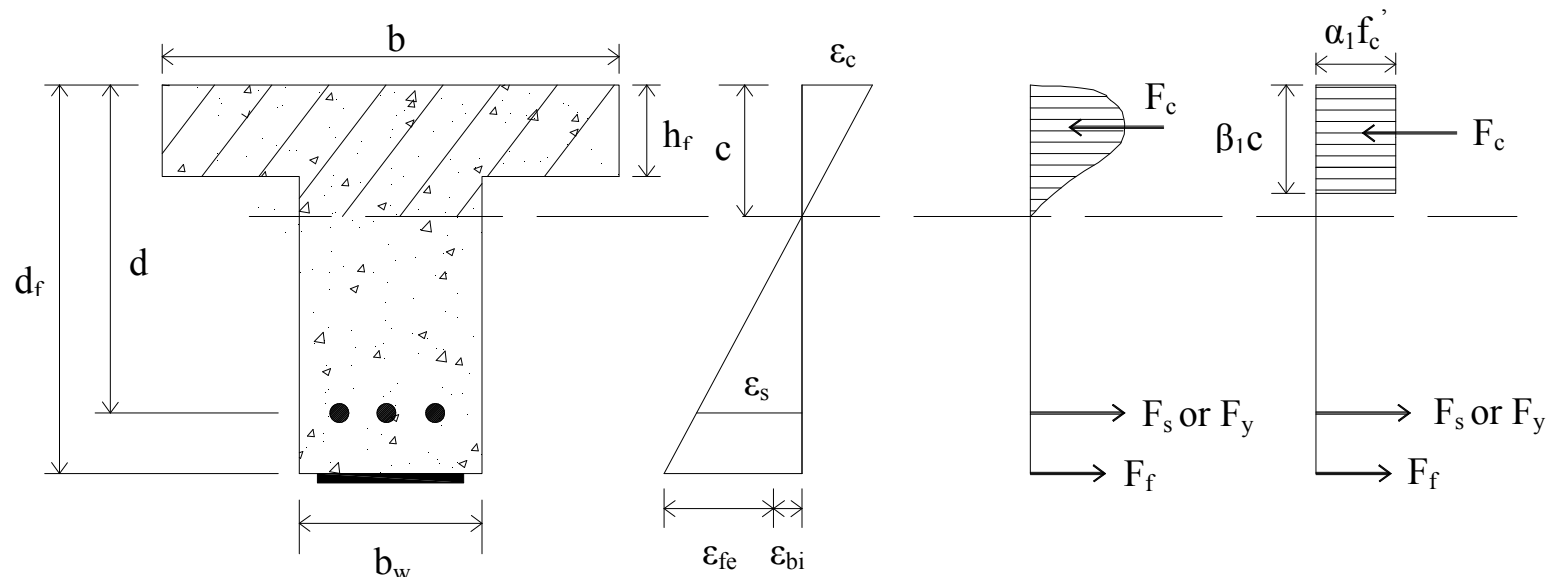

Figure 1.6 - 3 - Elastic Strain and Stress Distribution at Ultimate Limit State $\left(\beta_{1} \mathrm{c}>\mathrm{h}_{\mathrm{f}}\right)$

1.6.6.2.1 Force equilibrium may be checked by using equation (1-20) when the depth of the stress block is greater than the flange thickness.

$$
c=\frac{A_{s} f_{s}+A_{f} f_{f e}}{\alpha_{1} f_{c}^{\prime} \beta_{1} b_{w}}+\frac{t_{f}}{\beta_{1} b_{w}}\left(b_{w}-b\right)
$$

The depth to the neutral axis is found by simultaneously satisfying equations (1-7), (1$8),(1-14),(1-15)$, and (1-20).

1.6.6.2.2 With the value of c known, the design moment strength can be determined using equation (1-21).

$$
\Phi M_{n}=\Phi\left[\begin{array}{c}
A_{s} f_{s}\left(d-\frac{\beta_{1} c}{2}\right)+ \\
\psi_{f} A_{f} f_{f e}\left(d_{f}-\frac{\beta_{1} c}{2}\right)
\end{array}\right]
$$

1.6.6.2.3 Service condition properties are determined using a cracked section analysis. The neutral axis depth, kd, at service loads can be calculated by solving the polynomial of equation (1-22) using the coefficients given in 
equations (1-23), (1-24), and (1-25).

$a_{1} k^{2}+a_{2} k+a_{3}=0$

$a_{1}=\frac{b_{w} d}{2 b}$

$a_{2}=h_{f}\left(1-\frac{b_{w}}{b}\right)+d\left(n_{s} \rho_{s}+n_{f} \rho_{f}\right)$

$a_{3}=\frac{h_{f}^{2}}{2 d}\left(\frac{b_{w}}{b}-1\right)-n_{s} \rho_{s} d-n_{f} \rho_{f} d_{f}$

1.6.6.2.4 The cracked moment of inertia, $\mathrm{I}_{\mathrm{cr}}$, can be calculated using equation (1-26).

$$
\begin{array}{r}
I_{c r}=\frac{b\left(h_{f}\right)^{3}}{3}+ \\
+\frac{b_{w}\left(k d-h_{f}\right)^{3}}{3}+b h_{f}(k d)(k d-h f) \\
+n_{s} A_{s}(d-k d)^{2}+n_{f} A_{f}\left(d_{f}-k d\right)^{2}
\end{array}
$$

\subsubsection{Side Bonded FRP Laminates for Flexural Strengthening}

The flexural properties of a member may also be increased by applying FRP reinforcement to the sides of a member. If this method is used for strengthening, the guidelines of Articles 1.6.7.1 and 1.6.7.2 shall apply.

1.6.7.1 For any such side bonded FRP laminate, if the width of the laminate is less than $2 d_{c}, d_{f}$ may be taken as the distance from the extreme compression fiber to the centroid of the laminate. For laminate widths greater than $2 \mathrm{~d}_{\mathrm{c}}$, the laminate shall be divided into a series of equal width strips, with the width not exceeding $d_{c}$. $d_{f}$ for each strip shall then be the distance from the extreme compression fiber to the centroid of that strip. This will help to more accurately account for the linear-elastic behavior of FRP. 
1.6.7.2 The applicable sections contained in Article 1.6 shall be used in determining the contributions of externally bonded FRP applied in the manner presented in Article 1.6.8.

\subsubsection{Stress in Reinforcing Steel Under Service Loads}

The stress level in the reinforcing steel can be calculated using a cracked section analysis for the FRP strengthened section in accordance with equation (1-27). $\quad \mathrm{M}_{\mathrm{s}}$ is equal to the moment due to all sustained loads plus the maximum moment induced in a fatigue loading cycle.

$$
f_{s, s}=\frac{\left[M_{s}+\varepsilon_{b i} A_{f} E_{f}\left(d_{f}-\frac{k d}{3}\right)\right](d-k d) E_{s}}{A_{s} E_{s}\left(d-\frac{k d}{3}\right)(d-k d)+A_{f} E_{f}\left(d_{f}-\frac{k d}{3}\right)\left(d_{f}-k d\right)}
$$

This stress should be checked against the limits described in section 1.6.4.4.

\subsubsection{Stress in FRP Under Service Loads}

Equation (1-28) can be used to calculate the stress in the FRP reinforcement under service loads.

$$
f_{f, s}=f_{s, s}\left(\frac{E_{f}}{E_{s}}\right) \frac{d_{f}-k d}{d-k d}-\varepsilon_{b i} E_{f}
$$

The stress calculated using equation (1-28) should be checked against the limits set forth in section 1.6.4.5.

\subsection{SHEAR DESIGN}

Wrapping or partially wrapping members can increase the shear strength. The fibers are

\section{C1.6.8}

Distributions of strain and stress are illustrated in Figure 1.6-2. In the same method as detailed in Section C1.6.4.2, the depth to the neutral axis, stated as $\mathrm{kd}$, can be determined using a transformed section analysis. As opposed to conventional reinforced concrete analysis, the FRP component has to be incorporated, and therefore complicating the analysis. Similar to the transformed area of reinforcing steel, the transformed area of FRP can be obtained by multiplying the area of FRP with the modular ratio of FRP to concrete. This method doesn't consider the initial substrate strain as it causes a negligible difference in the depth of the neutral axis within the elastic range.

\section{C1.6.9}

The stress in the reinforcing steel under service loads can be directly related to the stress in the FRP under service loads as a result of a linear strain distribution and known material properties. Therefore, $f_{s, s}$ can be used in Equation (1-28) after it has been obtained from Equation (1-27). The stress level given by Equation (1-28) is the stress under an applied moment within the elastic response range of the member.

\section{C1.7}

The amount of additional shear strength 
oriented transverse to the longitudinal axis of beam members or perpendicular to potential shear crack locations in order to achieve this increase in shear strength.

This section presents guidance for determining the shear strength contributions of FRP when used as shear reinforcement.

\subsubsection{Wrapping Schemes}

Three types of wrapping schemes are typically used for shear reinforcement and are presented in Figure 1.7 - 1. that can be obtained by an FRP system is dependent of several factors. These factors include beam geometry, wrapping scheme, and the existing shear strength of the concrete.

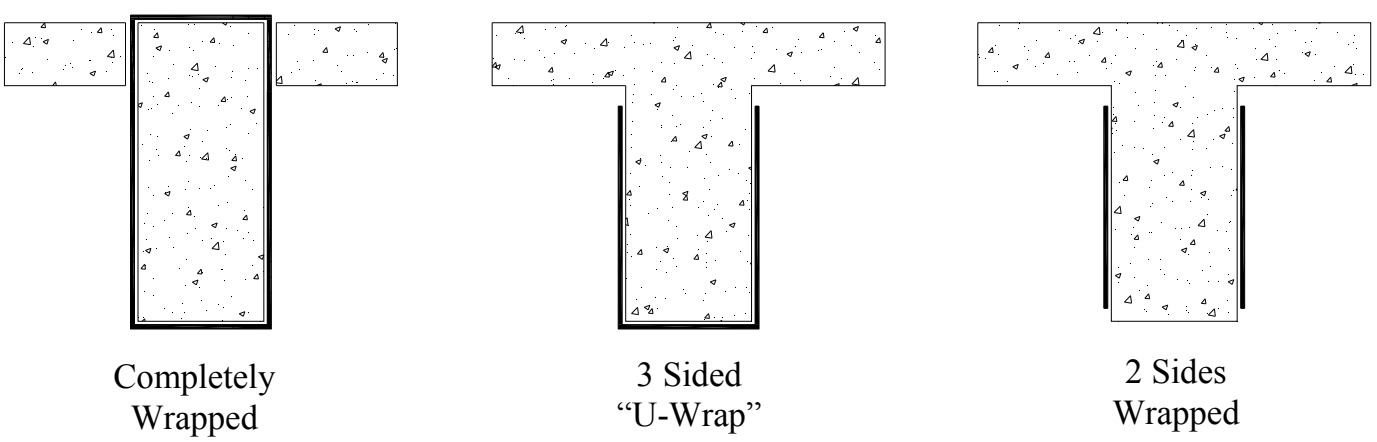

Figure 1.7 - 1 - Typical Wrapping Schemes for FRP Shear Strengthening

very practical. In any of the three wrapping schemes, the FRP system may be installed continuously along the longitudinal length of the member or applied as discrete strips. Many FRP systems are moisture impermeable, and hence, there is much concern with using continuously placed U-wrapping schemes as they may possibly entrap contaminants and accelerate the corrosion process. For this reason, FRP reinforcement that encases a member entirely and may prevent the passage of moisture is discouraged.

\section{C1.7.2}

The current value of the strength reduction 1.7.2.1 The design shear strength can be calculated by multiplying the nominal shear strength by the strength reduction factor, $\Phi$. factor, $\Phi$, is 0.75 for shear in accordance with ACI $318-08$. 
1.7.2.2 For an FRP-strengthened concrete member, the nominal shear strength can be determined by summing the contributions due to the FRP shear reinforcement, the reinforcing steel, and the concrete, as presented in equation (1-29).

$V_{n}=V_{c}+V_{s}+\Psi_{f} V_{f}$

In equation (1-29),

$$
\begin{aligned}
\mathrm{Vn}= & \text { nominal shear strength } \\
\mathrm{V}_{\mathrm{c}}= & \text { nominal shear strength contribution } \\
& \text { from the concrete } \\
\mathrm{V}_{\mathrm{s}}= & \text { nominal shear strength contribution } \\
& \text { from the steel } \\
\mathrm{V}_{\mathrm{f}}= & \text { nominal shear strength contribution } \\
& \text { from the FRP } \\
\Psi_{\mathrm{f}}= & \text { reduction factor for the FRP shear } \\
& \text { strength contribution }
\end{aligned}
$$

Values for the reduction factor, $\Psi f$, are given in Table $1.7-1$.

Table 7-1.7 - 1 - Recommended Additional Reduction Factors for FRP Shear Reinforcement

$$
\begin{array}{cc}
\Psi_{\mathrm{f}}=0.95 & \text { Completely wrapped members } \\
\Psi_{\mathrm{f}}=0.85 & \text { Three sides and two opposite side } \\
\text { schemes }
\end{array}
$$

1.7.2.3 The design of cross-sections for shear shall be based on equation (1-30).

$\phi V_{n} \geq V_{u}$

\subsubsection{Concrete and Steel Shear Strength Contribution}

The contribution of shear strength provided by the concrete and steel can be determined with reference to Article 5.8.3.3.
ACI recommends the reduction factor $\Psi_{\mathrm{f}}$ as presented in Table 1.7-1 based on a reliability analysis that uses data from Bousselham and Chaallal (2006), Deniaud and Cheng (2001, 2003), Funakawa et al. (1997), Matthys and Triantafillou (2001), and Pellegrino and Modena (2002). 


\subsubsection{FRP Shear Strength Contribution}

The dimensional variables used in calculating the FRP contribution to shear strength are illustrated in Figure $1.7-1$. Calculations are based off a proposed fiber orientation and an assumed shear crack pattern. The following sections present the applicable calculations.
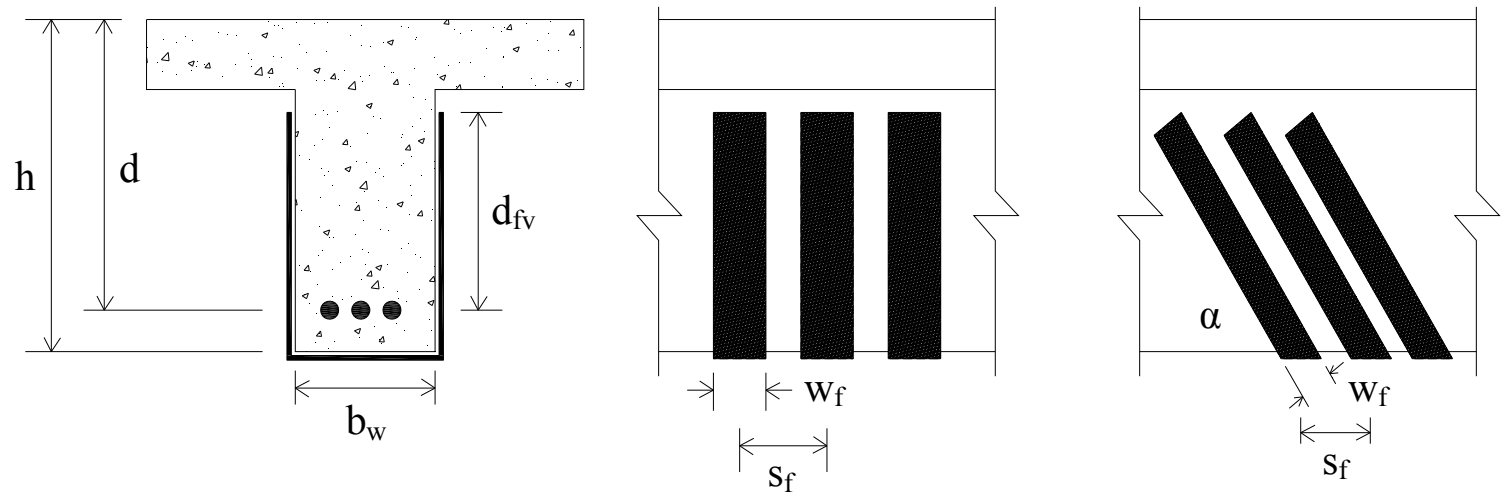

Figure 1.7 - 1 - Shear Strengthening Illustration Including Dimensional Variables Used

1.7.4.1 If the design shear strength provided by the concrete and steel, $\Phi\left(\mathrm{V}_{\mathrm{c}}+\mathrm{V}_{\mathrm{s}}\right)$, does not surpass the factored shear force, $\mathrm{V}_{\mathrm{u}}, \mathrm{FRP}$ shear reinforcement may be applied in order to satisfy equation (1-30). The FRP contribution to shear may not be less than that required in accordance with Article 1.7.5.

1.7.4.2 Where flexural capacity has been increased for an increase in loading condition, it is important to check that shear strength is adequate to withstand the corresponding increase in shear force. Shear reinforcing FRP may be required in this situation.

1.7.4.3 If FRP reinforcement perpendicular to the axis of the member is used, the contribution to shear strength may be computed using equation (1-31),
C1.7.4.1 Article 1.7.5 is only relevant with completely wrapped members and is applied to prevent a mode of failure in which loss of aggregate interlock of the concrete occurs. 
$V_{f}=\frac{A_{f v} f_{f e} d_{f v}}{s_{f}}$

where,

$$
A_{f v}=2 n t_{f} w_{f}
$$

1.7.4.4 If FRP reinforcement inclined to the axis of the member is used, the contribution to shear strength may be computed using equation (1-33).

$V_{f}=\frac{A_{f v} f_{f e}(\sin \alpha+\cos \alpha) d_{f v}}{s_{f}}$

\subsubsection{Effective Strain in FRP Shear Reinforcement}

The effective strain is the strain that is achieved within the FRP system at the nominal strength. This strain is governed by the failure mode of the FRP system and the failure mode of the strengthened reinforced concrete member.

The sections that follow provide guidelines on determining the effective strain for different configurations of FRP shear reinforcement.

\subsubsection{SECTIONS COMPLETELY WRAPPED}

To prevent a mode of failure in which loss of aggregate interlock of the concrete occurs, the maximum strain used for design should be limited to $0.4 \%$ when members are to be completely wrapped. This limit is shown in equation (1-34).

$\varepsilon_{f e}=0.004 \leq 0.75 \varepsilon_{f u}$

\subsubsection{SECTIONS NOT COMPLETELY WRAPPED}

For two and three sided wraps, delamination

\section{C1.7.5.1}

The strain limit presented was determined adequate through experience and testing (Priestley et al. 1996). Any higher strains for FRP applications in which the member is completely wrapped should not be used.

\section{C1.7.5.2}

The bond-reduction coefficient, $\kappa_{\mathrm{v}}$, was developed after an analysis of bond stresses to 
from the concrete has been shown to occur before loss of aggregate interlock. A bondreduction coefficient, $\kappa_{v}$, is used in calculating the effective strain for this type of shear reinforcement layout. The procedure is presented in equations (1-35) through (1-39) as follows:

$$
\varepsilon_{f e}=\kappa_{v} \varepsilon_{f u} \leq 0.004
$$

where,

$$
\kappa_{v}=\frac{k_{1} k_{2} L_{e}}{468 \varepsilon_{f u}} \leq 0.75 \text { in in.-lb units }
$$$$
\kappa_{v}=\frac{k_{1} k_{2} L_{e}}{11,900 \varepsilon_{f u}} \leq 0.75 \text { in SI units }
$$

and $L_{e}$ is the active bond length, given by equation (1-37).

$L_{e}=\frac{2500}{\left(n_{f} t_{f} E_{f}\right)^{0.58}}$ in in.-lb units

$$
L_{e}=\frac{23,300}{\left(n_{f} t_{f} E_{f}\right)^{0.58}} \quad \text { in SI units }
$$

Two modification factors, $\mathrm{k}_{1}$ and $\mathrm{k}_{2}$, are used to account for the concrete strength and the type of wrapping scheme and are determined by equations (1-38) and (1-39).

$$
\begin{aligned}
& k_{1}=\left(\frac{f_{c}^{\prime}}{4000}\right)^{2 / 3} \text { in in.-lb units } \\
& k_{1}=\left(\frac{f_{c}^{\prime}}{27}\right)^{2 / 3} \text { in SI units } \\
& k_{2}= \begin{cases}\frac{d_{f v}-L_{e}}{d_{f v}} & \text { for } \mathrm{U} \text { - wraps } \\
\frac{d_{f v}-2 L_{e}}{d_{f v}} & \text { for two sides bonded }\end{cases}
\end{aligned}
$$




\subsubsection{Spacing Limits}

The spacing limits for FRP shear reinforcing strips should conform to the limits set forth in Article 5.8.2.7 for internal steel reinforcement. Spacing of FRP strips is the distance between the center lines of the strips.

\subsubsection{Reinforcement Limits}

The shear strength provided by reinforcement alone is the sum of that contributed by steel and FRP. This shear strength contribution from reinforcement should be limited as stated in equation (1-40).

$V_{s}+V_{f} \leq 8 \sqrt{f_{c}{ }^{\prime}} b_{w} d \quad$ in in.-lb units

$V_{s}+V_{f} \leq 0.66 \sqrt{f_{c}{ }^{\prime}} b_{w} d$ in SI units

\subsection{DETAILING}

Adequate FRP reinforcement details are necessary to ensure that the expected FRP system performance is achieved. This section presents guidance for detailing FRP sheets or laminates.

\subsubsection{General Detailing Concerns}

1.8.1.1 Do not turn inside corners. For example, do not turn the inside corner where a beam meets the bottom of the slab.

1.8.1.2 When turning an outside corner, provide at minimum, a $1 / 2$ inch radius of curvature.

1.8.1.3 Provide adequate development length.

1.8.1.4 When splicing FRP plies, sufficient overlap should be provided. 


\subsubsection{Prevention of FRP End Peeling}

1.8.2.1 Transverse FRP stirrups or anchorage can be used to prevent FRP end peeling failure.

1.8.2.2 Locating the curtailment as close as possible to the region of zero moment minimizes the stress at the FRP curtailment and can help mitigate FRP end peeling failure.

1.8.2.3 If the factored shear force at the termination point exceeds $2 / 3$ the concrete shear strength, transverse reinforcement such as FRP anchors should be used to prevent the concrete cover layer from splitting.

1.8.2.4 Equation (1-41) can be used to determine the area of the transverse clamping FRP U-wrap.

$A_{\text {fanchor }}=\frac{\left(A_{f} f_{f u}\right)_{\text {longitudinal }}}{\left(E_{f} \kappa_{v} \varepsilon_{f u}\right)_{\text {anchor }}}$

In equation (1-41), $\mathrm{Kv}$ is calculated using equation (1-36).

\subsubsection{CUTOFF POINTS}

The following guidelines apply for both positive and negative moment regions.

1.8.2.5.1 In the case of simply supported beams, the termination point for a single-ply laminate should be at least a distance $l_{d f}$, as determined by equation (1-42), past the point along the span that corresponds to the cracking moment, $M_{c r}$.

1.8.2.5.2 In the case of simply supported beams, the termination points for multiple-ply laminates should be tapered. The termination point for the outermost ply should be at a distance $l_{d f}$ past the point along the span that

\section{C1.8.2}

FRP end peeling is also referred to as concrete cover delamination and can occur as a result of the normal stresses developed at the ends of externally bonded FRP reinforcement. These normal stresses are presented conceptually in Figure C1.8.2-1 along with the interfacial shear stresses as taken from ACI 440.2-08. In concrete cover delamination, the existing reinforcing steel may act as a bond separator in the horizontal plane and cause the concrete cover to pull away from the upper portion of the beam as presented in Figure C1.8.2-2 reprinted from ACI 440.2-08.

It should be considered good practice to incorporate transverse FRP stirrups as anchorage and locate the curtailment as close to the region of zero moment as possible to limit the possibility for FRP end peeling failure.

If end peeling has been adequately mitigated, or the member has a relatively long shear span, debonding can possible initiate at flexural cracks, flexural/shear cracks, or both, near the region of maximum moment. This can happen because when loaded, these cracks tend to open and create large interfacial shear stresses. In this case, debonding will propagate along the shear span in the direction of decreasing moment through the thin, largely mortar composed layer creating the surface of the concrete girder. This mode of failure can be more probable in sections having high shear-moment ratios.

The possibility for this debonding failure may be lessened by increasing the stress transfer through the effective implementation of mechanical anchorages (Khalifa et al. 1999). The success of such anchorages is believed not to result from an enhancement of interfacial shear capacity but rather from their ability to resist the tensile normal stresses (Quattlebaum et al. 2005). In any case, there is limited data that leads to the conclusion that 
corresponds to the cracking moment, $M_{c r}$. Each additional ply should be terminated at least 6 inches past the previous ply.

1.8.2.5.3 In the case of continuous beams, the termination point for a single-ply laminate should be at least a distance $\mathrm{d} / 2$ or 6 inches beyond the inflection point.

1.8.2.5.4 In the case of continuous beams, the termination points for multiple-ply laminates should be tapered. at least a distance $d / 2$ or 6 inches beyond the inflection point. The termination point for the outermost ply should be no less than 6 inches beyond the inflection point. Each additional ply should be terminated at least 6 inches past the previous ply. only a modest increase in FRP strain at debonding can be obtained with anchoring FRP wraps (Reed et al. 2005).

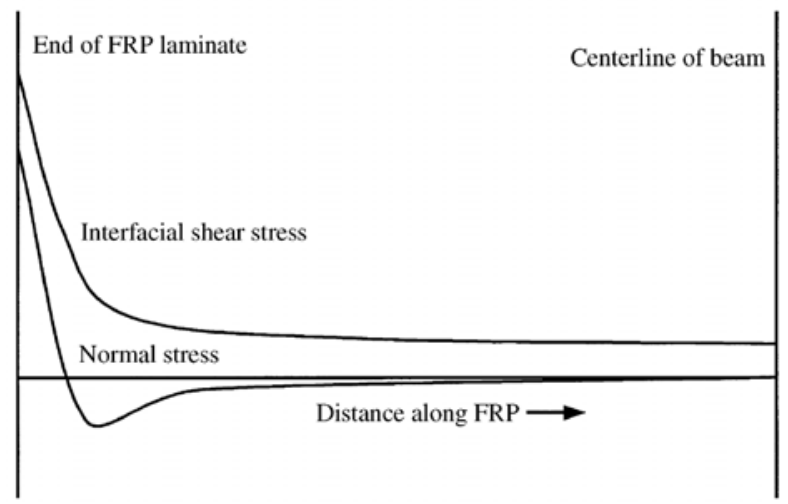

Figure C1.8.2-1 - Conceptual Interfacial and Normal Stresses along a Bonded FRP Laminate (Roberts and Haji-Kazemi 1989; Malek at al. 1998)

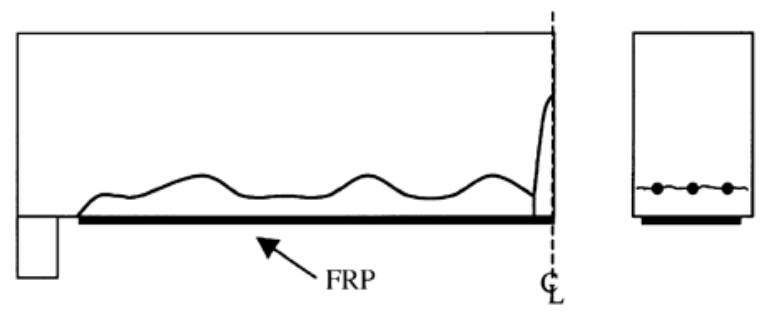

Figure C1.8.2-2 - Delamination Caused by Tension Failure of the Concrete Cover

\subsubsection{Development Length}

The available anchorage length of FRP should surpass the value given by equation (142) in order to develop the effective FRP stress at a section.

$$
\begin{aligned}
& l_{d f}=0.057 \sqrt{\frac{n E_{f} t_{f}}{\sqrt{f_{c}^{\prime}}}} \text { in in.-lb units } \\
& l_{d f}=\sqrt{\frac{n E_{f} t_{f}}{\sqrt{f_{c}^{\prime}}}} \text { in SI units }
\end{aligned}
$$




\subsubsection{Laps and Splices}

Lap splices may be used to ensure that the fibers of FRP systems are continuous and oriented in the direction of the largest tensile forces. Fibers should be overlapped along their length. Ample overlap should be provided to support failure of the FRP laminate before debonding of the overlapped laminates.

1.8.4.1 The required overlap for individual FRP systems should be set forth by the material manufacturer and validated through testing which is independent of the manufacturer.

1.8.4.2 In the case of unidirectional FRP laminates, lap splices are only required in the direction of the fibers.

1.8.4.3 To maintain the continuity of fibers and overall strength of the FRP laminates, multidirectional fabrics require lap splices in more than one direction.

1.8.4.4 Lap splices shall not be placed in the central third of simply supported spans.

1.8.4.5 Lap splices shall not be placed in the central quarter or the end $1 / 8$ of continuous spans.

\section{C1.8.4}

Splices for FRP laminates shall be placed in accordance with drawings, specifications, and as certified by the licensed design professional in agreement with recommendations from the system manufacturer. The thickness of the FRP system, tensile strength, and the bond strength between adjacent layer of laminates should control the required overlap for lapsplices.

\subsection{EXAMPLE DESIGN PROBLEMS}

\subsubsection{Flexural Strengthening of a Reinforced Concrete T-beam with FRP laminates}

After inspection and proper testing, it is determined that a reinforced concrete T-beam bridge is in poor condition and needs repair. The bridge is selected for retrofit with FRP.

Examining one of the interior beams, it is determined that only about $65 \%$ of the reinforcing tension steel remains after many years of deterioration. With 10 \#11 bars 
being used in the original design, only $10 \mathrm{in}^{2}$ of steel area remains. The beam has the dimensions as shown in Figure 1.

A BAR7 analysis gives an inventory load rating factor of 0.83 , and it is decided to strengthen the beam to achieve a minimum inventory load rating factor of 1.0. This requires increasing the nominal moment capacity of the beam from $1037 \mathrm{k}$-ft to $1138 \mathrm{k}$ ft.

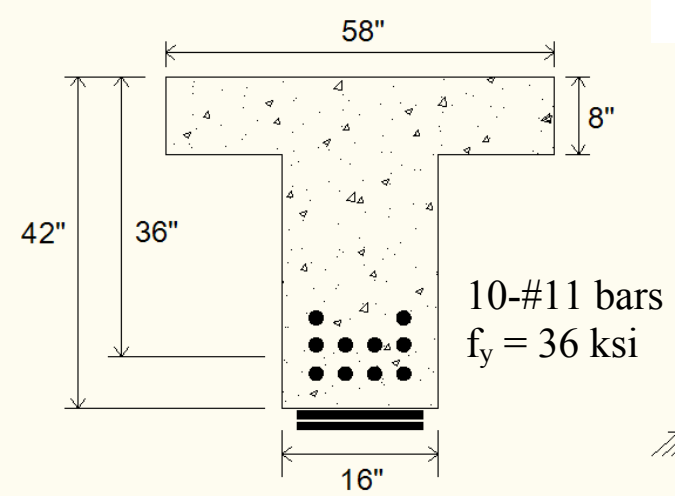

Cross-Section

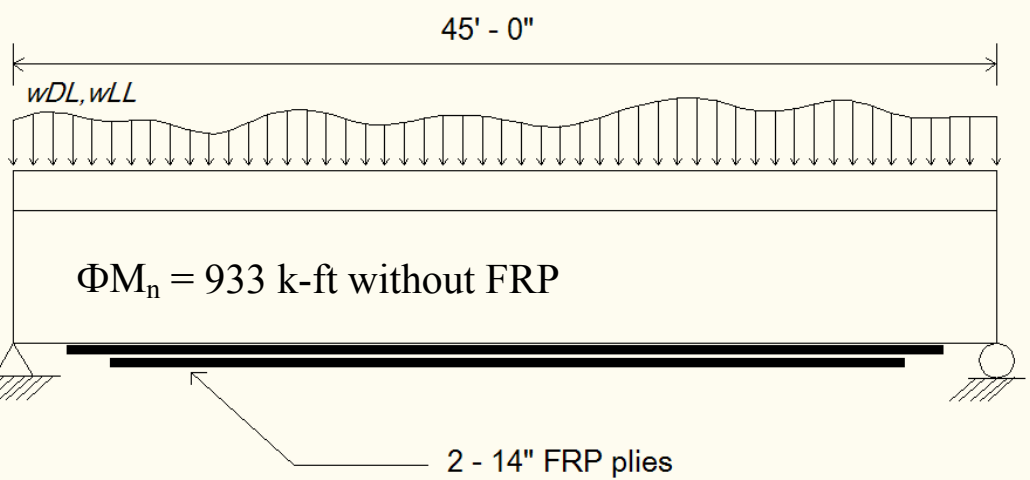

Elevation

Figure 1: Simply Supported T-Beam with Externally Bonded FRP

Beam dimensions and properties are presented in Table 1.

Table 1: Beam Dimensions and Properties

\begin{tabular}{|c|c|}
\hline $\mathrm{L}$ & $45 \mathrm{ft}$ \\
\hline $\mathrm{b}_{\mathrm{w}}$ & $16 \mathrm{in}$. \\
\hline $\mathrm{b}$ & $58 \mathrm{in}$. \\
\hline $\mathrm{h}$ & $42 \mathrm{in}$. \\
\hline $\mathrm{d}$ & $36 \mathrm{in}$. \\
\hline $\mathrm{f}_{\mathrm{c}}$ & $3000 \mathrm{psi}$ \\
\hline $\mathrm{f}_{\mathrm{y}}$ & $36 \mathrm{ksi}$ \\
\hline $\mathrm{A}_{\mathrm{s} \text { original }}$ & $15.6 \mathrm{in}^{2}$ \\
\hline $\mathrm{A}_{\mathrm{s} \text { remaining }}$ & $10 \mathrm{in}^{2}$ \\
\hline$\Phi \mathrm{M}_{\mathrm{n} \text { existing }}$ & $933 \mathrm{k}-\mathrm{ft}$ \\
\hline$\Phi \mathrm{M}_{\mathrm{n} \text { required }}$ & $1024 \mathrm{k}-\mathrm{ft}$ \\
\hline $\mathrm{M}_{\mathrm{DL}}$ & $415 \mathrm{k}-\mathrm{ft}$ \\
\hline $\mathrm{M}_{\mathrm{LL}}$ & $214 \mathrm{k}-\mathrm{ft}$ \\
\hline $1.1 \mathrm{M}_{\mathrm{DL}}+0.75 \mathrm{M}_{\mathrm{LL}}$ & $617 \mathrm{k}-\mathrm{ft}$ \\
\hline
\end{tabular}


Note that the unstrengthened moment limit is less than the existing moment strength without FRP as per Equation (1-4). The beam is to be strengthened with an FRP system as detailed in Table 2. Two 14 in. wide layers will be applied using the wet layup technique.

Table 2: Manufacturer's Reported FRP System Properties

\begin{tabular}{|c|c|}
\hline $\mathrm{t}_{\mathrm{f}}$ & $0.0065 \mathrm{in} / \mathrm{ply}$ \\
\hline $\mathrm{f}_{\mathrm{fu}}{ }^{*}$ & $550 \mathrm{ksi}$ \\
\hline$\varepsilon_{\mathrm{fu}}{ }^{*}$ & $0.0167 \mathrm{in} / \mathrm{in}$ \\
\hline $\mathrm{E}_{\mathrm{f}}$ & $33000 \mathrm{ksi}$ \\
\hline
\end{tabular}

The strengthening design calculations are as follows.

\section{STEP 1 - Preliminary Calculations}

- FRP system design material properties

Table 1.5-2 presents the environmental reduction factors.

Exterior exposure: $\mathrm{C}_{\mathrm{F}}=0.85$

$$
\begin{aligned}
& f_{f u}=C_{E} f_{f u}{ }^{*}=0.85(550)=467.5 \mathrm{ksi} \\
& \varepsilon_{f u}=C_{E} \varepsilon_{f u}{ }^{*}=0.85(0.0167)=0.0142 \mathrm{in} / \mathrm{in} \quad \text { Equations (1-1) and (1-2) }
\end{aligned}
$$

- Properties of the concrete, steel, and FRP (Section 1.6.5.1)

$$
\begin{aligned}
& E_{c}=57000 \sqrt{f_{c}^{\prime}}=57000 \sqrt{3000}=3122 \mathrm{ksi} \\
& A_{s}=10 \mathrm{in}^{2} \text { (as previously stated) } \\
& A_{f}=n t_{f} w_{f}=2(0.0065)(14)=0.182 \mathrm{in}^{2}
\end{aligned}
$$

- Initial substrate strain, $\varepsilon_{b i}$ (Section 1.6.4.2)

A cracked section analysis provides that $\mathrm{c}=9.26 \mathrm{in}$. With this, $I_{\mathrm{cr}}=81821$ in $^{4}$

$$
\varepsilon_{b i}=\frac{M_{D L}(h-c)}{I_{c r} E_{c}}=\frac{415(12000)(42-9.26)}{81821(3122)(1000)}=0.00064 \quad(\text { See Section C1.6.4.2) }
$$

- Determine the design strain of the FRP system (Equation (1-12)) 


$$
\begin{aligned}
& \varepsilon_{f d}=0.083 \sqrt{\frac{f_{c}^{\prime}}{n E_{f} t_{f}}} \leq 0.9 \varepsilon_{f u} \\
& \varepsilon_{f d}=0.083 \sqrt{\frac{3000}{2(33000000)(0.0065)}}=0.0069 \\
& \varepsilon_{f d}=0.0069 \leq 0.9(0.0142)=0.0128
\end{aligned}
$$

Design strain is lower than the rupture strain and, therefore, debonding controls the design of the FRP system.

$$
\varepsilon_{f d}=0.0069
$$

\section{STEP 2 - Estimate the depth to the neutral axis, c}

First estimate: $c=0.20 \mathrm{~d}=0.20(36)=7.2 \mathrm{in}$.

\section{$\underline{\text { STEP } 3 \text { - Calculate material strains }}$}

- Effective strain level in the FRP (Equation (1-7))

$$
\begin{aligned}
& \varepsilon_{f e}=\varepsilon_{c u}\left(\frac{d_{f}-c}{c}\right)-\varepsilon_{b i} \leq \varepsilon_{f d} \\
& \varepsilon_{f e}=0.003\left(\frac{42-7.2}{7.2}\right)-0.00064=0.0139 \\
& \varepsilon_{f e}=0.0139>\varepsilon_{f d}=0.0069 \\
& \therefore \varepsilon_{f e}=\varepsilon_{f d}=0.0069
\end{aligned}
$$

Since the second expression controls, FRP debonding is the failure mode and hence, concrete strain may be less than 0.003 and can be determine by using similar triangles. (Equation (1-13))

$$
\varepsilon_{c}=\left(\varepsilon_{f e}+\varepsilon_{b i}\right)\left(\frac{c}{d_{f}-c}\right)=(0.0069+0.00064)\left(\frac{7.2}{42-7.2}\right)=0.0016
$$


- Strain in the existing reinforcing steel (Equation (1-14))

$$
\begin{aligned}
& \varepsilon_{s}=\left(\varepsilon_{f e}+\varepsilon_{b i}\right)\left(\frac{d-c}{d_{f}-c}\right) \\
& \varepsilon_{s}=(0.0069+0.00064)\left(\frac{36-7.2}{42-7.2}\right)=0.0062 \\
& \varepsilon_{s}=0.0062
\end{aligned}
$$

\section{STEP 4 - Calculate stresses in the FRP and reinforcing steel}

$$
\begin{aligned}
& f_{f e}=E_{f} \varepsilon_{f e}=33000(0.0069)=227.7 \mathrm{ksi} \\
& f_{s}=E_{s} \varepsilon_{s} \leq f_{y} \Rightarrow f_{s}=29000(0.0062)=179.8 \mathrm{ksi} \\
& \therefore f_{s}=f_{y}=36 \mathrm{ksi}
\end{aligned}
$$

\section{STEP 5 - Determine internal force resultants and check equilibrium}

For a more accurate analysis, concrete stress block factors may be calculated based on the parabolic stress-strain relationship for concrete as follows:

$$
\beta_{1}=\frac{4 \varepsilon_{c}{ }^{\prime}-\varepsilon_{c}}{6 \varepsilon_{c}^{\prime}-2 \varepsilon_{c}} \quad \alpha_{1}=\frac{3 \varepsilon_{c}{ }^{\prime} \varepsilon_{c}-\varepsilon_{c}{ }^{2}}{3 \beta_{1} \varepsilon_{c}{ }^{2}}
$$

Where $\varepsilon_{c}{ }^{\prime}$ is the strain that corresponds to $f_{c}^{\prime}$ and is calculated as follows:

$$
\begin{aligned}
& \varepsilon_{c}^{\prime}=\frac{1.7 f_{c}^{\prime}}{E_{c}} \\
& \varepsilon_{c}^{\prime}=\frac{1.7(3000)}{3122000}=0.0016 \\
& \beta_{1}=\frac{4(0.0016)-(0.0016)}{6(0.0016)-2(0.0016)}=0.750 \\
& \alpha_{1}=\frac{3(0.0016)(0.0016)-(0.0016)^{2}}{3(0.750)(0.0016)^{2}}=0.889
\end{aligned}
$$


With the stress block factors known, force equilibrium can be verified by computing the value of $\mathrm{c}$.

$$
\begin{aligned}
& c=\frac{A_{s} f_{s}+A_{f} f_{f e}}{\alpha_{1} f_{c}^{\prime} \beta_{1} b} \\
& c=\frac{10(36)+0.182(227.7)}{0.889(3)(0.750)(58)}=3.46 \\
& c=3.46 \text { in. } \neq 7.2 \text { in. } \therefore N G
\end{aligned}
$$

As can be seen, the calculated value of $\mathrm{c}$ does not match the initial estimate. Steps 2 through 5 must be repeated until the initial estimate matches the calculate value, and hence, equilibrium is achieved.

This process was repeated several times with different values of $\mathrm{c}$ and the results of the finial iteration are shown below.

$\underline{\text { Final iteration results }}$

$$
\begin{aligned}
& c=4.82 \mathrm{in} . ; \varepsilon_{s}=0.0063 ; f_{s}=f_{y}=36 \mathrm{ksi} ; \beta_{1}=0.708 ; \alpha_{1}=0.676 ; f_{f e}=227.7 \mathrm{ksi} \\
& c=\frac{10(36)+0.182(227.7)}{0.676(3)(0.708)(58)}=4.82 \\
& c=4.82 \mathrm{in} . \mathrm{OK}
\end{aligned}
$$

\section{STEP 6 - Compute nominal moment strength, $M_{n}$}

The design flexural strength is calculated using Equation (1-17)

$$
\Phi M_{n}=\Phi\left[\begin{array}{l}
A_{s} f_{s}\left(d-\frac{\beta_{1} c}{2}\right)+ \\
\psi_{f} A_{f} f_{f e}\left(d_{f}-\frac{\beta_{1} c}{2}\right)
\end{array}\right]
$$

The reduction factor $\psi_{\mathrm{f}}=0.85$ is applied to the contribution of the FRP system.

- Steel contribution: 


$$
\begin{aligned}
& M_{n s}=A_{s} f_{s}\left(d-\frac{\beta_{1} c}{2}\right) \\
& M_{n s}=10(36)\left(36-\frac{0.708(4.82)}{2}\right) \\
& M_{n s}=12346 k-i n .=1023 k-f t .
\end{aligned}
$$

- FRP contribution:

$$
\begin{aligned}
& M_{n f}=A_{f} f_{f e}\left(d_{f}-\frac{\beta_{1} c}{2}\right) \\
& M_{n f}=0.182(227.7)\left(42-\frac{0.708(4.82)}{2}\right) \\
& M_{n f}=1670 k-i n .=139 k-f t .
\end{aligned}
$$

- Design Flexural Strength:

$\varepsilon_{s}=0.0063>0.005$

Therefore, a strength reduction factor of $\Phi=0.9$ is appropriate as in accordance with Section 1.6.4.1.

$$
\begin{aligned}
& \Phi M_{n}=\Phi\left[M_{n s}+\psi M_{n f}\right] \\
& \Phi M_{n}=0.9[1023+0.85(139)]=1027 k-f t . \\
& \Phi M_{n}=1027 k-f t>\Phi M_{u}=1024 k-f t . \quad O K
\end{aligned}
$$

The strengthened section reaches the required moment capacity.

\section{FINAL STEP - Check service stresses in the reinforcing steel and FRP}

Calculate the elastic depth to the cracked neutral axis by using Equation (1-18).

$$
k=\sqrt{\left(n_{s} \rho_{s}+n_{f} \rho_{f}\right)^{2}+\left(2 n_{s} \rho_{s}+2 n_{f} \rho_{f} \frac{d_{f}}{d}\right)}-\left(n_{s} \rho_{s}+n_{f} \rho_{f}\right)
$$




$$
\begin{gathered}
k=\sqrt{((9.3)(0.00479)+(10.6)(0.000075))^{2}+\left(2(9.3)(0.00479)+2(10.6)(0.000075) \frac{42}{36}\right)} \\
-((9.3)(0.00479)+(10.6)(0.000075))
\end{gathered}
$$

$k=0.260$

$c=k d=0.260(36)=9.36$ in

Next, the stress level in the reinforcing steel should be checked using Equation (1-27) as follows.

$$
f_{s, s}=\frac{\left[M_{s}+\varepsilon_{b i} A_{f} E_{f}\left(d_{f}-\frac{k d}{3}\right)\right](d-k d) E_{s}}{A_{s} E_{s}\left(d-\frac{k d}{3}\right)(d-k d)+A_{f} E_{f}\left(d_{f}-\frac{k d}{3}\right)\left(d_{f}-k d\right)} \leq 0.80 f_{y}
$$

$M_{s}$ is maximum distributed live load + impact factor $\left(\mathrm{M}_{\mathrm{LL}}(1.3)\right)$ obtained from an HS20 Truck loading. $M_{s}$ is determined to be $(214 \mathrm{k}-\mathrm{ft})(1.3)=278 \mathrm{k}-\mathrm{ft}$. in accordance with the AASHTO Standard Specification for Highway Bridges.

$$
f_{s, s}=\frac{\left[278(12)+0.00064(0.182)(33000)\left(42-\frac{9.36}{3}\right)\right](36-9.36) 29000}{10(29000)\left(36-\frac{9.36}{3}\right)(36-9.36)+0.182(33000)\left(42-\frac{9.36}{3}\right)(42-9.36)}
$$

$f_{s, s}=10.3 \mathrm{ksi} \leq 0.8(36 \mathrm{ksi})=28.8 \mathrm{ksi}$

Therefore, the stress level in the reinforcing steel is within the recommended limit.

The stress level in the FRP under service loads can be calculated using Equation (1-28). This stress needs to be less than the creep-rupture stress limit as given in Table 1.6-1.

$$
\begin{aligned}
& f_{f, s}=f_{s, s}\left(\frac{E_{f}}{E_{s}}\right) \frac{d_{f}-k d}{d-k d}-\varepsilon_{b i} E_{f} \\
& f_{f, s}=10.3\left(\frac{33000}{29000}\right)\left(\frac{42-9.36}{36-9.36}\right)-(0.00064)(33000)=-6.76 k s i
\end{aligned}
$$

Sustained plus cyclic stress limit $=0.55 \mathrm{f}_{\mathrm{fu}}$

$$
f_{f, s}=-6.76 k s i \leq(0.55)(467.5 k s i)=257 k s i
$$

Therefore, the stress level in the FRP is within the recommended sustained plus cyclic stress limit. 


\section{Note:}

In detailing the FRP reinforcement, the FRP should be terminated a minimum of $1_{d f}$, calculated in accordance with Equation (1-42), past the point on the moment diagram where cracking should occur. FRP end peeling should also be checked at the FRP termination point by seeing that the factored shear force at that point is not greater than $2 / 3$ the concrete shear strength. If the factored shear force is greater than $2 / 3$ the concrete shear strength, the FRP flexural reinforcement should be terminated closer to the supports. U-wraps may also be used to eliminate cover delamination.

\subsubsection{Shear strengthening of an interior reinforced concrete T-beam}

A reinforced concrete $\mathrm{T}$-beam $\left(\mathrm{f}_{\mathrm{c}}{ }^{\prime}=3000 \mathrm{psi}\right)$ is shown to have approximately a uniform $20 \%$ decrease in shear reinforcing steel area as a result of many years of corrosion. It is found that this loss in area decreases the shear strength to an inadequate level. The nominal shear strength provided by the concrete is calculated to be $V_{c}=72 \mathrm{kips}$, and that provided by the remaining shear reinforcement steel is $\mathrm{V}_{\mathrm{s}}=31 \mathrm{kips}$. Therefore, in accordance with AASHTO Standard Specifications for Highway Bridges, $\Phi \mathrm{V}_{\mathrm{n}}$ existing $=$ $0.85(72+31)=87.6 \mathrm{kips}$. The factored required shear strength at a distance $\mathrm{d}$ from the support is $\mathrm{V}_{\mathrm{u}}=100 \mathrm{kips}$. The shear diagram showing the section of the span length where shear strengthening is required is illustrated in Figure 2.

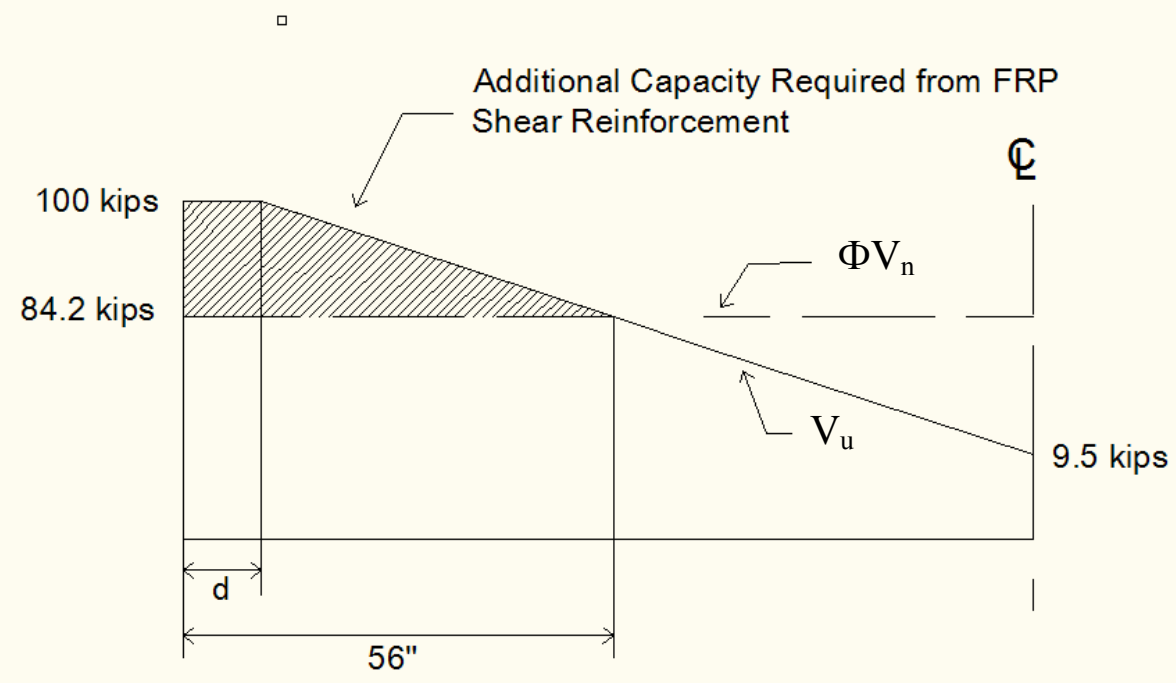

Figure 2: Shear Diagram 

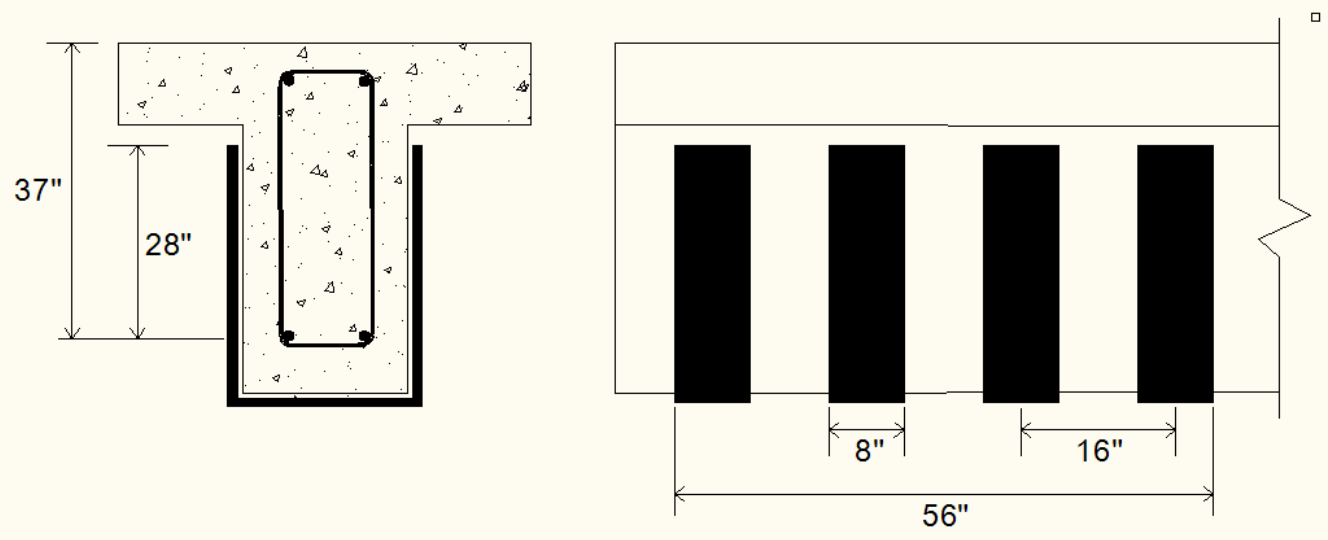

Figure 3: Schematics of FRP Shear Reinforcement

Figure 3 illustrates the schematics of the design which uses single ply U-wraps of CFRP. Table 3 summarizes the design configuration and Table 4 presents the manufacturer's reported FRP system properties.

Table 3: Configuration of Supplementary Shear Reinforcement

\begin{tabular}{|c|c|}
\hline $\mathrm{d}$ & $37 \mathrm{in.}$ \\
\hline $\mathrm{d}_{\mathrm{fv}}$ & $28 \mathrm{in}$. \\
\hline Width of each sheet, $\mathrm{w}_{\mathrm{f}}$ & $8 \mathrm{in}$. \\
\hline Span between each sheet, $\mathrm{s}_{\mathrm{f}}$ & $16 \mathrm{in}$. \\
\hline FRP strip length & $56 \mathrm{in}$. \\
\hline
\end{tabular}

Table 4: Manufacturer's Reported FRP System Properties

\begin{tabular}{|c|c|}
\hline Thickness per ply, $\mathrm{t}_{\mathrm{f}}$ & $0.0065 \mathrm{in} / \mathrm{ply}$ \\
\hline Ultimate tensile strength, $\mathrm{f}_{\mathrm{fu}}{ }^{*}$ & $550 \mathrm{ksi}$ \\
\hline Rupture strain, $\varepsilon_{\mathrm{fu}}{ }^{*}$ & $0.0167 \mathrm{in} / \mathrm{in}$ \\
\hline Modulus of elasticity, $\mathrm{E}_{\mathrm{f}}$ & $33000 \mathrm{ksi}$ \\
\hline
\end{tabular}

The strengthening design calculations are as follows.

\section{STEP 1 - Compute the design material properties}

Table 1.5-2 presents the environmental reduction factors.

Exterior exposure: $\mathrm{C}_{\mathrm{F}}=0.85$ 
$f_{f u}=C_{E} f_{f u}^{*}=0.85(550)=467.5 \mathrm{ksi}$

$\varepsilon_{f u}=C_{E} \varepsilon_{f u}{ }^{*}=0.85(0.0167)=0.0142 \mathrm{in} / \mathrm{in}$

\section{STEP 2 - Calculate the effective strain level in the FRP shear reinforcement}

The effective strain should be determined using the bond-reduction coefficient $\kappa_{\mathrm{v}}$. The coefficient can be determined by using Equations (1-36) through (1-39).

$$
\begin{aligned}
& L_{e}=\frac{2500}{\left(n_{f} t_{f} E_{f}\right)^{0.58}}=\frac{2500}{[(1)(0.0065)(33000000)]^{0.58}}=2.0 \mathrm{in} . \\
& k_{1}=\left(\frac{f_{c}^{\prime}}{4000}\right)^{2 / 3}=\left(\frac{3000}{4000}\right)^{2 / 3}=0.825 \\
& k_{2}=\frac{d_{f v}-L_{e}}{d_{f v}}=\frac{28-2.0}{28}=0.929 \\
& \kappa_{v}=\frac{k_{1} k_{2} L_{e}}{468 \varepsilon_{f u}} \leq 0.75 \Rightarrow \kappa_{v}=\frac{(0.825)(0.929)(2)}{468(0.0142)}=0.2307 \leq 0.75
\end{aligned}
$$

Now, the effective strain can be computed using Equation (1-35).

$\varepsilon_{f e}=\kappa_{v} \varepsilon_{f u} \leq 0.004 \Rightarrow \varepsilon_{f e}=0.2307(0.0142)=0.0033 \leq 0.004$

\section{STEP 3 - Calculate the contribution of the FRP reinforcement to the shear strength}

- Area of FRP shear reinforcement

$$
A_{f v}=2 n t_{f} w_{f}=2(1)(0.0065)(8)=0.104 \mathrm{in}^{2}
$$

- Effective stress in the FRP

$$
f_{f e}=\varepsilon_{f e} E_{f}=0.0033(33000)=108.9 k s i
$$

Now, the shear contribution of the FRP can be calculated from Equation (1-31) since the FRP is oriented perpendicular to the longitudinal axis of the member.

$$
V_{f}=\frac{A_{f v} f_{f e} d_{f v}}{s_{f}}=\frac{0.104(108.9)(28)}{16}=19.8 \text { kips }
$$




\section{STEP 4-Calculate the shear strength of the section}

The design shear strength can be computed from Equation (1-29) with $\Psi_{\mathrm{f}}=0.85$ in accordance with Table 1.7-1.

$\Phi V_{n}=\Phi\left[V_{c}+V_{s}+\Psi_{f}\left(V_{f}\right)\right]$

$\Phi V_{n}=0.85[72+31+0.85(19.8)]=102$ kips

$\Phi V=102$ kips $>V_{u}=100$ kips $\quad$ OK

The shear strength is now adequate.

Reinforcement Limit: $\mathrm{V}_{\mathrm{s}}+\mathrm{V}_{\mathrm{f}}=50.8$ kips $<8 \sqrt{ } \mathrm{f}_{\mathrm{c}}{ }^{\prime} \mathrm{b}_{\mathrm{w}} \mathrm{d}=259$ kips $\quad$ OK 


\section{APPENDIX E: CONSTRUCTION GUIDELINES}




\section{SECTION 1000 STRUCTURES}

\section{SECTION 1002-RC T-Beam Bridge Rehabilitation with Externally Bonded FRP Strips}

1002.1 DESCRIPTION----The intended use of these specifications is directed to the construction process incorporating repair by use of externally bonded FRP systems. The expected outcomes of such FRP retrofit are to enhance the shear strength, flexural strength, or ductility of members.

\subsection{MATERIALS----}

(a) Resins. A broad range of polymeric resins are used with FRP systems. These resins include primers, putty fillers, saturants, and adhesives. Environmental conditions should be taken into account when selecting and using resins. The most commonly used resin types, such as epoxy, vinyl ester, and polyester, have been further formulated for use in many different environmental conditions. Resins that are used by FRP system manufacturers have compatibility and high adhesion properties with concrete substrates and FRP composite systems; are resistant to environmental effects associated with exposed concrete on bridges; have filling and workability; have adequate pot lives; and develop the appropriate mechanical properties for strengthening.

- Primer----Primer provides an improved adhesive bond for the saturating resin or adhesive by penetrating the surface of the concrete.

- Putty fillers----Small surface holes in the substrate should be filled with putty. The putty provides a smooth surface for which to apply the FRP system and can prevent bubbles from developing during the saturating resin curing process.

- Saturating resin----Saturating resin must be used to impregnate the fibers and therefore provide a shear load path between the fibers for the effective transfer of load. In wet layup systems, the saturating resin also serves as the adhesive to provide a shear load path between the FRP and the concrete substrate.

- Adhesive----Adhesives are resins that are used when bonding precured or Near-Surface Mounted (NSM) systems to concrete substrate. As with saturating resins, the adhesive provides a shear load path between the FRP system and the concrete substrate. 
(b) Fibers. Fibers give the FRP system its strength and stiffness. Common reinforcing fibers used are continuous glass, aramid, and carbon fibers. Ranges of tensile properties for common types of fibers are presented in ACI 440.2R-08.

(c) Protective coatings. A protective coating should be used to greatly decrease the chances of the FRP system becoming damaged by environmental or mechanical effects. Once the saturating resin or adhesive has cured, the protective coating should be applied to the exterior of the FRP system in accordance with the manufacturer's recommendations. There are a wide range of forms available for protective coatings. Forms include: Polymer coatings; Acrylic coatings; cementitious systems; and intumescent coatings. The major reasons why protective coatings are used on finished FRP systems include: ultraviolet light protection; fire protection; vandalism; impact; abrasion; wear; aesthetics; and chemical resistance.

\subsection{SPECIAL CONSIDERATIONS----}

(a) Product Shipping Dimensions. FRP shipping roll widths may not be the same for different suppliers, but the typical width varies from 20 to 24 in. For this reason, it is important that the shipped width be known when determining the quantity to be ordered. If the design width for the flexural reinforcing FRP is less than the shipping width (which is normally the case) the strips will have to be cut to size and the excess may not be a width usable in the design. Therefore, care may have to be taken so that the correct quantity of FRP area above the design area can be ordered, to avoid a shortage of material.

(b) Long Term Structural Performance. It is important that all construction aspects be performed as economically as possible while achieving the greatest increase in life for the structure. New technologies and additional construction works may be incorporated into the rehabilitation project to provide for enhanced life expectancy. This concept should also be taken into careful consideration during the design phase as detailed in Section 1002.3(b)2.

1. Waterproofing. Limiting further ingression of chlorides should be a major consideration with any concrete bridge rehabilitation. Membrane waterproofing can be used to form an impermeable water barrier between the concrete deck and overlay surfacing material. The intent of applying a membrane is to prevent moisture, salts and deicing chemicals from infiltrating through the concrete surface, and thereby reducing damage caused by steel corrosion and freeze-thaw cycles. Royston Bridge Membrane 10A Easy Pave has been successfully used for this application.

2. Design. There has been much debate concerning the question as to whether or not certain FRP design configurations can potentially increase rates of deterioration. Other considerations include aspects such as reinforcement details that can seem adequate in accordance with design guidelines, but when viewed as achieving the greatest increase in life for the structure, may seem inadequate. 
2.a Web Encasement. Continuous FRP reinforcement along the web of a beam that completely encases the member and potentially prevents the migration of contaminants and moisture is not recommended, as it can possibly increase the rate of deterioration. Up to three layers of flexural reinforcing FRP strips may be applied to the soffit of a beam as recommended by ACI. This type of layout is, in the majority of cases, is sufficient to provide the increase in moment capacity required. Therefore, the use of continuous U-wraps or continuous side flexural reinforcing strips should be avoided, in order to enhance longer anticipated life for the structure.

2.b Design Requirement. The FRP strengthening design may be based on the required moment and shear to bring the member back to its original capacity or it may be based on the required moment and shear to satisfy a specific AASHTO truck loading, such as an HS20 truck loading. In most cases, it may be more appropriate to bring the structure to a level that satisfies a specific truck loading, based either on actual or anticipated loss of steel reinforcement area and full strengthening with externally bonded FRP.

2.c FRP Wrapping Scheme. The quantity of transverse FRP anchorage used in design shall, at minimum, meet the requirements of design guidelines. It has been found that using the minimum transverse FRP anchorage, as required by design guidelines, results in the same short-term performance as when more anchorage than required is used (Parish, 2008). Although the short-term performance may not be affected by using more anchorage, it is likely that long-term performance will be improved (Parish, 2008). For this reason, it is suggested that using more transverse FRP anchorage than that required may lead to increased life expectancy for the structure.

\subsection{CONSTRUCITON----}

(a) General. The intended use of these specifications is directed to the construction process incorporating repair by use of externally bonded FRP systems. The expected outcomes of such FRP retrofits are to enhance the shear or flexural strength or ductility of members such as beams or columns.

(b) Pre-repair Work. Care should be taken to ensure that proper methods are used in performing all tasks that are to precede the actual construction and those that arise as a result of the construction. Such tasks include, but are not limited to, comprehending all tolerances that may be set forth by the owner or manufacturer, attainment and proper review of submittals, evaluating all site considerations and challenges, and handling of materials from delivery to disposal.

1. Tolerances. Tolerances stated within these specifications or within the contract documents shall be followed unless more strict requirements are recommended by the manufacturer. Any uncertainties with respect to required tolerances shall be clarified by the engineer before proceeding. 
2. Site Considerations. All site challenges or obstacles shall be dealt with accordingly after approval from the engineer. The contractor shall make arrangements for all necessary removal of obstructions such as pipes, conduits, wiring, fences, or vegetation. Any necessary removal should only take place upon approval from the engineer and after all records have been taken so that proper replacement can take place at project completion. Required means of access for personnel, material, and equipment such as scaffolding and pathways should be provided by the contractor.

3. Submittals. Prior to the start of construction work, all required documentation must be submitted. Submittals should consist of working drawings, qualifications, and quality control and assurance plans.

3.a Drawings. Working drawings should include all relevant information, such as the type of FRP system, repair locations and dimensions, and the work plan. The work plan should be composed of all necessary preparations of the existing structure. Design calculations, MSDS, and the manufacturer's system data sheets that provide physical, mechanical, and chemical properties of the system components should accompany the drawings along with an application guide that shall state all aspects concerning installation and maintenance.

3.b Qualifications. Documentation proving the required level of qualifications shall be submitted by the system manufacturer/supplier and the contractor. Recommended information to be provided by the manufacturer/supplier includes the following:

- System data sheets and MSDS for each component of the FRP system;

- A minimum of 5 years documented experience or 25 documented similar field applications with acceptable reference letters form the respective owners;

- A minimum of 50 total test data sets from an independent agency approved by the owner on mechanical properties, aging, and environmental durability of the system; and

- A thorough hands-on training program for each FRP system to qualify contractors/applicators.

Whereas recommended information to be provided by the contractor includes the following:

- A minimum of 3 years of documented experience or 15 documented applications with acceptable reference letters form the respective owners; 
- A certificate of completed training from the manufacturer/supplier for at least one field representative who will be present on site throughout the project.

3.c QA/QC Plan. The contractor should be held responsible for the quality control of materials and the construction process. QC and QA plans submitted will be approved by the owner or the owner's representatives. Depending on the size of the project and the entities utilized, a third party such as a consulting firm or a University research team may greatly assist in the quality assurance and approval of QC and QA plans. The QC/QA plan should include at a minimum, detailed procedures for personnel safety, tracking and inspection of all FRP components before installation, inspection of prepared surfaces prior to FRP application, inspection of the work in progress, QA sampling, inspection of all completed work including necessary tests for approval, repair of defective work if applicable, and clean-up aspects. All work must comply with the contract documents and may otherwise be altered at the expense of the contractor.

4. Material Shipping. All applicable federal and state packaging and shipping codes must be followed when shipping FRP materials. CFR 49 is the controlling regulatory code for packaging, labeling, and shipping of thermosetting resins.

\section{Material Storage.}

5.a General. Components of the FRP system must be stored according to the manufacturer's recommendations. Normally in original factory-sealed and unopened packaging or in containers with proper labels that state the manufacturer, brand name, system ID number, and the date. Materials should be kept out of contact with anything that may cause physical damage, such as direct sunlight, dust, moisture, excess temperatures as specified in the material data sheets, and harmful chemicals. Components of the FRP system that are used as catalysts or inhibitors should be stored separately.

5.b Shelf Life. A set shelf life is recommended by the system manufacturer. Any duration of storage which is longer than the specified shelf life may result in property changes for the resin-based materials and therefore, the expected performance of such materials may be compromised. Any material that has reached its shelf life should not be used and disposed of in accordance with Section 1002.4(b)7.

\section{Material Handling.}

6.a General. When handling FRP system constituent materials, great care should be taken to ensure protection of the material and safety of work personnel. The MSDS for each component and all relevant information sources such as any literature provided by the system manufacturer, ACI, or ICRI reports should be present on site and used to aid in proper handling. 
6.b Material Protection. All material must be handled according to manufacturer's recommendations to ensure that no damage is caused that may compromise the system performance. With respect to causing damage, emphasis should be placed on proper handling of fiber sheets to decrease the chances of misalignment or breakage of the fibers. This can be caused by pulling, separating, wrinkling or folding the sheets. After sheets have been measured and cut, they can be rolled or stacked before installation. If stacked, they should be stacked dry with the use of separators. If rolled, they should be rolled gently at a radius not less than $12 \mathrm{in}$. $(305 \mathrm{~mm})$ or as specified by the system manufacturer.

6.c Personnel Safety. Safety hazards to work personnel can be avoided if all components of the FRP system are handled with care. Emphasis should be placed on proper handling of adhesives and resins to decrease the chances of safety hazards to personnel. Safety hazards can include skin sensitization, breathing in of harmful vapors, possible explosion or fire, and inhalation of fiber fly. Mixing of resins shall be monitored to avoid any of the preceding hazards. Hazards may vary with different FRP systems and the manufacturer's literature should be consulted for more detailed information.

To protect against hazards, personnel should be equipped with the proper clothing and accessories. The use of disposable suits and gloves that are resistant to resins and solvents are recommended when handling fiber and resin materials. The contractor is responsible for providing the proper means of protection for the personnel and the workplace, including informing personnel of the dangers associated with any aspect of the construction. Other forms of protection that should be provided include safety glasses or goggles and respiratory protection, such as dust masks or respirators.

Conformance to local, state, and federal environmental and worker's safety laws and regulations is required throughout all stages of the work and is the responsibility of the contractor.

7. Cleanup and Disposal. Cleanup is the responsibility of the contractor. Safety and environmental concerns are important issues to consider with cleanup as it often involves the use of flammable solvents. System data sheets should be referred to in an effort to perform the cleanup in the most efficient way possible while obeying all regulations prescribed by the established environmental authority.

FRP system components that have exceeded their shelf life or pot life or have not been stored properly shall be disposed of in a method that conforms to the MSDS recommendations and environmental regulations.

\section{(c) Pre-installation Repair Work.}

1. General. All repair work should conform to ACI 546R and ICRI No. 03733. FRP rehabilitation should be performed through four main stages of work. These stages of work are the following: removal of defective concrete, restoration of crosssection, surface preparation, and FRP system installation. The success of the repair project strongly relies on satisfactory completion of each construction stage. 
2. Removal of Defective Concrete. It is imperative that any defective concrete be removed and replaced, thus providing sound concrete substrate for the installation. Removal shall be in accordance with ACI 546R and ICRI No. 03730, which may include the use of proper equipment such as a saw and an air-powered or electricpowered jack hammer. An adequate depth of at least $1 / 2$ inch beyond the repair area should be reached to expose sound aggregates. In general, removal should reach a depth in which no loose aggregate is easily falling out of the concrete. When exposing reinforcing steel that is deteriorated or has lost its bond with the concrete, an additional $3 / 4$ inch or $1 / 4$ inch larger than the largest aggregate in the repair material shall be removed from behind the reinforcement. Restoration of the cross-section shall not take place until all sources of corrosion are located and properly treated. Research by Parish (2008), was conducted in which this traditional removal and restoration of defective concrete was compared with a method of repair in which only crack injection as presented in Section 1002.4(c)4.d was performed. The defective concrete removal and patch method demonstrated superior durability, compared to using only the crack injection method (Parish, 2008), and should be adopted where applicable.

\section{Restoration of Cross-Section.}

3.a General. After the concrete removal process is completed, work can be started to restore the cross-section. For proper concrete restoration, consideration should be given to repairing exposed reinforcement if necessary, surface cleaning, and the repair material.

3.b Repair of Reinforcement. Repair of defective reinforcement shall be performed in accordance with ICRI No. 03730 and to the satisfaction of the engineer. Corroded reinforcement can be prepared by abrasive cleaning or it can be replaced. If replaced, reinforcement should be cut out at a sufficient length as specified in the contract documents or to the approval of the engineer to ensure that only sound material remains. Splice lengths for replacement reinforcement shall be provided at sufficient length in accordance with contract documents or to the approval of the engineer.

3.c Surface Cleaning. To ensure adequate bond between the repair material and the newly exposed concrete substrate, proper surface preparations should be made prior to applying the repair material. Cracks within the solid concrete in the substrate shall be pressure injected with epoxy as specified in Section 1002.4(c)4.d. The substrate shall be cleaned from any dust, laitance, grease, oil, curing compounds, impregnations, foreign particles, wax, and other bond-inhibiting materials in the same manner of cleaning before FRP application as called for in Section 1002.4(c)4.f. After cleaning and just prior to applying the repair material, a water-based epoxy cementitious bonding agent shall be applied to the concrete and exposed reinforcement.

3.d Repair Material. Repair material shall conform to ICRI No. 03733. The mix design for any repair material shall be approved by the engineer. The FRP system manufacturer should be consulted on the compatibility of the FRP system with the repair material proposed. Repair materials that have been successfully used include Class 
AAA Polymer Modified Concrete and a BASF bag material product known as Emaco $\mathrm{S} 66 \mathrm{C} 1$ which is a flowable structural-repair concrete with integral corrosion inhibitor. The compressive strength of the repair material shall be at least the compressive strength of the original concrete, but it should be no less than 4,500 and 5,500 psi at 7 and 28 days, respectively. It is important that the bond strength developed between the repair material and the existing concrete be adequate. This bond strength can be determined by pull-off tests in accordance with ASTM D4541 and must be, at minimum, 200 psi. A minimum of 7 days, unless a shorter time period for cure and strength is verified through testing, should be allowed for the repair material to cure before installing the FRP system.

\section{Surface Preparation.}

4.a General. Surface preparation should not begin until all concrete removal, cleaning and cross-section restorations have been approved by the engineer. The intended application of the FRP system normally determines the required surface preparation methods. FRP applications are termed as either bond-critical or contactcritical. In bond-critical applications, an adhesive bond is mandatory between the FRP and the concrete. Whereas, contact-critical applications only require intimate contact between the concrete and FRP, but often an adhesive is used anyway to aid in the installation. Since both applications require intimate contact between concrete and FRP and adhesives are commonly used in contact critical application, these specifications detail the same surface preparation to be used in either application. Recommendations given by ACI 546R and ICRI 03730 should be followed. In general, a clean, smooth, and flat or convex surface shall be provided. Key aspects of surface preparation include surface grinding, chamfering corners, crack injection, surface profiling, and cleaning. Once the surface has been prepared and approved by the engineer, work may begin on the installation.

4.b Surface Grinding. Disk grinders or other similar devices shall be used to remove all irregularities, unevenness, sharp protrusions such as form lines, and surface substances such as stains or paints. After grinding, all protrusions must be less than $1 / 32$ inch $(1 \mathrm{~mm})$ or less than the requirements specified by the system manufacturer. If such variations are very small, it may be adequate to avoid grinding and simply smooth over the surface with resin-based putty.

4.c Chamfering Corners. When FRP is to wrap around corners of rectangular cross-sections, the corners should be rounded to a minimum radius of $1 / 2$ inch to reduce stress concentrations and eliminate voids that may develop between the FRP and concrete. Putty should be used to smooth over roughened corners. Inside corners and concave surfaces are problematic and may require special detailing if bond between the concrete and FRP system is to be sustained.

4.d Crack Injection. The performance of an externally bonded FRP system can be affected by cracks that are wider than $1 / 100$ inch $(0.3 \mathrm{~mm})$. Cracks of this size can cause delamination or fiber crushing and shall be filled using pressure injection of epoxy in accordance with ACI 224.1R. If aggressive environments are present, 
smaller cracks may require resin injection or sealing to prevent possible corrosion of reinforcing steel. ACI $224.1 \mathrm{R}$ gives crack width criteria for various exposure conditions. FRP systems shall not be installed until at least 24 hours after crack injection is completed and after any surface variations caused by crack injection have been repaired in accordance with Section 1002.4(c)4.b.

4.e Surface Profiling. A minimum concrete surface profile (CSP) of No. 3 should be prepared as identified by the ICRI surface-profile chips. The FRP system manufacturer shall be consulted if a stricter surface-profile is required. This CSP shall be prepared using putty made of epoxy resin mortar or polymer cement mortar with strength equal to or greater than that of the original concrete. A minimum of 7 days must be provided for curing of this patching material before installation of the FRP system.

4.f Cleaning. Cleaning shall remove any dust, laitance, grease, oil, curing compounds, impregnations, stains, paint coatings, or any other type of bond inhibiting materials. Cleaning shall be performed to the approval of the engineer. Any cleaned surface should be protected from possible redeposit of any bond inhibiting materials. It is important that the surface be allowed to dry thoroughly before the installation of FRP if a power wash system is used in the cleaning process. The recommended moisture content can be evaluated with reference to ACI 503.4.

\section{(d) FRP System Installation.}

1. General. This section discusses issues related to installing the FRP system. The procedures specified for the installation may vary slightly depending on the type of system and the manufacturer. Specific aspects to be discussed include: environmental conditions during installation, shoring, equipment, and the type of FRP system to be used. The two types of FRP systems to be described are wet lay-up and precured.

2. Environmental Conditions at Installation. Environmental conditions such as temperature, relative humidity, and surface moisture at the time of installation can affect the performance of the FRP system. Therefore, these conditions should be examined before and during the installation process to ensure conformity with contract documents and any manufacturer's recommendations. Primers, saturating resins, and adhesives shall not be applied to cold or frozen surfaces. Resins and adhesives in general should never be applied to damp or wet surfaces unless they have been formulated for such applications. The installation should not proceed if the surface moisture is greater than $10 \%$ as evaluated by ACI 503R. Pressurized air may be used to help dry the surface. The minimum level of the concrete surface temperature should be set forth by the system manufacturer, with a general range being $50-95^{\circ} \mathrm{F}\left(10-35^{\circ} \mathrm{C}\right)$. A heat source may be used to raise the ambient and surface temperature during installation. Moisture vapor transmission is a problem that may be encountered during installation and usually appears as surface bubbles. FRP systems should never be applied to surfaces subject to moisture vapor transmission as this can greatly affect the bond. 
3. Shoring. Conventional methods can be used to temporarily shore repaired members if necessary. Any shoring shall remain in place until the FRP system has completely cured and gained its design strength, as approved by the engineer.

4. Equipment. All necessary equipment shall be provided by the contractor. Equipment shall be in clean, working condition. The amount and types of equipment shall be such that continuous installation can be performed.

\section{Wet Layup Systems.}

5.a General. This section describes the process used in applying wet layup systems. This system can be dry or prepreg fiber sheets. Saturants are used to impregnate the fiber sheets at installation. Details from resin mixing to stressing applications are included.

5.b Mixing Resins. The process of mixing resins should always be performed in a way consistent with the manufacturer's recommended procedure. All resin components must be mixed at the proper ratios and specified temperature until consistency is achieved. Often, the components are different colors and consistency has been obtained when the mix reaches one color and no streaks are visible. Batches can be stirred by hand, but are most commonly stirred by some type of electrically powered mixing blades. Batch sizes, mix ratios, and mixing times should be supplied by the material manufacturer. In general, the quantities of mix shall be small enough to ensure use of all material before the pot life has been reached. If the pot life has been exceeded or the mix begins to show signs of exceeded pot life such as increase in viscosity, the mix shall not be used and it should be disposed of in accordance with Section 1002.4(b)7. Mixing should be performed in an area with adequate ventilation, as some resins can give off harmful fumes that can adversely affect the environment or work personnel.

5.c Primer. Primer application typically precedes the application of any FRP system. Primer should be applied in one or two coats or to manufacturer's specifications. The concrete surface and ambient temperatures should be within the range specified in Section 1002.4(d)2. If it is realized that the desired CSP as described in Section 1002.4(c)4.e has not been prepared, putty may need to be used to smooth the surface. If the use of putty is needed, it should be applied at the time the primer is no longer sticky to the touch. Putty should be applied in thin coats of one or two layers to smooth over the surface and adequately fill any voids, cracks, or uneven areas. As with any prepared surface, the primer and putty should be protected from dust, moisture, and any other contaminants that may arise at the site. If contamination does occur, the surface shall be cleaned as specified in Section 1002.4(c)4.f before the application of FRP.

5.d Fiber Sheet and Saturant Application. The procedure for applying the fiber sheet and saturant should be performed without interruption. This procedure can be explained in general as three basic steps: first layer of saturant, fiber sheet, and second layer of saturant. The first layer of saturant shall be applied to all areas on the concrete 
surface where the FRP system is to be applied. It shall be applied in a uniform layer and have a viscosity that will allow for full impregnation of the fiber sheets. The proper viscosity can be maintained by ensuring that the ambient and the concrete surface temperatures are within the range specified in Section 1002.4(d)2. Once this first layer of saturant has been applied, work should begin immediately on applying the fiber sheet. Therefore, the fiber sheet must already be cut to the correct length as specified in the contract documents. The fiber sheet shall be placed on the intended area and gently pressed onto the wet saturant, allowing for full impregnation. Rollers can be used to further impregnate the fiber sheet while helping to eliminate any entrapped air between the fiber and concrete surface. Rollers should only be rolled across the sheet in the direction parallel to the fibers so as to help the fibers attain intimate contact with the substrate. If bidirectional fabrics are used, rolling should be performed in the fill direction end to end and then in the warp direction.

After the fiber sheet has been properly placed, a sufficiently thick layer of saturant shall be applied. This second layer of saturant ensures full saturation of the fibers and serves as an overcoat. It is important that this three step process be performed without interruption.

5.e Multiple Plies and Lap Splices. Multiple plies can be installed using the same procedure described in Section 1002.4(d)5.d. The overcoat saturant for each underlying ply should be applied with some excess so that it can also serve as a first layer for the overlying ply. If the plies are to be applied on the same day, the viscosity of the saturant must be maintained until all layers have been installed. The manufacturer should be consulted for the number of plies that can be installed in one day. The multiple ply installation shall meet the approval of the engineer. If all plies are not to be installed on the same day and intermediate layers are allowed to cure, surface preparation is needed before installation of the next layer. This surface preparation can include light sanding and filling with putty as specified in Section 1002.4(d)5.c.

It may be inconvenient to use exceptionally long pieces of fabric to strengthen long spans. Therefore, multiple lengths of fiber sheets can be used by incorporating lap splices to continuously transfer load. Lap splices should be detailed in accordance with the manufacturer's recommendations. The lap length of any lap splice should be as specified within contract documents but be no less than 6 in. $(152 \mathrm{~mm})$ in accordance with ACI 440.2-08. Lap splices should be staggered or meet the approval of the engineer with reference to the contract documents.

5.f Alignment of FRP Materials. The contract documents should specify the alignment of fiber plies. Variations as small as 5 degrees in angle from the design direction of plies can significantly change the strength and modulus and should not be accepted. The fiber sheets should be free of kinks and folds. Fiber orientation is discussed further in Section 1002.4(e)5.

\section{Precured FRP Systems.}

6.a General. Precured systems are normally installed with an adhesive and can include shells, strips, and open grid forms. The installation of these systems is 
generally similar to that of the single-ply wet lay-up. In instances of concrete confinement, adhesive may not be required. The surface for the precured system to be bonded should be prepared as specified in Section 1002.4(c)4 to a minimum concrete surface profile (CSP) 3.

6.b Adhesive. The adhesive should be applied uniformly to all surface areas to receive the procured system. The rate of application, thickness, and viscosity at which the adhesive is to be applied to the concrete substrate should be in accordance with the manufacturer's recommendations. The ambient and concrete surface temperatures should be within the range as specified in Section 1002.4(d)2 during the application. Care should be taken so that the adhesive's pot life is not exceeded.

6.c Placement. As with the wet lay-up systems, precured system strips and shells shall be clean and cut to the correct size prior to the installation. They shall be placed onto the adhesive immediately after the adhesive has been applied, within the adhesive's pot life. Air trapped within the system shall be released in the same manner as described in Section 1002.4(d)5.d. All excess adhesive should be removed without disturbing the applied FRP system.

6.d Grouting. Pressure grouting may be performed on precured shells used for confinement of concrete columns. The grouting process should be in accordance with contract documents and to the manufacturer's recommendations. Grouting should take place no earlier than 24 hours after installation. The shrinkage strain of the grout shall be no less than 0.0005 and have a minimum compressive strength of 4,000 psi (27.6 $\mathrm{MPa})$.

7. Anchoring of FRP Systems. If specified in contract documents or requested by the engineer, it may be required to anchor FRP sheets to the concrete substrate. Mechanical anchorages can be effective in increasing stress transfer. If mechanical anchorages such as clamps or fasteners are used, the installment should be used in a careful manner to avoid causing damage to the FRP or concrete substrate. Typically, anchoring is provided with the use of transverse FRP wraps or stirrups located near the ends of an FRP sheet or strip.

8. Temporary Protection. Temporary protection may be required during installation and until the resins have cured to eliminate the chances of damage to the FRP system. Damage could occur as a result of any one of the following: rain, vandalism, dust, adverse temperatures, or excessive sunlight. No shoring shall be removed until the FRP system has been fully cured. If damage does occur to the system before full cure, the engineer should be made aware of the situation and the system manufacturer should be consulted in an effort to resolve the issue.

9. Curing of Resins. Curing of resins should be performed in accordance with the manufacturer's recommendations. The cure process is time-temperature-dependent, and under normal ambient temperatures the complete cure can take several days. If instructed, elevated cure systems may be used in which the resin must be heated to a 
specific temperature for a specified period of time. Any field modification of resin chemistry is not permitted. If application calls for several plies to be placed in more than one day, full cure and monitoring of installed plies should be performed before installation of subsequent plies. The FRP system shall be protected in accordance with Section 1002.4(d)9 while curing.

10. Protective Coating or Finishing. All coatings should be applied in accordance with the manufacturer's recommendations. Coatings must be compatible with the FRP system. The FRP surface should be clean and dry before applying the coating. Cleaning with solvents is prohibited unless approved by the FRP manufacturer, due to the deleterious effects that solvents can have on the polymer resins. The owner should be consulted regarding the final appearance of the coatings. Normally, it is desired to match the color and texture of the adjacent concrete. The effectiveness of the coatings should be ensured through periodical inspections and maintenance.

\section{(e) Inspection for QA/QC.}

1. General. Quality assurance is attained through a set of inspections and applicable tests to document the acceptability of the installation. A requirement to provide a QA plan for installation and curing of all FRP materials should be included in the project specifications. The entities involved with inspections and testing will depend on the project size and complexity. In a complicated or large project it is likely that the inspections and tests will be performed by an outside consultant acting on behalf of the owner for QA. With minor projects, the owner itself may perform inspections and tests for QA. On site inspections and tests shall be performed in the presence of the contractor and the engineer.

Quality control shall be maintained by the contractor, possibly incorporating the use of its own inspector. The QC program should be detailed in the project specifications and cover all aspects of the strengthening project. The project size and complexity will also influence the degree of QC and the extent of testing, inspection, and record keeping.

2. Daily Inspection. Inspections should be held to high standards and should be performed regularly. Throughout the FRP system installation process, daily inspections should be conducted that include the following:

- Date and time;

- Ambient temperature, relative humidity, and any weather observations;

- Concrete surface temperature;

- Surface dryness;

- Method of surface preparation and resulting CSP;

- Surface cleanliness; 
- Fiber laminate batch number and approximate location in the structure;

- Any cracks not injected with epoxy;

- Batch numbers, mixing times and ratios, and mixed resin appearance for putties, primers, saturants, adhesives, and coatings mixed on that day;

- Progression of resin curing;

- Installation procedures;

- Any pull-off test results including bond strength, mode of failure, and location;

- Tests and results of any field samples;

- Size and location of any delaminations or voids; and

- Overall advancement work in progress.

Copies of inspection records should be submitted to the owner or engineer. Witness panels shall also be submitted. The contractor should maintain sample cups of resin and records on the placement of each batch.

3. Acceptance. Acceptance or rejection should be based on compliance or noncompliance with design drawings and specifications. Evaluation for acceptance should include any material properties, placement tolerances, delaminations present, resin curing, and adhesion to substrate. Important aspects of placement of the FRP system include fiber orientation, cured thickness, ply alignment, fiber sheet dimensions, corner radii, and lap splice lengths. Once the FRP system has been installed, witness panels and pull-off tests should be used for evaluation and acceptance. If necessary, load testing may be used to verify strengthening of members.

4. Materials. Before starting the project, the manufacturer's certifications for all delivered FRP components shall be inspected to ensure compliance with contract documents. The number and types of samples to be tested will be indentified within the contract documents. If deemed necessary due to unseen project complexity, additional material testing may be conducted. Any material that does not comply must be rejected unless it receives approval from the engineer in special situations. Inspection of FRP materials may include, but are not limited to, tests for tensile strength, infrared spectrum analysis, gel time, pot life, glass transition temperature $\left(\mathrm{T}_{\mathrm{g}}\right)$, and adhesive shear strength that are in accordance with ASTM standards, such as ASTM D3039. While tests for pot life and curing hardness are usually performed on site, most tests will be conducted on samples sent to a laboratory. The testing location and preceding curing location if applicable shall be specified within the QC test plan. 
Special care should be taken in preparing any witness panels for the evaluation process. When specified, witness panels may be used to determine the tensile strength and corresponding modulus, hardness, $\mathrm{T}_{\mathrm{g}}$, and strength of any lap splices of the installed FRP system. Witness panels provide this information within reasonable accuracy as they are prepared and cured under the same conditions as the actual FRP strengthening system. After match curing, panels should be transported to the laboratory for testing. Elastic modulus and strength of FRP materials may be established in accordance with ACI 440.3R (Test Method L.2) and with reference to the material specifications. If fabrication of flat witness panels on site is not possible, the test plan may incorporate panels that are to be provided by the system manufacturer.

The level of cure shall be determined by testing sample cups of mixed resin that have been prepared in accordance with the sampling plan.

5. Fiber Orientation. Fiber orientation shall be inspected by visual inspection for wet lay-up and precured systems. In wet lay-up systems, care should be taken to determine if any kinks and waviness are present after the application. Conformance with contract documents is important and any misalignment of more than 5 degrees (approximately $1 \mathrm{in} / \mathrm{ft}[80 \mathrm{~mm} / \mathrm{m}]$ ) should be reported to the engineer. If removal and repair is deemed necessary, it shall be performed in accordance with Section 1002.4(f)5.

6. Delaminations. Inspection for delaminations shall start as a visual inspection that should be performed after a minimum of 24 hours of cure time. Acoustic sounding (hammer sounding), ultrasonics, and thermography can be used to detect delaminations if deemed necessary after the visual inspection. Delaminations and air voids can occur between multiple plies or between the fiber sheets and the concrete substrate. When evaluating delaminations and other inconsistencies, size, location, and quantity with relation to the total area of installation should be considered. Acceptance guidelines for wet lay-up systems as recommended by ACI are as follows:

- Delaminations less than 2 in $^{2}$ each $\left(1300 \mathrm{~mm}^{2}\right)$ are permissible as long as the delaminated area is less than $5 \%$ of the total laminate area and there are no more than 10 such delaminations per $10 \mathrm{ft}^{2}\left(1 \mathrm{~m}^{2}\right)$;

- Delaminations greater than $25 \mathrm{in}^{2}\left(16,000 \mathrm{~mm}^{2}\right)$ can affect the performance of the installed FRP and should be repaired by selectively cutting away the affected sheet and apply an overlapping patch sheet with the equivalent number of plies; and

- Delaminations less than $25 \mathrm{in}^{2}\left(16,000 \mathrm{~mm}^{2}\right)$ may be repaired by resin injection or ply replacement, depending on the size, number, and locations of the delaminations.

Completion of any repairs should be followed by another inspection to determine if the repair was adequate. In the case of precured FRP systems, inspection and repair of delaminations should be performed under the engineer's guidance. 
7. Cure of Resins. Relative cure of resin in FRP systems shall be examined by visual inspection, in which resin tackiness and hardness of surface or cup samples are noted, or by laboratory testing of witness panels or cup samples. In either case, ASTM D3418 shall be followed. The resin manufacturer should be consulted for determining the quality of cure acceptable. The manufacturer should recommend the method of evaluating adhesive hardness for precured systems. If the cure of any resin is found to be unacceptable, the applicable area will be outlined and repaired in accordance with Section 1002.4(f)5.

8. Adhesion. Tensile adhesion testing shall be performed using methods as specified in ACI 503R or ASTM D4541. ACI 440.3R, Test Method L.1 may be followed as well. Tensile adhesion testing should be performed at least 24 hours after initial cure and before applying the protective coating. Various test locations should be specified in the contract documents, defined by the engineer, or recommended by the contractor and approved by the engineer. Tension adhesion strengths should be recorded. Failure should take place within the concrete substrate and only after exceeding a stress of 200 psi $(1.4 \mathrm{MPa})$. Test locations that fail to meet this criterion, such as failure between plies or failure between FRP and concrete, should be reported to the engineer for evaluation and acceptance. NSM systems can not be tested for adhesion strength in the same manner. For NSM systems, sample cores may be extracted to visually confirm the consolidation of resin adhesive around the FRP bars or strips. These cores must be taken at the ends of the bars or strips so as to not cause discontinuity within the strengthening system.

All test locations shall be repaired in accordance with Section 1002.4(f)4. If defective work is indicated as a result of tensile adhesion testing results, repair should follow as recommended in Section 1002.4(f)5.

9. Cured Thickness. The cured laminate thickness or number of plies may be visually ascertained by taking small core samples of $1 / 2$ in diameter. Samples resulting from adhesion testing may be used, when adequate, to verify laminate thickness or number of plies. The sampling frequency shall be specified in contract documents or recommended by the engineer. Cured thickness samples shall never be taken from splice areas or high stress areas. If the samples do not present the proper number of plies, or if they present a cured thickness that is $1 / 32$ in $(0.8 \mathrm{~mm})$ less than that which is specified, the area shall be marked as unacceptable and repairs shall follow Section 1002.4(f)5. However, if the samples are acceptable for cured thickness, repairs to extracted sampling regions may be performed in accordance with Section 1002.4(f)4.

10. Additional Testing. In addition to inspection methods detailed in Sections 1002.4(e)1-(e)10, further testing may be performed if specified in contract documents. In-situ conventional load testing on the retrofitted structure and tensile testing of witness panels may be used. In-situ load testing of the structure can provide an overall evaluation of the effectiveness of the repair system and load rating of the structure. Tensile testing of witness panels, in accordance with ASTM D3039, can be used to measure strength, elastic modulus, and ultimate strain. If the average tensile strength and the lowest tensile 
strength are below 5\% and 10\% respectively, than those values specified in the contract documents, the system shall be deemed unacceptable.

\section{(f) Post Inspection Repairs.}

1. General. This section presents acceptable methods of repair for the types of defects identified in the inspection process. The adequacy of any repair procedure will depend on the type, size, and extent of the defect. For conditions or defects not presented within these specifications, repair procedures shall be proposed by the contractor and approved by the engineer before proceeding. The following sections detail repair methods for protective coatings, epoxy injection, minor defects, and major defects.

2. Protective Coating. Defects in protective coatings can cause long-term degradation of the FRP system as a result of localized moisture ingress. These defects consist of small cracks, blisters, and peeling. Any detected defects on the protective coating shall warrant further visual inspection to determine if the defect extends into the FRP system itself. If the defect does extend into the FRP system, repairs shall follow Sections 1002.4(f)3-(f)5.

Cracks are often nonstructural and are likely due to excessive coating thickness, shrinkage during cure, or FRP surface preparation. If small areas with cracks are found, the area shall be gently sanded and a new coating reapplied after application of any appropriate primer recommended by the manufacturer. In general, engineering judgment shall be used in determining an adequate area of coverage for the new coating, but as a minimum, the new coating shall extend $1 \mathrm{in} .(25 \mathrm{~mm})$ beyond the damage perimeter.

Blisters are often caused as a result of moisture entrapment. In any case, moisture content of the substrate should be below $0.05 \%$ before the application of any new coating. This will ensure that no further damage is caused after applying the new coating. If blistering is seen, the area up to $12 \mathrm{in.}(305 \mathrm{~mm})$ within the surrounding location shall be gently scraped clean. Recoating without complete removal of the existing defective coating is unacceptable. Once the old coat is removed, the area should be wiped clean and dried thoroughly. If required by the manufacturer, a primer shall be applied before applying the protective coating.

Excessive peeling indicates that the original coating may have been applied incorrectly as a result of inadequate surface preparation of the FRP system. If excessive peeling is identified, the entire coating should be scraped off and the surface shall be lightly sanded, wiped clean, and thoroughly dried prior to applying a new coating in accordance with the manufacturer's recommendations.

3. Epoxy Injection. Small defects can often times be adequately repaired by epoxy injection. Types and sizes of defects that can be corrected with epoxy injection are presented in this section. Voids or surface discontinuities less than $1 / 4 \mathrm{in}$. $(6.4 \mathrm{~mm})$ in diameter shall be considered negligible and require no repair work, unless they occur next to edges or occur in more than five locations within an area of $10 \mathrm{ft}^{2}\left(0.9 \mathrm{~m}^{2}\right)$, in which case, repairs shall be performed in accordance with Section 1002.4(f)4. Defects having sizes between $1 / 4$ and $1 \frac{1}{4}$ in. $(6.4$ and $32 \mathrm{~mm}$ ) in diameter can be repaired using lowpressure epoxy injection unless the defect extends through the complete thickness of the 
laminate. It is possible for delamination to increase as a result of epoxy injection. If any delamination increase is detected, the repair procedure should be halted and repair shall be continued with methods of Section 1002.4(f)4.

4. Minor Defects. Defects with diameters between $1 \frac{1 / 4}{4}$ and 6 in. (32 and 152 $\mathrm{mm})$ and an occurrence of less than five per any unit surface area of $10 \mathrm{ft}(3 \mathrm{~m})$ length or width can be considered minor defects. These minor defects can include cracking, abrasion, blemishes, chips, and cuts. Repair of these defects shall start with removal of the defect area up to at least $1 \mathrm{in} .(25 \mathrm{~mm})$ beyond the perimeter of the defect. After removal, the area should be wiped clean and dried thoroughly. FRP of the same type as the original laminate shall be used to patch the area. The patch shall be of sufficient size to extend at least $1 \mathrm{in} .(25 \mathrm{~mm})$ beyond the area removed. If deemed more suitable, repair may be performed with the procedures of Section 1002.4(f)5.

5. Large Defects. Defects with diameters greater than 6 in. $(152 \mathrm{~mm})$ can be considered large defects. Large defects normally represent significant debonding between layers, insufficient adhesion to the concrete substrate, or large amounts of moisture entrapment. They may be in the form of peeling and debonding of large areas that are not localized and can lead to full replacement of the FRP system. Large defects should be carefully marked and cut out to at least 1 in. $(25 \mathrm{~mm})$ beyond all sides of the defect area. Cutting shall be continued until reaching a depth that exceeds the defect area. In some cases, the entire thickness of the multi-ply system may need to be removed. After removal and before patching, the area should be properly prepared. For these large defects, application of the patching FRP system shall follow the same procedures as the initial FRP application. As an extra step with large defects, an additional layer extending a minimum of 6 in. $(152 \mathrm{~mm})$ on all sides of the cut area shall be applied as an outer patch. Once these steps have been performed and the system has cured, the protective coating should be applied over the entire area. 
APPENDIX F: LONG-TERM TESTING AND MONITORING

GUIDELINES 


\section{Guidelines for Bridge Testing and Long-Term Inspections and Monitoring of Repair and Rehabilitation Work}

\section{Bridge Testing}

\subsection{General}

Bridge load testing, when applicable, should be performed before FRP strengthening and after FRP strengthening. In this manner, the characteristics of the retrofit can be directly investigated through comparison. Load testing can also be performed at specified time intervals, such as once a year, after the repair has been completed as a means of long-term monitoring as specified in Section 2.3. The type of truck and corresponding axel loads used before and after repair should be as identical as possible. Static loading and dynamic loading should be performed. Currently, the recommended data to be collected include, but are not limited to, deflection, strain, and dynamic characteristics such as natural frequency.

\subsection{Static Loading}

Static load cases should be developed to place the maximum load possible on particular beams. Loads on exterior beams should be maximized by placing trucks as close as AASHTO standards will allow to the parapet of the bridge. Once the trucks have been moved into the desired position, adequate time should be allowed for the braking effects of the trucks to negate and the deflection to level off. It is recommended that the centriod of load for each loading case used be placed over the quarter, half, and three quarter points of the span and data be taken for each location.

\subsubsection{Deflection Measurement}

Deflection measurements can be used to check for any changes in stiffness that may be obtained as a result of the retrofit. An increase in stiffness, indicated by a decrease in deflection measurements, should lead to the conclusion that strain is being developed within the FRP strips and hence, the FRP system is taking on load as intended.

LVDTs (Linear Variable Differential Transducers) can be placed at key points along the span to measure deflections. It is recommended that LVDTs be placed at quarter points along the span of each primary member of the bridge. At minimum, deflection measurements should be made at mid-span.

LVDTs should be securely mounted so that no movement of the instrumentation is possible. The possibility of magnetic interference with near metallic objects should be eliminated as well.

The specifications of the chosen LVDT should be adequate to measure the expected response of the bridge components under observation. Specifically, an adequate range and sensitivity of the LVDT should be known. Concrete T-Beam bridges of moderately short spans can have very small deflections. Therefore, using an LVDT with high sensitivity is important so that very small changes in deflection can be measured. In 
general, an adequate range and sensitivity for the selection of an LVDT can be \pm 0.5 inches and 0.001 inches respectively.

It is imperative that the chosen LVDTs be accompanied by accurate calibration data. If required under manufacturer's recommendations, LVDTs should be recalibrated before any testing is performed.

\subsubsection{Strain Measurement}

Strain measurements may be achieved using foil strain gages or any new type of strain measuring equipment that has become available. Strain gages can be attached to many different bridge components. Gages can be mounted to reinforcing steel, exterior concrete surfaces, interior concrete (embedded gages), and mounted to FRP strips.

Gages can be mounted to existing reinforcing steel for the un-repaired bridge load testing by simply chipping away the concrete in selected locations and applying the gage in accordance with the manufacturer's recommendations. The removal of defective concrete during the repair process can create the opportunity to again mount strain gages at the same steel locations. In this manner, the strain can be measured in the reinforcing steel before and after repair. Changes in strain levels in reinforcing steel during prerepair load testing and post-repair load testing can indicate that the flexural FRP strips are actually taking on load as intended.

Mounting gages to the concrete surface should be performed to determine the strain distribution throughout the depth of the section and to locate the neutral axis. This can be successfully performed by placing gages at quarter points along the depth of beam webs. Placing gages to concrete surfaces can be a very time consuming process due to surface irregularities inherent to most concrete finishing work. When in the repair process, it may be warranted to mount strain gages to concrete surfaces before the application of FRP. Once the FRP has been applied, another gage may be placed at the same location on the FRP. The strain measurements obtained from gages in the same locations on the concrete surface and FRP surface can be used to determine if potential slip exists between the concrete and FRP strip. It is imperative that all strain gages be mounted in exact accordance with the manufacture's specification so that proper performance of the instrument can be expected. Protective coatings and guards should also be used in accordance with the manufacturer's recommendations to protect against any adverse environmental conditions.

Gages used for measuring internal concrete strain can be used at selected locations and placed after defective concrete removal and before restoration of the cross-section. Embedded concrete gage readings can be used to validate data obtained from exterior strain readings and reinforcing steel strain readings.

\subsection{Dynamic Loading}

Dynamic loading can be achieved by providing forced excitation to the bridge so that vibration frequencies and damping effects can be measured. The recommended method of excitation is to drive a weighted dump truck over the bridge at speeds of 30-50 $\mathrm{mph}$ and slam on the brakes once the truck reaches the center of the bridge. Once the 
truck has crossed the bridge completely, the structure should be subject to free vibration in which the natural frequency and damping effects can be recorded.

\subsubsection{Measuring Dynamic Response}

Dynamic characteristics such as the frequency of a structure can be directly related to the stiffness and geometry. Any changes in these properties that may result due to the FRP strengthening system can be determined from dynamic testing. The dynamic response from testing may be measured with accelerometers mounted to primary components of the bridge. Accelerometers should be mounted following the manufacturer's guidance. Special mounting techniques may need to be developed for attaching accelerometers to concrete beams due to the deteriorated condition of many beams. Whatever the technique used, it is important that the instrument be mounted firmly to the member and therefore have zero movement in relation to the member, assuring a solid base for accurate data collection.

\subsection{Data Acquisition Setup}

All instrumentation placed on the bridge shall be connected to proper data acquisitioning systems. The acquisition system shall be capable of measuring the required or desired data collection rate. It is recommended that deflection and strain data be collected at 10 scans/second while acceleration data be collected at 10,000 scans/second. Successful tests have been performed with Vishay System 6000 data acquisition systems and Strain Smart software. Battery backups should be used in case problems are encountered with the primary power supply. If desired, it is possible to make the data acquisition system along with selected instrumentation a permanent fixture at the bridge site to aid in long-term monitoring as described in Section 2.3.

\section{Long-Term Monitoring}

\subsection{General}

Long-term monitoring of concrete bridges rehabilitated with externally bonded FRP strips should be achieved through periodic nondestructive testing and bridge load testing procedures. It is recommended that visual inspection be performed yearly, aided by other testing procedures as required, as specified in Section 2.1.1.

\subsection{Nondestructive Inspection and Testing}

Nondestructive inspection (NDI) and testing (NDT) should be used to detect defects such as resin starvation, resin richness, fiber misalignment, discoloration, and delaminations. NDI and NDT techniques for structures strengthened with FRP have not been very widely researched. Therefore, most guidance for long-term monitoring and inspection for concrete structures strengthened with FRP is general in nature and can be enhanced with ingenuity as desired. NDI and NDT techniques may include visual 
inspection, audio or tap testing, ultrasonics, thermography, and selective bond pull-off testing.

\subsubsection{Visual Inspection}

Currently, visual inspection should be considered the most economical and reliable NDI method. If flaws are found through visual inspection, the area should be adequately marked and subjected to closer visual inspection and forms of nondestructive testing such as ultrasonics and thermography to further classify the defect and type of repair that may be needed. The use of flashlights, magnifying glasses, or borescoped may be employed if deemed necessary.

\subsubsection{Audio Testing}

Audio testing or tap testing may be incorporated into the visual inspection process. This method of testing is not very favorable due to its highly subjective and time consuming nature. Tap testing should only be performed by skilled and experienced inspection personnel (ACI, 2007). It should be performed by tapping the subject area with a lightweight hammer while listening to the audible response. Making use of the audible range (10 to $20 \mathrm{~Hz}$ ), a clear and sharp ringing sound is indicative of a wellbonded solid structure, while a dull sound may be a sign of damage such as delaminations.

\subsubsection{Ultrasonics}

Ultrasonic inspection can be used to detect internal delaminations or inconsistencies that may not be visible with the human eye or tap testing. Ultrasonic testing is performed by introducing a high-frequency sound wave into the structure at some specified angle to the surface (normal, parallel, inclined). Many different angles should be used during testing since flaws may not be noticeable in a particular direction. Defects are located as a result of ultrasonic waves striking an object and transmitting part of the energy back to the surface while the rest of the energy is transmitted through (ACI, 2007). A receiving transducer picks up the diminished sonic energy and displays it on a screen. In this manner, the defected areas can be located by comparison with flawless areas. Impact echo testers have been specially modified and successfully used to detect artificially created delaminations (Maerz et al. 2007).

\subsubsection{Thermography}

Long-term inspection is a vital component of the health monitoring of FRP repair and rehabilitation projects. In addition to the most commonly used techniques such as visual inspection for visible patches or discoloration and tap testing to locate debonding and delamination areas at FRP/concrete beam or slab interface. For long-term monitoring, more advanced methods such as infrared thermography (IRT) can be used in the field to detect delaminations, air-filled and water-filled debonds at the interface, by measuring the differences of thermal conductivity, specific heat of defective and defect- 
free zones, and produce real-time images that can be interpreted effectively to evaluate the integrity of the FRP bond. IRT can effectively locate the size and extent of the delamination or debond. With the IRT method, a heat source is used to elevate the surface temperature of the testing area. Areas that are defect free will conduct heat more efficiently than areas with underlying defects. The quantity of heat that is either absorbed or reflected back to the surface can indicate defects within the FRP/concrete interface. Types of defects that can affect the thermal properties can include cracks, damage from impact, ingression of water, and debonding (ACI, 2007). IRT can be most effectively used to detect defects near the surface.

Although in the past IRT has been used successfully for field monitoring, this technique needs experienced technicians and equipment with specialized knowledge to successfully conduct the testing in the field and interpret the results. Tap testing and selective pull-off testing may be conducted to confirm the debond areas.

\subsubsection{Pull-Off Strength Testing}

The epoxy bond between the FRP and the concrete is critical for the long-term performance of the FRP system. As pull-off testing can be considered destructive if performed to a load carrying member such as a primary beam, possible degradation of the bond shall be tested by incorporating areas of low structural importance for periodic bond testing. It is recommended that FRP sheets be bonded to areas on bridge abutments in the same manner as they are applied to the load carrying components so that these bonded sheets can be tested and conclusions can be made concerning the durability of the FRP/substrate bond. These bonded test areas may also be subjected to intentional delaminations via forced air or water. Therefore, with delamination locations known, the accuracy of nondestructive testing equipment may be validated prior to use on primary members (Maerz et al. 2007).

Pull-off strength testing may also be performed on test specimens cast at the bridge during the concrete restoration process and then layered with the FRP during the normal application process. These specimens can be kept at the site and therefore exposed to the same environmental conditions. When NDI is performed to the rehabilitated bridge, pull-off bond strength testing may be conducted on the test specimens.

\subsection{Periodic Load Testing}

Periodic load testing can be used as an effective means of monitoring the long-term health of a rehabilitated bridge. Periodic load tests should be performed in the same manner as load testing just prior to and just after repairing the structure. In this way, periodic load tests can be compared to load tests conducted on the newly repaired bridge and any discrepancies can be noted while evaluating the changes in structural characteristics.

If it is specified that periodic load testing is to be conducted, strain gages as detailed in Section 1.2.2 may be permanently attached to the structure so that reapplication may not be necessary. 